\title{
Defying Obsolescence
}

\section{Steven Almond}

Supervisors: Natasha Perkins and Tim Miller

Victoria University of Wellington, School of Design Innovation

Master of Design Thesis

2020 


\section{Abstract}

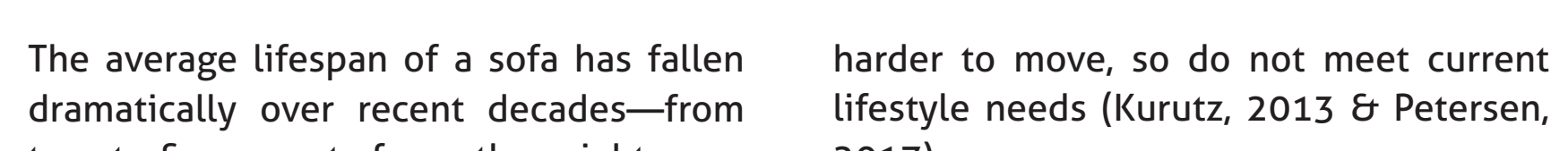

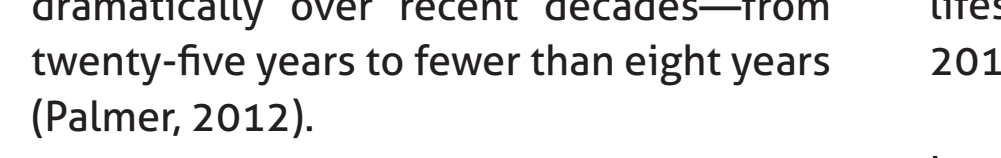

Two key factors are
function and fastion

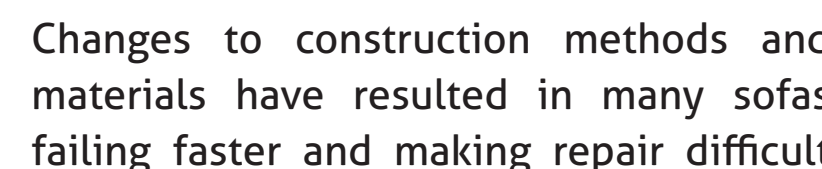

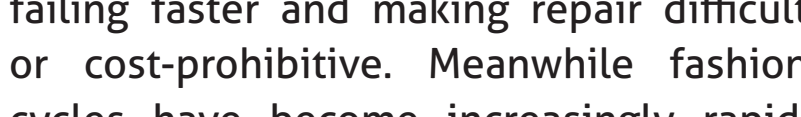

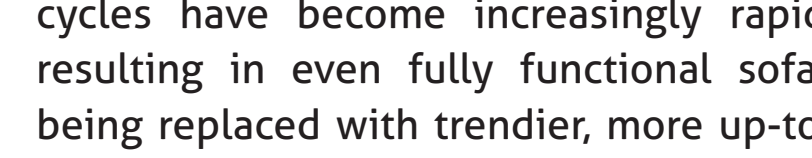

dite syly

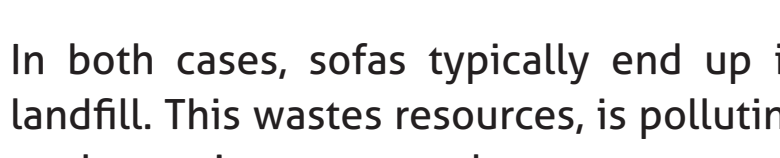

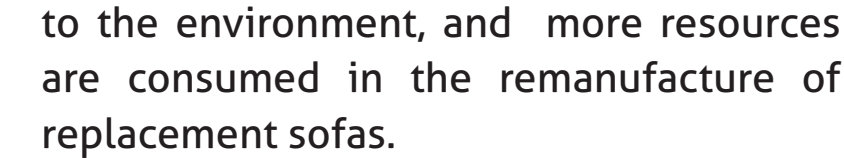

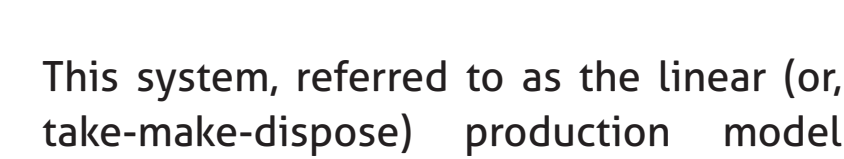

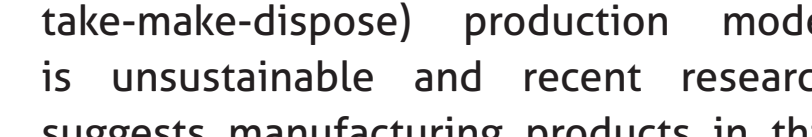

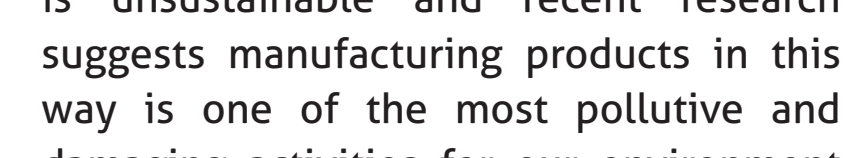

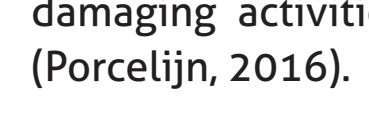

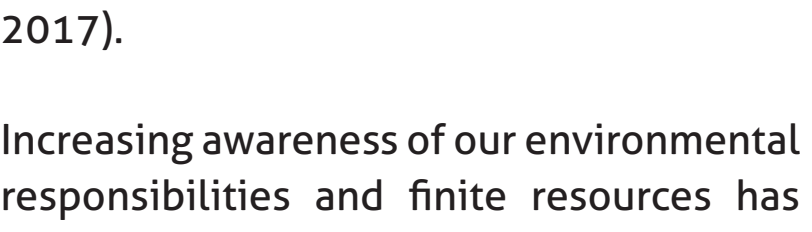

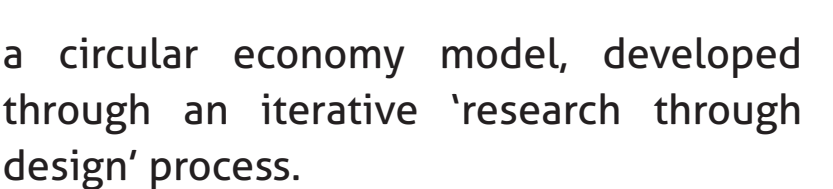

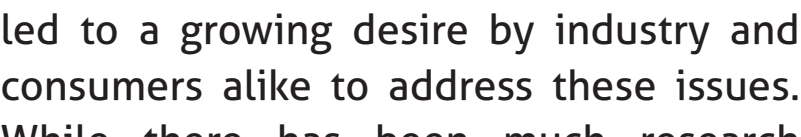

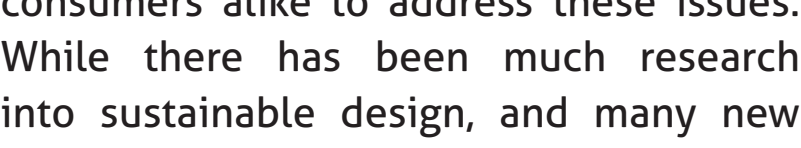

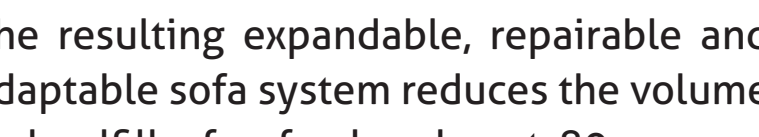

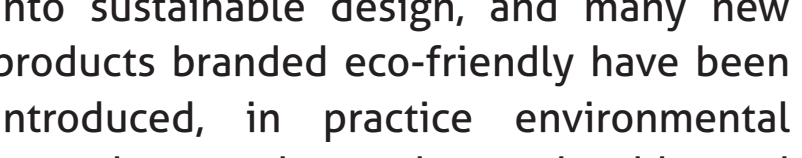

hirty years (section 20).

This scycle is being further accelerted dith

(1)

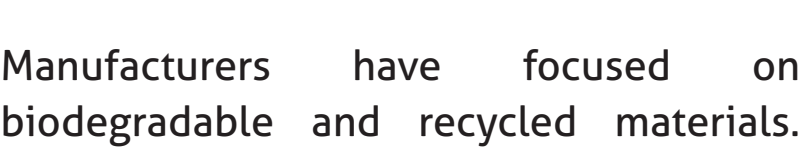

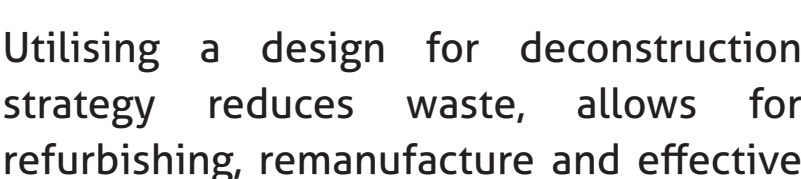

Necentresearch, and the emerging concept

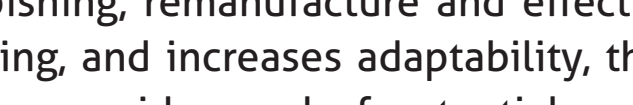

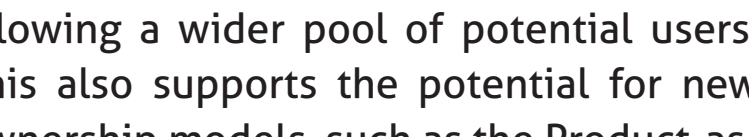

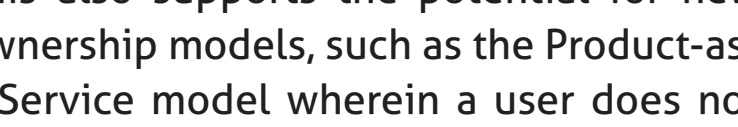

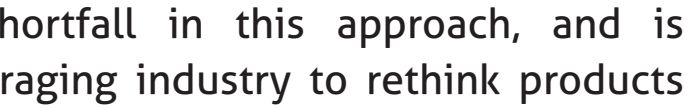

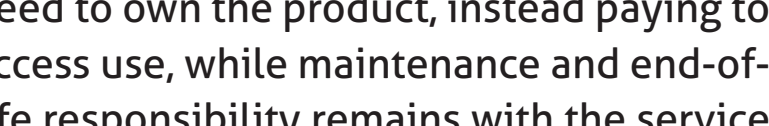

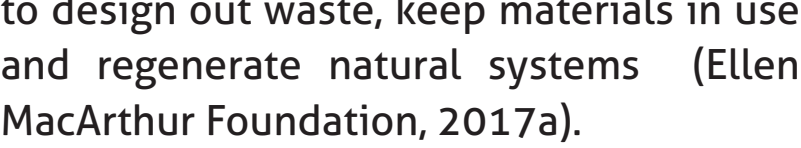

Tis study of a soff design is in intended of

This approach has not yee been widely
esearched in, or appieid to, turniture

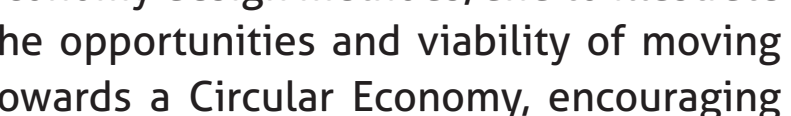

With core themens of repair, adpapability

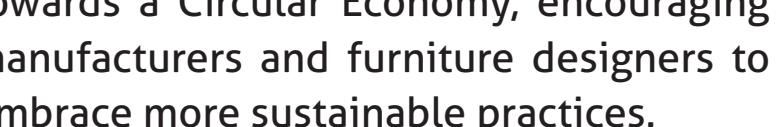

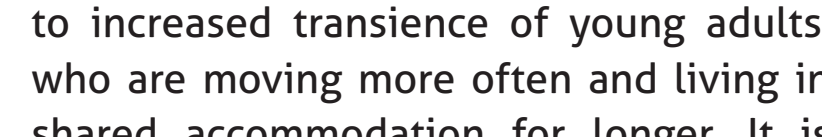

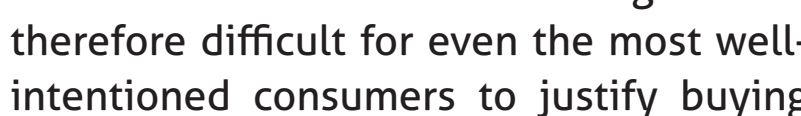

and considering how this affects
ownesship modeles susch as leasing vas

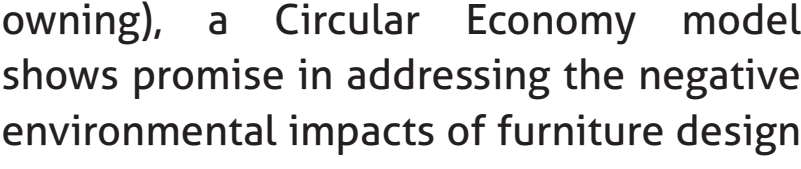

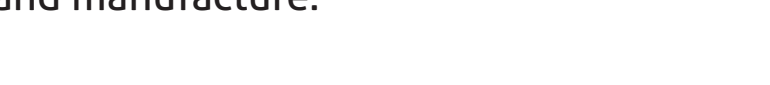

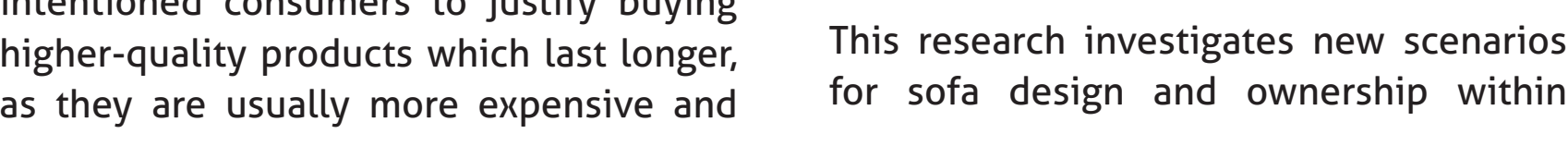




\section{Contents}

Abstract
Contents

1. Foreword

2. List of tables, figures and illustrations

Glossary

What's the 'wicked' problem?

Developing the research question

7. Research methodology: Research through Design

8. A brief history of the sofa

9. Sofa construction
10. Sofa obsolessence

11. Planning for obsolescence

12. Environmental Impacts

13. Change by design

14. How to defy obsolescence

15. Landmark sofas: the state of play

$\begin{array}{ll}\text { 16. } & \text { Hypothesis } \\ \text { 17. } & \text { Inspiration }\end{array}$

18. Design experimentation and critical reflection

20. Validation-eco-cost indicators

22. Conclusions
References

Appendices

Appendix A.1 Potential negative impacts from sofa manufacturing Appendix A.2 Material validation table

Appendix A.3 Eco-costs table

Appendix A.4 Impacts of repair and replacement materials

Appendix A.5 Charts: Linear model sofa vs Circular economy sor

Appendix B-Prototypin

Appendix C-Working prototype production 


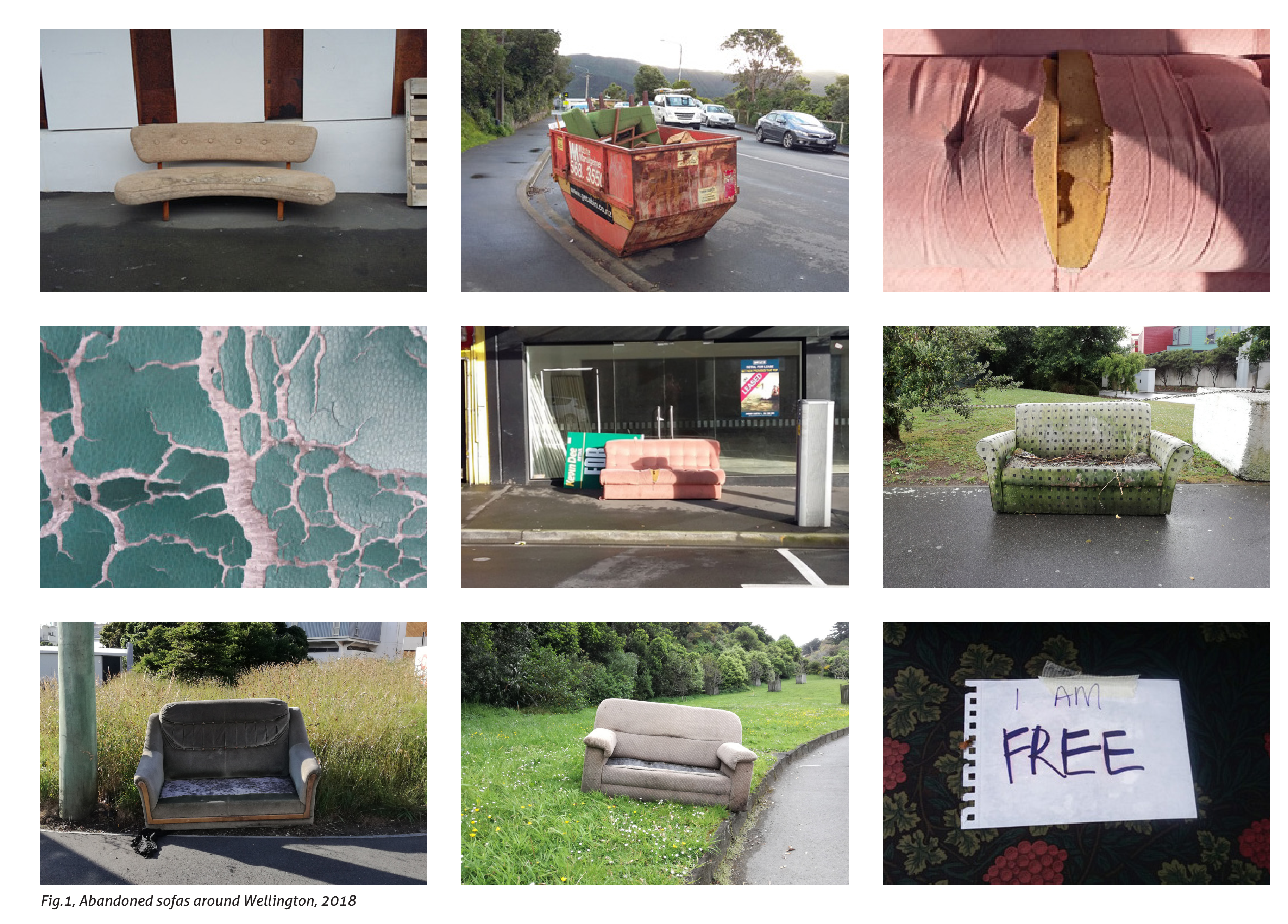

1. Foreword

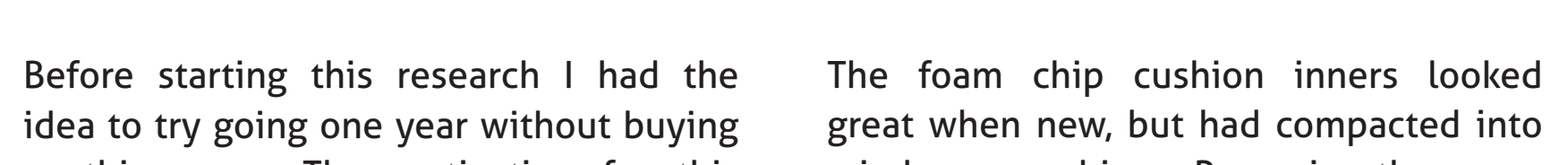
anything new. The motivation for this misshapen cushions. Removing them was

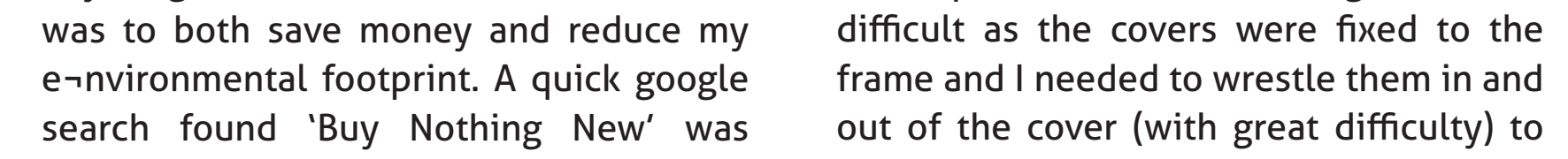
in 20010 . Buy Nothing New encourages
borrowings reparing and buying second sod new fram. As a designer, this lack of foresight for
repair and reyclability made me thinks
this cant be an acceptable way to design

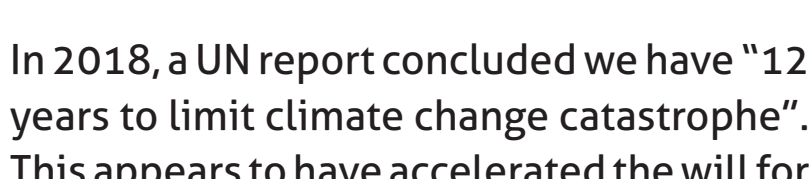

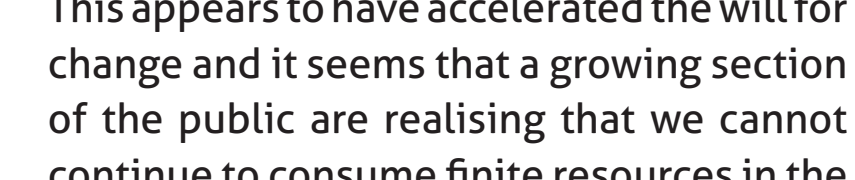

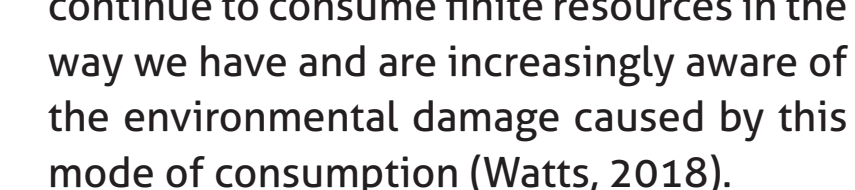

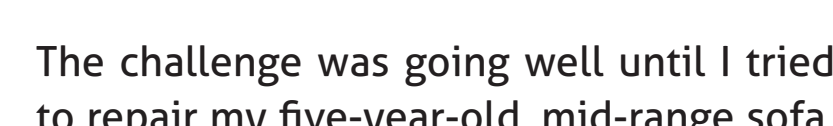
(he mere looled ino tis problem

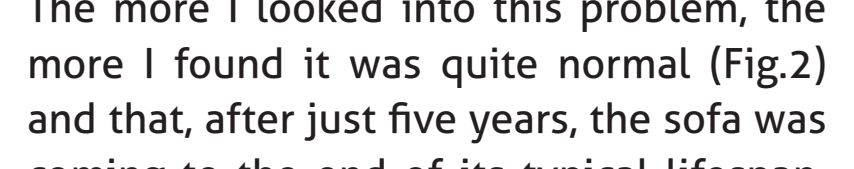
coming to the end of itits typical lifespan.
There was no

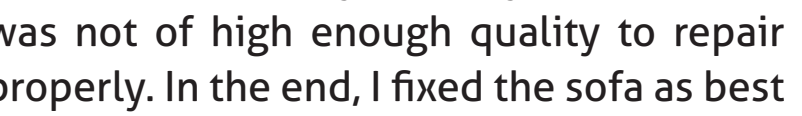

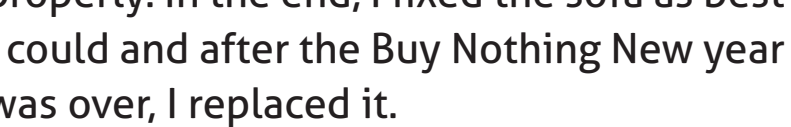
.

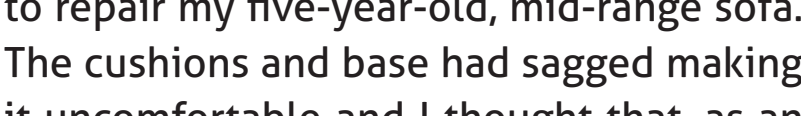

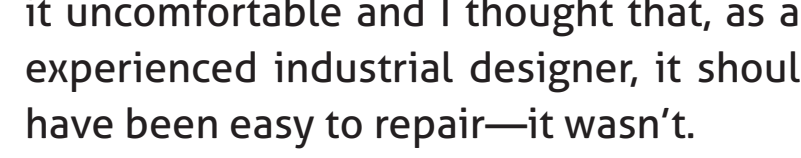

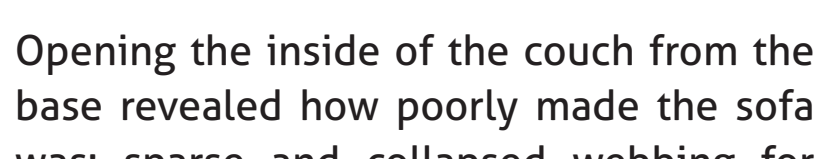

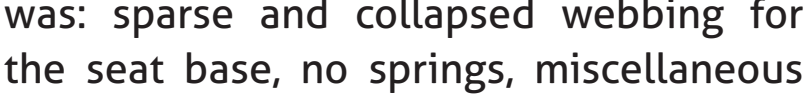

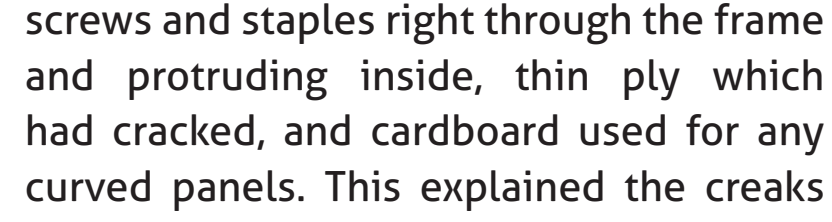

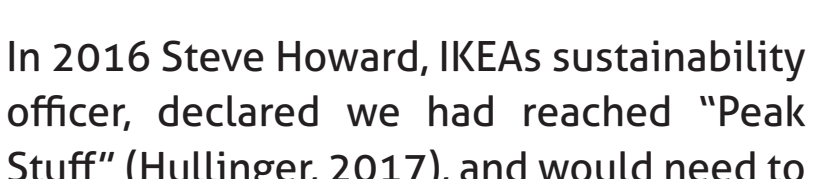

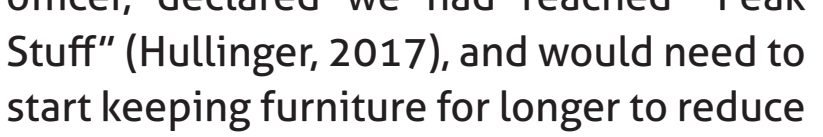

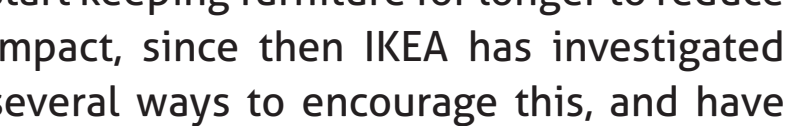
comited to using only renewable and
recycled materalls by 2030 (Ringstrom,

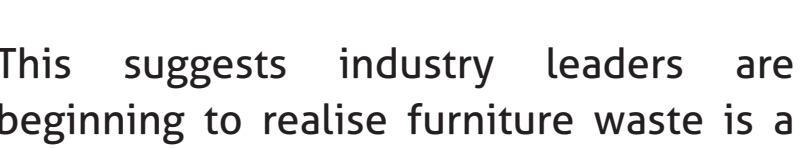
and cracks is in the frate 


\section{List of tables, figures and illustrations}

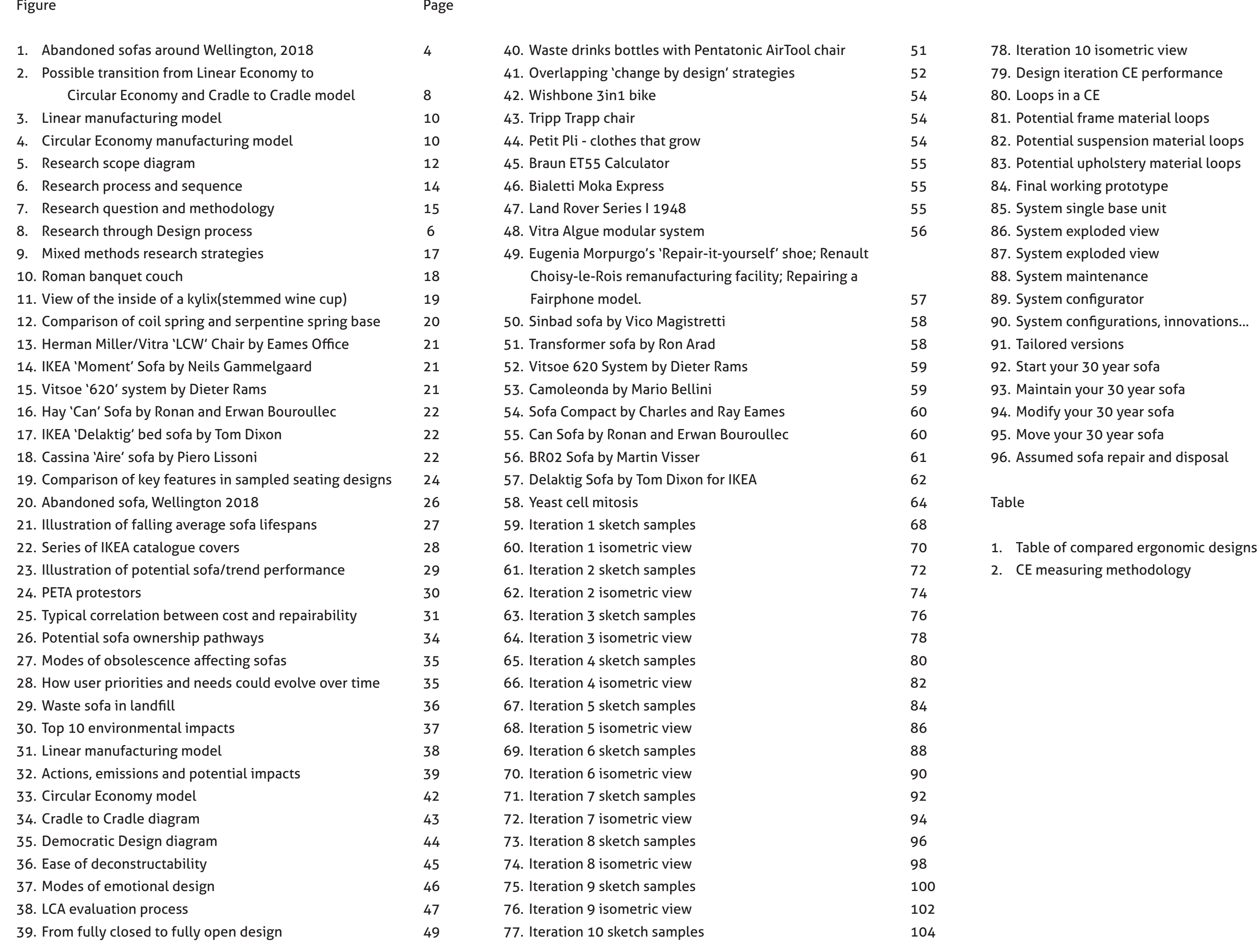

\section{Glossary}

Carbon sink-Materials which absorb Co2 from the atmosphere during growt

CNC-Computer Numerically Controlled, machinery used for production

Dacron-Polyester Hbrelining oppled to foam uphostery

FSC - Forestry Stewardship Council

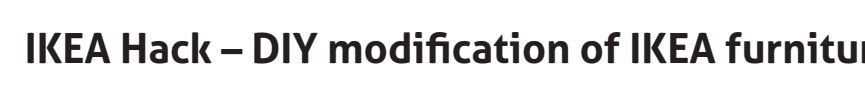

LCA-Life Cycle analysis

LDPE-Low-density polyethylene

MDF - Medium Density Fibreboard, engineered panel product

Mestrous hybrid - Combined

Paas - Product as a service

Theod fibres and rest

isterial resulting from disposal of products, after use by the consumer

Pre-consumer waste - Material by-products resulting from the manufacturing process of products

Serpentine spring - Curved "S" shaped spring common in modern sofa production 
4. What's the 'wicked' problem?

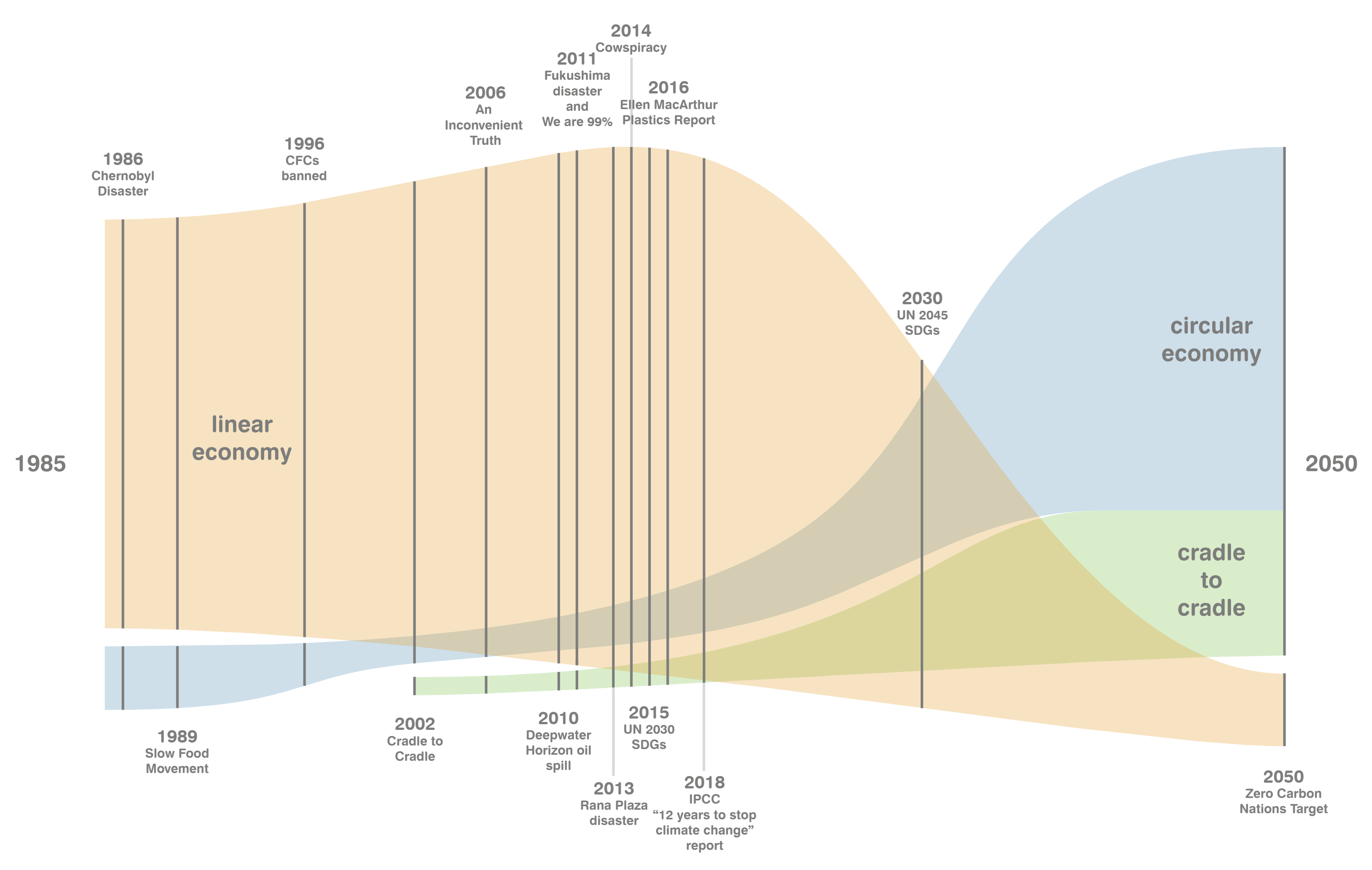

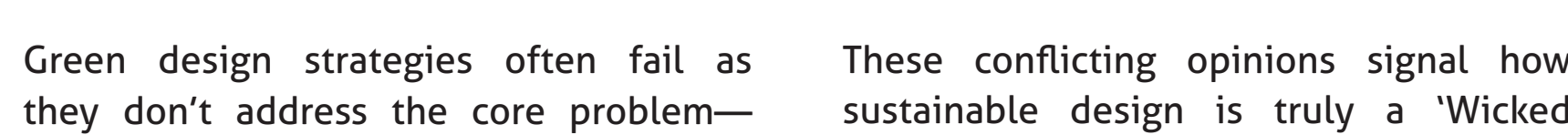

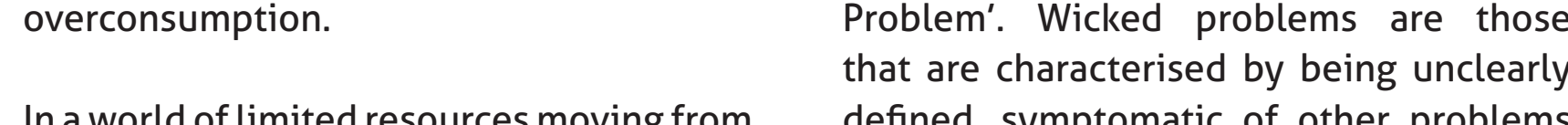

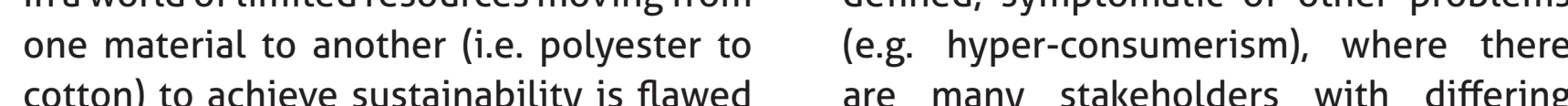

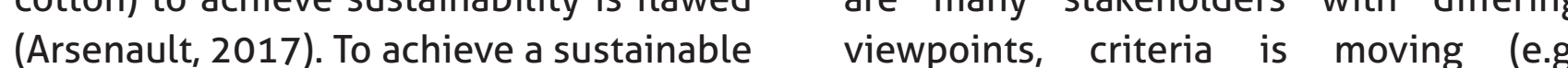

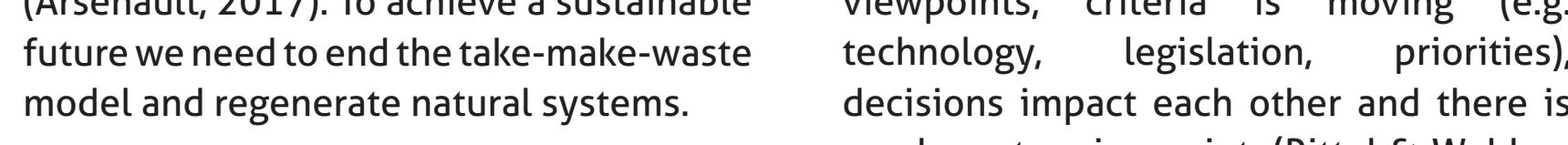

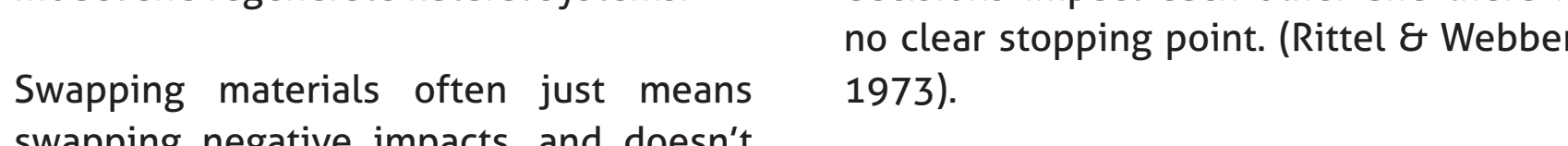

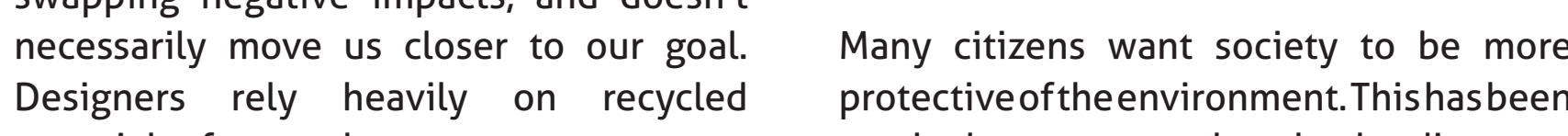

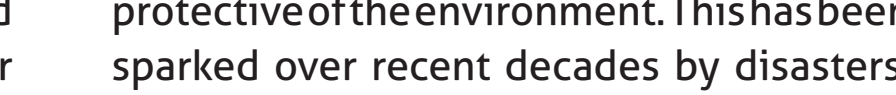
biodegradable material Neither of these

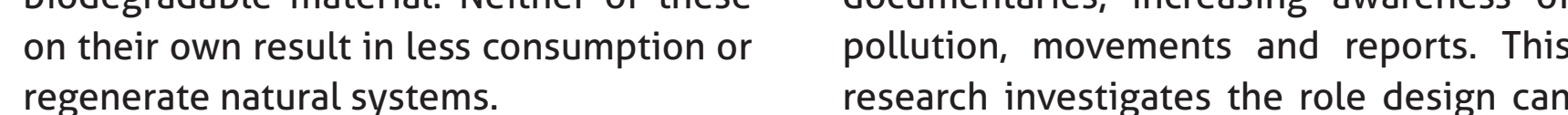

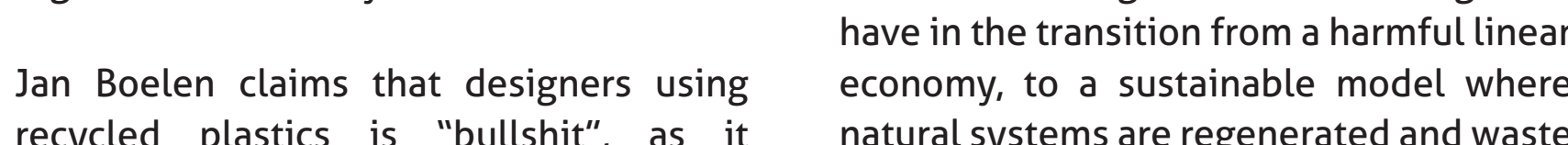

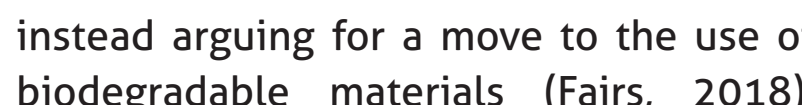

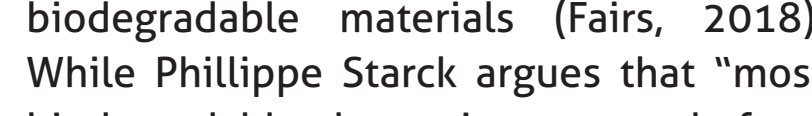

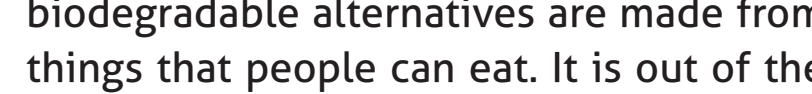
question that food should be sacrificed

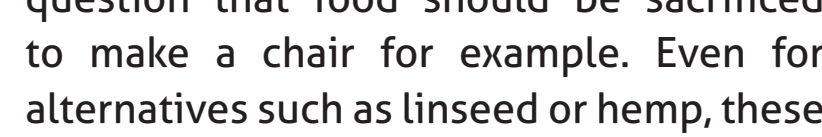

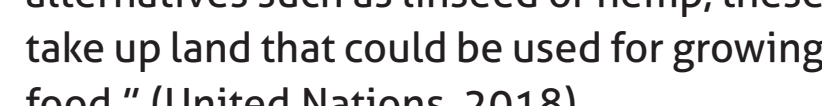
"lod." (United Nations, 2010 


\section{Developing the research question}

Linear manufacturing model

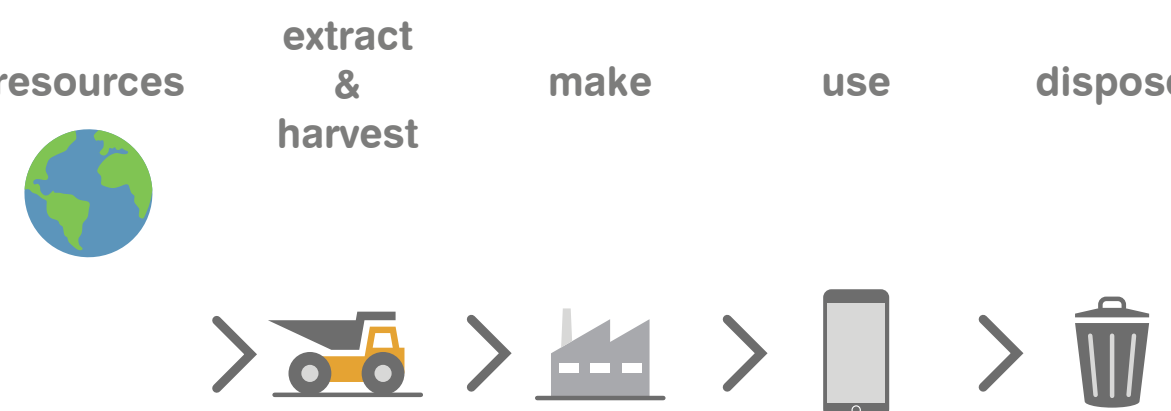
ษँษ

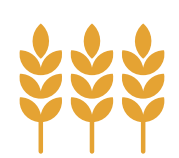

Circular economy manufacturing model

\section{Initial research found that there are no sofa Circular Economy (CE) principles were} This may beafter multiple owners, however $>0.0$

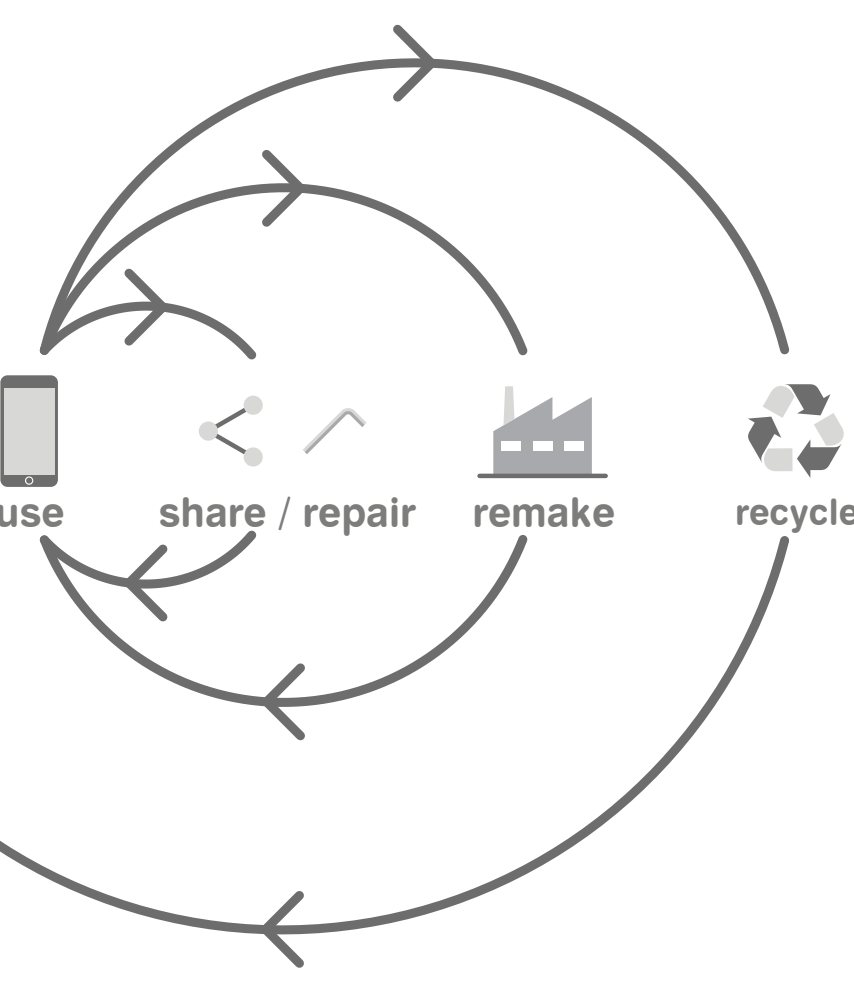
Fig.4. Circular Ec Eonomy manufacturing model
Adapted from: EMF n... $\begin{array}{ll}\text { so most modern sofas will be landfilled } & \text { bring together many other sustainable } \\ \text { at end-of-lifie. It it common to see sofas } & \text { design strtetegies as part of a holistic and }\end{array}$

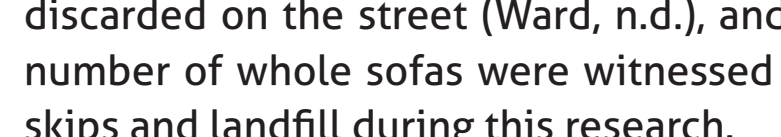
unless it has a recyclable frame le.g. steel

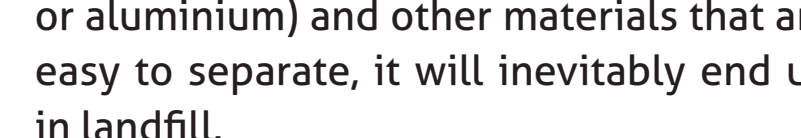

Contemporary sofa assembly method
make i itrohibitivive to repait or d disassemble for reycling. The cost for revounholstely
fefen similar or more than, a new sof

is often similar or more than, a new sol
so is usually dismiised in favour of full
repplacement.

Can a circular economy design approach that prioritises repair and adaptability transform sofa design to reduce post-consumer waste and the environmental impact of sofa

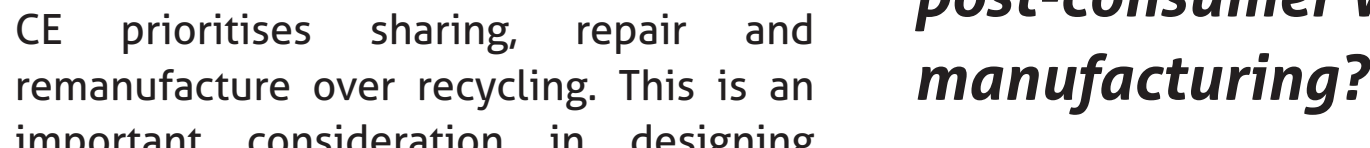




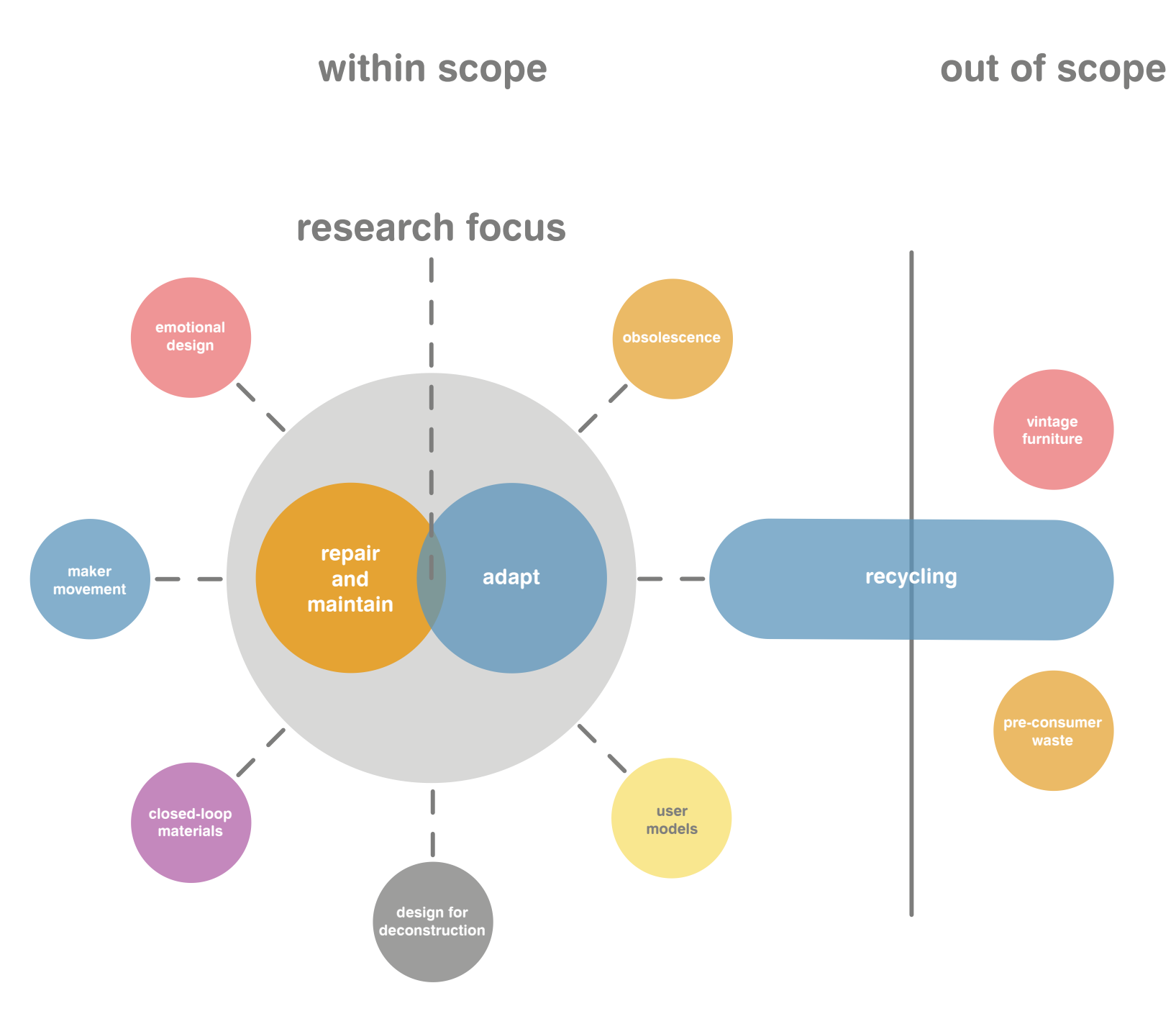

Fig.5, Research scope diagram

\section{Research scope}

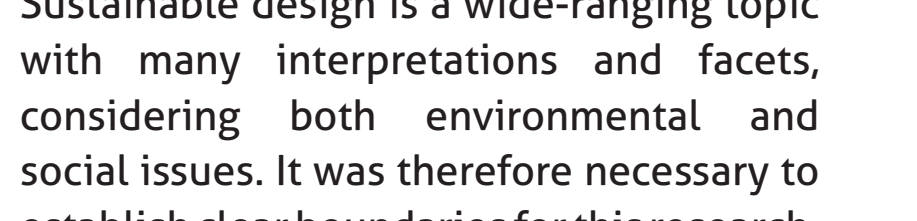

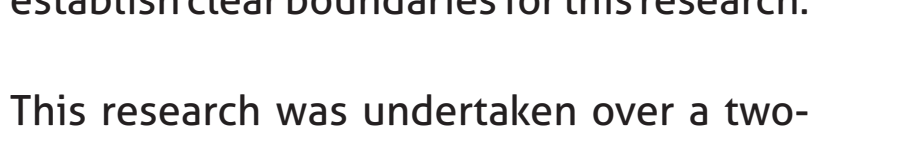

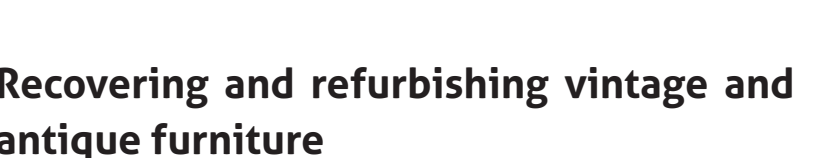

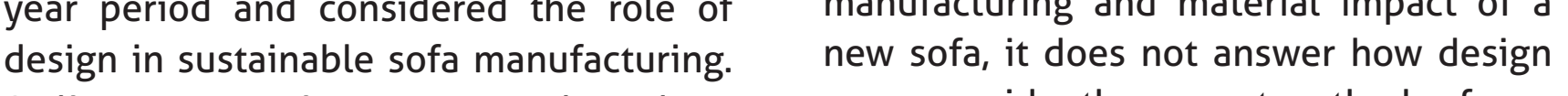

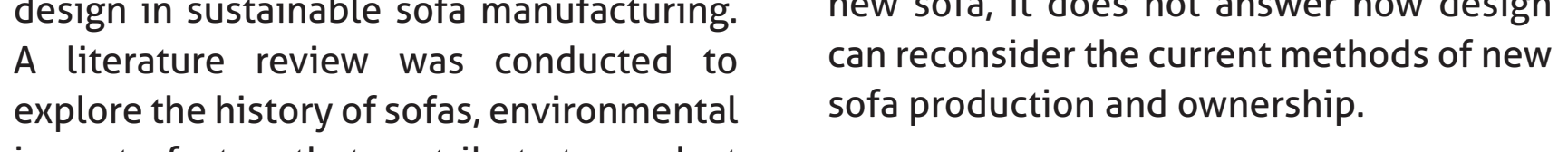

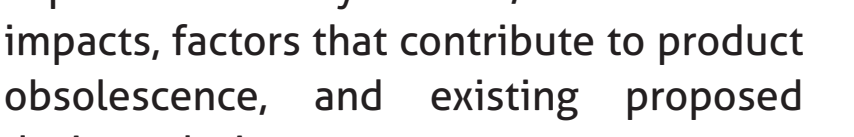

$\begin{array}{ll}\text { This showed that while the environmental } & \begin{array}{l}\text { Where possible, materials suitable for } \\ \text { closed-doop recycting were chosen, as }\end{array} \\ \text { long as they }\end{array}$

$\begin{array}{ll}\text { impacts of manufucturingand consumption } & \text { long as they fit the functionat needs of } \\ \text { are a key concern for many, very few of } & \text { the project. } \\ \text { adepair, maintenance and } \\ \text { the current proposed solutions have beenn } & \text { adaptability. This follows the priorities }\end{array}$

the current proposed solutions have been adaptability. This follows the priorities
successful in addressing these issues. The
of a CE model.

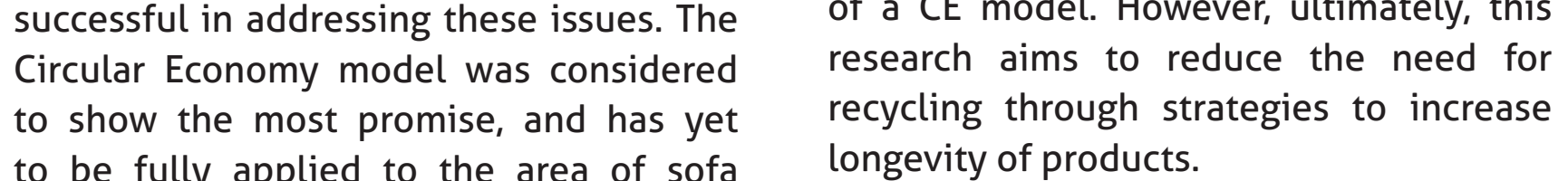

to be fully applied to the area of sofa
manufacturing and

bngevity of products.

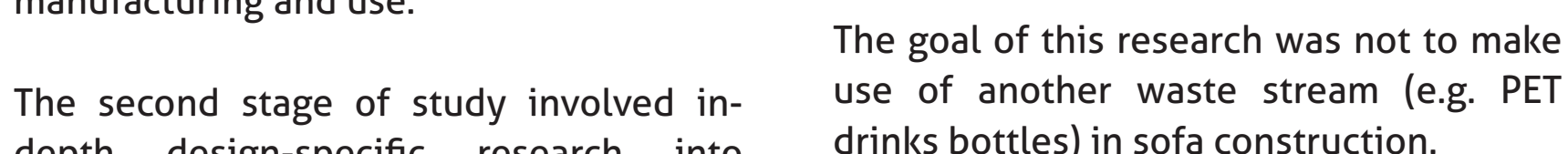

depth design-specific research into
strategies for sustory

Pre-consumer waste

While social considerations, such as worker
health and factory conditions, are critically

The wide variety of approaches to
obtaining processingandusing materialsin

important when considering sustainability
holistically, for the purpose of this research

the focus is narrowed to the role ef edesign
in the development of an environmentally

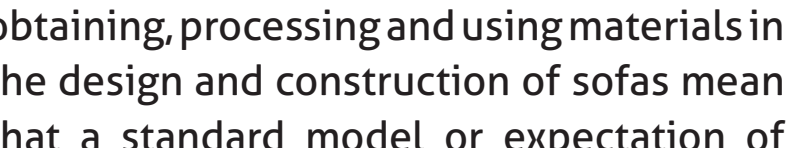

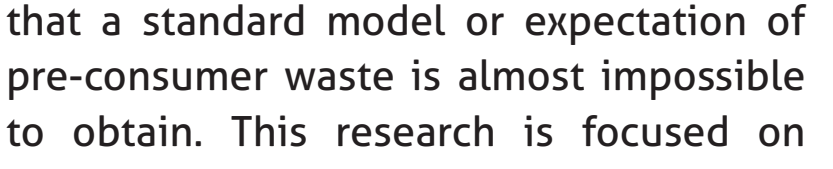
what happens to the sofa after it thas been 


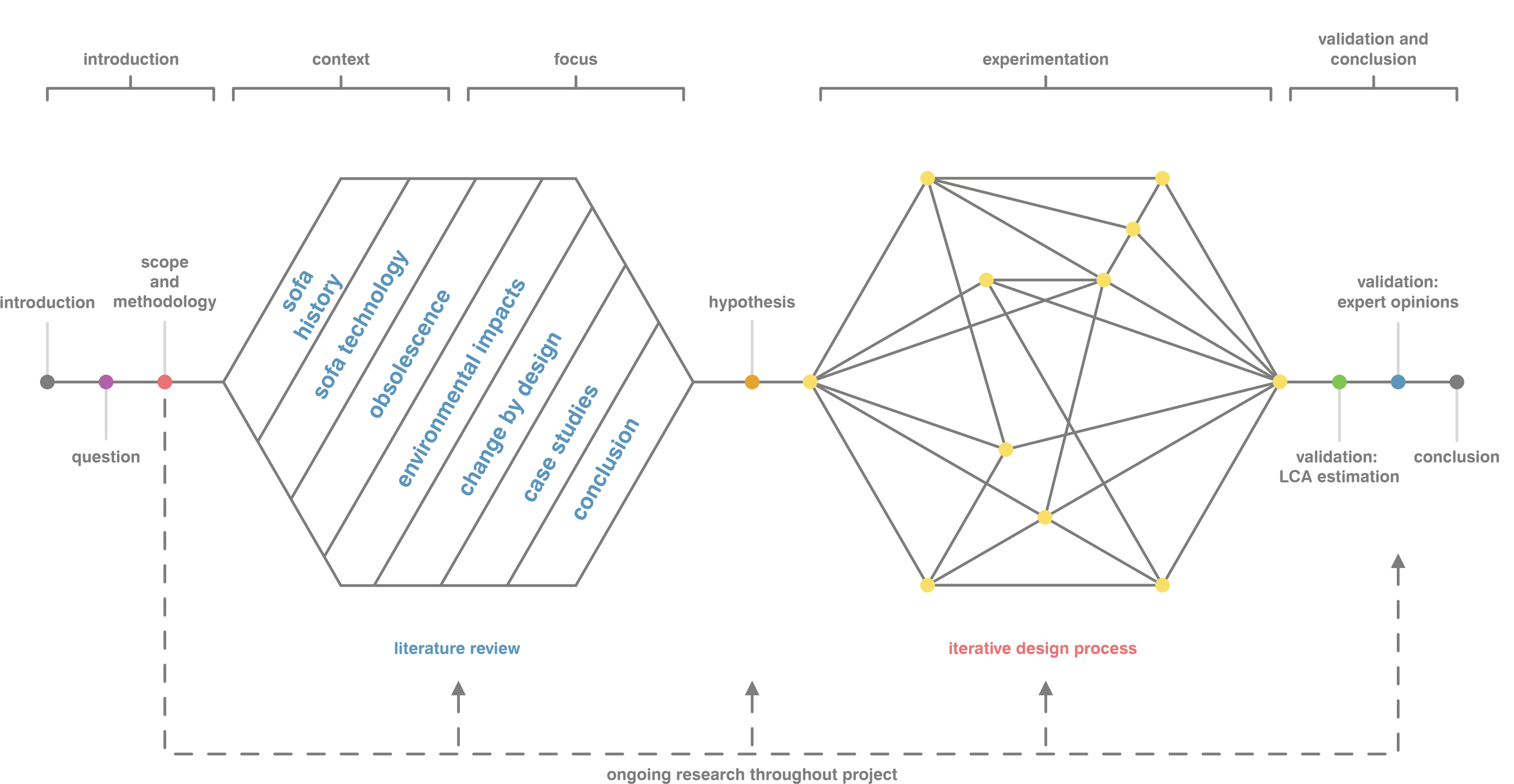

7. Research methodology: Research through Design

"Research through Designs asks Qualitative and quantitative research methods
researchers to investigate the speculuative future, probing on what the world could
and should be." (Zimmerman $\&$ Forizzz.
2014)

This research employs both qualitative
and quantitative methods of research to address the two distinct parts of the
research question. To investigate, and assess, how sustainable
design strategies could be applied to
sofa design a research-through-desions sofa desigg a research-through-design
approach was chosen, and a sequentid

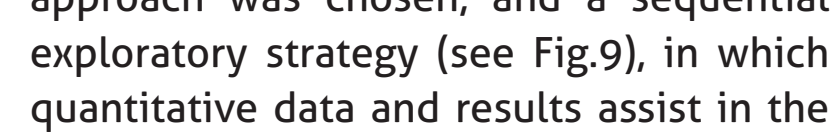

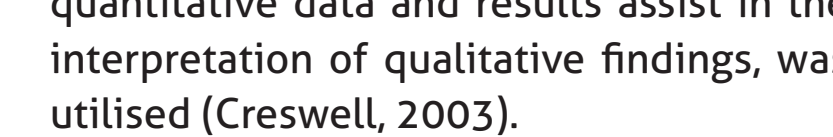
qualitative measures design experiments
empirical and iterative design reflection
and expert interviews

Can a circular economy design approach that prioritises repair and adaptability transform sofa design
to reduce post-consumer waste and the environmental impact of sofa manufacturing? quantitative measures
for example: $\mathrm{Kg} / \mathrm{Co2} 2$ emission
$\mathrm{Kg}$ material waste avoided

hils approach was chosen over the more
familiar concurrent research strategy as
tis approach was deemed less able 
Research through Design

$\begin{array}{ll}\text { The focus of this research is to address } & \text { The method and tools used are consistent } \\ \text { repairability and adpaptability. Problems } & \text { with those used in industry, and as }\end{array}$

demonstrated by Konstantin Gricic is

$\begin{array}{ll}\text { Research through Design (RtD), which was } & \text { 3D CAD model to generate patterns to } \\ \text { chosen as the key research strategy. } & \text { fabricate a cardboard or paper model. }\end{array}$

This process lends itself to addressing $\begin{aligned} & \text { The result is checked and modified and } \\ & \text { results fed back into the CAD model. These }\end{aligned}$

physical problems through an iterative iterative models (30 sketches at $1: 1$ scale
process of testing and critical reflection

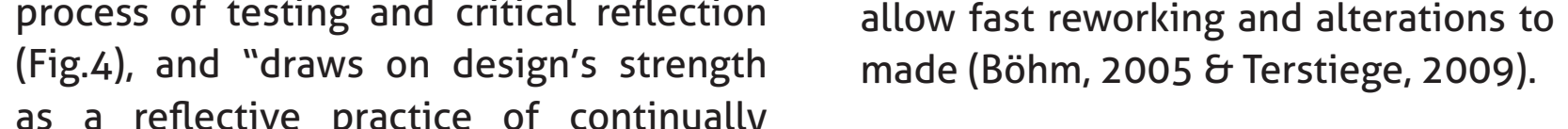

reinterpreting and reframinga problemat

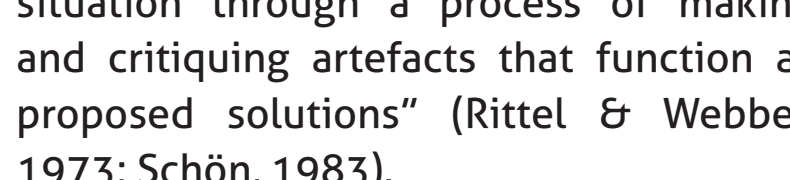

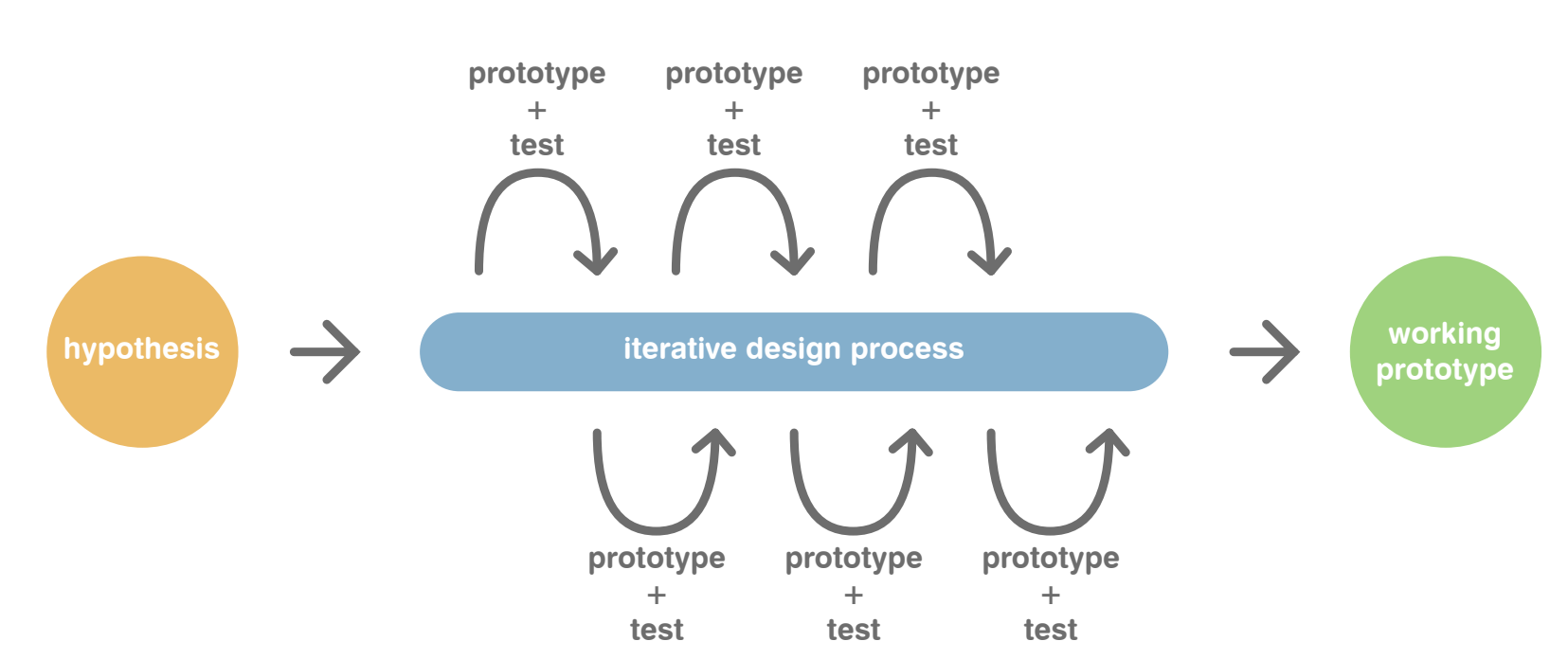

Fig., Research through Design process:
Adapted from: Ziimmerman and Forizizi, 201, ntial Exploratory Researc

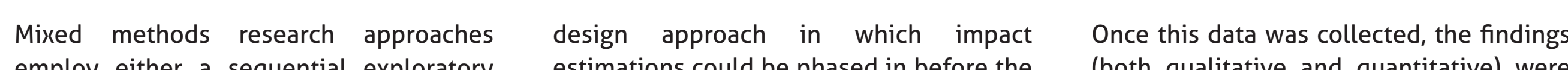

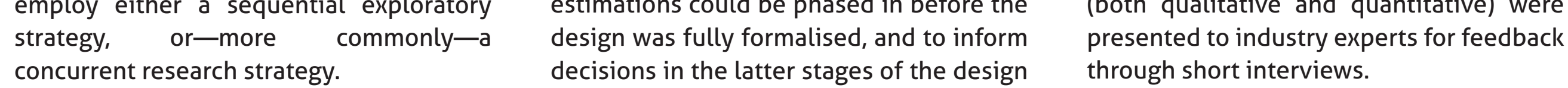
The former approach favours a process, a sequential exploratory research These interviews are approved by the "quantitative data and results to assist in At stages throughout the iterative design $\begin{aligned} & \text { Etchics Committee: Application } \\ & \text { ID: } \\ & \text { o. } 0000024294\end{aligned}$ (Creswell, 2003). While in the latter both process, the efrectiveness of these

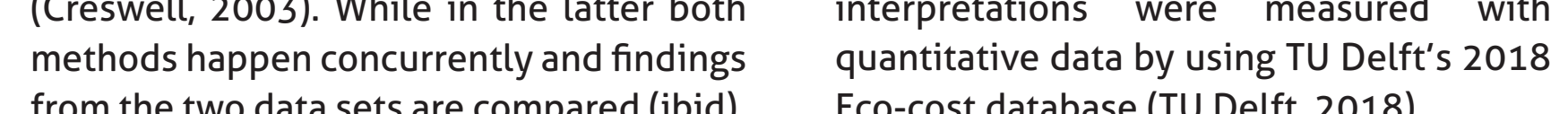

This feedback, material validation and Lo-cost database (Tu Delit, 2018).

leflection were, material validation and
conclused to form the final

Sequentialexploratoryresearch(selected)

Concurrent exploratory research

$$
\begin{aligned}
& \text { QUAL } \rightarrow \text { quan }
\end{aligned}
$$

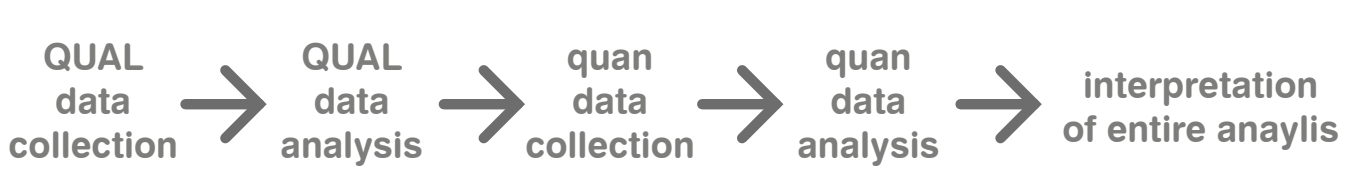

$$
\begin{aligned}
& +
\end{aligned}
$$

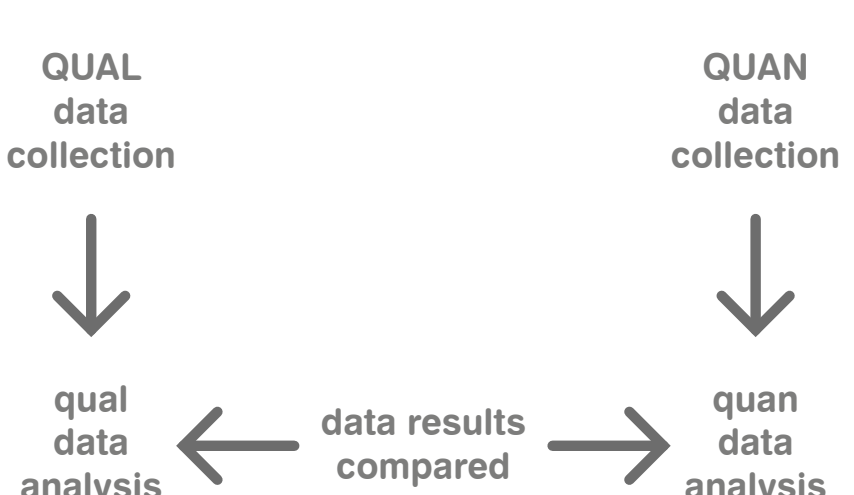


8. A brief history of the sofa

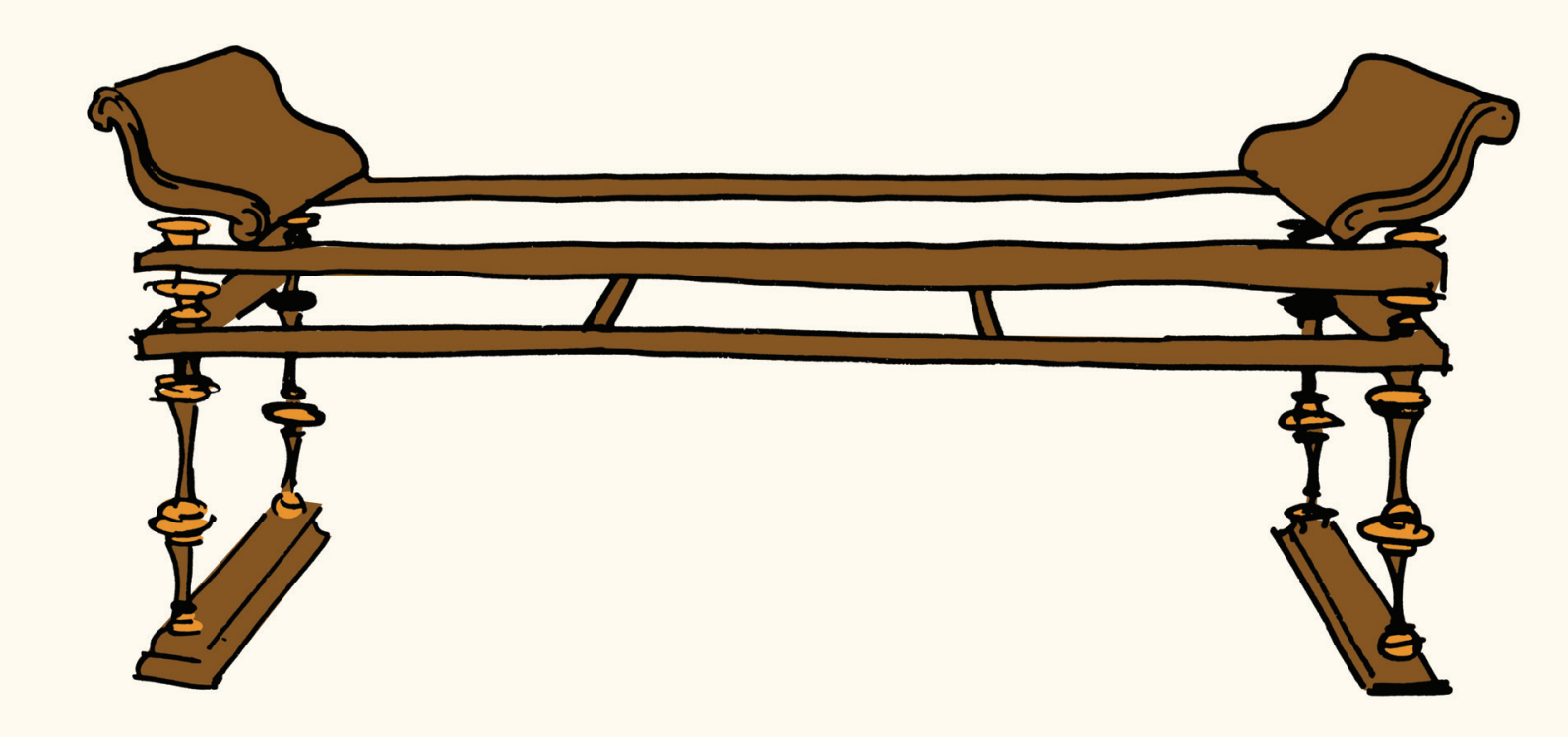

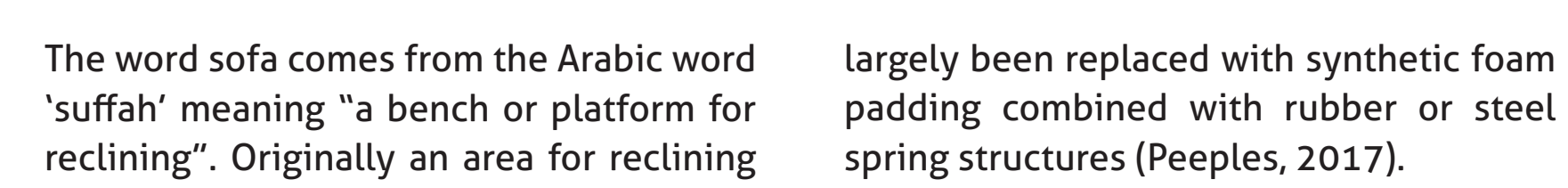

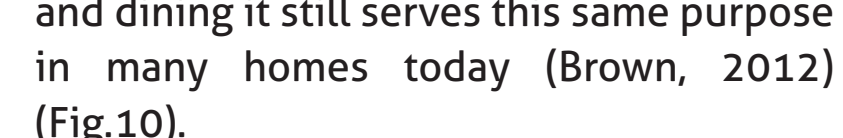

vet, while the basic function of the soft
has seminined unchanged for thousands

Throughout the 20th century new sylles
of sofis emereged such as the formal chestefified and cabriole, and the more
casual daverport, modernist, and futor Fig.10, Roman banquet couch

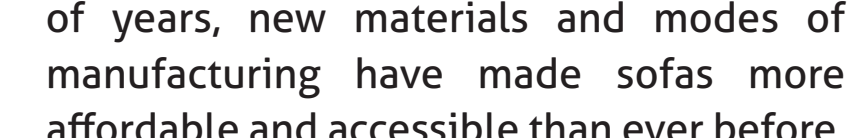

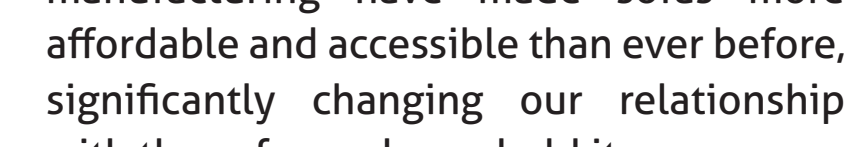

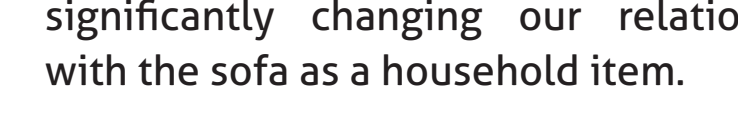

The soft developed from rasised platorom into more sophisicicted diving with
spoun base and

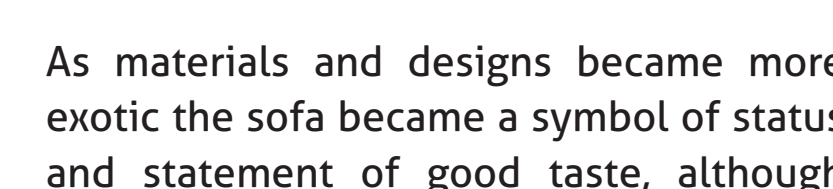

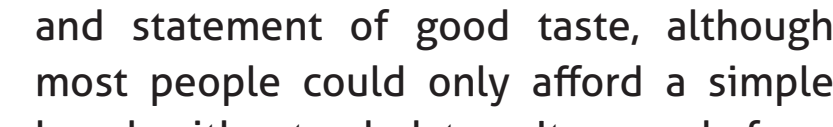
bench without upholstery, It wess only from

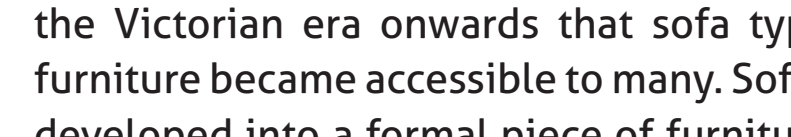

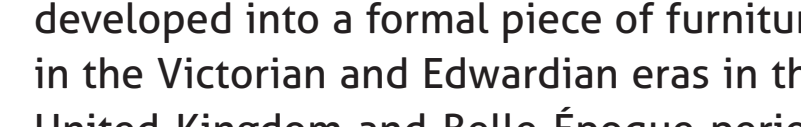

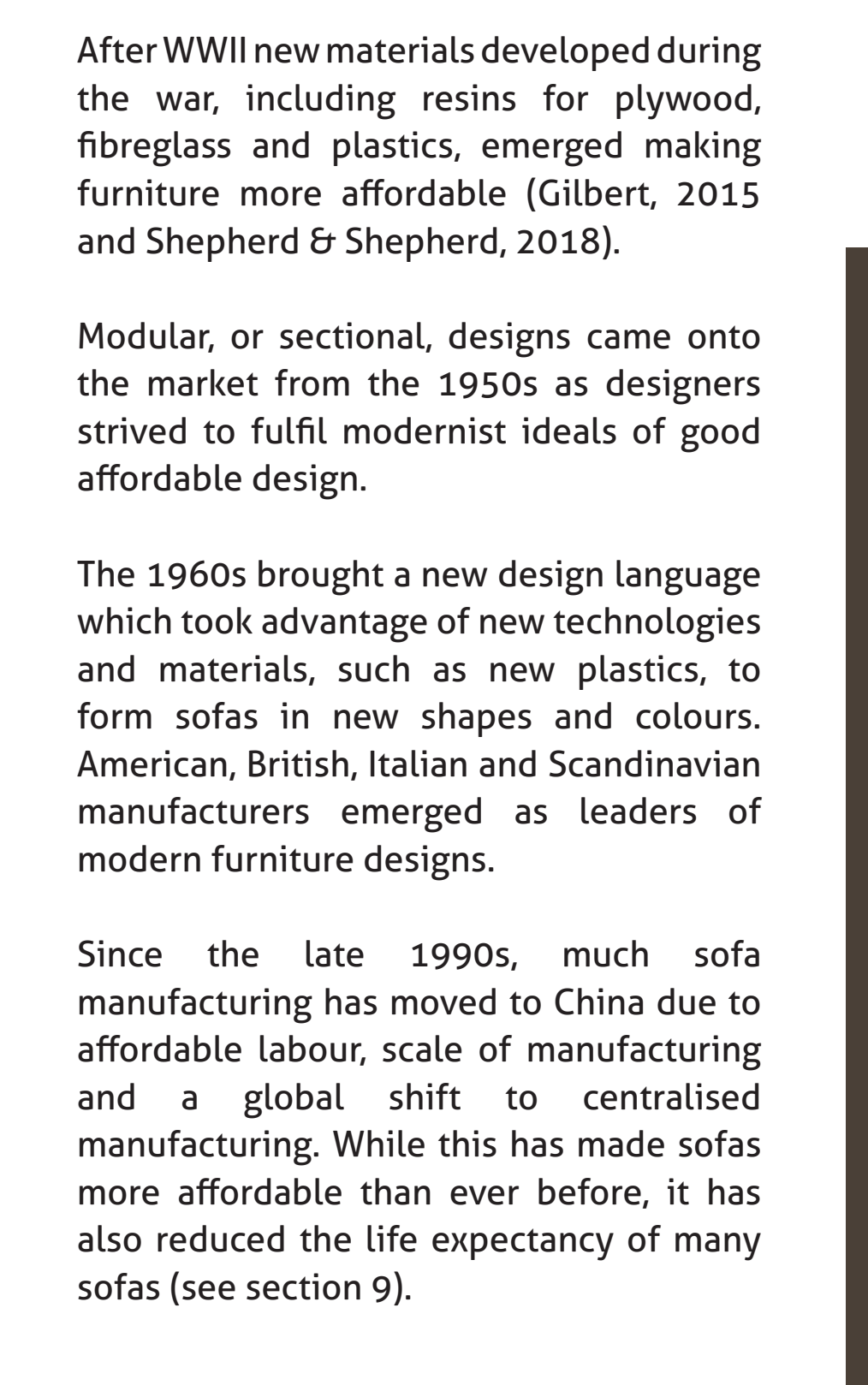

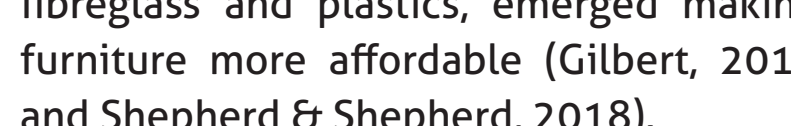

Modular, or sectional, designs came onto strived to fulfil modernist ideals of good
affordable design

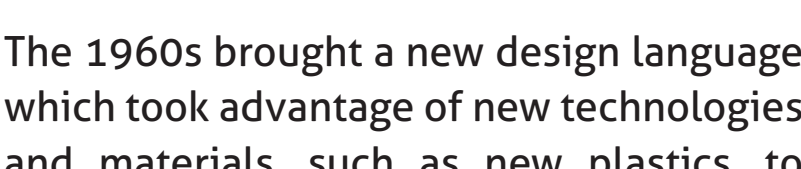
sofas in new shapes and colours Demand for sofas increased as liv
conditions improved post industrat revolution and chosen maternals included
local hardwoods and exotic timbers such as teak and mahogany. Upholstery padding at this time was often made
horsehair tree moss, dried grass cotton

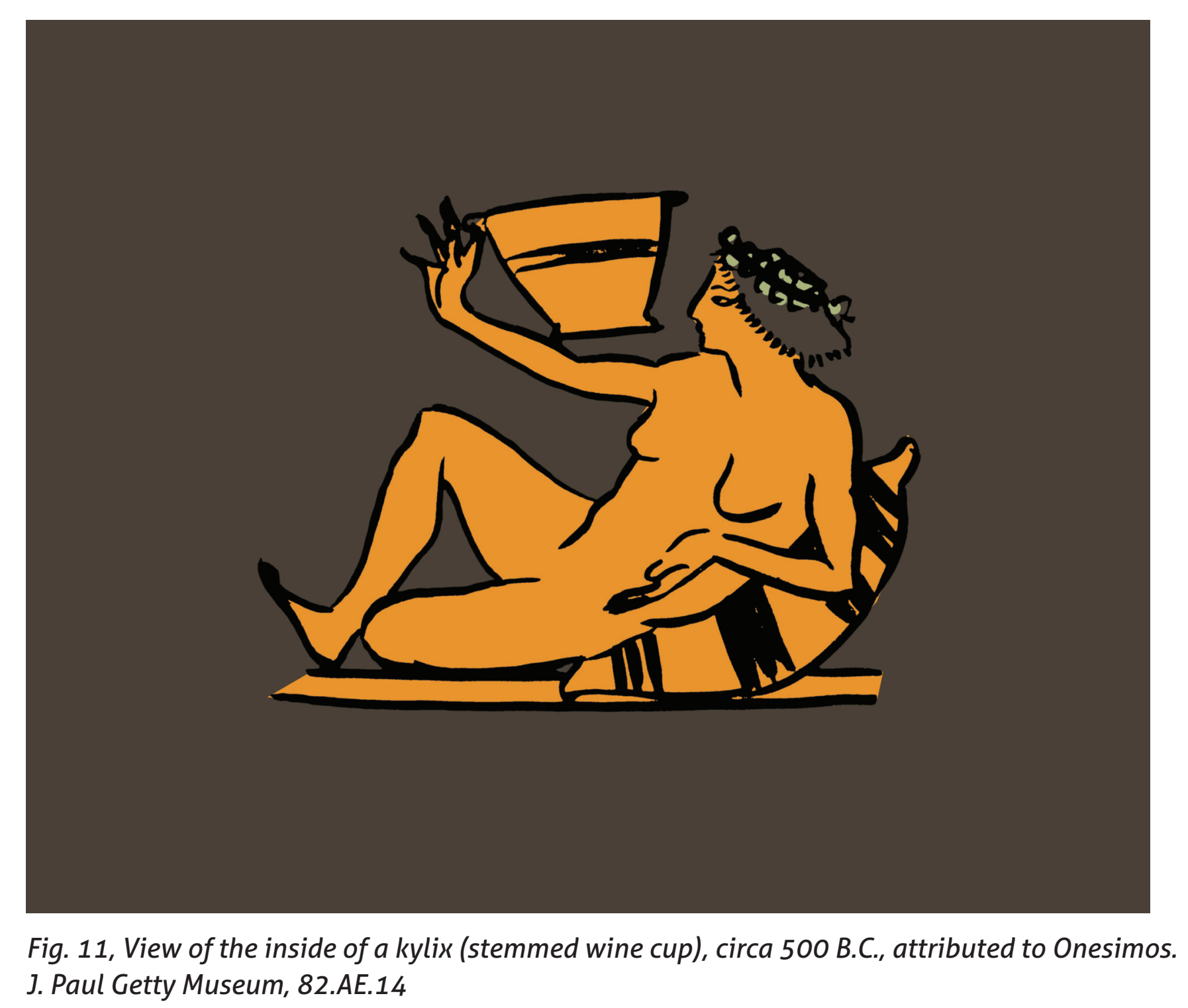




\section{Sofa construction}

a. Modern sofa construction: a problem in the making

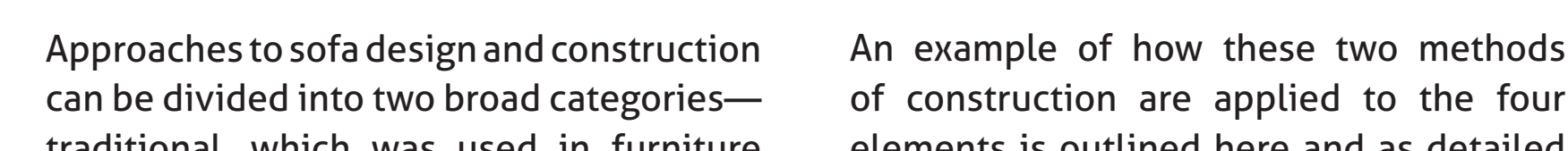

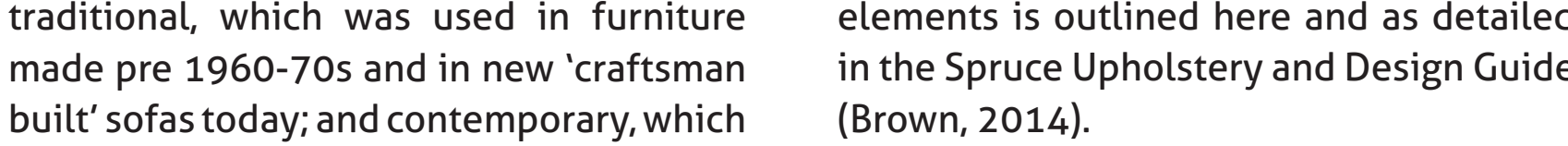

can been seen in mass-produced sofas
calde from the 1970 os onwards, and allows

for faster production, less manual labour
and therefore a more affordable sofa.

The emphasis of traditional construction
is on craftsmanship, comport and uality.
whereas contemporary methods are

Whereas contemporarary methods
more affordable and typically more ddvantage of new materials (particle board,
polyurethane form to to owerthe cost tand

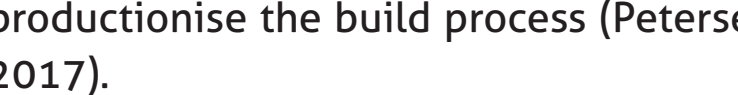
As the traditional method is built largely by hand from high quality materials by
skilled furniture maker and upholsterer, it
con be repaired by other furniture makerers The contemporary mass produced sofat
buitit using materials and techniques more
suited to a factory, reupholstsering these to traditional repair methods. Upholstery
Gnishing is still largety a manual stilled 2014). While there are many variations of the
methods and materials used, the average soff is comprised of just four elements:
frame, suspension system, wadding and
filling and unholstery.
Traditional construction

A hardwood frame is jined with dowels
screws and dnimal or rynnthetic gue and wanted, frame earts shaped to crear
curved forms. Feet are typically joined to to

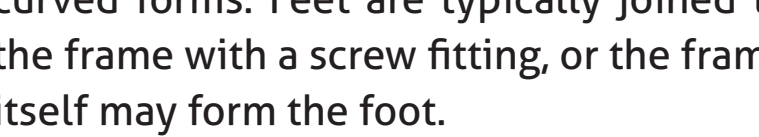
Suspension

Webbing is strtecthed across and tacked
or stapled to the frrme to add tension and strength. This creates a base for the
oil spring suspension which forms to the shape of the user to give even support
when sitting and lift when standing. Steel coil springs are tied or cinched the springs in four directions to secur
them to the frame and force them to ac suspension is very durable and rarely
suts suspension is very durable and
need to be replaced (Brown, 2014).

A modern alt
unit ff(fi.12).

Finally, heavy linen fabric is laid over the
springs and sewn to the coils to protect the

Wadding and filling

Wadding softens the surface of the spring
base, gives the piece a plush surface, art

Doulds the shape of the chair. Horsehan
cotton or straw are built up over the

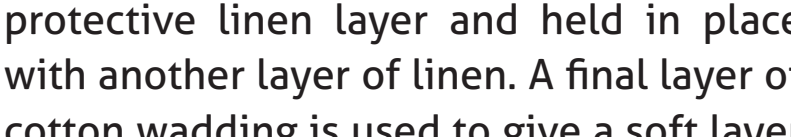

Contemporary construction Frame

to sit under

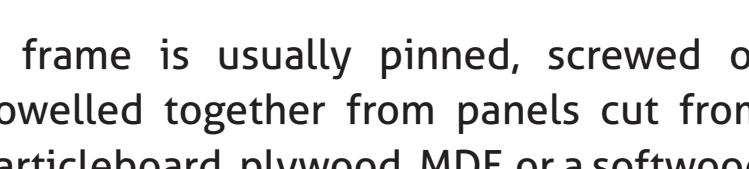
Leather, linen, velvet and wool are all
popular upholstery fabric choices, and are either sewn to fit over the form, or made to
ift in place by folding the fabric under and fit in place by folding the fabric under and
tacking it to the frrme. Decorative tacks such as brass dome headed tacks, may also
be used as a design feature around arms The seat base or back may be buttoned to detali, and these buttons tighty tited
lhrough the upholstery and wadding to indent them. A 'box cushion' may be used for the seat
base to keep it separate it from the frrme. This is fabric pocketet typicially with thiping This is a fabric pocke,
around the edges
over a wadding core. sch as pine. Timber corner reinforcement
may be gived in place, or steel brackets
shed, to increase strength and used, to

KEAs Klippan sofa has replaced an earlies

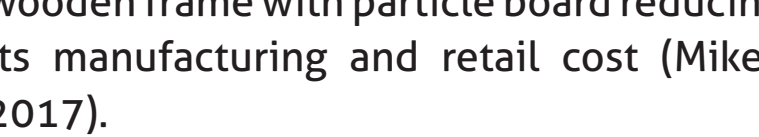
Frames may also be made from low-
carbon steel sections cut and welded

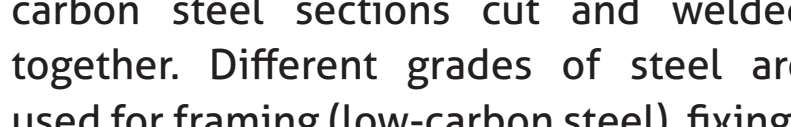
usedf for framing (low-carbon steel), fixing
(medium carbon steel) or springs (hiis suspension

Serpentine, or zig-zag, springs are
commoniny ysed in lacce of the more costly commonly used in place of the more costly
and labur intensive coil springs sud in
raditional construction methods (fig.12). These are tacked to the frame from back to front using special clips form ning a sprung
seat base, and jutue cord is tited between them to form aspring unit. This is covered
with heavy fabric to protect the materials above from wearing on the edges of the
springs (Brown, 2014). For the seat back, webbing, serpentine
springs, or sometimes onny a tensioned
fobric sheet may be used, and is stapled to
Wadding and fillin

Polyurethane foam is built up in chosen dhesive. Polyester 'Dacron' fibre sheeting upholstery layers to slide easily over the Boox cushions', are also common in this
construction style, and are vuit up in se chipped foam created from offcuts to give a more rounded and plush form than upholstery

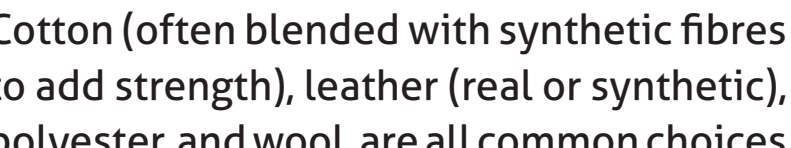
polyester, and wool, are all common choices

A base layer may be applied to smooth
he sofa before the top layer dresses the atd polypropyenene cambric dust cover is

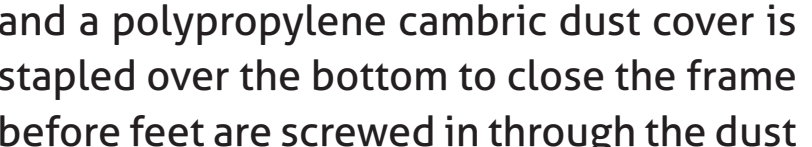
stapled over the botcom
before feet are screwe
cover (Brown, 2014). 


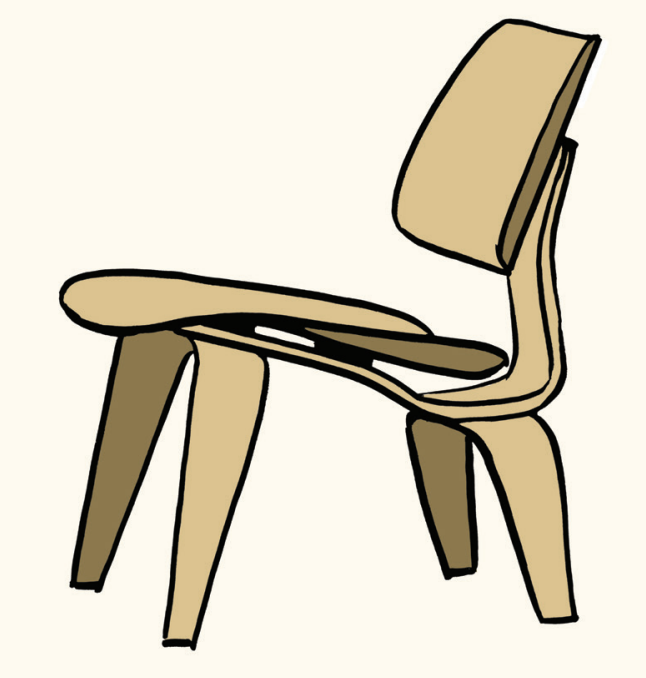

Fig.13, Herman Millervitra 'LCW' chair by Eames office The LCW chair has contoured moulded plywood sead
and back panels which support the body evenly withour
pressure points. The seat is angled down backwards

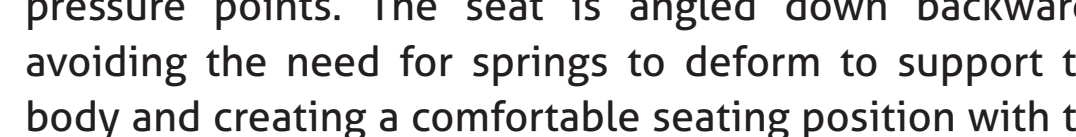
body and creating a comfortable seating pos
buttocks and thighs staking most of the weight

The LCW chair doesn't adjust to different body types as
an unholstered chair would and only accommodates one
resting position.

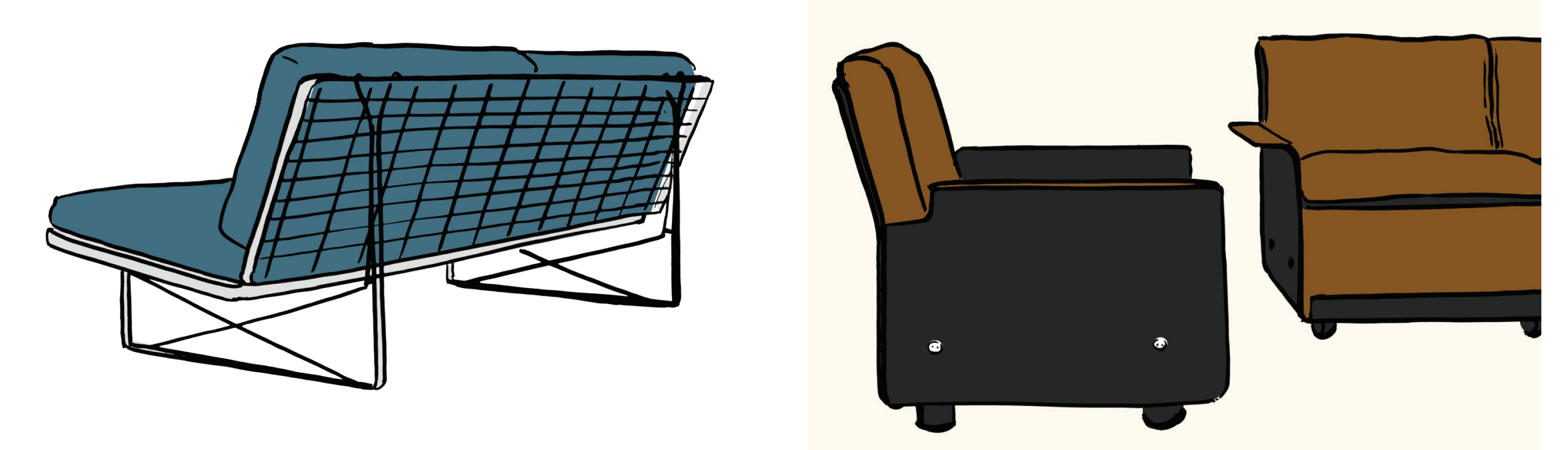

Fig.14, IKEA' 'Moment' sofa by Niels Cammelgaard

The Moment sofa also uses an angled seat base, placing The Vitsoe chair uses a traditional steelt coil spring

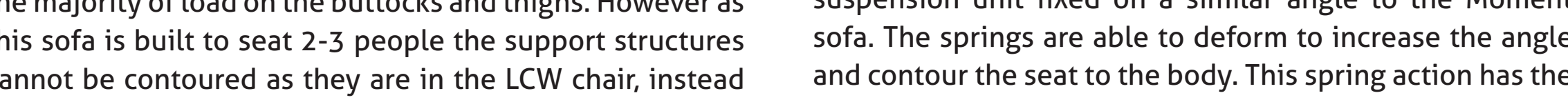
ded benefit of helping the sitter stand up. On top of the spring systema coir (coconut fibre) pad further
softens the spring surfacce and a a layer of foam moulds the support to the body (Vitsoe, n..). This is a sophisticated
system using three layersto create suspension and suppor Unike the other examples in this section, the vitsoe has a
high hack which suppoort he neck and shoulders
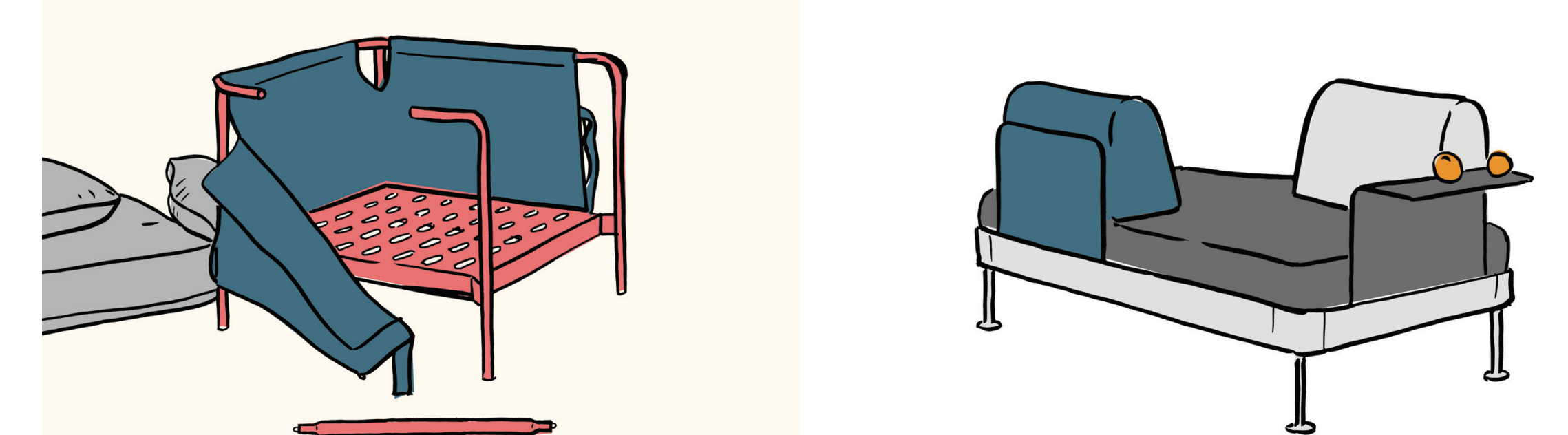

1.

19.16, Hay 'Can' Sofa by Ronan and Erwan Bouroultec The Can Sofa has a flat sheet metal base with a loose
bam cushion on top providing both pressure support and chioning

The eseign is conceived to be self assembled with a flat seat cushion is used in place of the spring base.

Jaby Tom Dixon

The Delakkitig sof uses a flat mattress-ype seat on a timber pocket springs inside the mattress, with foom slabs
he outside edges and top under an uphostery layer slows the object to function equally as a soff, or a bed. The frame structure, as with the Can sofa, has been
simplified to assist with ease of a assembly and allow for the simplified to assist with ease of assen
potential replacement of the mattress
Fig.18, Cassina Aire' sofa by Piero Lisson

This sorta uses a tensile support cover which reduces the .equired polyurethane foum by 65 percent compared to
typical sofa padded with foam (Stylyeark nd)

The foam layer on top of the cover helps spread the load support and padding. As this structure relies on tension haye with multiple occupants both moving independently. A downside of this system is that a small area of damage
to the membrone may result in the whole cover being
replaced. 
Comparison of key features in sampled seating designs

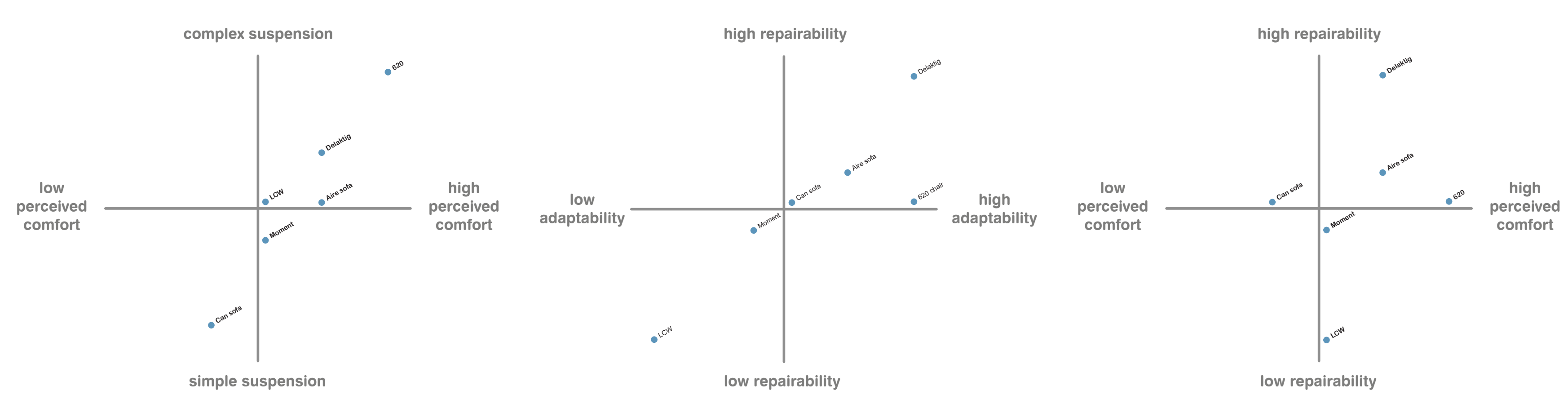

Fig.19, Comparison of key features in sampled seating designs.
Discussion

$\begin{array}{ll}\begin{array}{ll}\text { Clear linear relationships can be seen in } \\ \text { these examples demonstrating: }\end{array} & \begin{array}{l}\text { potentially comfortable system but this } \\ \text { requires munch more material (and material } \\ \text { types) than the other systems. }\end{array}\end{array}$

- More sophisticated suspension
provides higher levels of comfort - Highly adaptable systems are more
repairable

More comfortable systems are
generally also more repairable

The LCW chair is the simplest, avoiding the
need for foam, springs or upholstery, bu

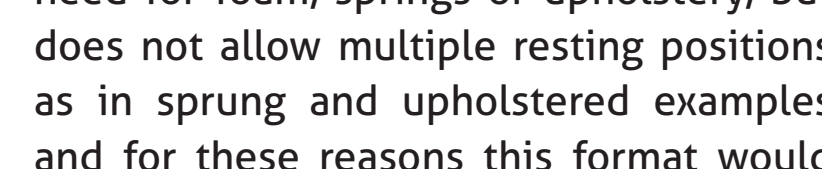

and for these reasons this this
not adpet well to a sog

not adapt well to a sofa.

The Moment, Can and Delaktiigsofasseschew
typical seating technology for the ability

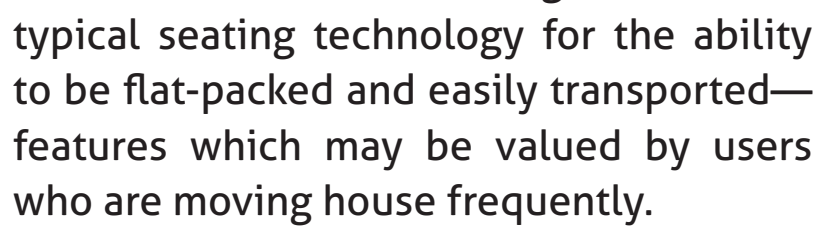

who are moving house frequently.

conceal the springstrin in the seat custion
achieving a sofa which is both comfortable

Aire applies a tensile membrane typically
seen in task chairs such as Herman

$\begin{array}{ll}\text { Miller's Aeron Chair. This works well for } & \text { With the exception of the Vitsoe } 620 \text { chair, } \\ \text { one oc ccupant but may react differently } & \text { these examples share a similar low back, } \\ \text { with two people seated, due to the added } & \text { this gives lumbar support, though does not }\end{array}$

Angling the seat can also enhance comfort
while being more material effcient

Ceating the suspension system from

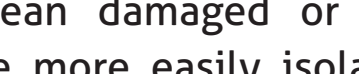

support the shoulders and neck. This could
be acceptable due to fashion of function

Overall this comparison shows that a non- considerations- as many modern sofis

dequate suspension to increase comfort.
Thit on. Tom Dixon's Delaktig 'bed-sof́
This benefit fabrication, assembly and
demonstrates the line between sofa and

demonstrtates the line between sofa and
bed cold be beginning to blur (Farguhar,
2018).

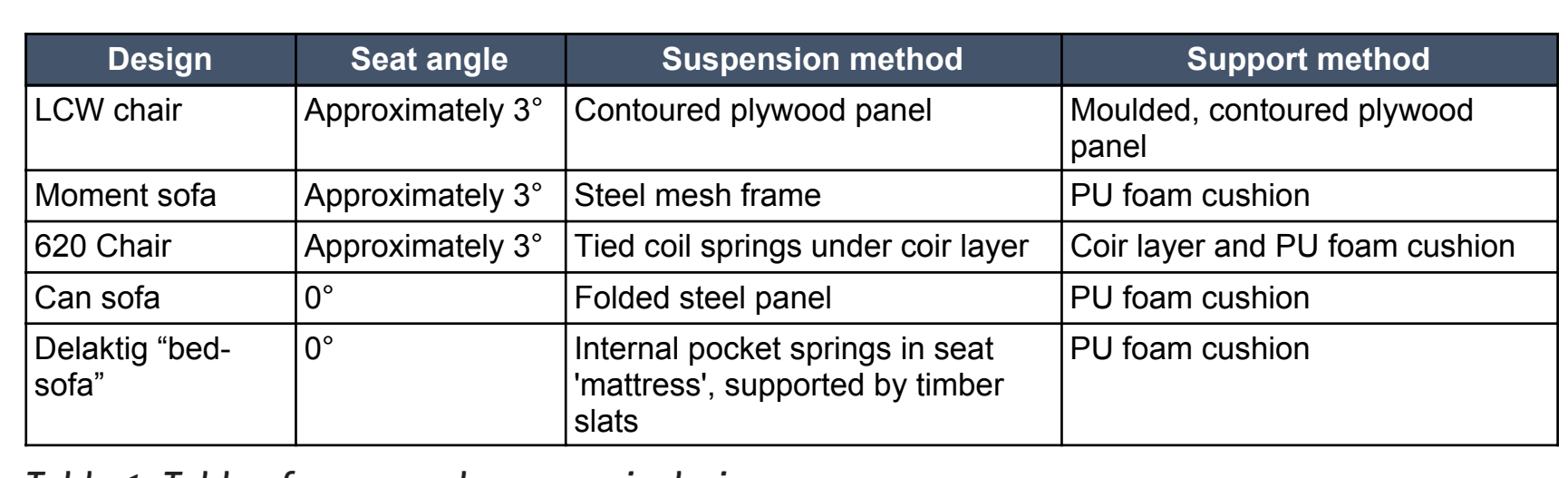

Table.1, Table of compared ergonomic designs 


\section{Sofa obsolescence}

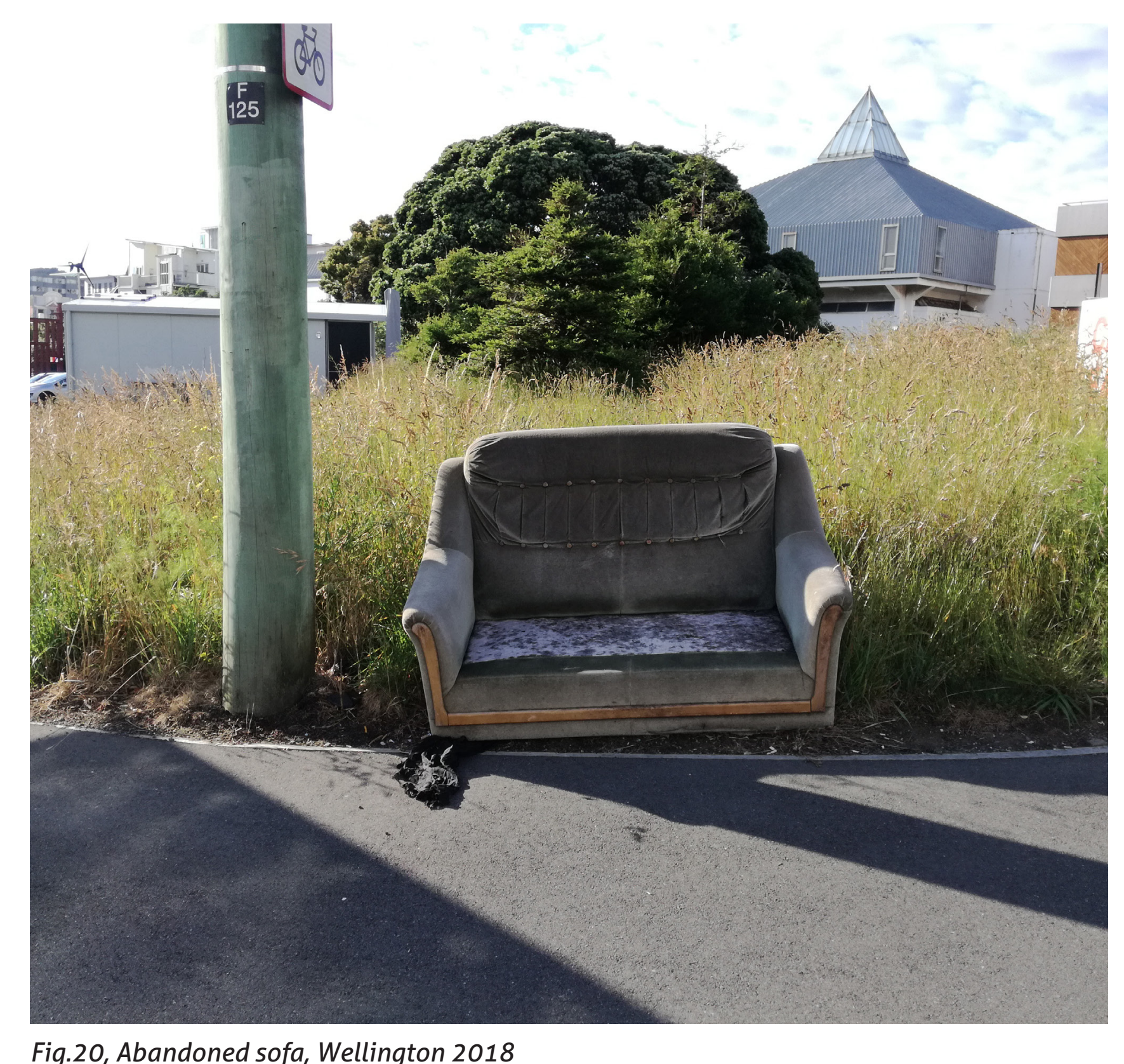

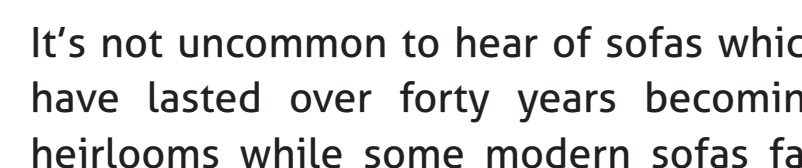

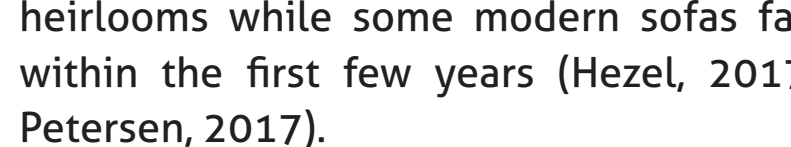

This is because over recent decades the
life expectancy of a sofa has shortened

from 15 . years to 7.8 years or less (Palmen
2012). Despite this, at least

consumers expect furniture to last 20 years

"That blue couch survived as long as it did because it's

framing was solid wood; whatever its stuffing was, it held on

for decades, not years." Anne Helen Petersen (2017)

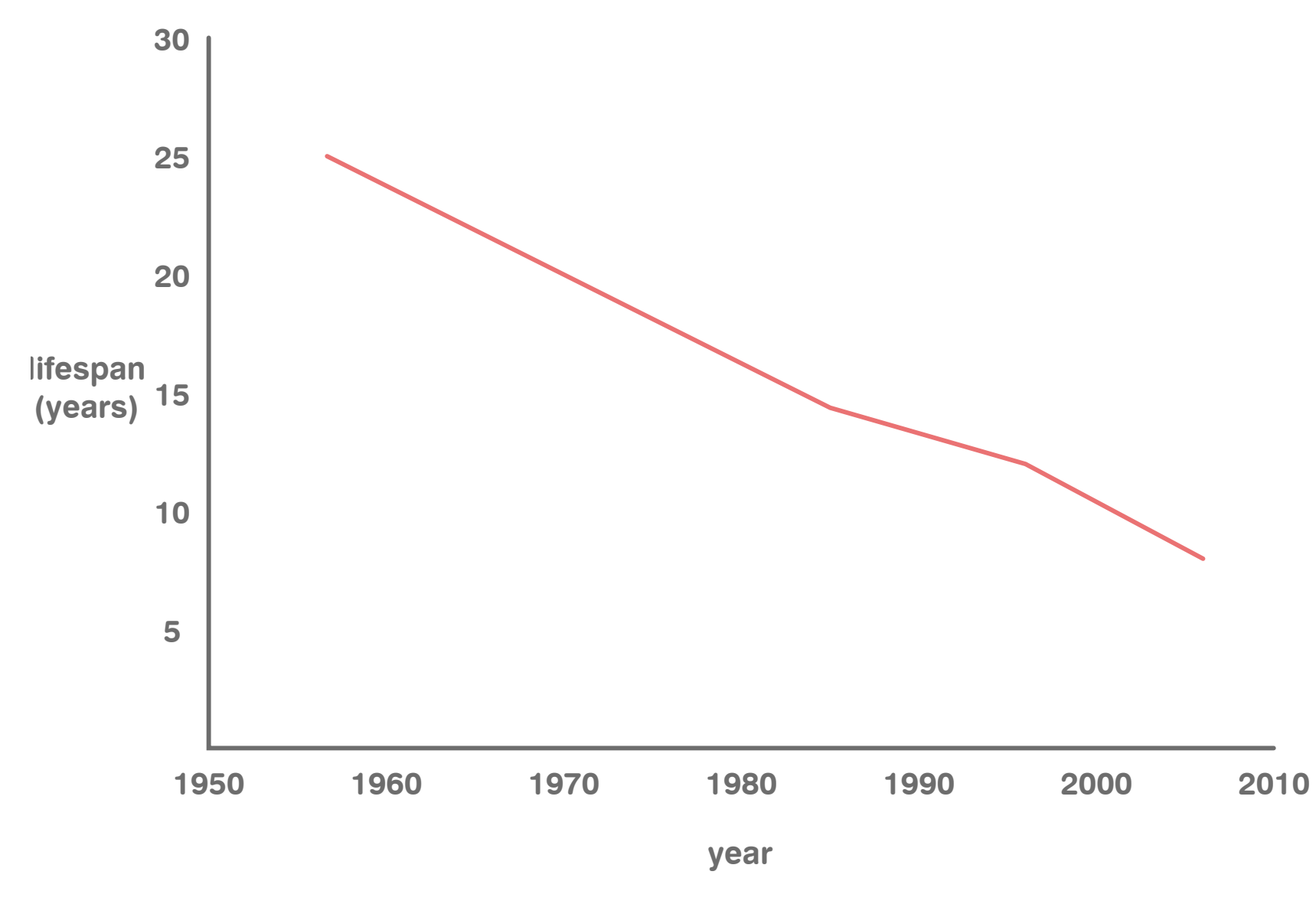

Fig.21, Illustration of falling average sofalifespans,
Figures from: Hezel 2017: Petersen, 2017: Palmer. 2012 . 
Modes of non-functional obsolescence

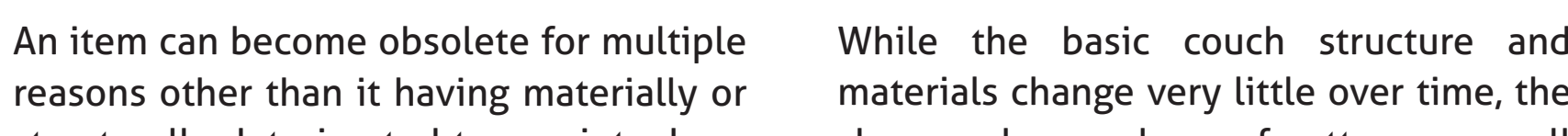
it no longer performs acceptably.

The eastheticmay nolonger be ontrend, the
format and size may no longer be suitabs due to change in circumstances such as a
growing family or do tonnsizingl or the cost Burrs (2010) suggests these modes of categories: Aesthetic, economic, socis
and technological As outhined below, aesthetic and economic on sora obsolessence. This can happen when an item is ither no
longer fashionable or is visually worr and Fashion-based

Clothing, hairstyles, accessories and even
household items are subiect to feren rends and often replaced or discarret when they go out of style rather than when
they cease to tunction Fashion cycles for some items move rapidly
(clothing, electronics), while for others

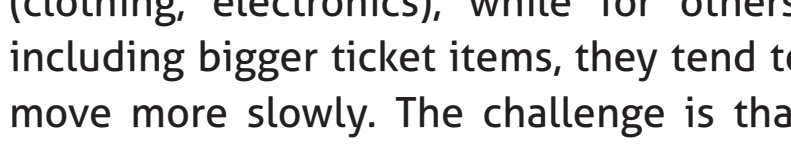
Furnitur is s sen as a signifier of progress
in life and good taste Peetersen 20017$)$ (

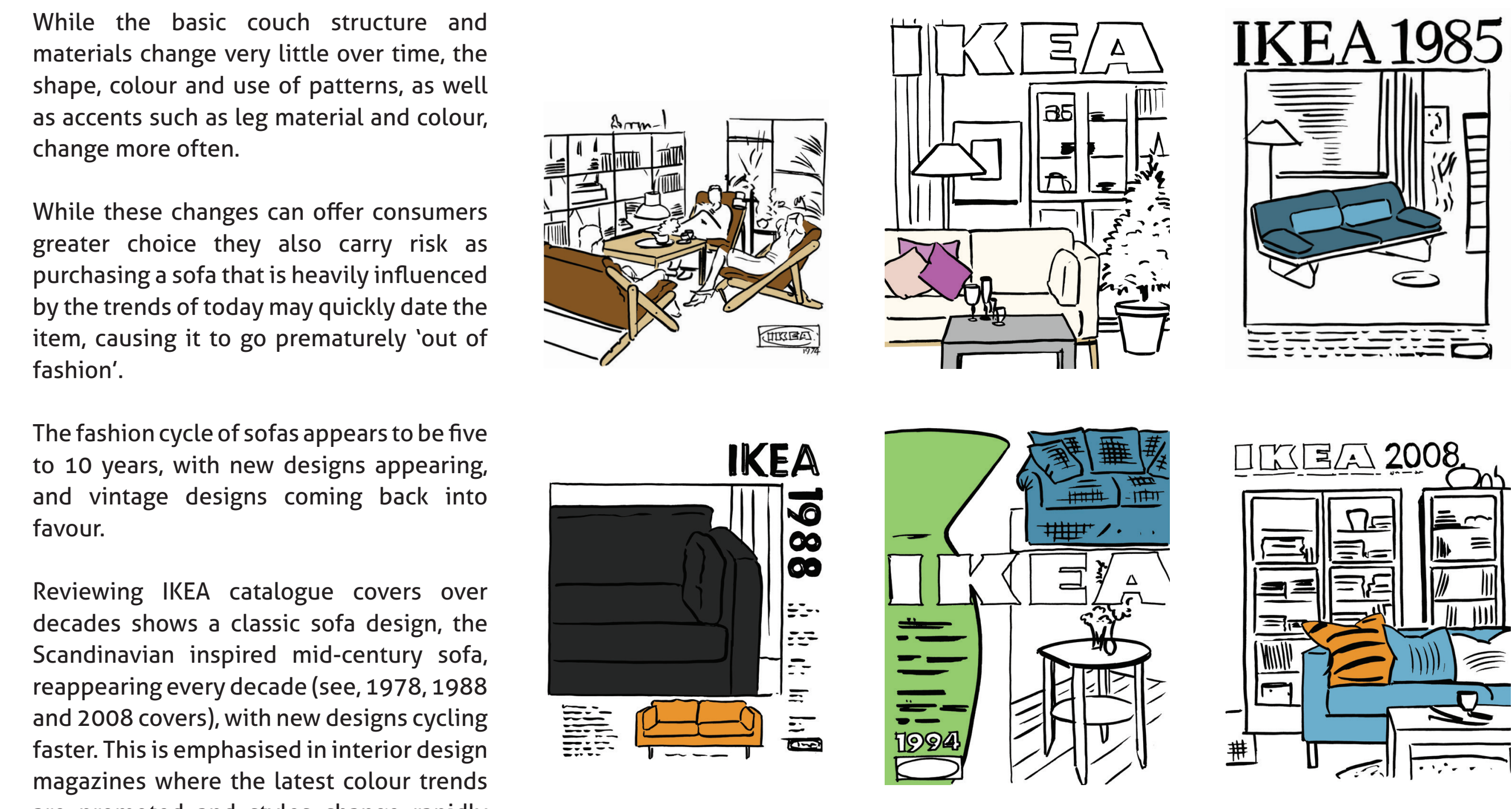

Fig 222 Series of IKEA catalogue covers illustrating changing fachion cycles

1974- Peak pine fashion

1978 - Classic recurring 'mid-century' inspired sofa design

1985 - Edgy design, has now become a sought after classic

1988 - Classic recurring ' 'mid-century' inspired sofa design

1994 - Patterns and rolled arm sofas become fashionable

2008 - Classic recurring 'mid-century' inspired sofa design

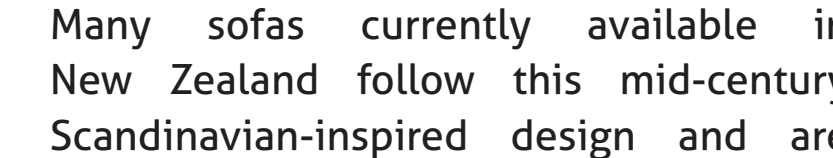

upholstered in a muted colour polette
This minimises the risk of a sofad dating quickly or classhine with hexisting or future
decor, these are important considertions

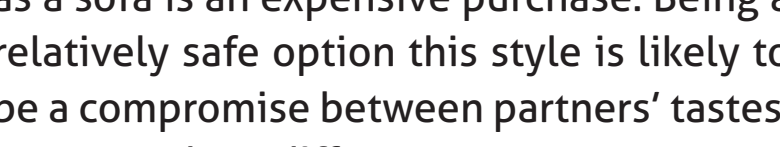

Unless a consumer replaces their sofa for
the latest seasonal trends it will almose always be somenumath ' 'off trenc', even soon remain desirable over decades and so are

As there are many compromises involved
when choosing from off-the shelf designsit suitable, especially over a longer period There is s learly an opportunitity for design
to offer greater aesthetic customisation

This suggests there are two paths available
for overcoming fashion-based aesthetic
obsolescence.

Design a sofa which will be unaffected by fashion cycles
Designn asystem able to be adapted to While it is technically harder to des existing popplar designs, and aiming to cruccess. Many new designs appeare every
suts

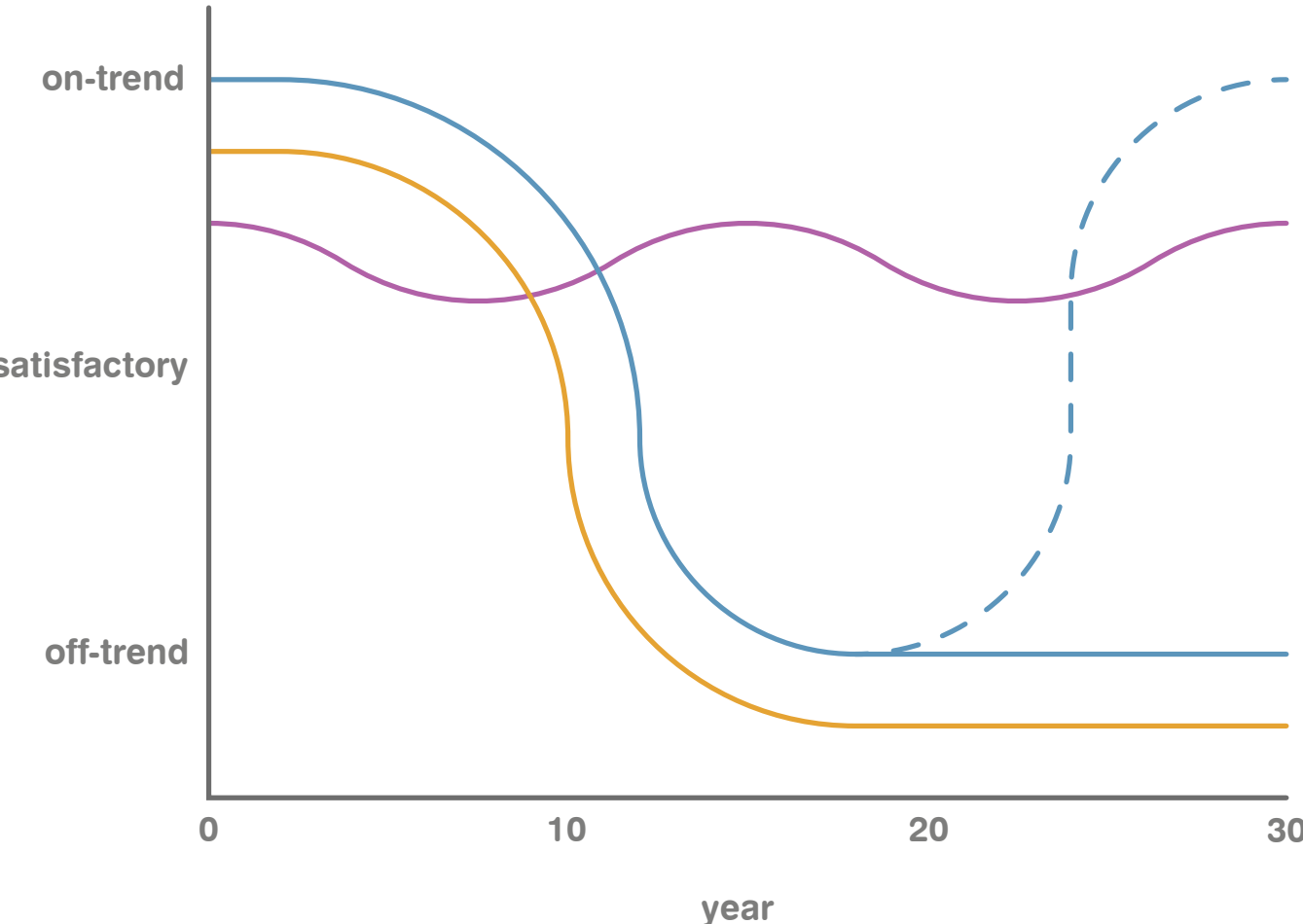

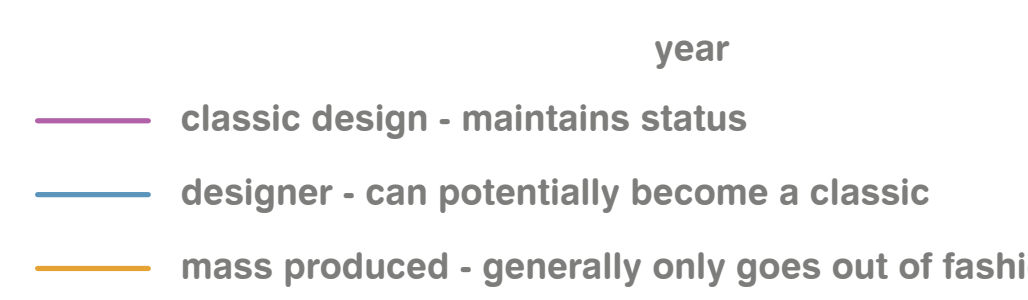

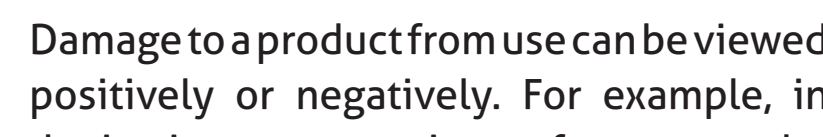

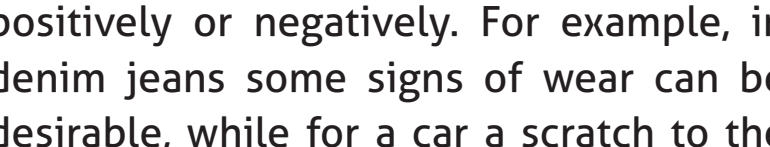

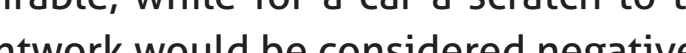
Applied to sofas both scenarios could be

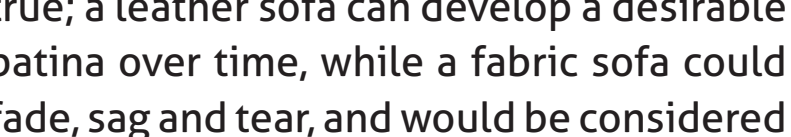

some areas, such as corners, edges and

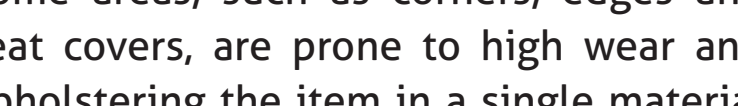
highlight fading due to UV photo-

sign decisions, such as upholsterin opparent wear and may yeven make the sofa longer lifespan.

Coper (2010) and Burns (2010) describe low worm a product appears as
"useness" versus its "newness".

Fig.23, Illustration of potential sofa / trend performance] In Worn Out or Worn In?? Ross Stevens

"As a rule, beautiful things tend to have a longer history than produced products to age and devele ugly ones. We take good care of beautiful things, invest in maintaining them and perhaps even try to preserve them for the future." Fredrik Bengtsson (2010) the bond we have with our belologings.
stevens proposes that desigers could design products with the added dimension 作 
Social obsolescence affects products when they become unacceptable
shifting values; consider gollywog dolls, fur coats, and even cigarettes.

While sofas are unlikely to become so
examples leather and synthetic fabrics.
Leather- Leather sofas

Leather: Leather sofas may become
undesirible as people look to move away
fromanimal products. While leather has not
yet been as targeteded as other animal skins

yet been as targeted as ather animal skins
and fuus, perhaps beccause it $t$ is considered

aby-product of the meat industry, this
change in the future (Edwards, 2018).
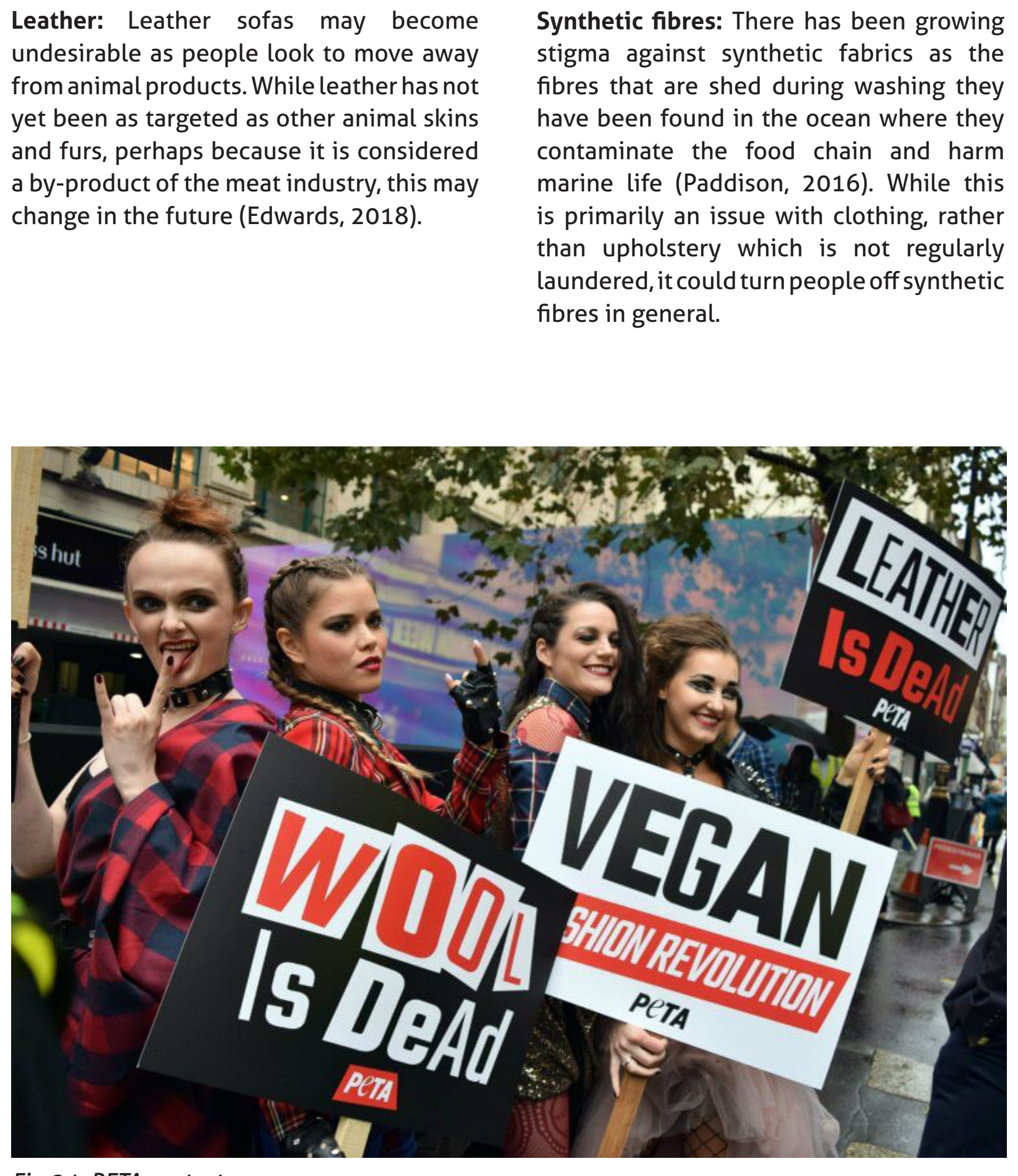
as it is the result of innovation and the
creation of In the past many products were built to
Possibly the most well-known form of
ossolescence, this is when whological obsoledescence can be
are superseded by new technology and
avoided without discouraging innovation
by designing systems that allow future become undesirable despite functioning
well This tinovations to be integrated into current
negatively.

For example, typewriters have been

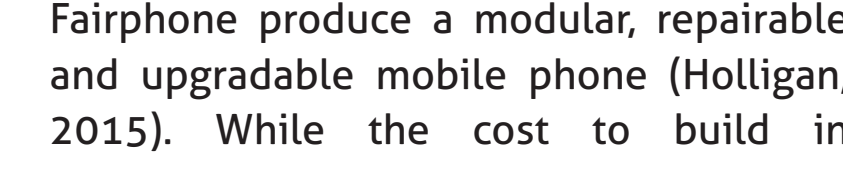
this compatibility means the initial
manufacturing and retail cost is often Technological obsolescence is usually sreaminining the ports on their Macbook,
making it impossible to connect hardware (Mut a new adapter. (Matney, 2010) manufacture cheaper goods has redu
quality and lifespan (Cassidy, 2014). This products are not supported with spare subassemblies have to be disposed of annoy customers and negatively impact
brand loyaty (Burns, 2010). Today repairable and adaptable products
are typically niche, high-end products, and are typically niche, high-end products, and
the high price of these makes it difficult to Justify paying extra when technology and
fashion is evolving Consider the repairble
Dualitit toaster, which retailsat $4445-$ many

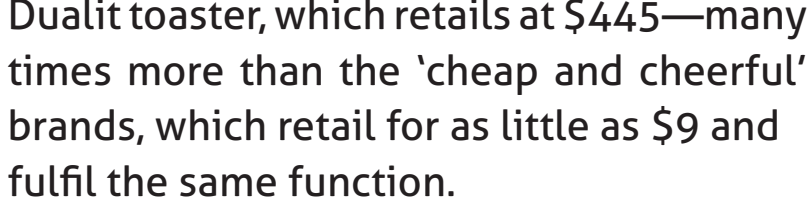

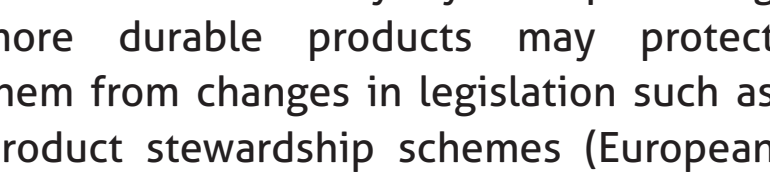
EU legilators are developing legislation
that would require greater product hat would require greater product
epairability and replacability, particularly

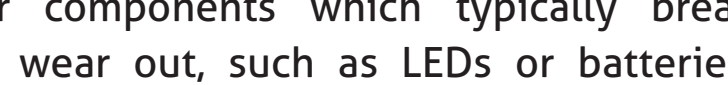
In Sweden sales tax on repairs has been some other industries; the method the same since the mid-2oth century (see these poor quality materials are prones

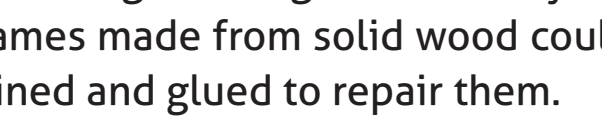

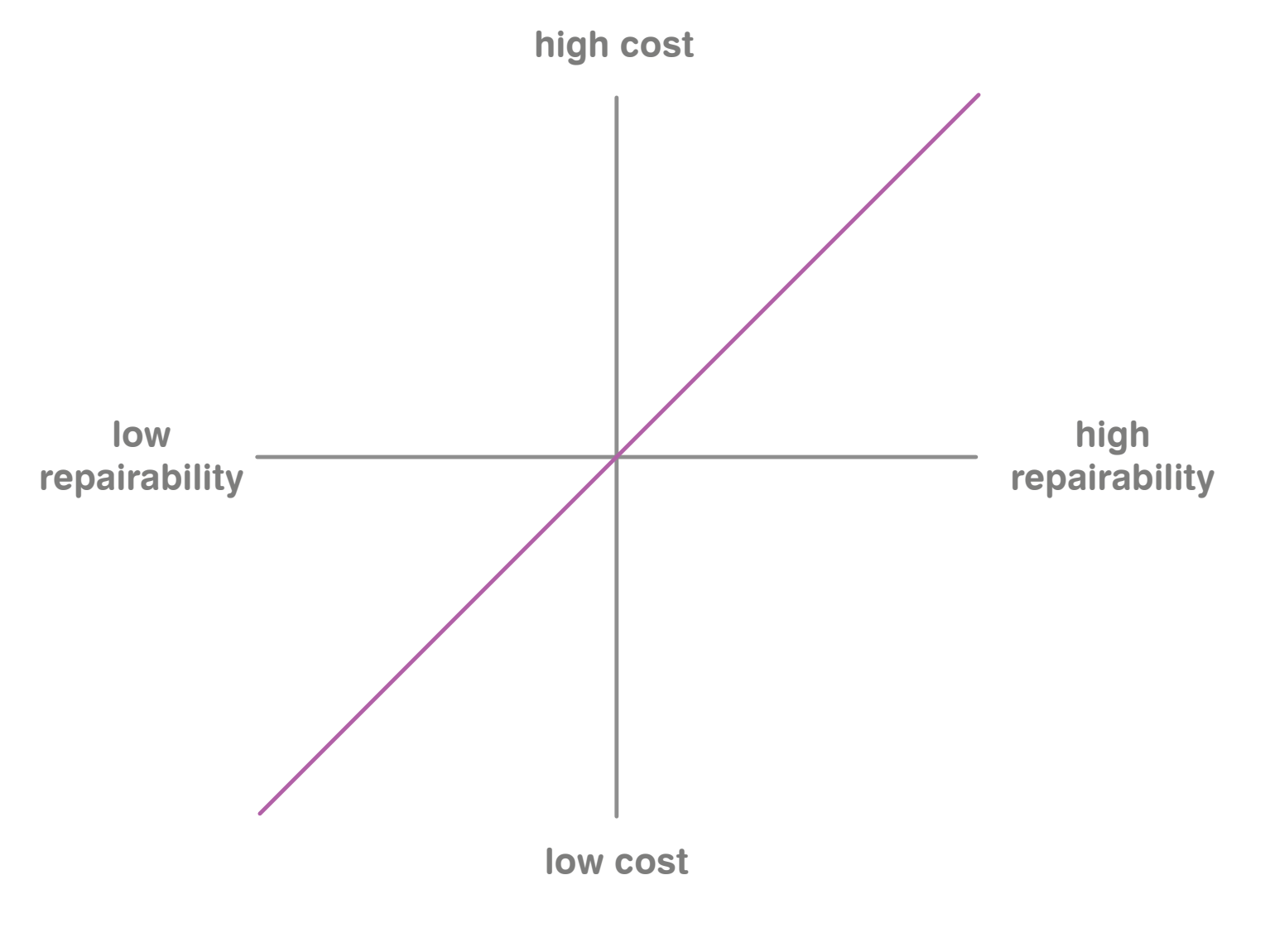

Fig.25, Typical correlation between cost and repairability
Economic obsolescence

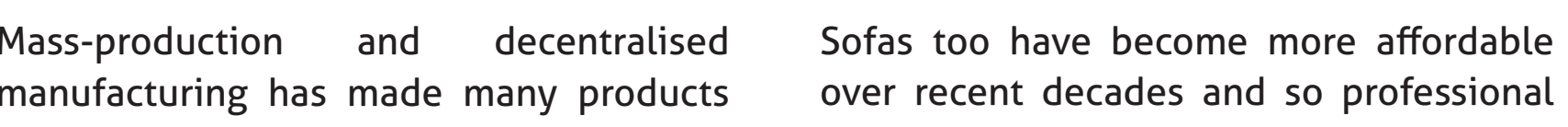
purchase more effordablee and accessible.
puten, this means that if a product broken it may be easier an
to replice rather than repar

A number of design strategies can
be implemented to avoid economic of replacement and re-upholstery. As an
example, the upholstery materials and bour for the prototype sofa developed than comparative sofas currently on the

- Ensuring ease of repair to minimise

Functional adaptability for changing

user needs
Aesthetic customisation for changing taste and fashion
Knock-down' fotwes for frames made from solid wood could be re
"Thismodecommonlyoccurs when repair, maintenance, reuse (2) the consumer." - Brian Burns (2010) 
11. Planning for obsolescence

\begin{tabular}{|c|c|c|c|}
\hline 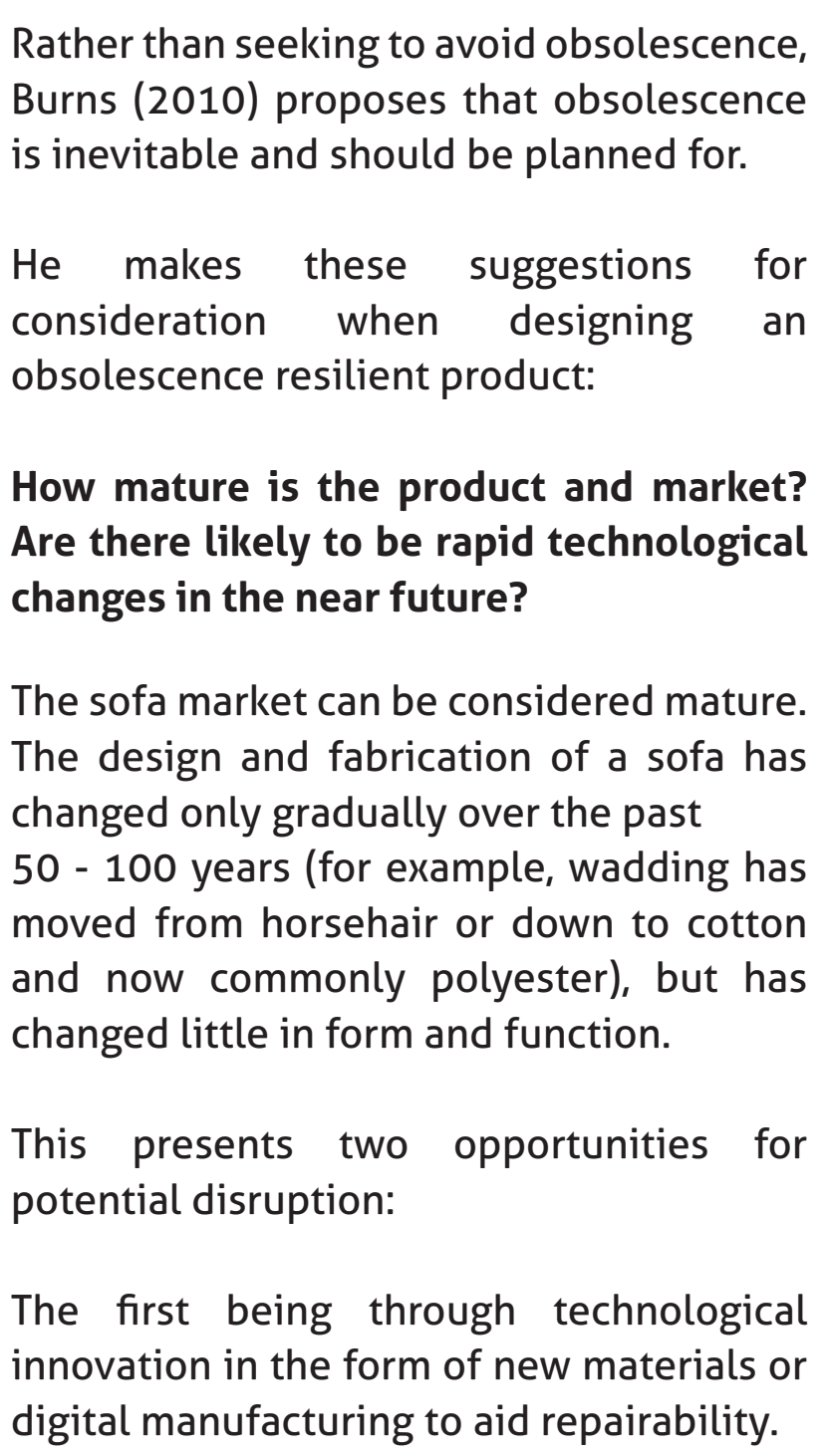 & 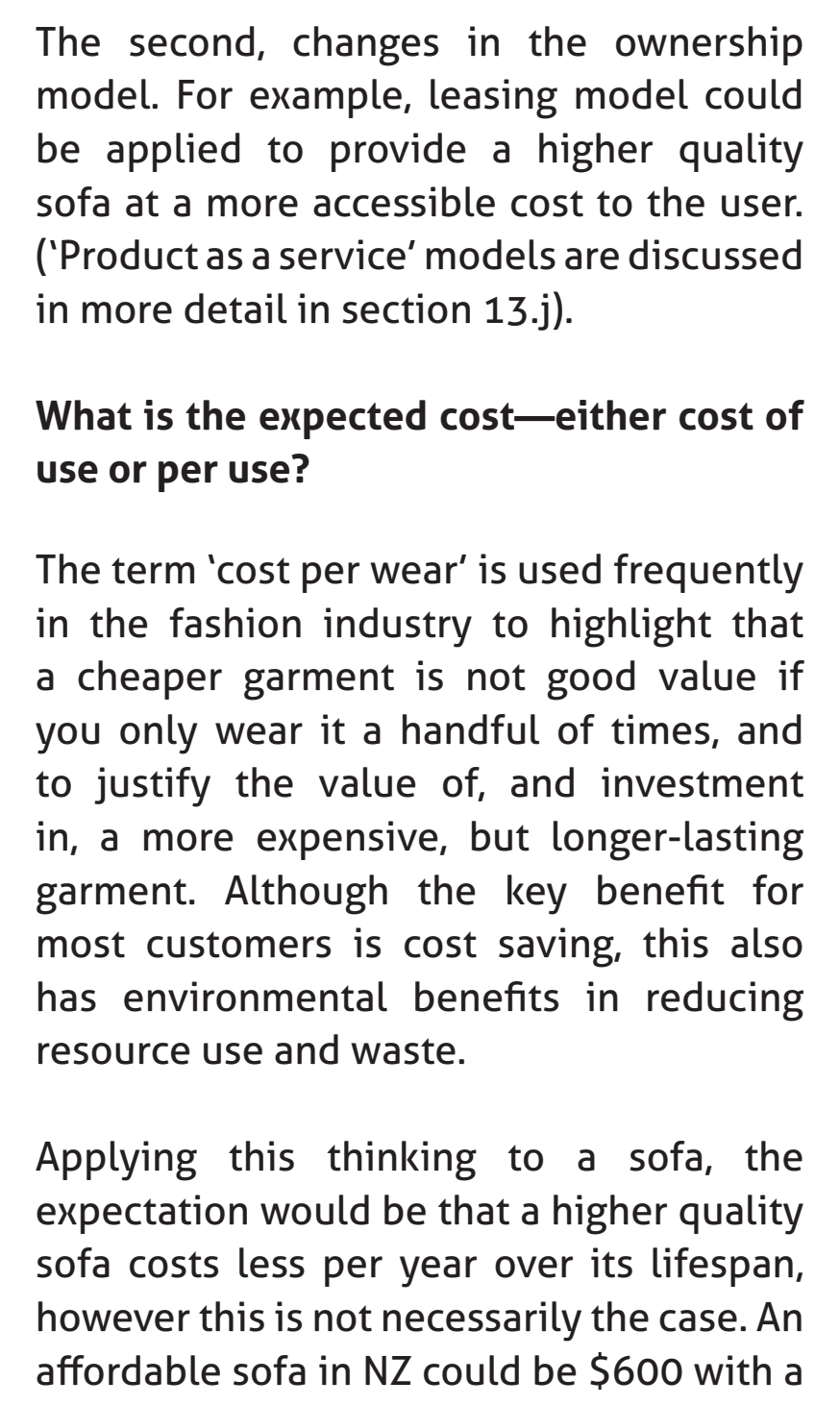 & 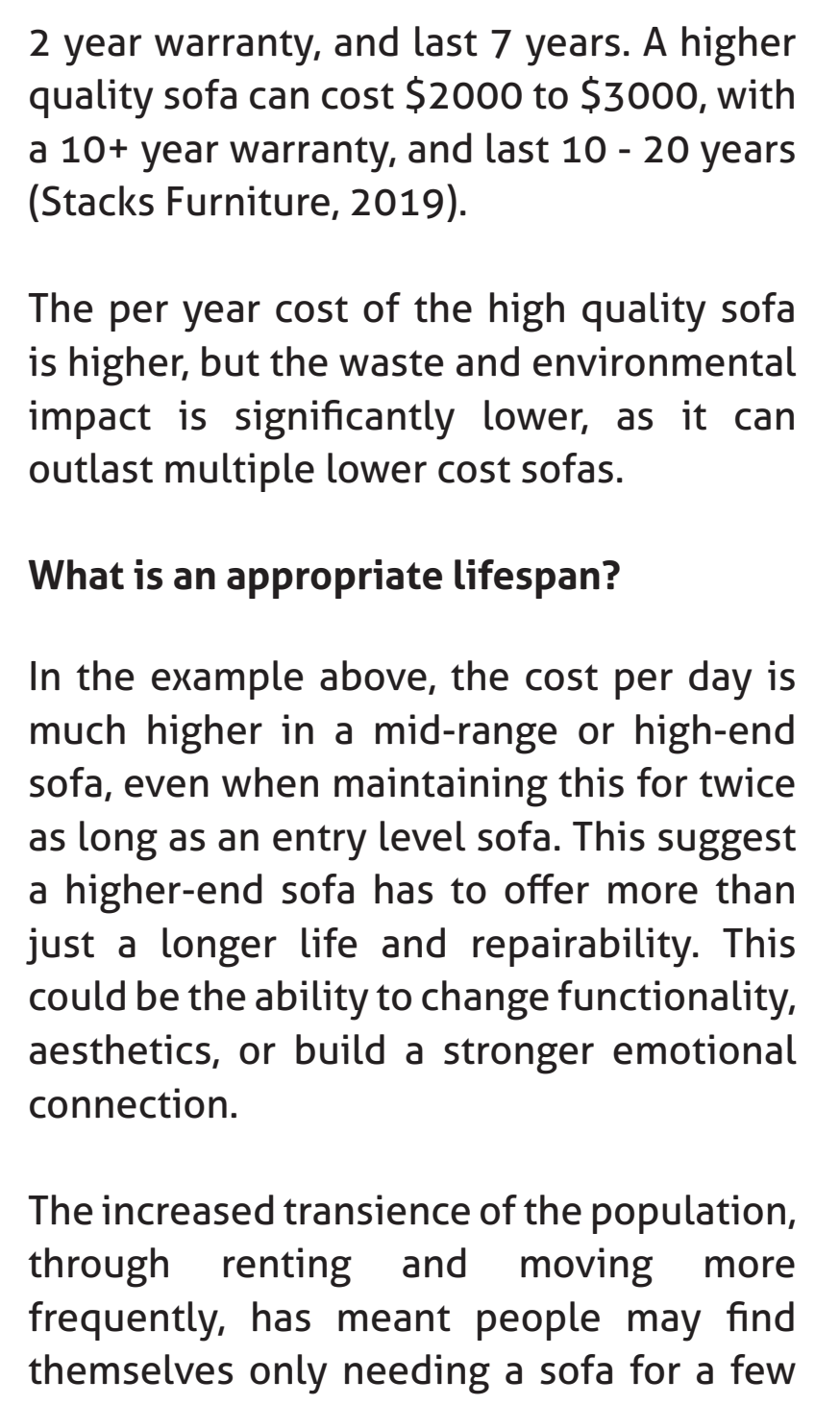 & 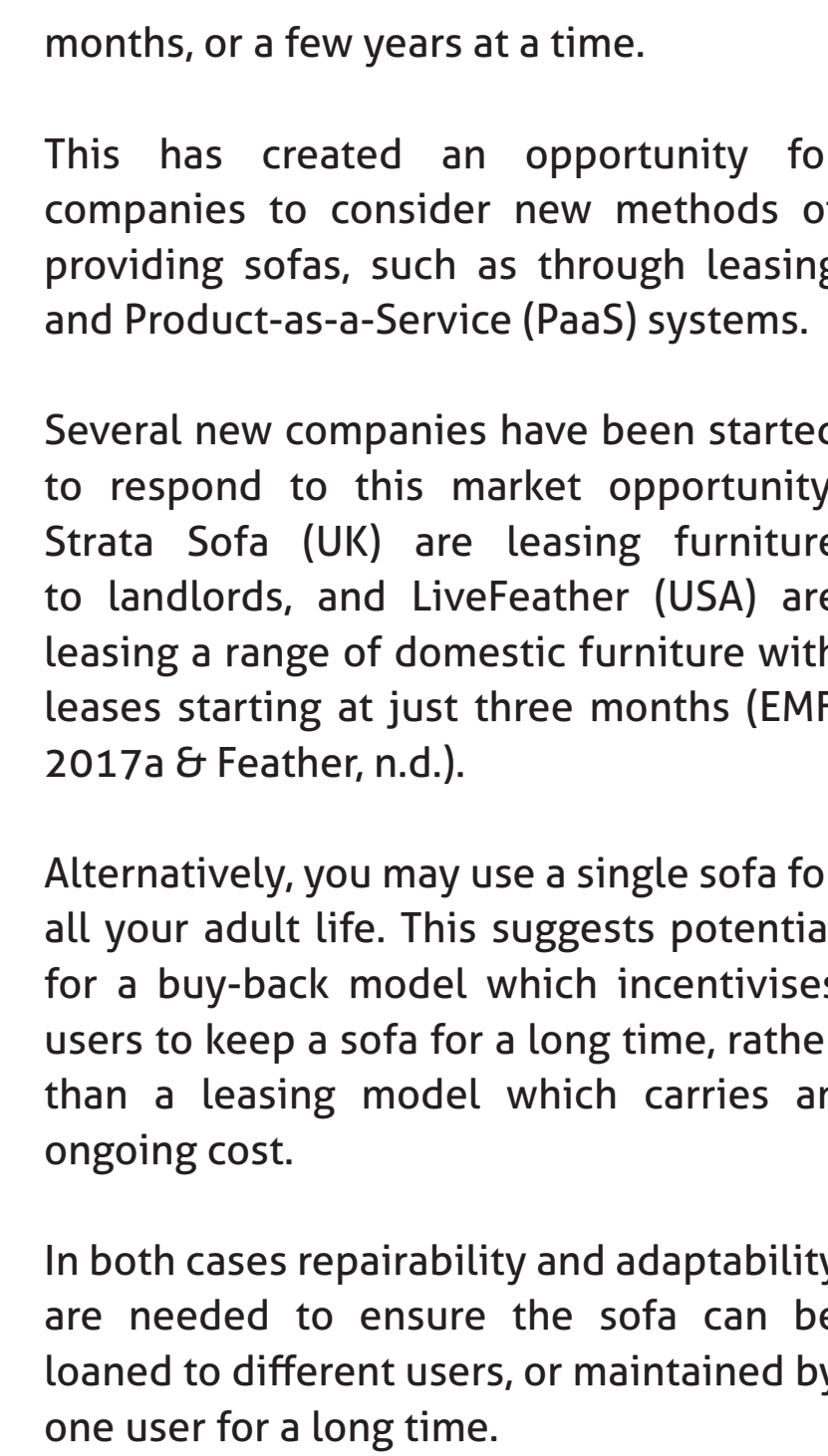 \\
\hline
\end{tabular}


What are the likely technological changes
in this time?

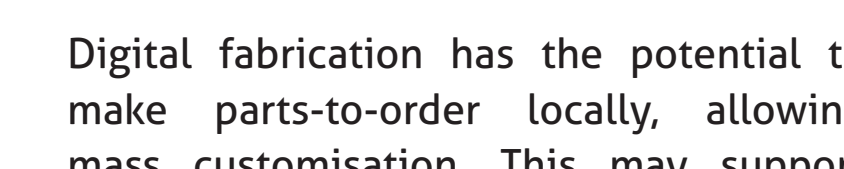

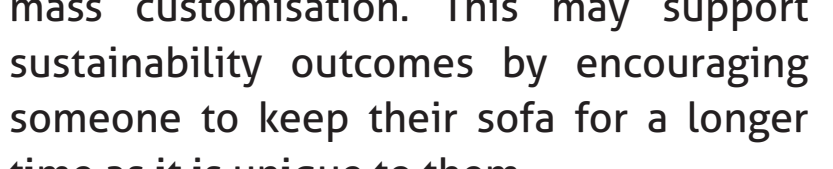
someone to keep their soff for a longer
time as it is sunique to them.

An example of digitally manufactured
seating is sketch Chair (2011), whichallows

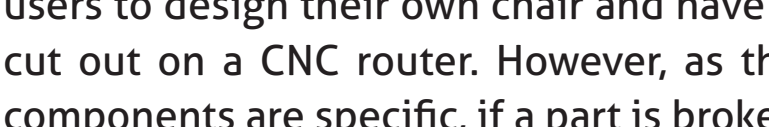

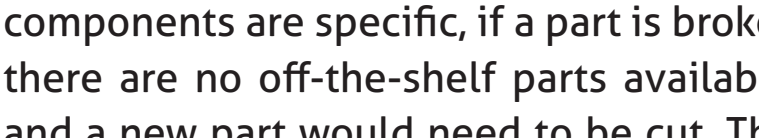
and a new part would need to
could make it harder to repair.

Digital customisation of covers s s an option
which would allow creative freedom while maintaining the ability to repair and replace
most of the sofa with standard parts. More sustainable materials are emergins
sush as timber products (Scion, n.d.). Designing for
deconstruction allows these new materials deconstruction allows these new materias
to be phased into old units. What is the likelinood of laws and
standars changingin? Clobally, pro-environmental legistation
is emerging. As discussed above, new Uu legistation is introducing product with recommendations for tother productucts
to ensure repairability (Anastasio, 2018). The New Zealand government is also considering stewardship schemes for
lithium batteries and used tryes, and
are currently debating introduction dadditional landifl trexes on all waste (New
Zealind Covernments Ministry for the
Enviromment, 2018).

Stewardship schemes apply a fee at the
point of sale of a prorduct to cover the
cost of responsibly recyching or disposing

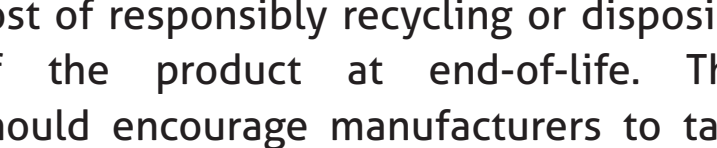
responsibility for heir products waste, and
design with disassembly and repariability Stewardship schemes generally target agrichemicalls) so are unikikely to affect
sofas (ibi). Additional landfill taxes are designed to
encourgage businesses and individuals to be less wasteful. Manufacturers may be to reduce their disposal costs, while owners may consider a longer lasting product,
repairing or selling the sofa instead of Unike stewardship schemes, additiona
landfill taxes weould cover all titems sent to

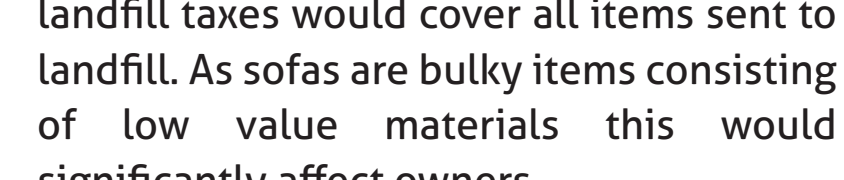
.

促

(

\section{Cascading sofa ownership}

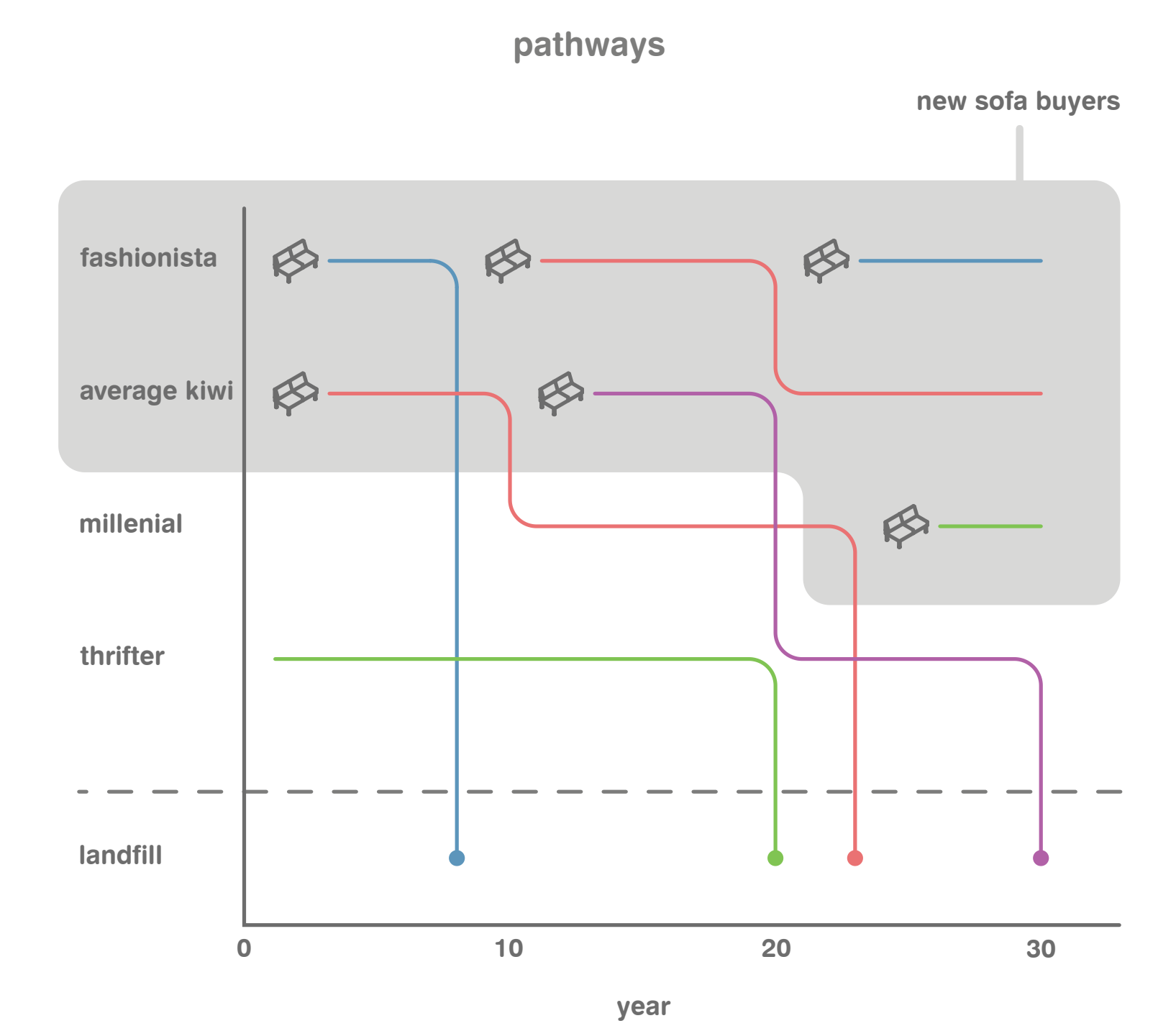

Fig.26, Potential sofa ownership pathways

Given the different reasons for s sofo being passed on or disisposed of it tmay not go to tolandfill
after one owner. Typically sofas are given to other family members or friends, donated to

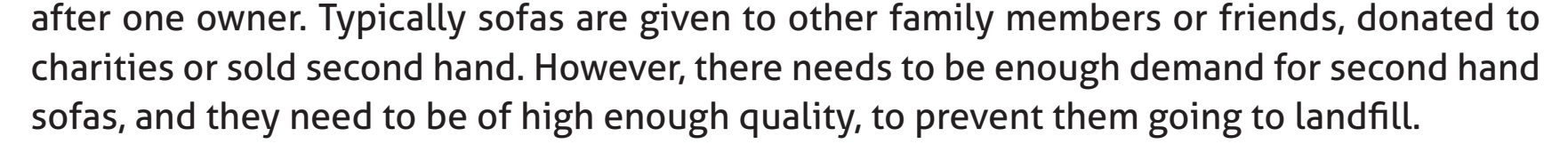

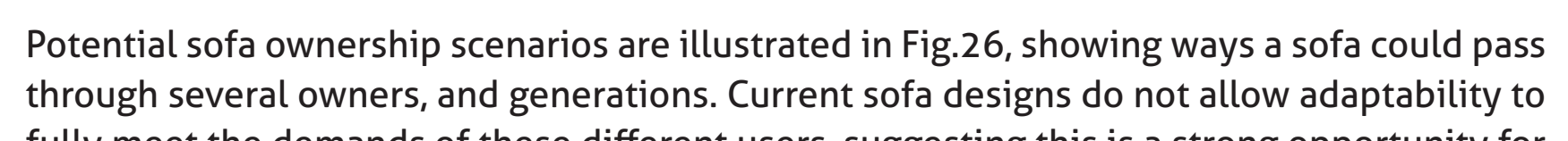

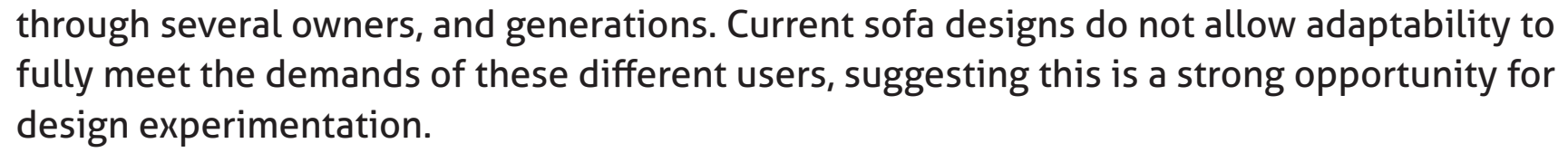

Discussion

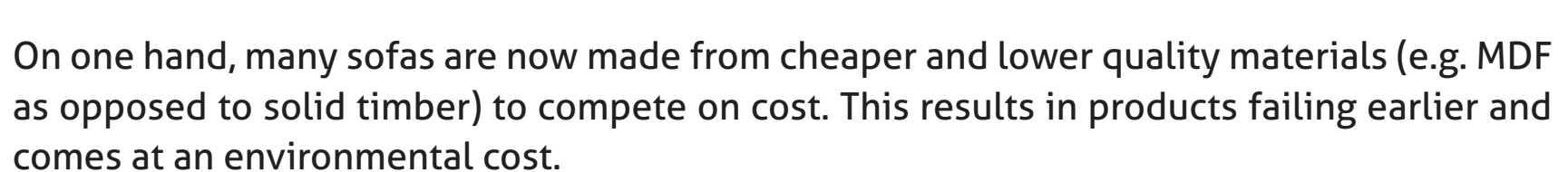

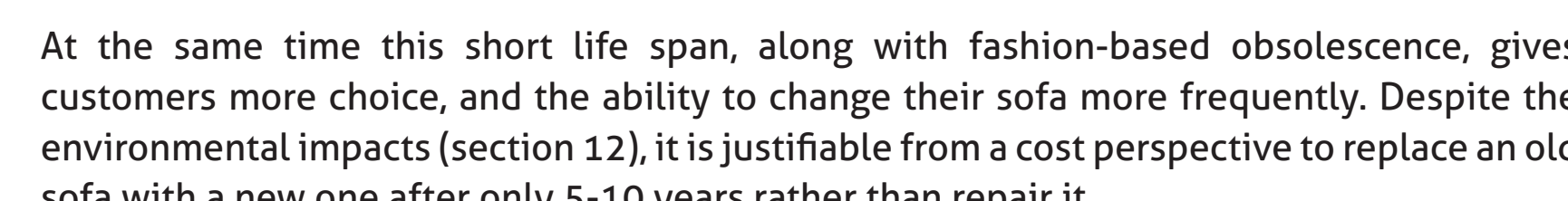

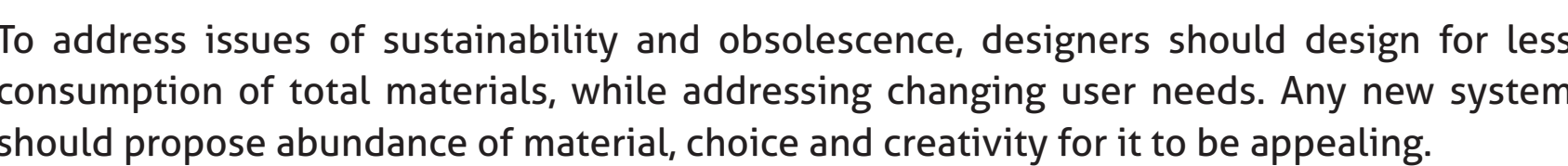

sofa with a new one affer only 5 -10 years rather than repair it.

modes of obsolescence

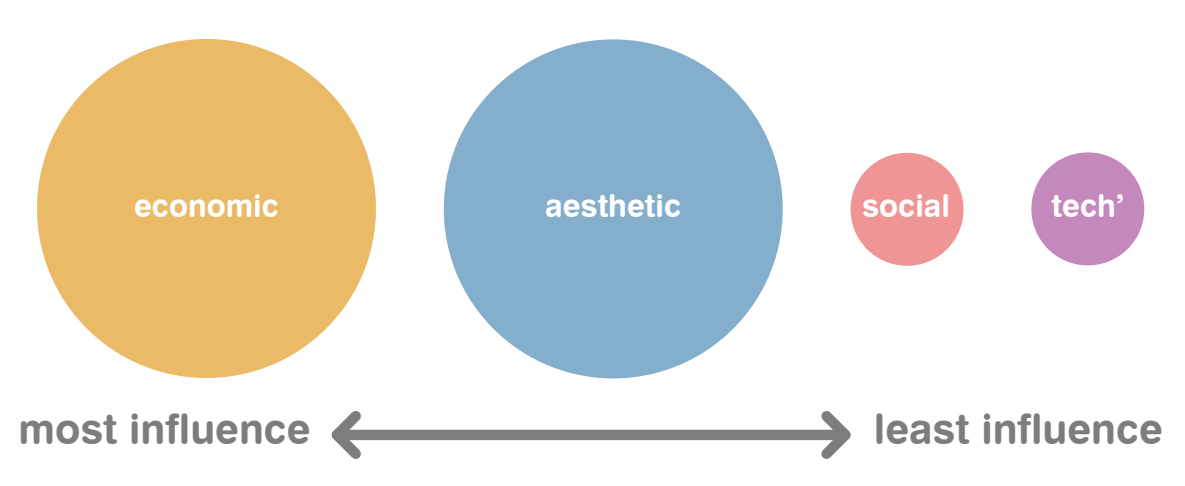

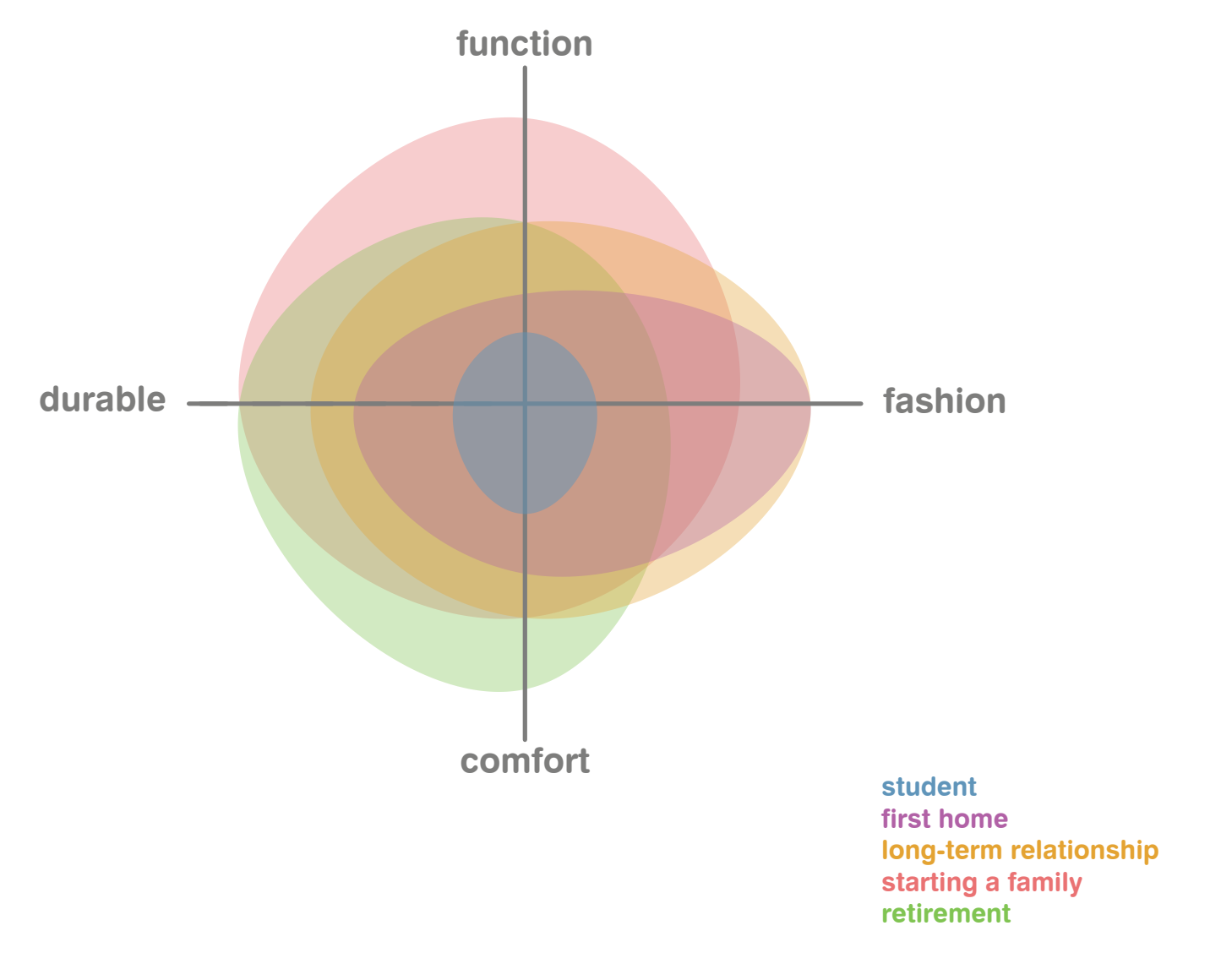




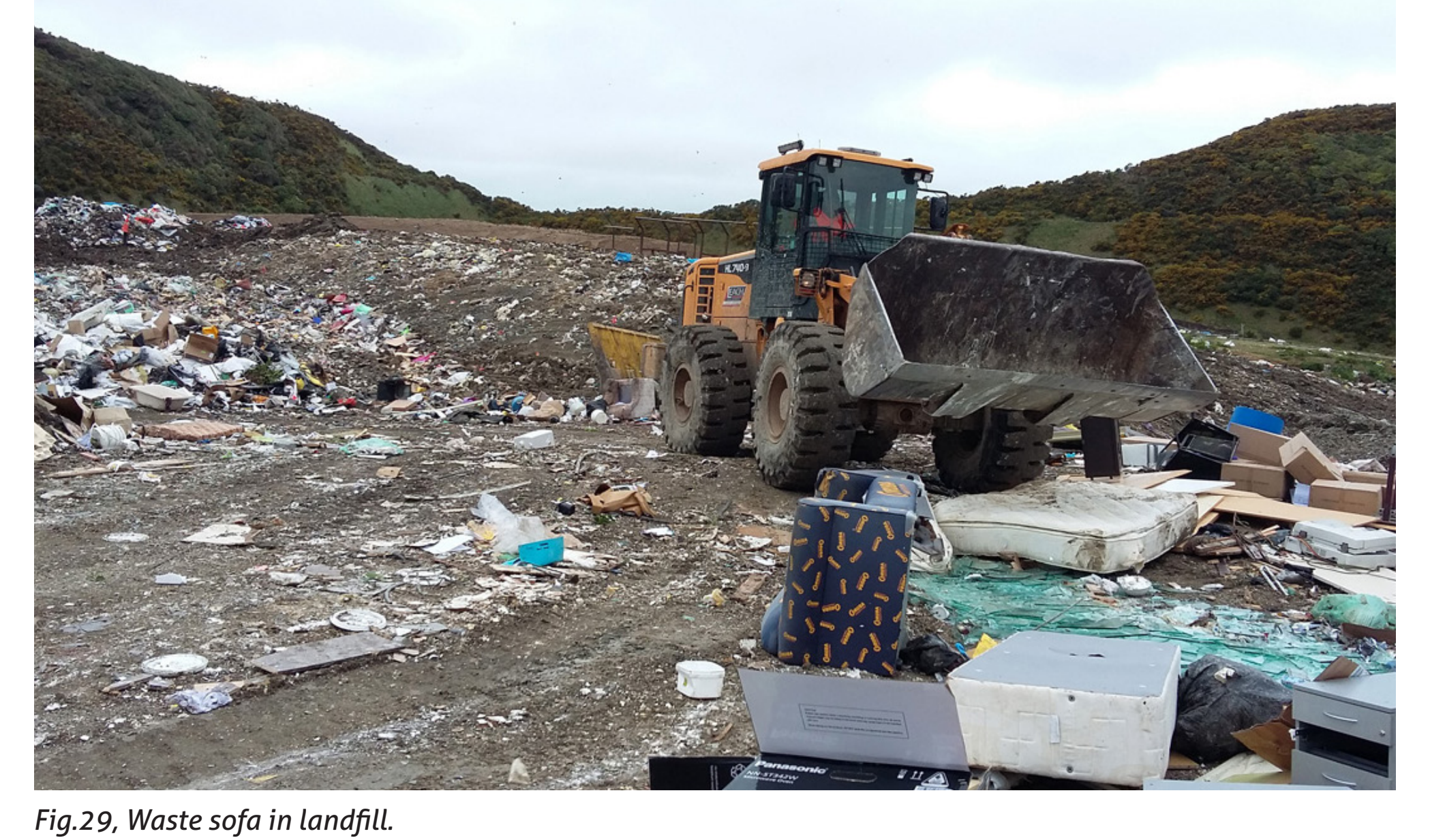

\section{Environmental Impacts}

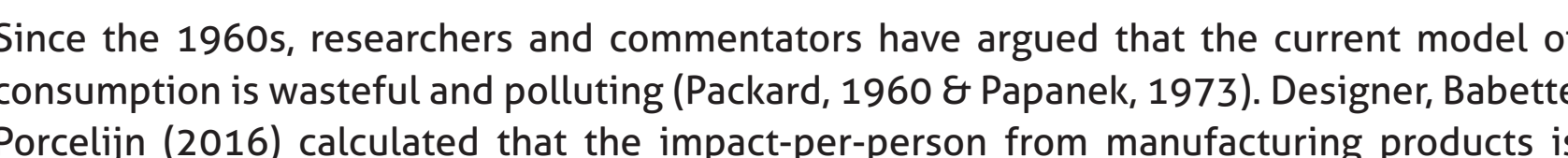
Porcelin (2016) calculated that the impact-per-person from manufacturing products Public awareness has also increased in recent years resulting in consumers asking for more
sustainable products, and somemanufracturers are starting to change in response (Colmar Brunton, 2017).
.

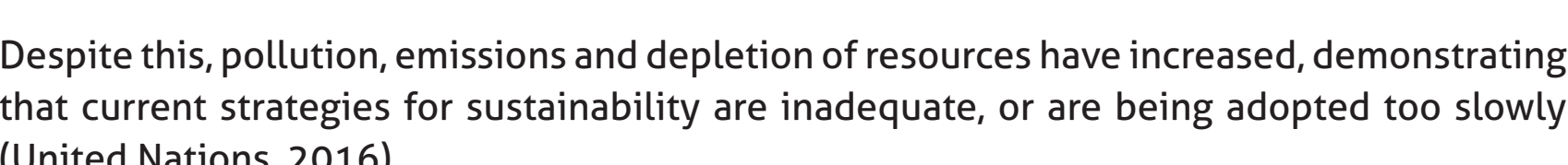


The model that contributes most to this

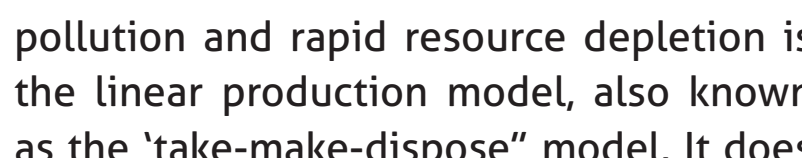

as the 'take-make-disposes" modele. II does
not design for responsibe materil use or
regenererative systems (fig.31).

To ensure positive design decisions are
being made to limit these impacts it :

being made to limit these impacts it is
important to understand the speciic
effects on the envirionment from furniture

This understanding should prevent design
choices which remove some impacts only
to add others elsewhere.

There are four key stages to consider when
assessing ghthe envirionmental aimpect of of the
linear production modeli Extraction and

linear production modele: Extraction and
harvesting, manutacturing and profuction.
use. distribution, and finally disposal.

Extraction and harvesting

Mining and driling impacts

Open-cast mining removes top soil and
ecosystems to access deposits. This

damages natural vegetation which would
provide natural carbon sinks, habitits,
and prevent erosion helping to protect

and prevent erosion helping to protec
waterways from pollution.

The heary machinery used for extraction
and transport has high energy needs
enittins greenhouse gases Dewing

emilting greenhouse gases. During
transport, particularly sea cargo, there is
a further risk that extracted materials are

further risk that extracted
spitit into the environment produced by livestock contributes to
greenhnouse gasses and, athough arnned

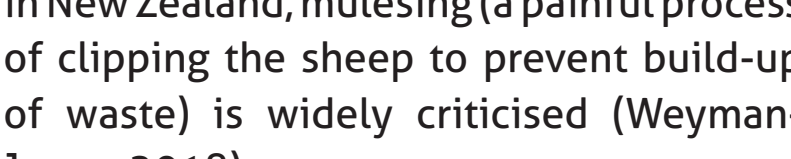

In all these cases land used may be diverted
from food production, meaning a resource
valuable to tocal communities s lost

Manufacturing 䒢部

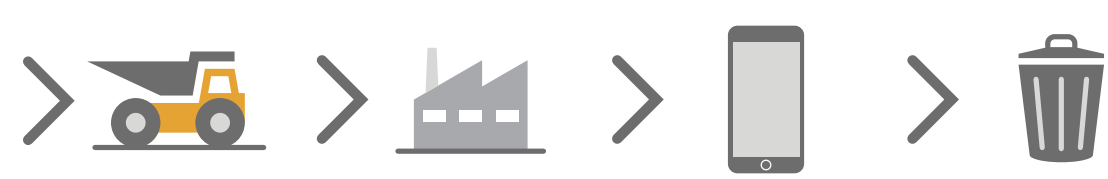

Fig.31, Linear manufacturing model
Adapted from: EMF, 2015.

In addition to these effects, there is also
the risk that processing chemicals and

Harvesting impacts

Harvesting materials for manufacturing
oten requires either removing an existing

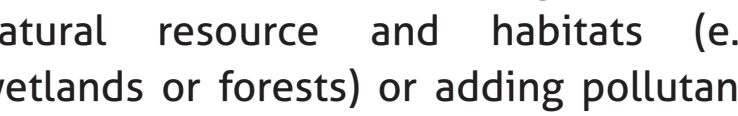

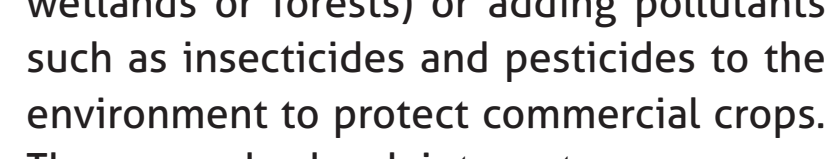

cork which is cut from the tree bark, and
therefore the trese are left tin place and the
forestis maintained

purify the raw material, such as limeston
Forestry also presents a number of eco-
are offen left over (Jernkontortz2018). eplants trees to maintain a stock, nonfertifed timber could be from native
forsts which may not be replanted.

In wood processing material loss is
invevitable, for

processing textiles and paper the

chemicals used, such as the chlorine and
bleach, can flow into water systems. Large

volumes of water are orter systems us in dying

and washing materials, and discharged as
wastewater (Solomon, $1996 \&$ \&WF, n.d.).

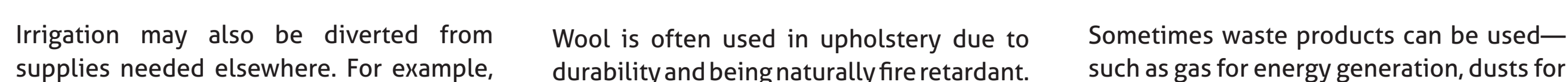

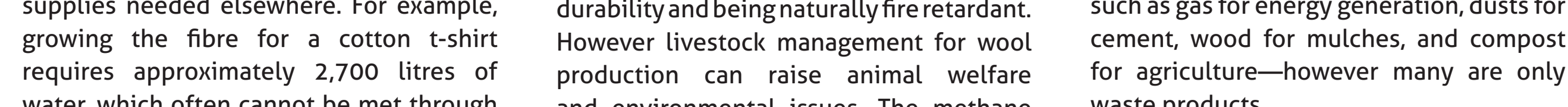

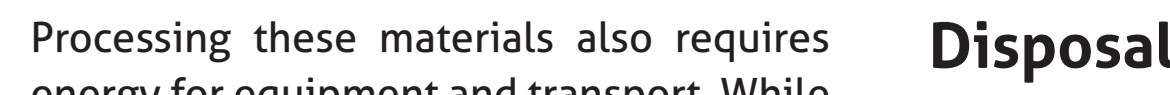

in New Zealand a significant proroportion
of our energy is renewable, elsewher

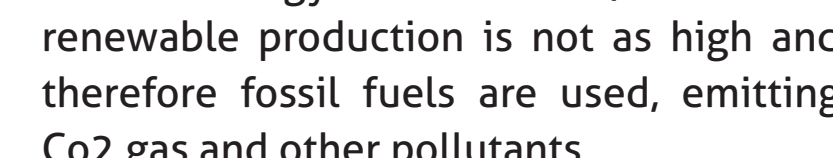

Engineered timber bords (e.g. MDF,
particlebards) often require chemicals or These can continue to off-gas afters production, optentially affecting owners
(Solant, 2008). Distribution

A consequence of the efficiencies gained
through centralalising manuffacturing has

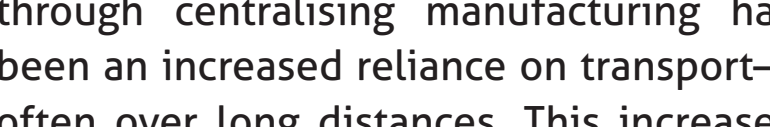

often over long distances. This increases
the risk of spillage or leakgage of hazardous

naterials, for example, plastic nurdes
(peletets for plastic production) have

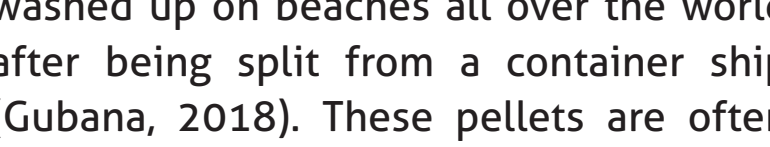

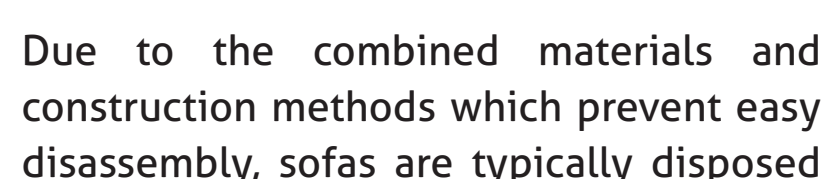

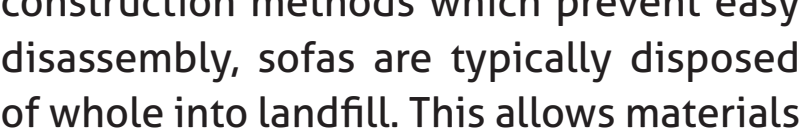

to leach into the ground and groundwater
while loose wasse can blow into the
surrounding enviromment

Photographer Andrew Ward documents
the phenomenon of street sofas in Sofas

of $L$, where they are dumped awaiting that there are onat forther demate enstrtating
solutions for sofas (Ward, n...).

Organic materials le.g. cotton, timber, and
wool are not typicily separated to be
biodegraded and therefore break down

biodegraded and therefore break down
anaerobically releasing methane, a p potent

greenhouse gas, unless it is captured for
energy (Lee, Han $\&$ Wang, 2017).

As well as pollutive impacts, disposal

For more on the environmental impacts of
furniture production see Appendix A.1

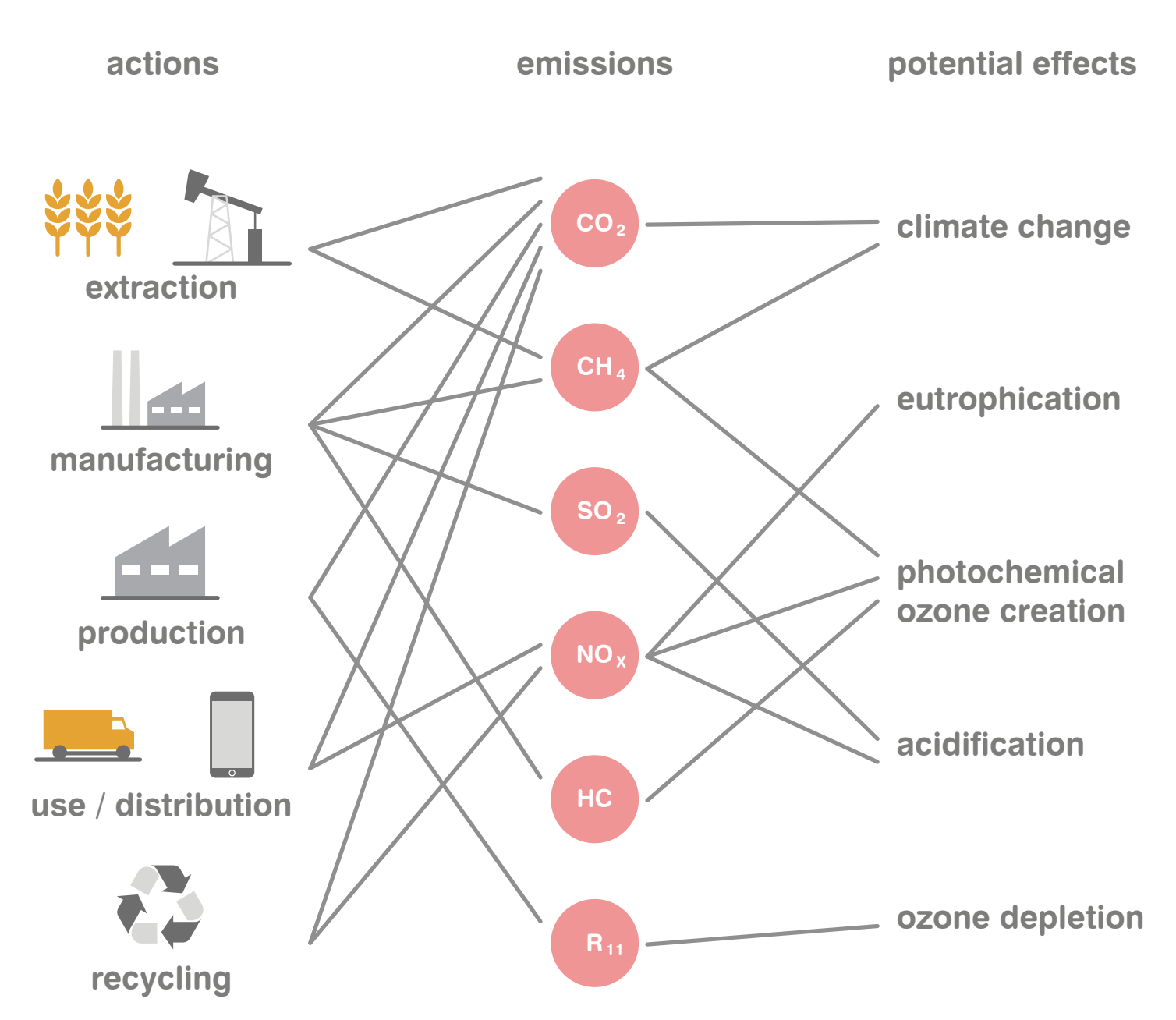

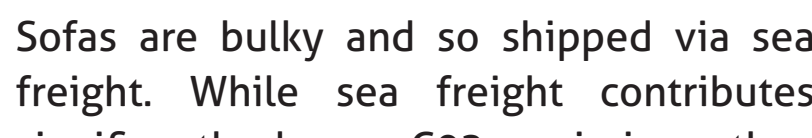

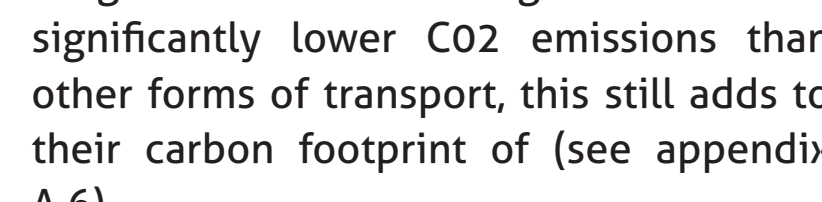

Fig.32. Actions, emissions and potential impacts.
Adapted from: Audi, 2012 . 
b. Alternatives to linear production model

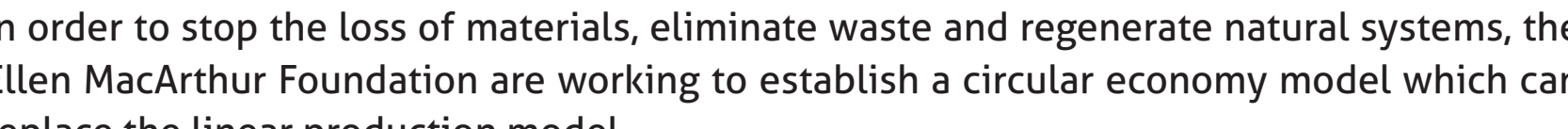

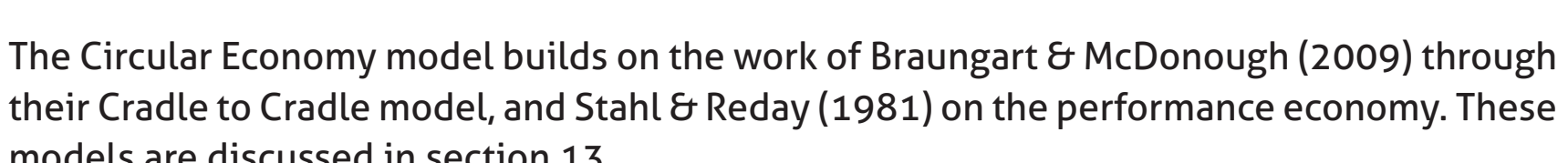

c. Discussion

All materials and processese invulved in sofa production have some negative impacts and
risks, and must be managed to livit envirom

As we have moved to centralised manufacturing, supply chains have become larger and less
transparent, this can result in lowere envirommental standards.

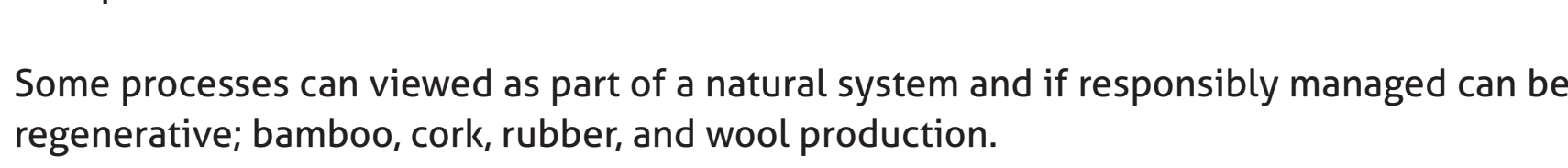

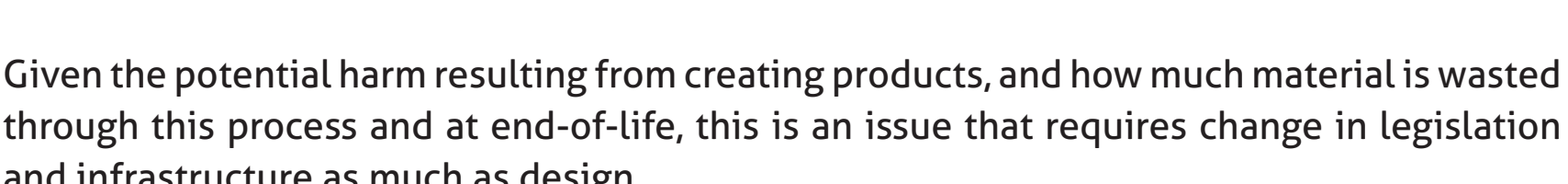

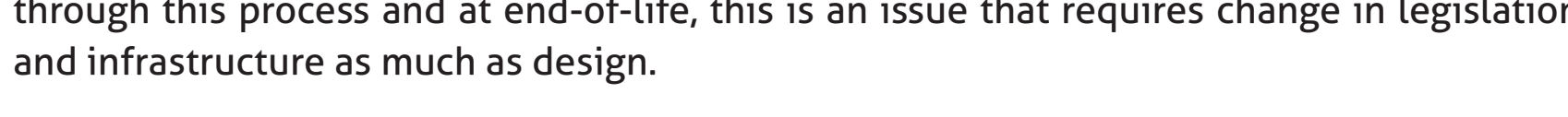

No facilities were found to recycle sofas, and given the time needed to disassemble them
fully and the low value of materials it would not be viable with current designs.

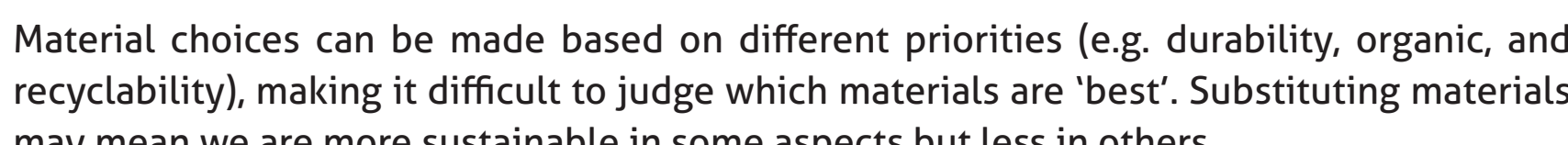

Considering that all materials have an impact, less material consumption and production is

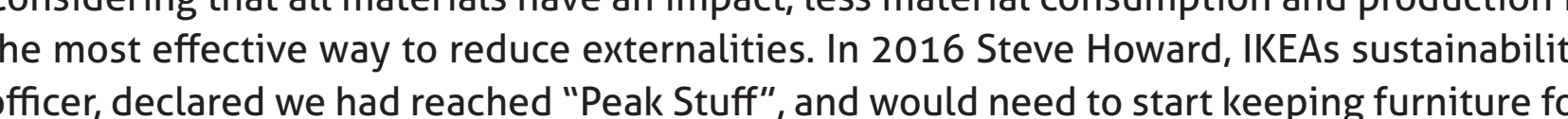

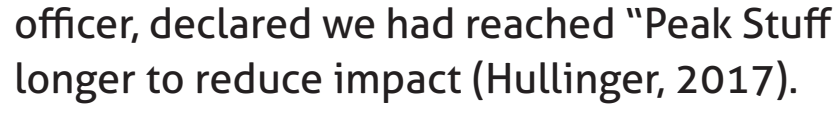

13. Change by design

"A new (made in China) chest of drawers has a carbon footprint 16 times higher than the antique equivalent per year." - Alice Grahame (2015)

\section{cator Victor Papare}

designer is more heavily implicated than most people.e." (Papaneke, 1973)

We can clearly see that through changes to manufacturing and material choice design has
continued to play an increasing role in pollution to this day.

Papanek (1973) also sadi," "if design is ecologicially responsive, then itis also revolutionary."
This section presents an overview of existing design strategeies to foster sustainability. 
Circular economy

Suggested as an alternative to the linear economy, the
Ellen Macarthur Foundataio (2015) are working to move us

: Designing out waste and pollution
Keeping products and materials in use

The Circular Economy (CE) builds on a number of previous
models, including Cradle to Cradle (Poppelars, 2014).

Following these models, CE emphasises the need to
keep biological and technhical materials separate, arguing that combining them increases complexity and reduces
our abiiity to recover materials, or in the case biological
materials, return them to the biosphere at end of life. What makes CE Elifferent from these modele is it its emphasis
on reducing virgin material input through actions such as soraring (e.g. leasing), reparing, and remanufaccturing These also reduces the need for recyclins

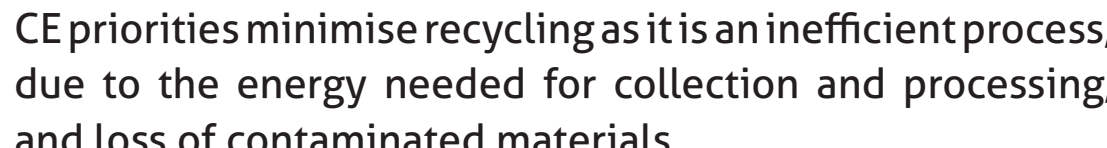
For example, only a small proportion of plastics are truly
recycled in a closed loop to create materials of equal performance, while the rest is cascaded into less valuable materials or leaked into the environment EEllen Maccrth
Foundation 2016) circular economy

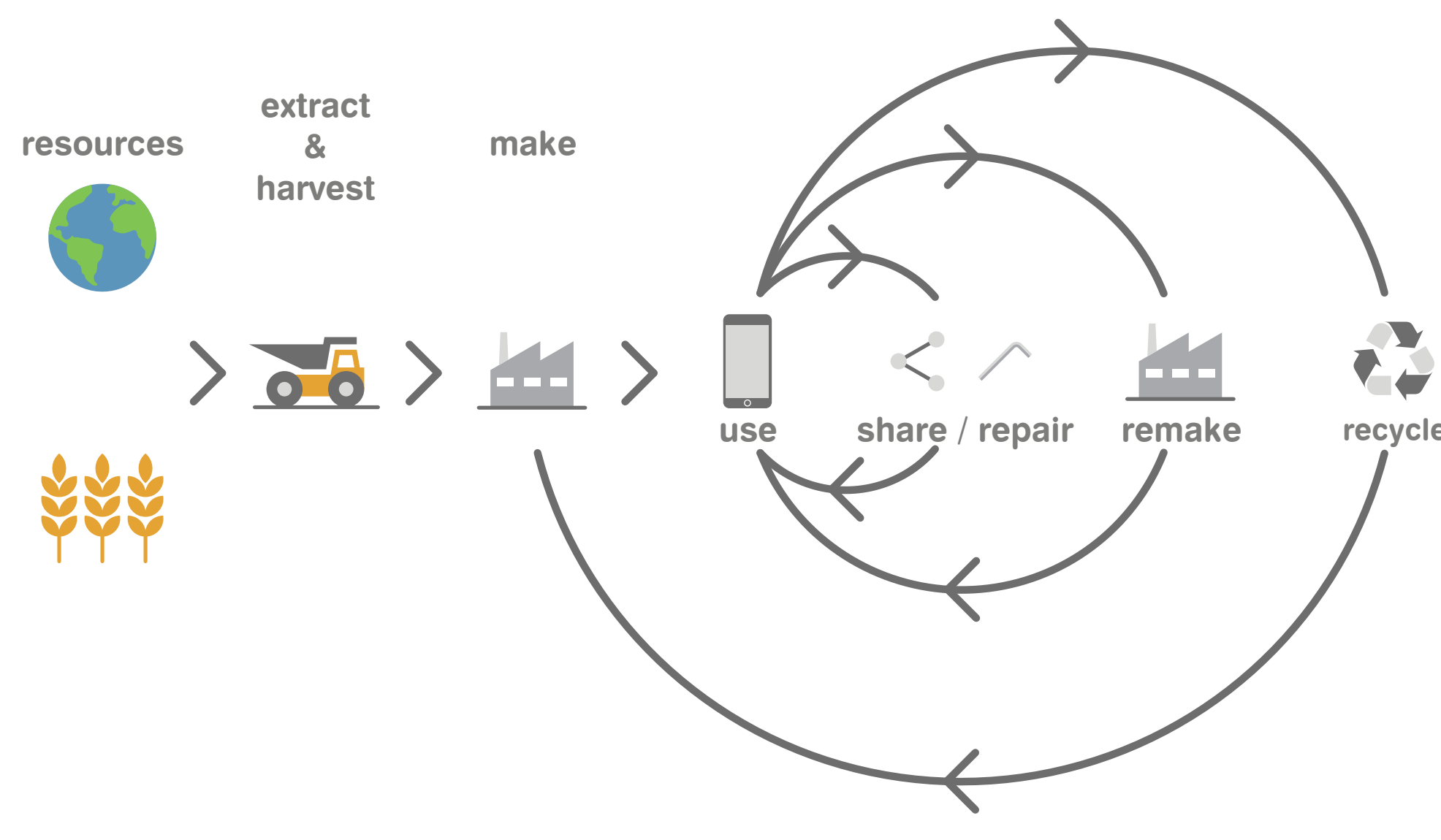

Fig.33, Circular Economy model
Adapted from: EMF, 2015 b. Cradle to Cradle

Cradle to Cradle $(C 2 C)$ maps human industry against
natures processes and encourgages an approach to design Creators, Braungart and MCDonough (2009) stress that ecodoes not open the door to regenerative design. "Being less bad is not being good." - Braungart 8
McDonough (2008) They are also critical of combined materials, describing
them as "monstruous yybrids" sat they yake recovery and
separation complicted and unfeasible. In addition to condemning monstrous hybrids,, $22 C$ maintains a list of banned materials deemed too harmful
to use. For example, PVC (polyvinyl chloridel) a proven

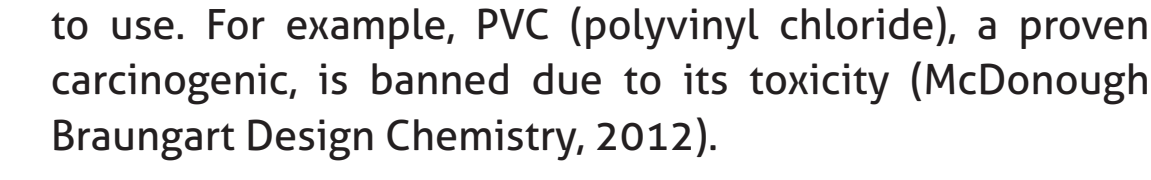
The $\mathrm{C} 2 \mathrm{C}$ design approach goes beyond the product. At Herman Miller the principles were applied to the factory. worker health and satisfaction (Braungart \& Mc Mo Donough
2009)

The ultimate vision of $\mathrm{C} 2 \mathrm{C}$ is for products and factories energy, purifying water, and producing by-products which Fig. 34, Cradle to Cradle diagram
Adaptedffrom: Braungart 8 McDonough, 2009

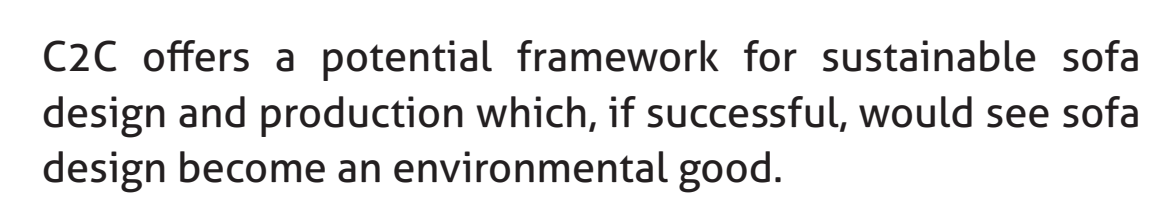

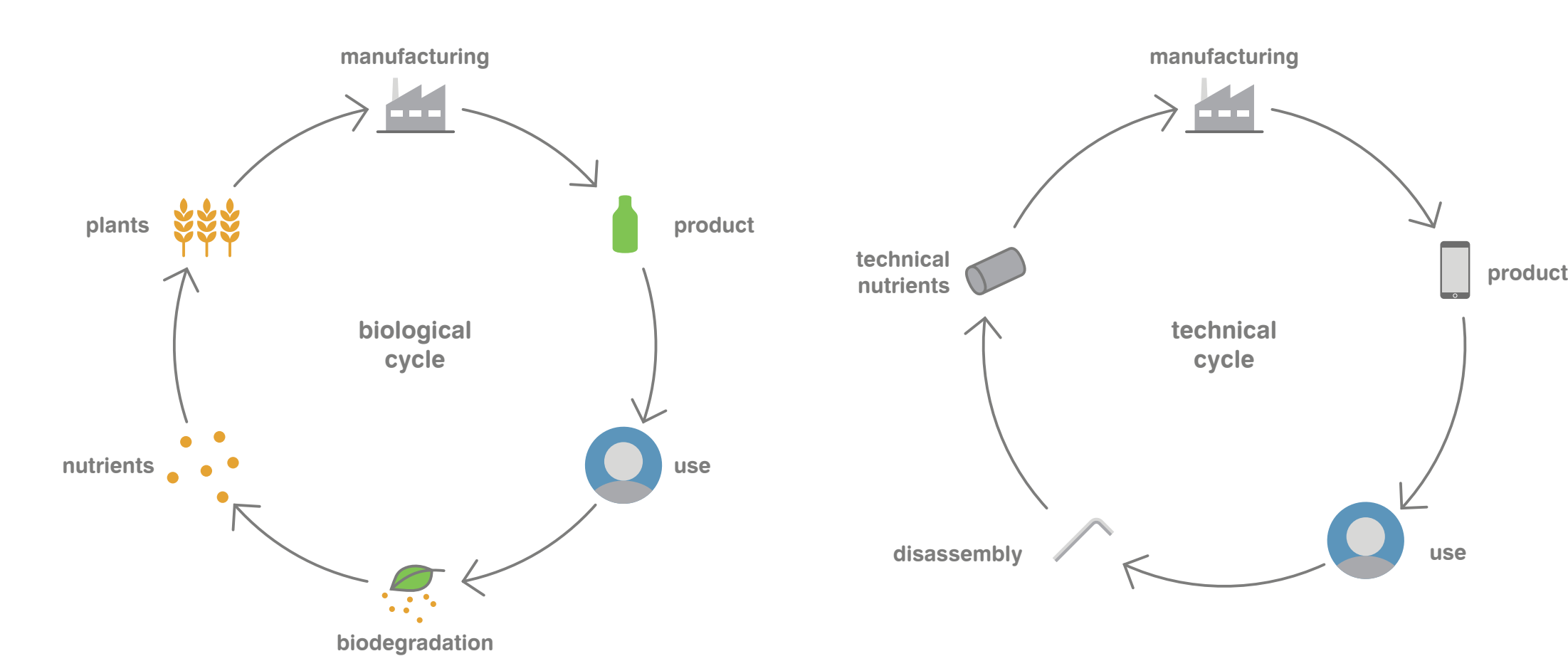


Phillipe Starck described Democratic Design as: "inspired
by the organic and a will to inititiate asustainable de-growth Woyys looking for the most in the least" and "consiss Starck stresses that there are huge benefits from mass
production (e.g. quality and affordability) but many
products become standardised and so lose their ability 作 As discussed in section 10, fashion is a major factors
contributing to the increassing speed of soffa obsolescence

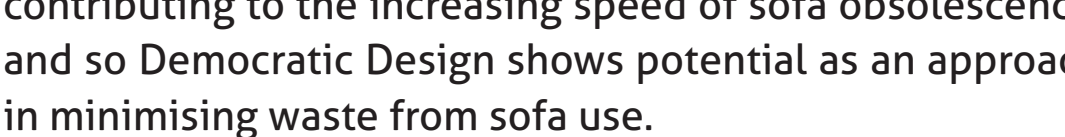
The TOC (All Creators ToGether) project has adopted which allows buyers to co-create objects in an app and TOC combines the benefits of mass production with craftsmanship to create bespoke objects that are not drive Jesthetic obsolescence and increase the emotional bond

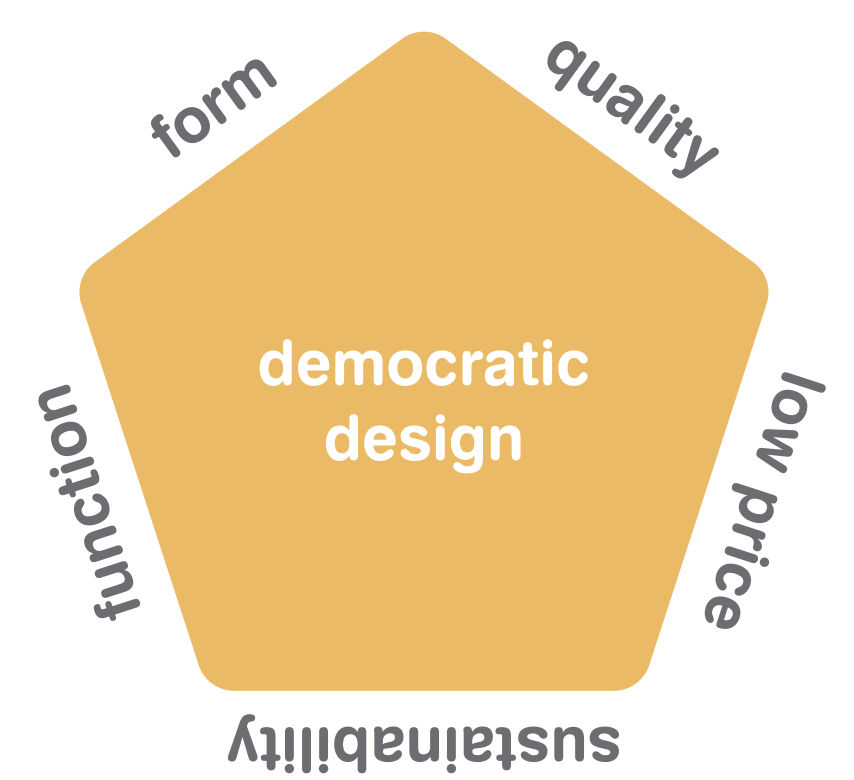

Fig.355, Democraticic Design diagram
Adapted from: Wingfield, n.d. d. Design for Deconstruction

Many products involve acombination of parts and materials
fixed or or bonded togenther of The more permanent the hor foily, the less likely repair and This can mean products and materials requiring specialist

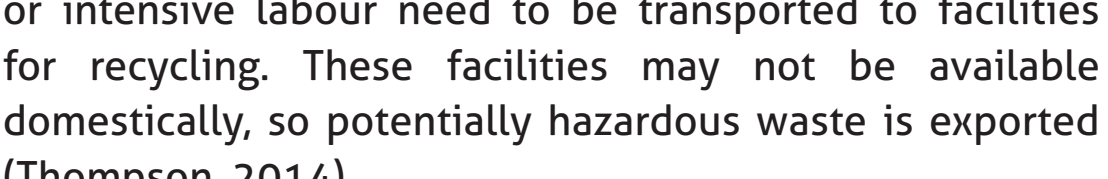
Designing for deconstruction would allow more recycling
be done locally as processing would be easier. This would also have the added beneft of reducing transport
emissions. This would be further supported by local Not only do materials have to be separable, but recycled Not only do maternals have to be separable, but recycled
materials have to be in demand to vuarantee reycling.
This is where a buy-back model ldiscussed later in this section) can be benefficial, by building in demand for these
materials. As a model, design for decenstruction has increasing
support from government agencies to major commanies in the designg industry, such as Autudosesk who's Design for simple and universal tools, minimal fixings, and avoiding
adhesives and other contaminating procses (a)

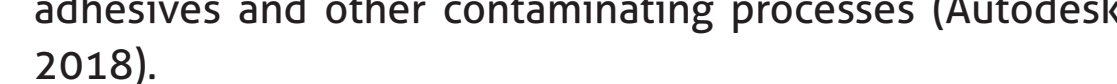
In 2016 the EU parliament published a resolution to
guaranatee consumers durable and high-euality products.

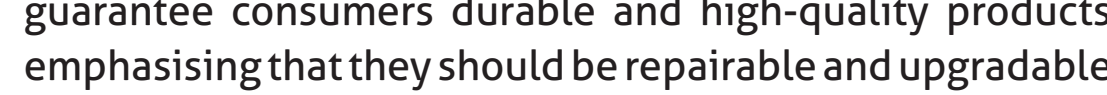
essential components should be removoble, and spbre
parts available (European Parliament, Environ ment Public parts available (European Parliament, Environment, Public
Heath and Food Safety Commintee, 2017). single bolt snap rivet glue composite

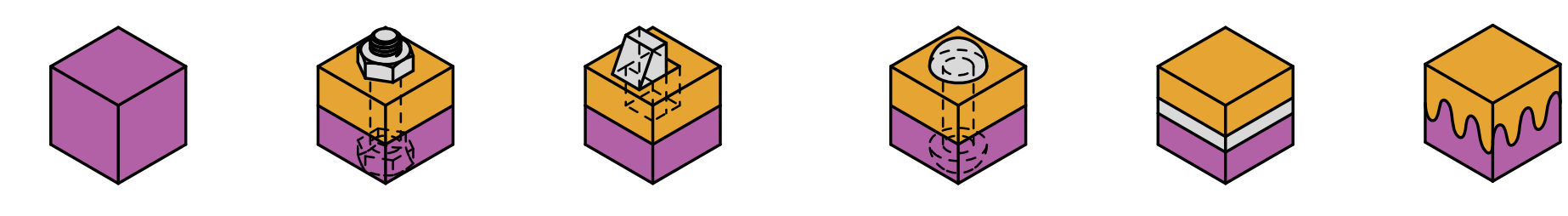

easy to $\rightarrow \begin{gathered}\text { difficult to } \\ \text { separate }\end{gathered}$ 
Emotional Design: Norman's Three Levels of Design

Don Norman (2005) summarises the emotional aspects of
Design on thee levelss.

$\begin{array}{ll}\text { 1. } & \text { Visceral } \\ \text { 2. } & \text { Behavioural } \\ \text { 3. } & \text { Reflective }\end{array}$

"We need to love our stuff" - Richard Dennis, Economist (2017)

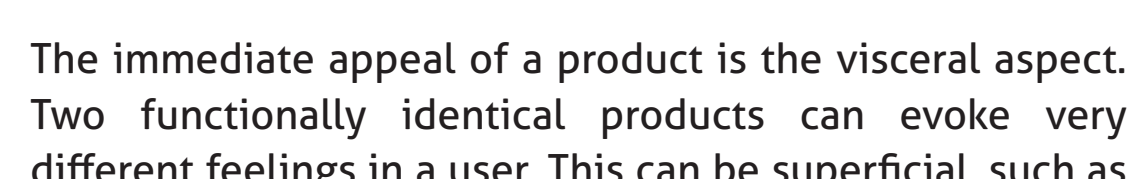
different feelings in a user. This can be superficial, such
use of colour to singify masculinity, speed, performance,
sophistication, or form to to evole nostalaicic feelings.

The second layer is behavioural design, and addresses the

and performs with minimal effort then it tends to scores

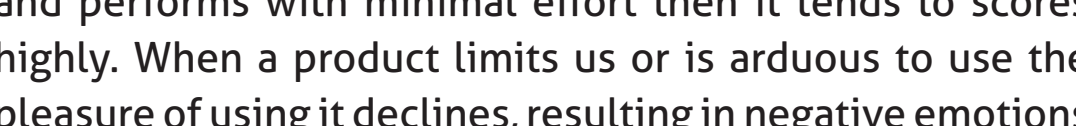

(2)

Reflective design occurs when we reflect on our belologings
when we a

ourselves we like and want to project. This is the highes

Products which become classic and timeless tend to score
well across all categories.

The Braun ETT6 calculator is an example of this. It is
immediately readable, its form is well organised and

sed easily and

it says the user valuese good design, and maybe portrays

Th has been reissued as a classic designn (Griffiths, 2017)

Norman's model suggests that if the sofa performs
expected owners willhave astronger enotional connection

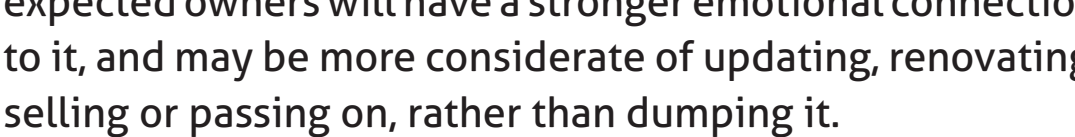

f. Life cycle analysis

Life Cycle Analysis (LCA) considers the lifetime of a

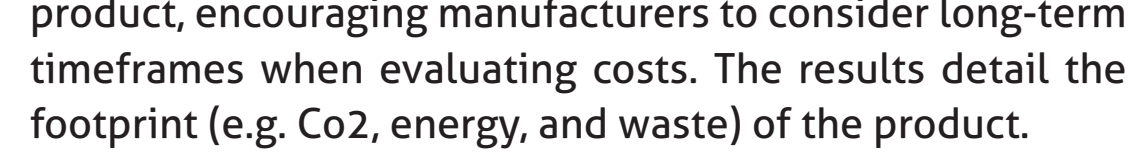

Audi used LCA to demonstrate that while moving to

aluminium car bodies increased the initial footprint
from manufacturing it inhtenen the car and reduced the
footprinnt from fuel for an overall gain (Audi, 2012).

Herman Miller Inc, used LCA methods to compare the
impacts of installing (and re-installing fitted and modular

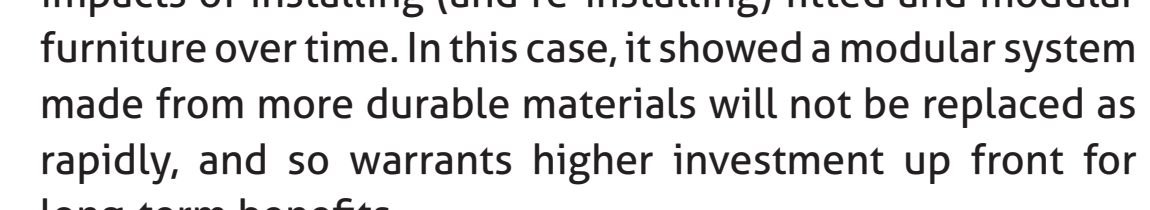

LCA is a powerful tool to inform design decisions but has
received some criticism. Braungart 2018 ) who favours the

received some criticism. Braungart (2018) who favours the
$C 2 C$ approach, argues that LA A is too focussed on reducing

harm, rather than thinking in a transformative way to make
products better. In his words it ijust makes things, "less bad".

LCA requires investigation of the full sourcing,
manufacturing and disposal processes. This could be done

after major design decisions have been made, limiting its

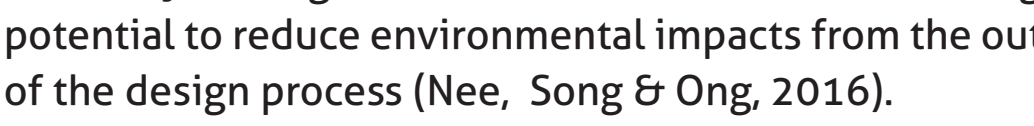

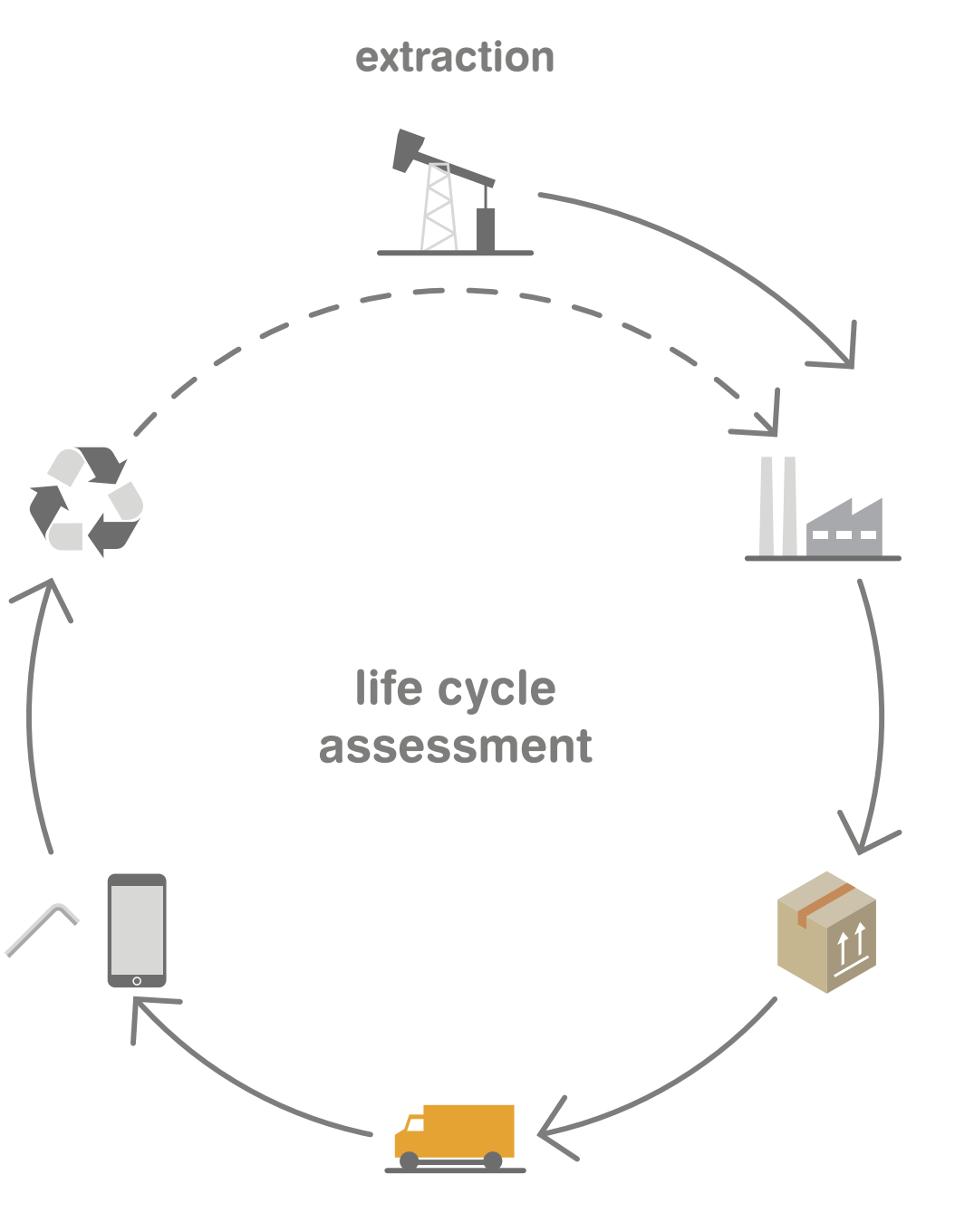

Fig.38, LCA evaluation process.
Adaptedffom: Audi, 2012.
"There is little point in designing physical durability into consumer goods if consumers have no desire to keep them." - Johnathan Chapman (2005) 
Digital manuffecturing technology has contributed to th
movement as it reduces the need for traditional craft skilts and so enables would-be makers to statr builining project
quickly. The movement also has social and commercial benefits-the process of learning from doing can help
reverse the decline in making and repair skills, and the ability to prototype products faste
ba number of successful start-ups

The maker movements shows is a desire to orelearn skills, and
build and repair your own items, but wider impact has been

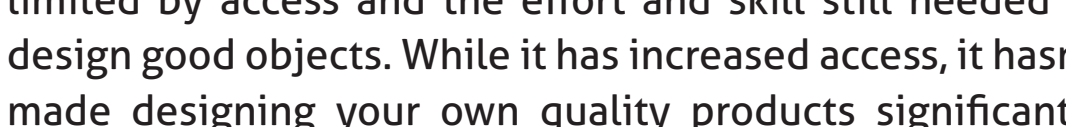
made designing your own quality products significantity assier, and so the maker movement has become
than may have been anticipateded (Fallows, 2016).

However, there are sitilinsights from this movementthatc can
be applied to the development of repairable, sustainable sof. The challenges foced by the maker movement show
that repair has to be within reasonable ability, skill and will

"In reality, this stuff takes years of difficult, painstaking work and hard won experience. It is more accessible, but not necessarily easy." - James Fallows (2016) i. Open design

open design strives to democratise creativity

casework will use up to 151 percen

Hermaterials than fixed

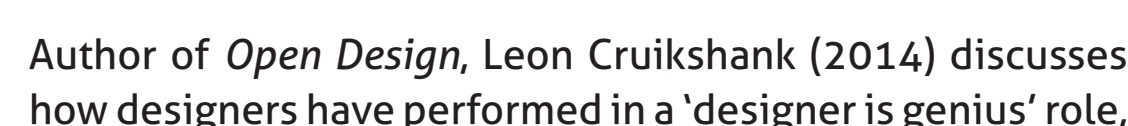
expressing themselves through their vision for a product. Open Design challenges this by opening up tools of design
to many people. Indeed, Open Design poses that design should be flexible enough that the user can create something the designer
would hate (Cruikshank, 2014). This freedom for creative
innut on the part of the owner can also support the earlier input on the part of the ouner can al als support the earlier
discussed concept of emotional deseign.

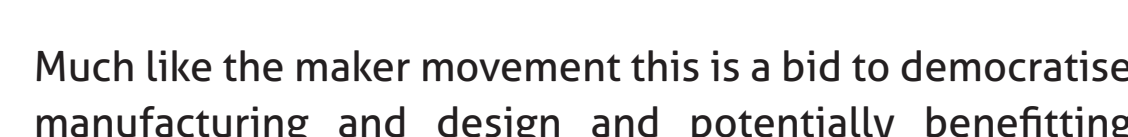
manutacturing and design and potentially beneneftiting
sustananbitity by allowing for local manufaccture which
increases the potential for local repair. The rapid rate at which digital manufacturing technology users are able to create complex and fully functioning

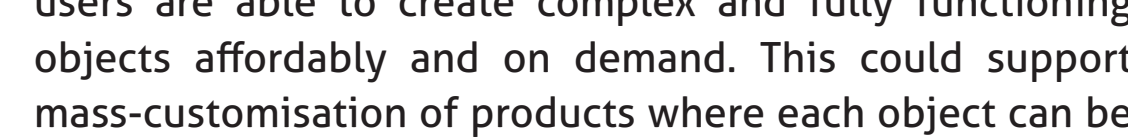
mass-customisation of products where each object can be
tailored to the user.

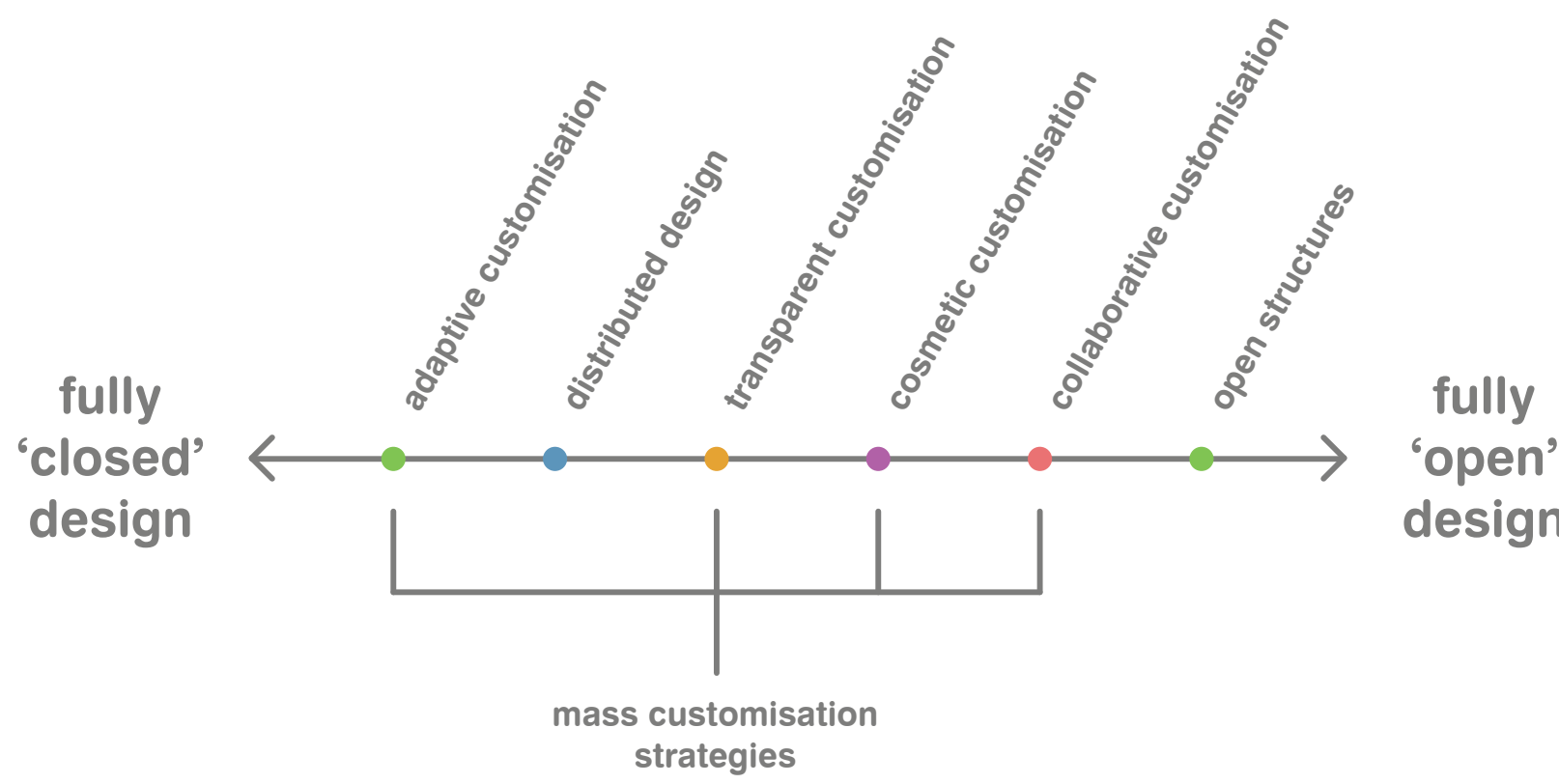

A modular design approach also lends itself to othe

Some suggest there is arole for open design and traditional
design to co-exist, or even be combined through couthoring, which gives enough control to the designer to ensure a successtul product, and enough freedom to the
usser to express themselves (Cruicicsshank, 2014 \& Wong
2011 )

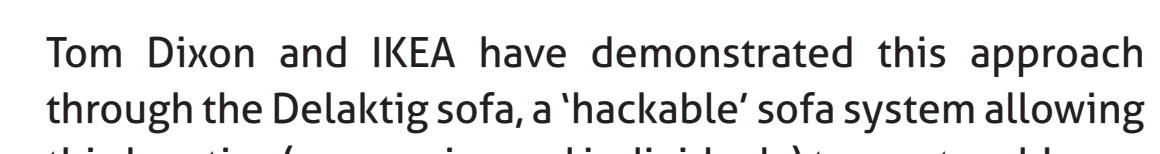
Open Design can foster greater emotional connection to ability to customise. 


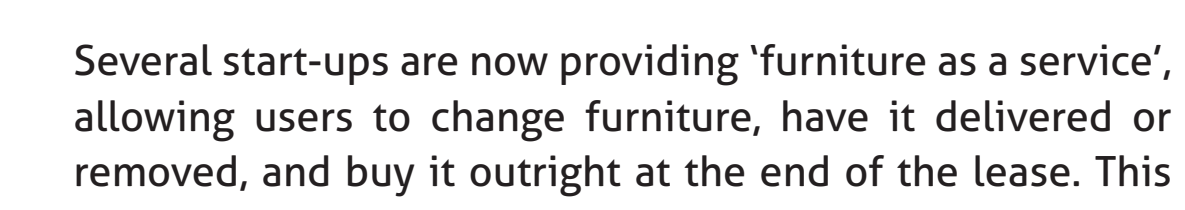

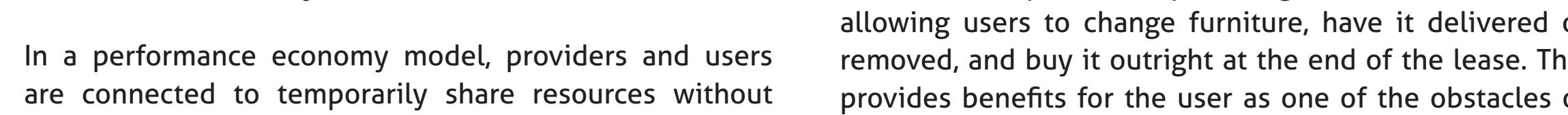
transferring ownership. This encompasses a range of
systems from trationan leasisg. to the relatively new Product-as-a-service model (Paas).

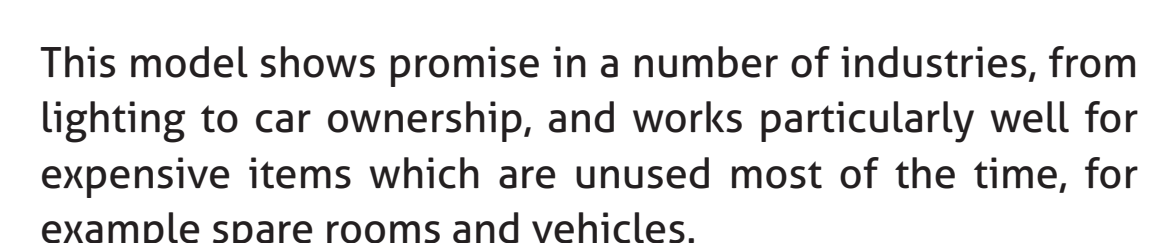
On average, a personal car is parked and unused for as
much as 92 percent of the time (EMF, 2015). Wellington The Strata System, created by RCA graduates Katrine the outer layer can be changed easily by the owner. Straat Suggest that people may not even need to own the sof
base, and this could stay with the rental property (Tuckee

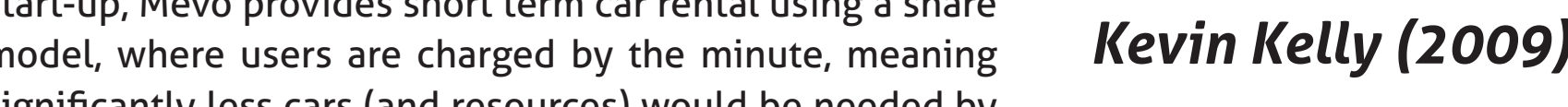
significantty less cars
a community (Mevo, n.d). jverage for just 12 minutes of thei life. Some communities and businesses have responded to this opportunity by
setting up tool libraries or libraries of things'. In addition to a more efficient use of resources, this mode
shifts the responsibility for maintenance and produc stewardship to the provider, which in turn incentivises high Philips have even begun to apply this model to the the Netherlands to rovide his as a service Sthipol pays only for the light they need and Philips is incentivised

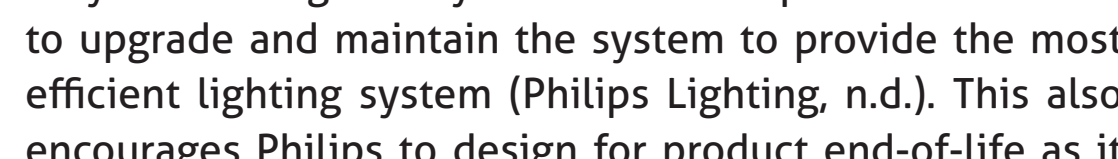

Buy-back model

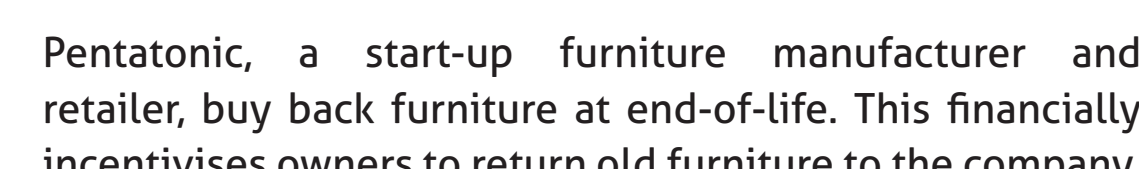
incentivises owners to return old furniture to the company, a closed-loop, prioritising deconstructability This reduces the resource depleteion to manuffacture new
furtiture, and decreasesespotential futurere cossts from product
stewardship schemes.

In 2016 , IKEA's sustainability officer declared we were at
the point of "peak stuff', and in an effort to reduce their back model (Hullinger, 2017). Items are rated on condition in store credit for the product when it is returumed.

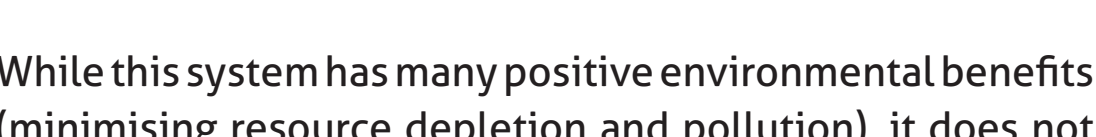
In itself address obsolescence of products, nor necessarily

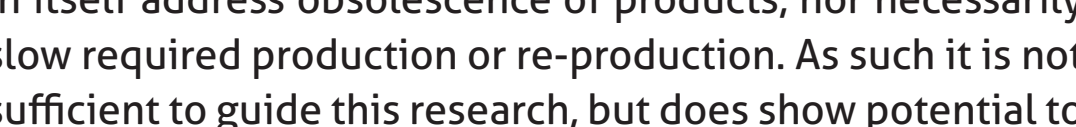
suffficient to guide this reser,
fit as part of a wider system,

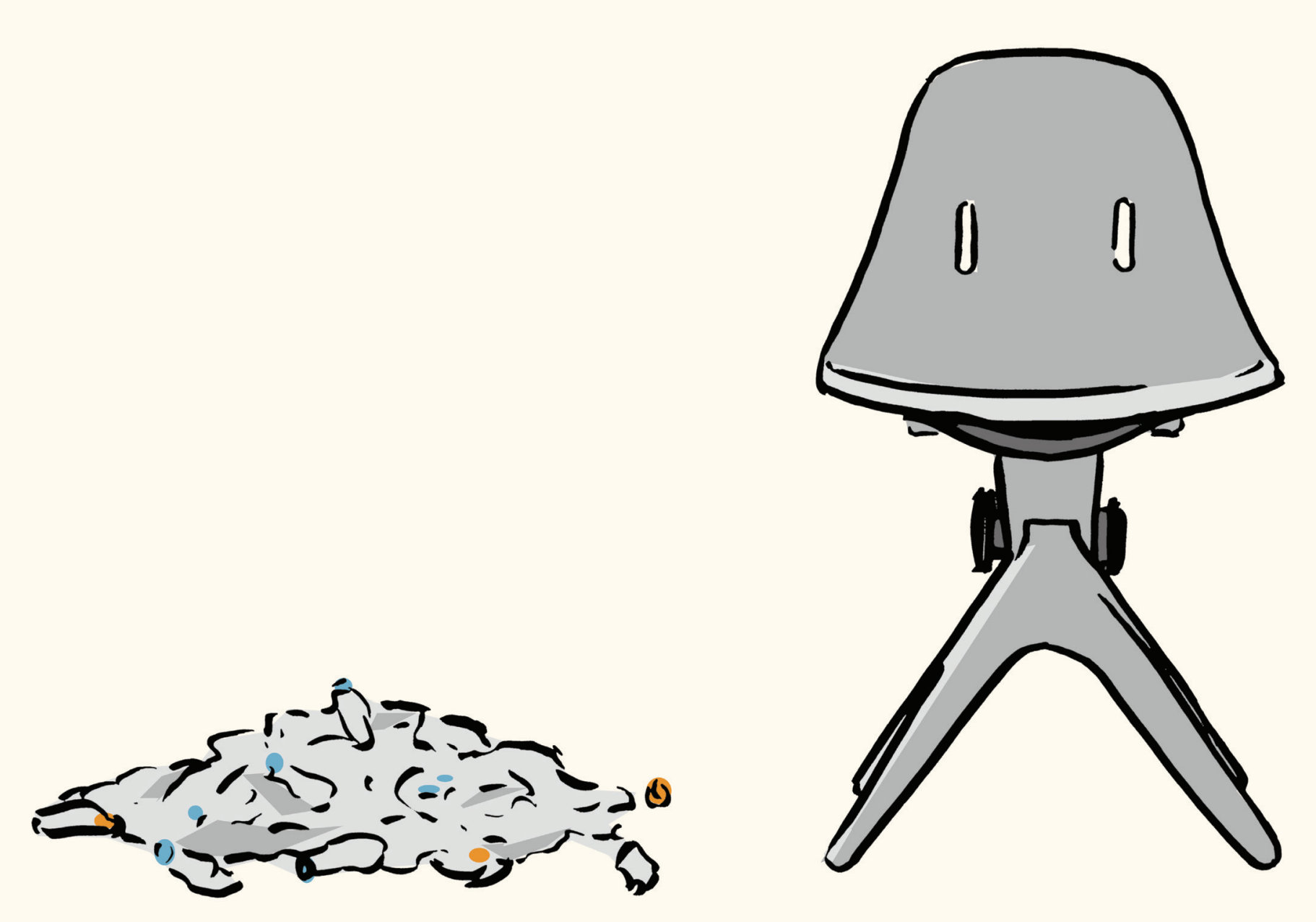




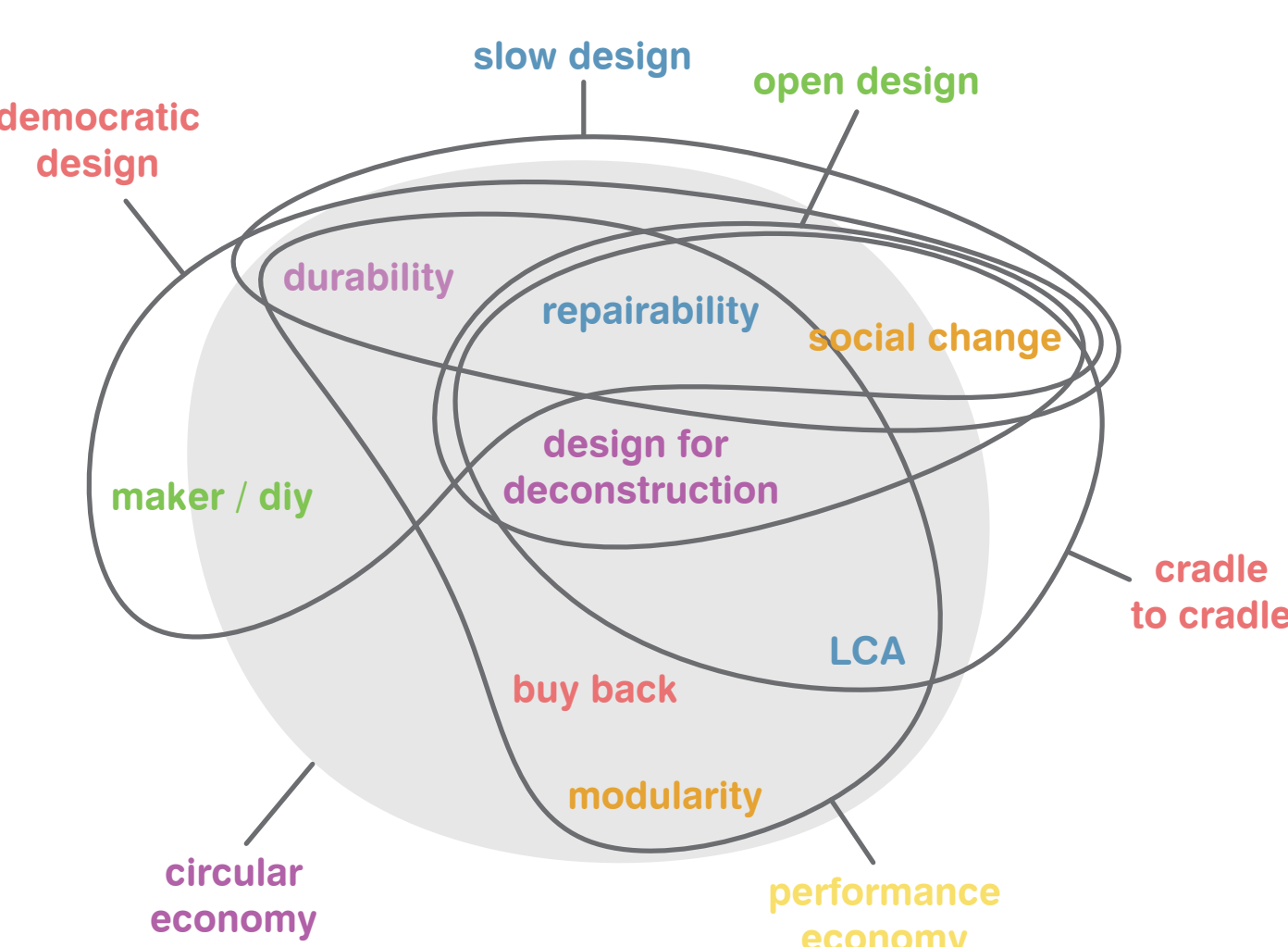

Fig.41, Overlapping 'change by design' strategies k. Discussion

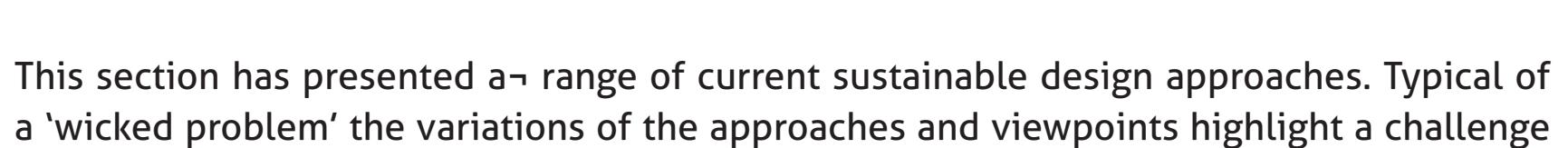

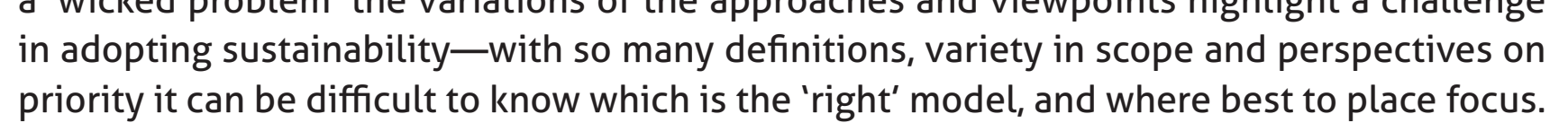

However, through these examples several core themes emerge.

Design for deconstrtuction
Alternative user models

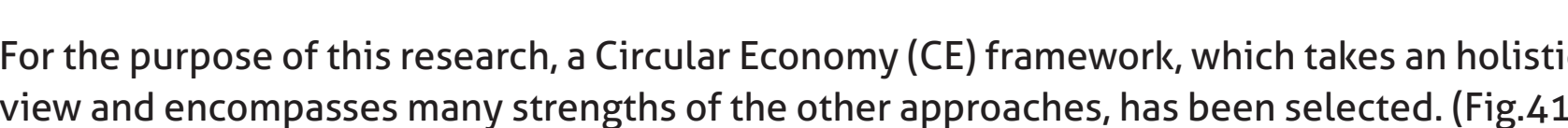

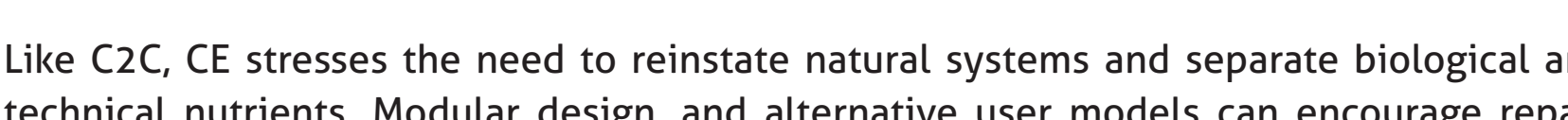

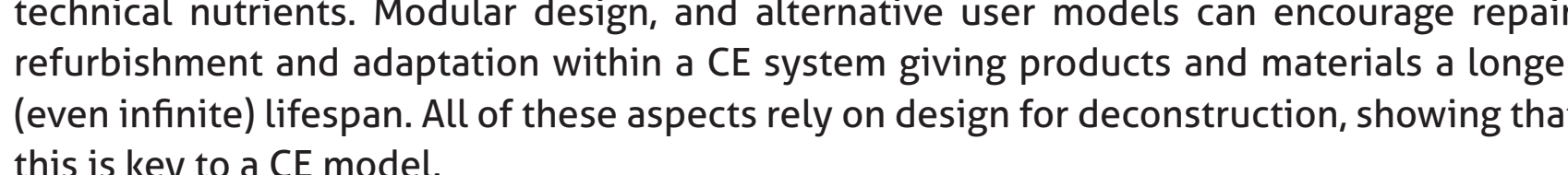

"Design is integral in the shift to the circular economy" - Ellen MacArthur Foundation (2017) 


\section{How to defy obsolescence}

Mutliple strategies utilised by designers
to defy obsolescence-including material functional, emotional or cultural.

Building on findings (section $10 \& 13$ ) this
section presents case studies of design

precedents which showcesse the following
strategies:

Products that are able to adapt and grow
to meet new wser needs can significantly

Wishbone Design Studios 3 in1 bike

sibing, All finings use the same $5 \mathrm{~mm}$ hex
key (Wishbone Bikes, nd.).

A similar system, the Tripp Trapp high
chair. allows newbersusually more expensivive and have to to be
buit in an attached higher standards to last longer.

basin, later replaced with a table and foot
rest. The table can be removerd and the

However, users gain from the addition

outlay through long-term material and cost
savings.

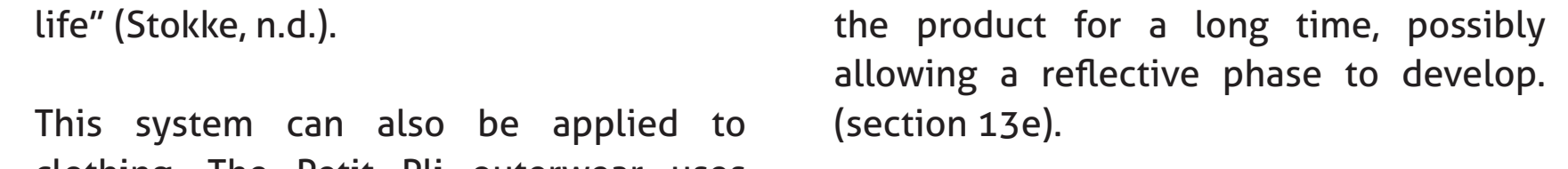

small child, and later the curved frame
component tan be inverted to raise the
seat accommodating older children

This results in surplus parts but replaces

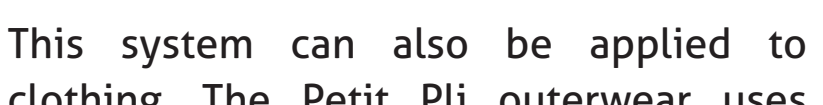

pleated clothing which can expand bi-

directionally to accommodate growth from
4 to 36 months-approximately seven size

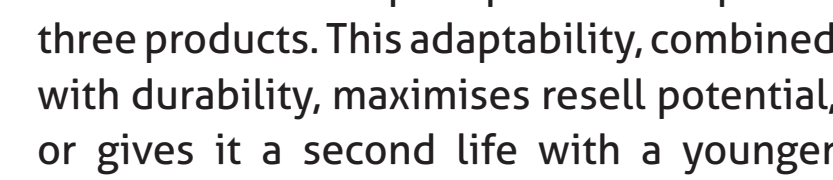
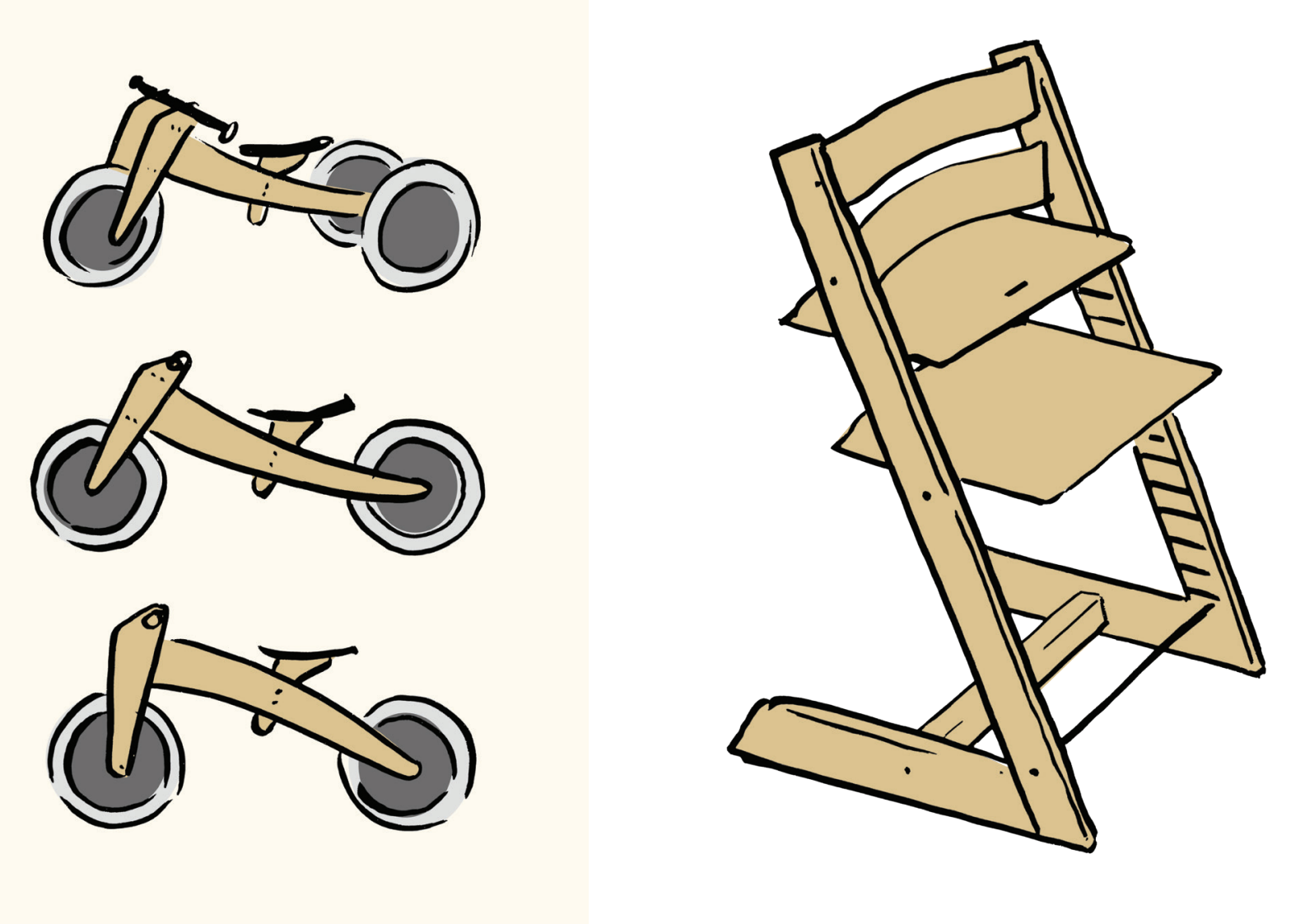

Fig.43, Tripp Trapp chair

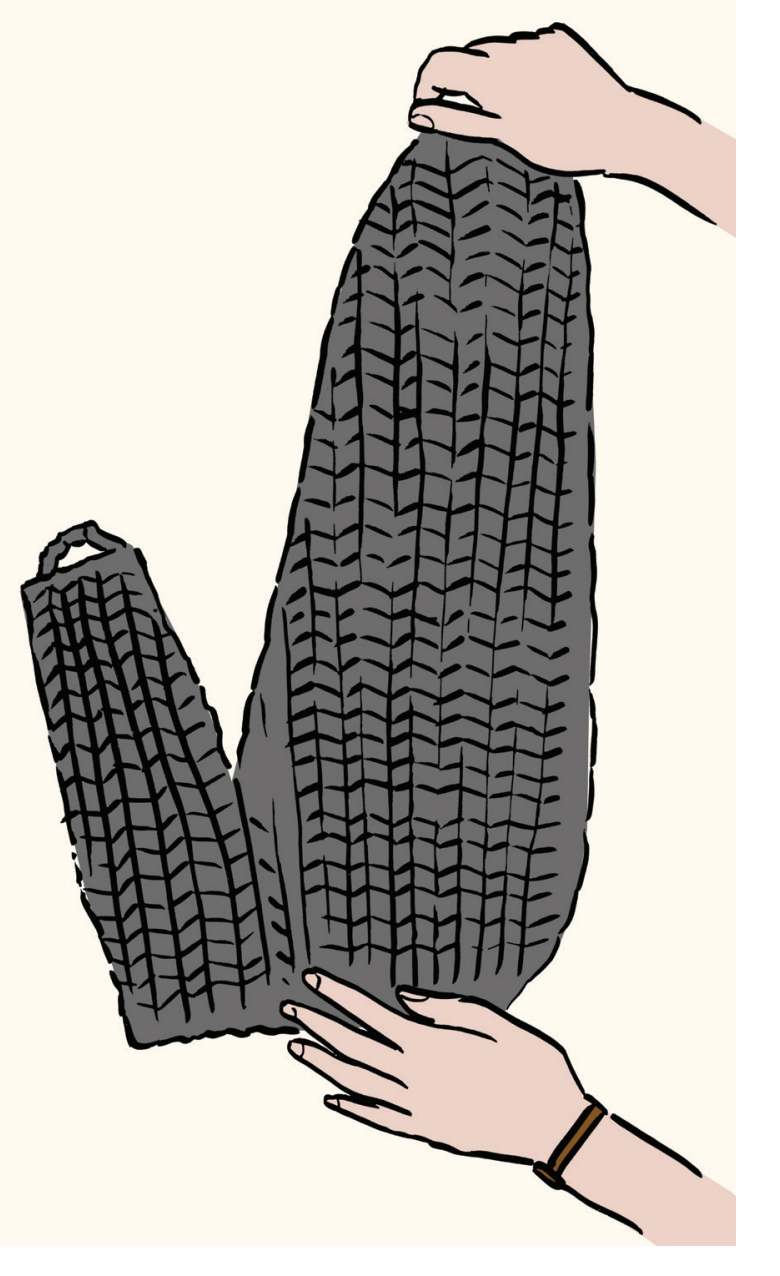

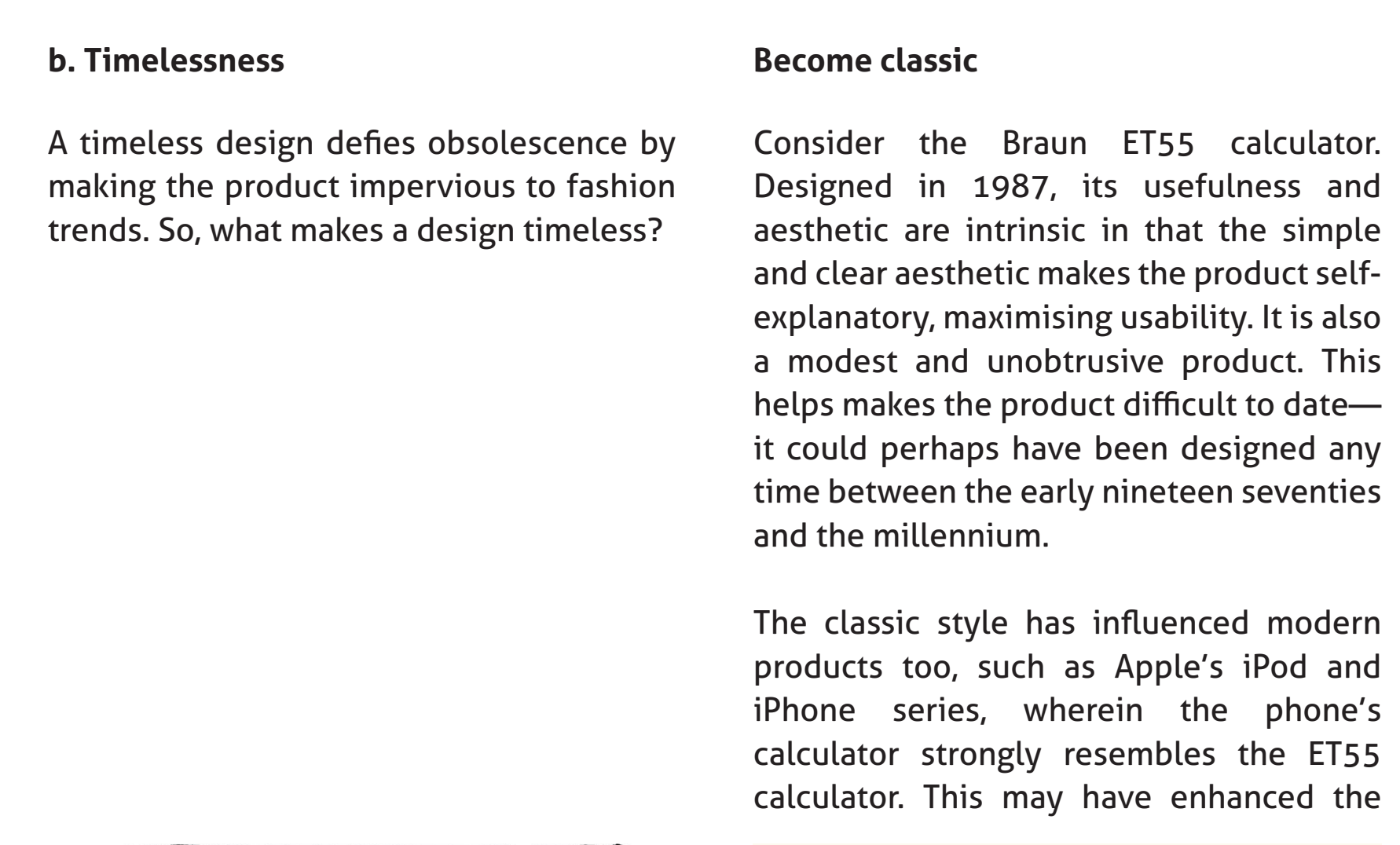

ET5's position as a design classic.

Another enduring example of timeless
design is the Dr Martens boot, which has hely is due to its clear and understate Be 'Super Norma'

When products become the iconic example
of that object they can become timeless

stove top coffee maker, or a simple da Evolve carefully

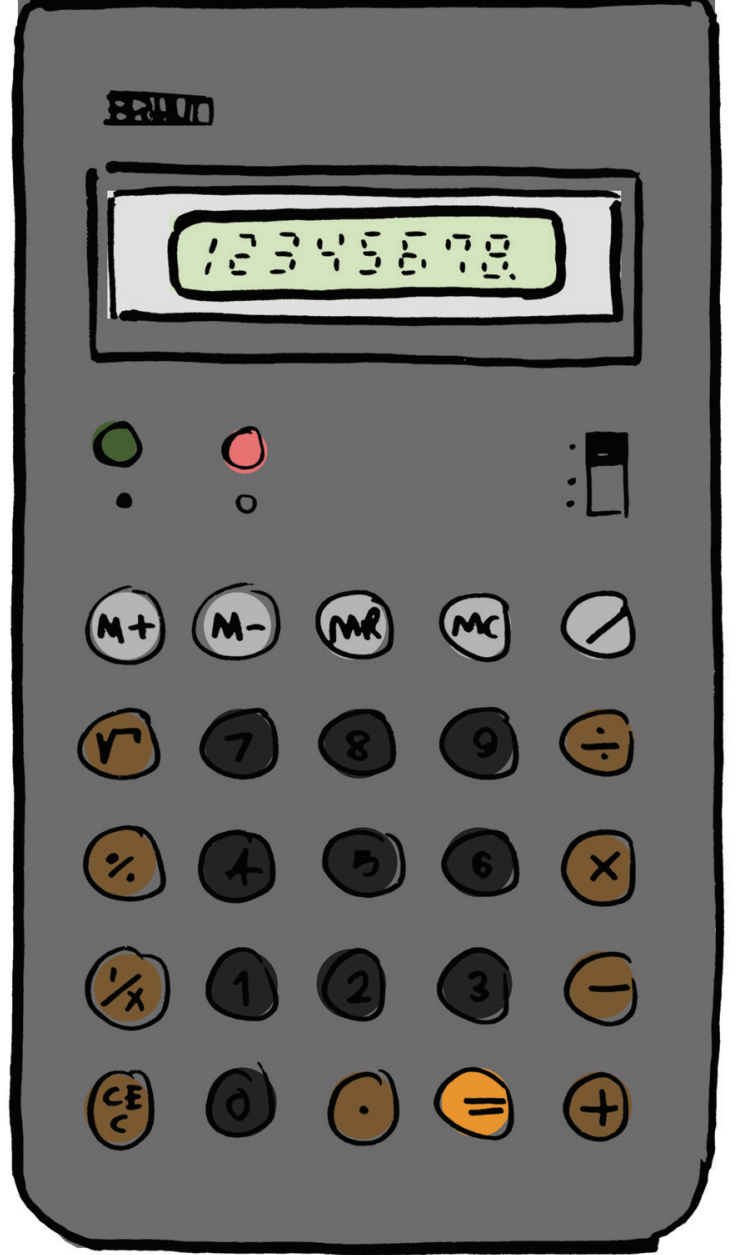

Fig.45, Braun ET55 Calculator

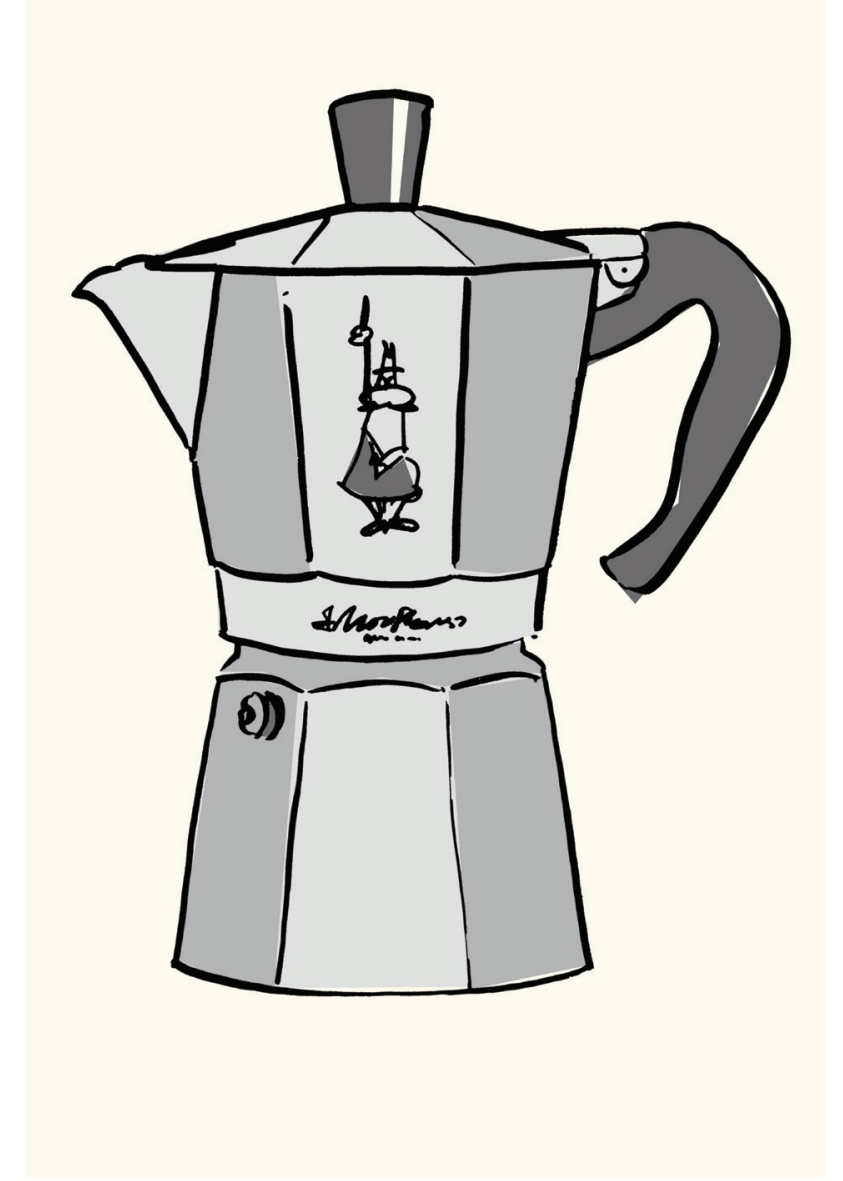

Fig.46, Bialetti Moka Express
Fig.47, Land Rover Series 1948
Author: Defacto
SO C

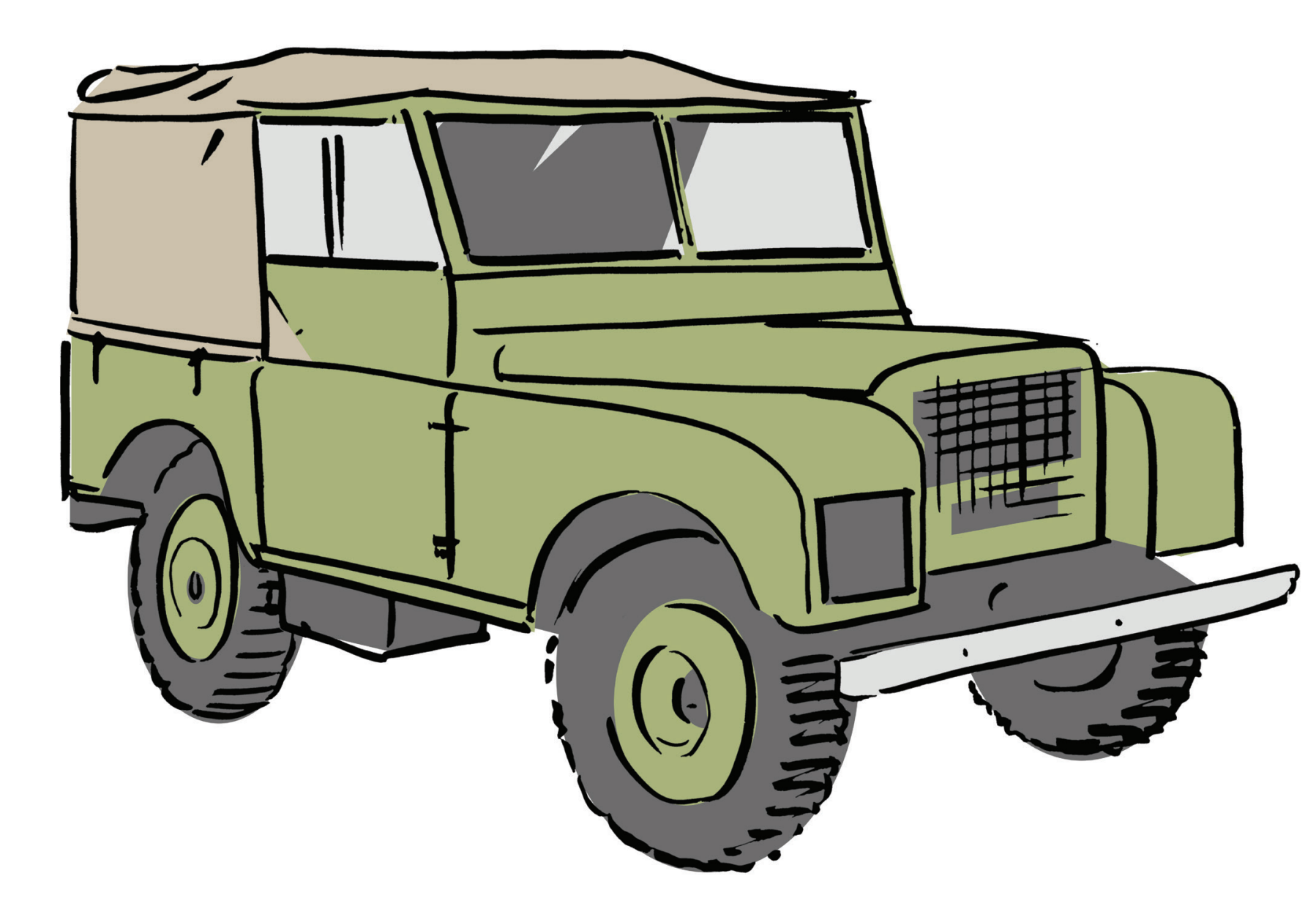

Land Rovers Defender vehicle series,
produced for vover 6 y years, has modernised gradually to meet new standards and
expectations of comfort and performance.

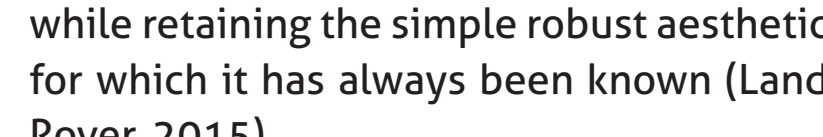
From conception the Land Rover design
has allowed for customisation, retaining a separate chassis and multiple body many purposes-it can be driven sland without looking out of place (Pitas this known for its simplicity and durability. 

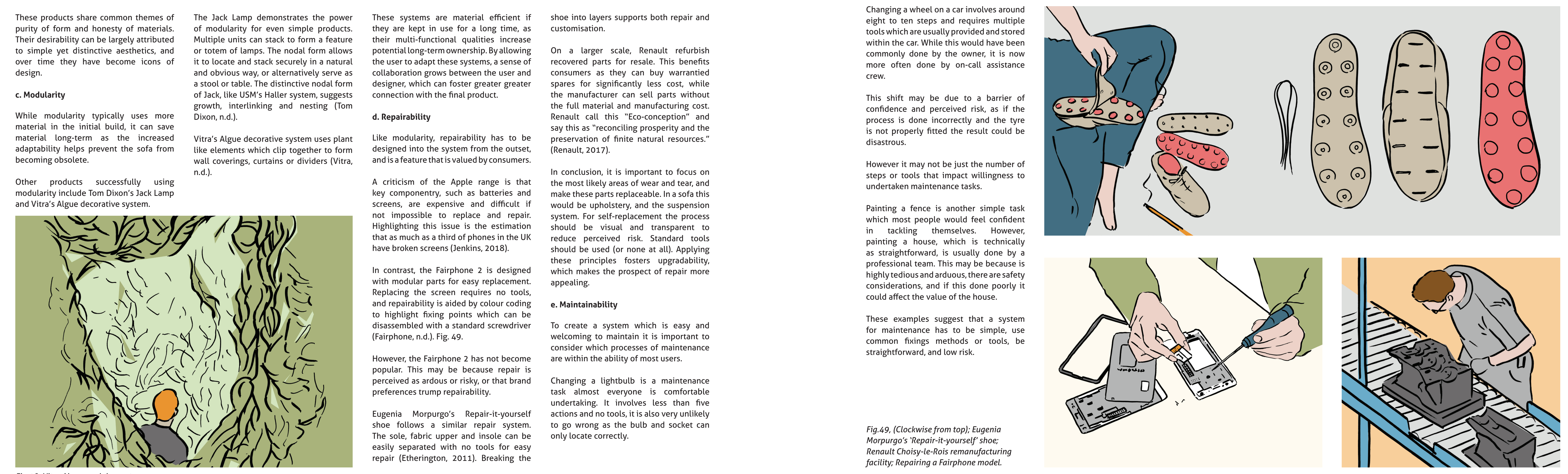


\section{Landmark sofas: the state of play}

This sections considers key sofa designs which incorporate elements of Circular Economy (CE) design.

a. Changeable draped covers

Fitting covers without staples and fixings helps the user to easily remove covers for washing and update the aesthetic with new covers
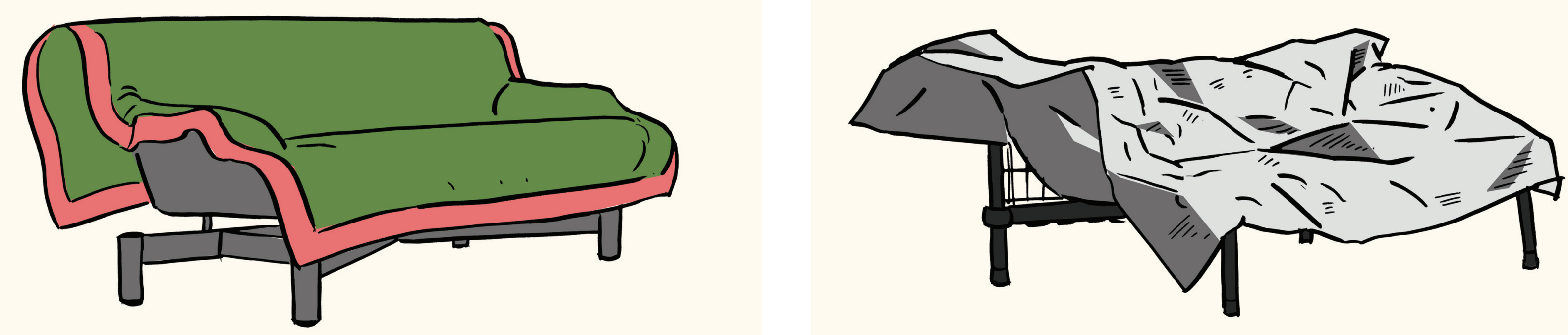

Magistretti drew his inspiration for the Sinhad soff from a horse blanket display. (Luminaire,
n.d.). This is simple, but quite radical comporeded to many contemporary sofas. Grici's Cape Sofa is an evolution of this, with a more tailored cover.

A similar approach was taken by Ron Arad for the Transformer sofa, combining the cover
upholstery padding into a PVC sack, which is deflated to be 'frozen' into shape b. Sectional systems

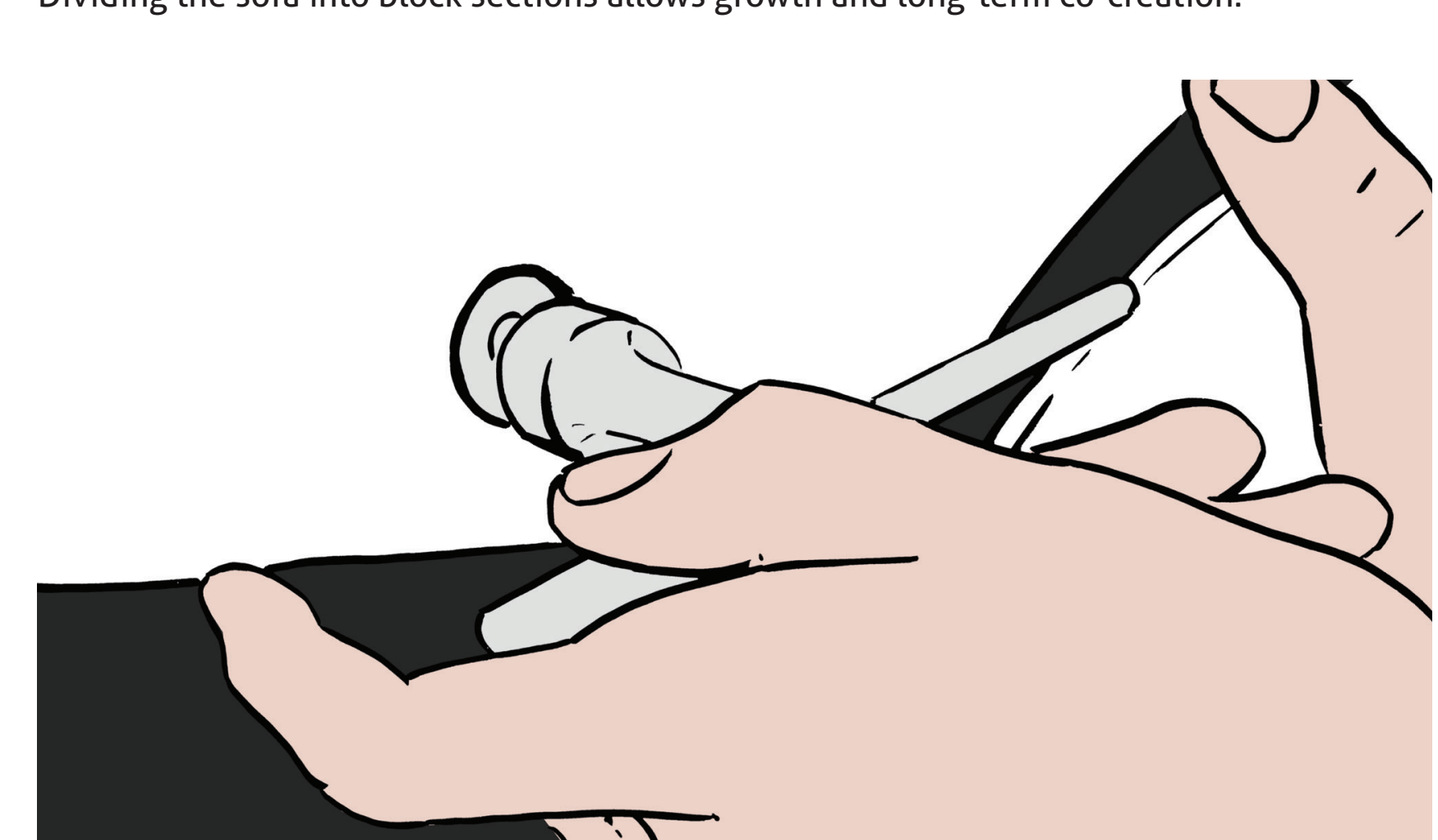

.52. Vitsoe 620 System by Dieter Rams

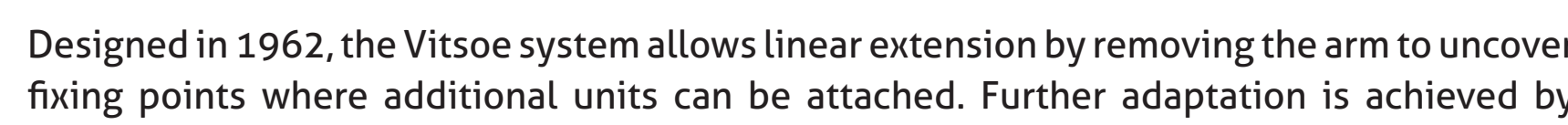
replacing the castoris with a swivel base.

The design was updated for a 2013 re-release, and a new tool was developed to make
adaptation easier. In Mario Camaleonda's Bellini sofa, cube bases join in four rirections, using a series of

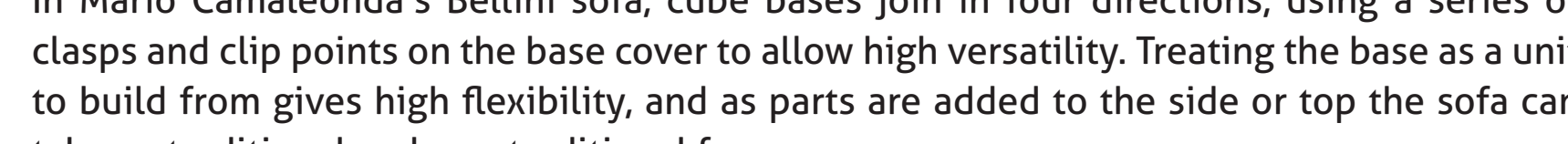

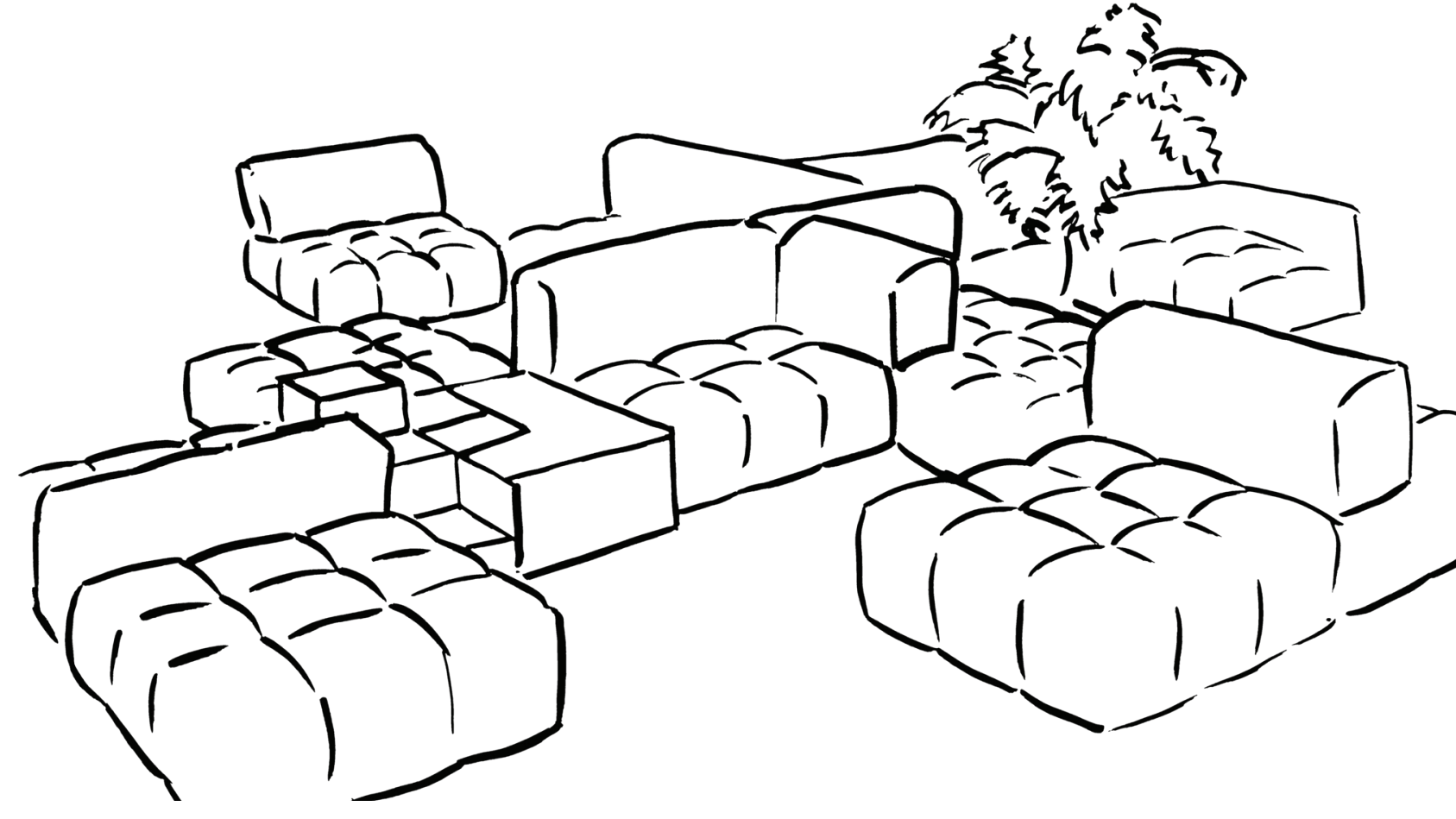

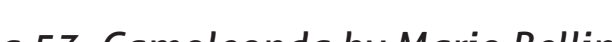

Designing in this way relies on clever details to make the process easy. while adding flar

A similar format to the Bellin
covers from other designers 


\section{$\frac{\sqrt{100}}{\sqrt{50}}$}

Fig.54, Sofa Compact by Charles and Ray Eam

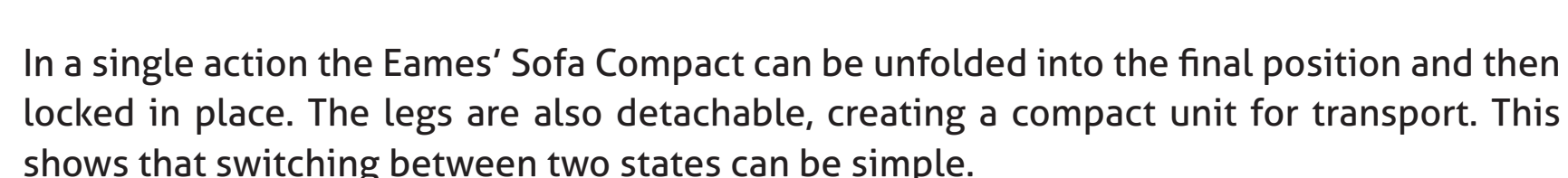

The Can Sofa (Fig.55) uses technology resembling a tent frame to form the structure. This

provides a familiar precedent for the User to referernce, making assembly less daunting. The
use of tubing makes the structure lightweight, an important factor for transport.

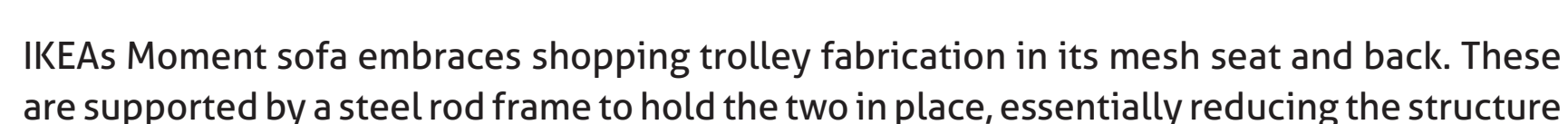

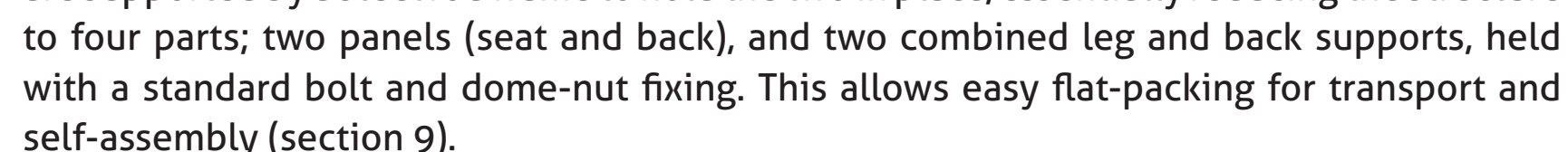

These preceder
disassembly.

d. Adaptable sofas

Adaptability allows sofass to fulfil greater functionality and has been investigated in muttiple ways.

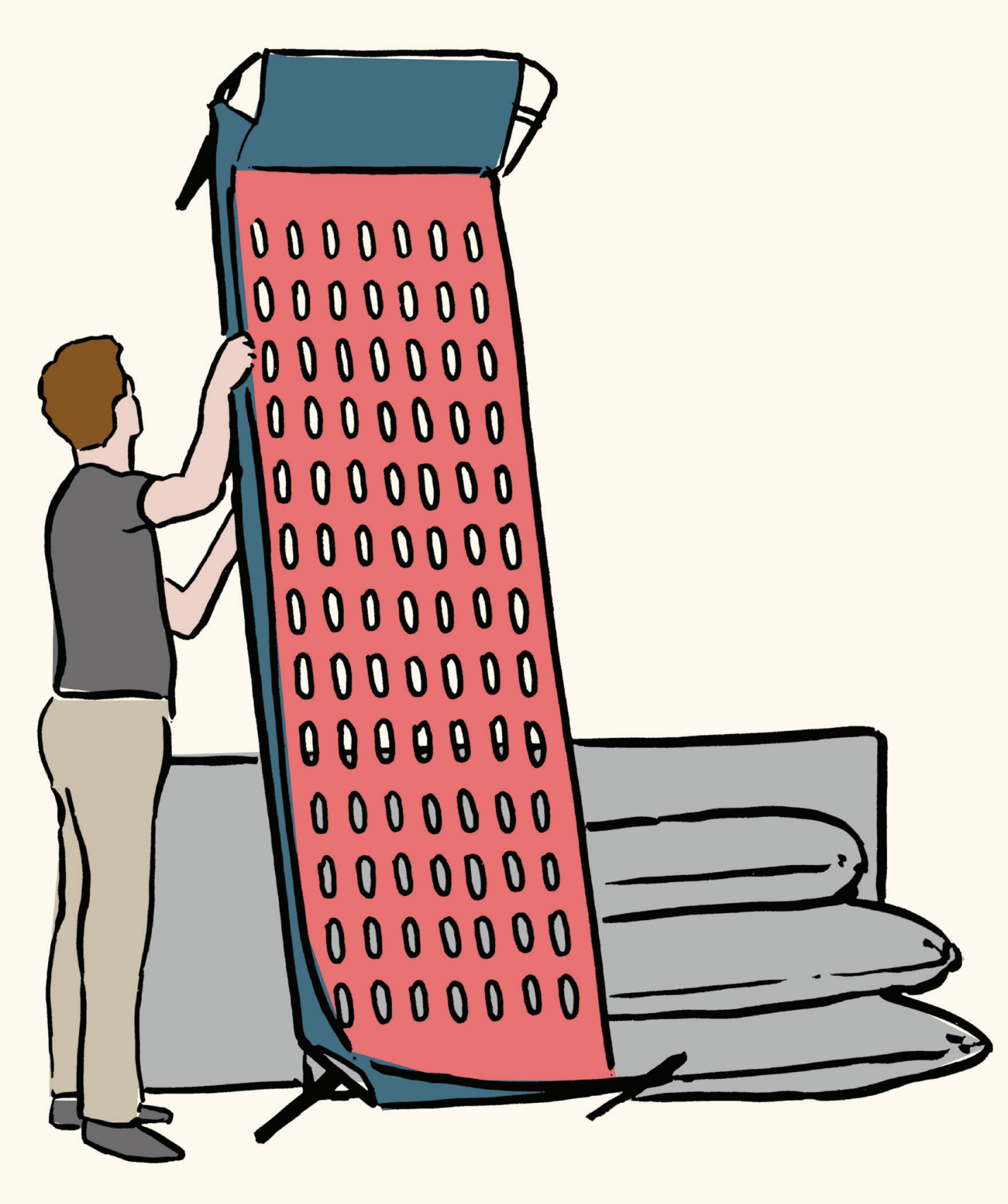

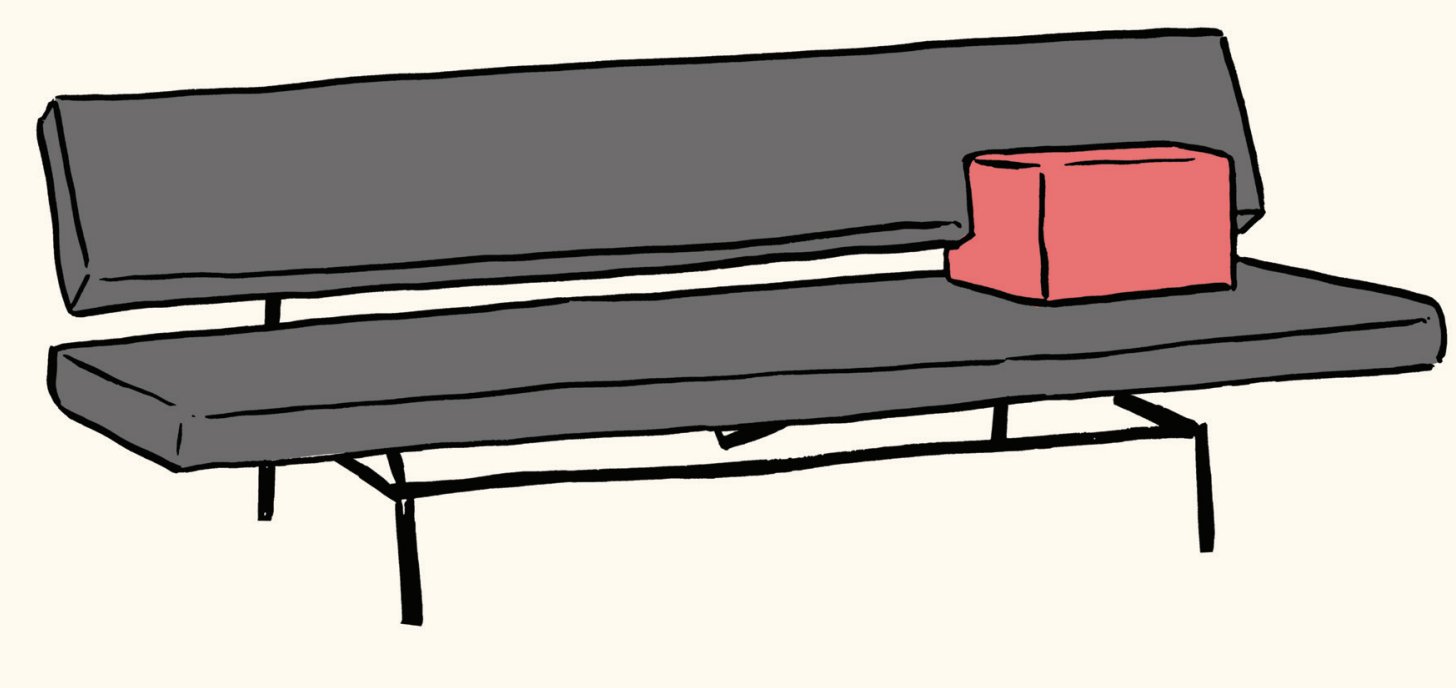

Fig.56, BRoz Sofa by Martin Visser

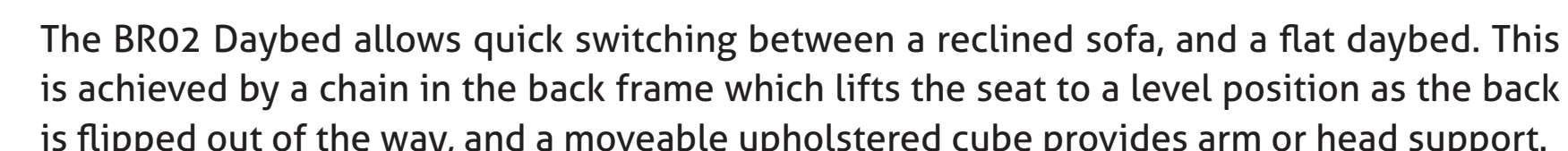

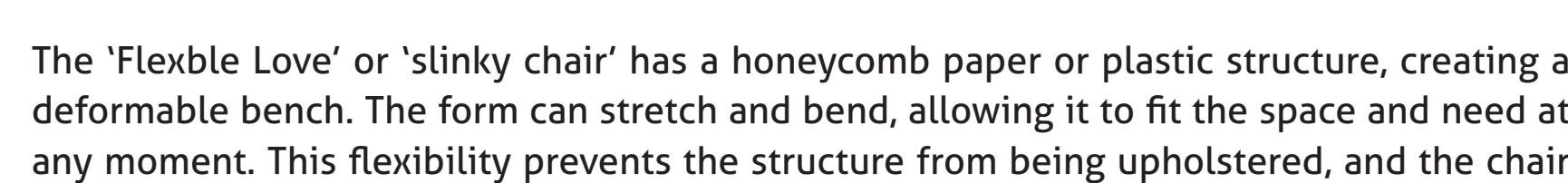

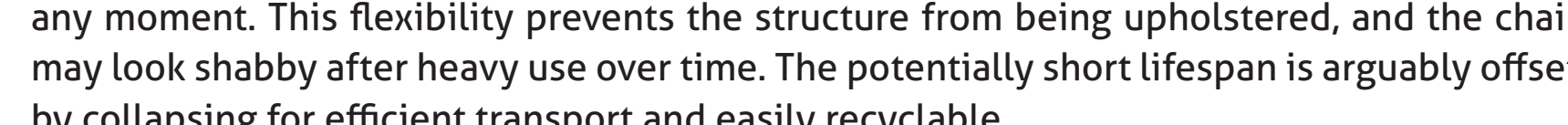

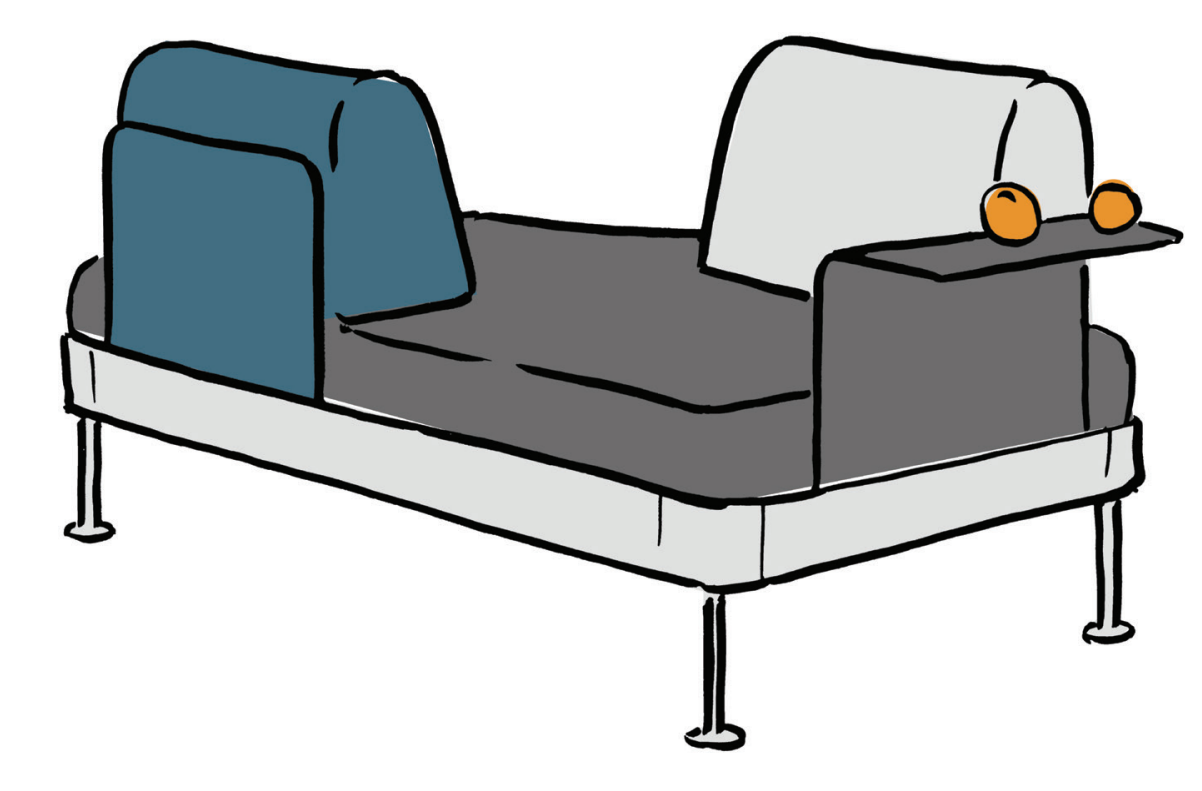

97. 57. Delaktia Sofa by Tom Dixon for IKEA

The Delaktig sofa embraces adaptability through 'hacking'. By reducing the frame to an
extruded alumininium track, a range of official and third-party components can be fitted in many positions. This is a strong example of co-creation. and the success of the design relies the user choosing a kit of parts and engaging in ongoing adaptat tos 


\section{e. Discussion}

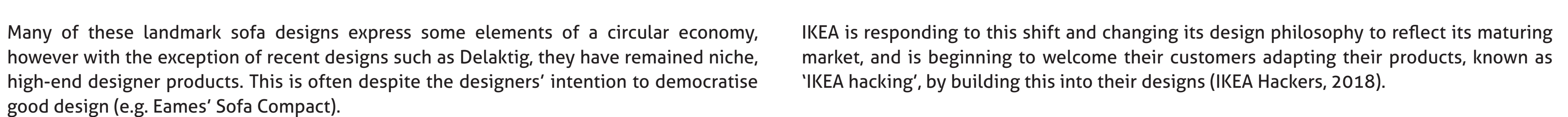

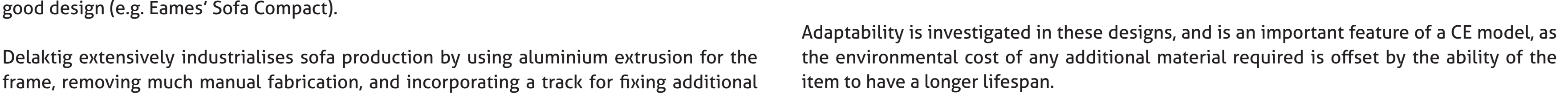
components to the sofa, providing the modularity of high-end systems at an affordable
price. This also allows transparency of materials, reducing the need for added coverings to conceal cheaper, poor quality framing.

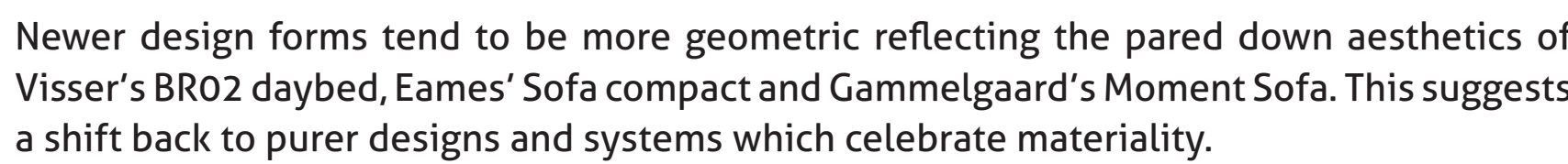
This overlaps somewhat with Slow Design, and it may be that this sincreased transparency
communicates the durability, sense of minimalism and quality valued by these consumers.

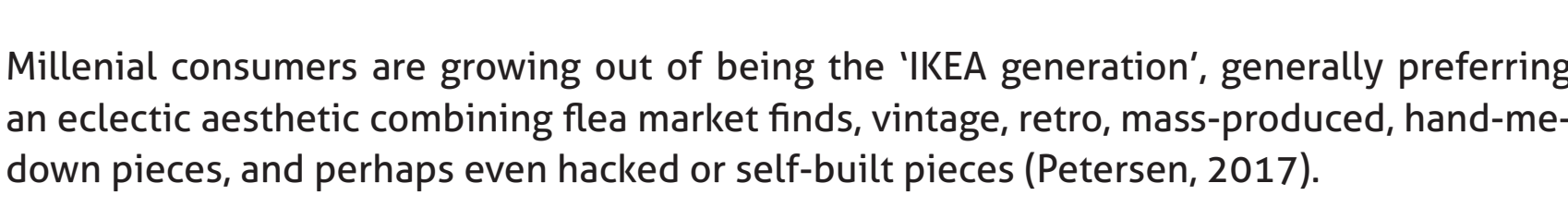

Designs such as Delaktiig and Can fit hese mish-mash aesthetis
statement, but without the bravado typical of d designer sofas.

The adpptability of classic systems such as sectional designs-which are essentially a sofa

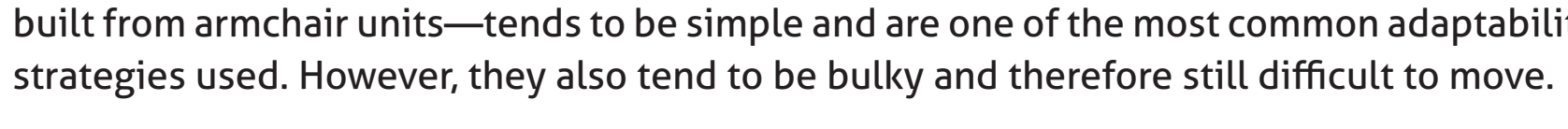
Delaktiig and Soff Compact tare also adapptable, but designed to collapse for ease of transport. Vitso's soft is one of the most advanced-combining the benefits of a sectional system
with hhe abiity to customise features such as as back height, colours, and swivel or leg base.

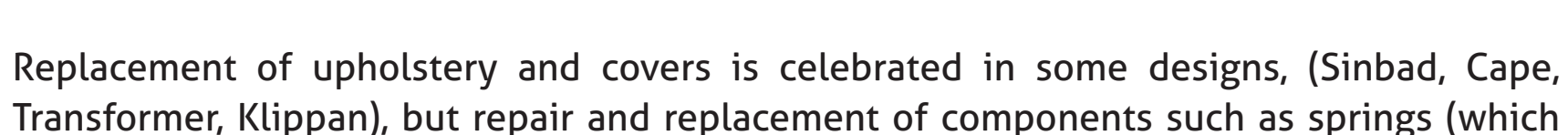

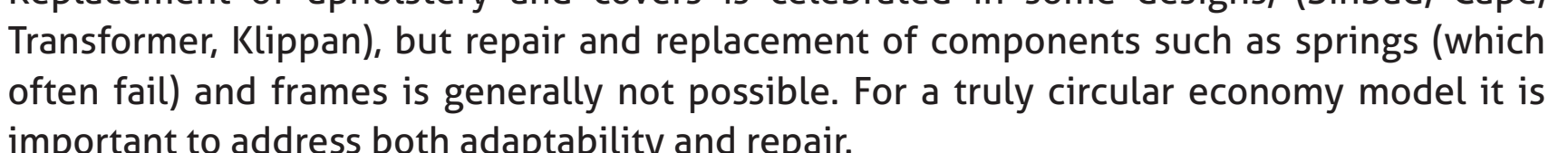

\section{Hypothesis}

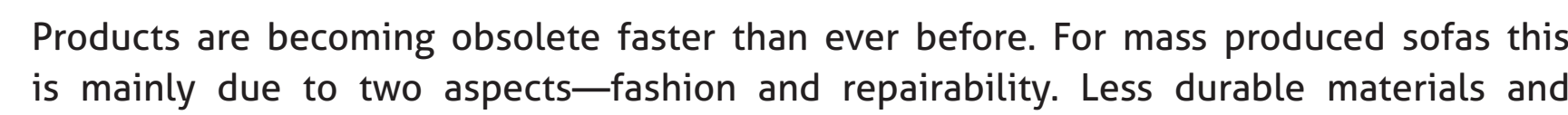

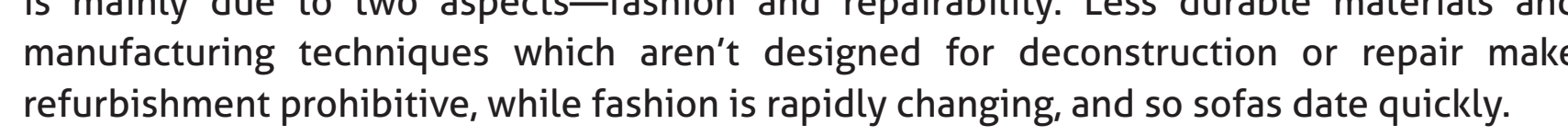

This results in sofas going to landfill with no materials being recycled.

Increasing transience of users has an impact on user needs, meaning sofas should be
designed to be more transportable and adaptable.

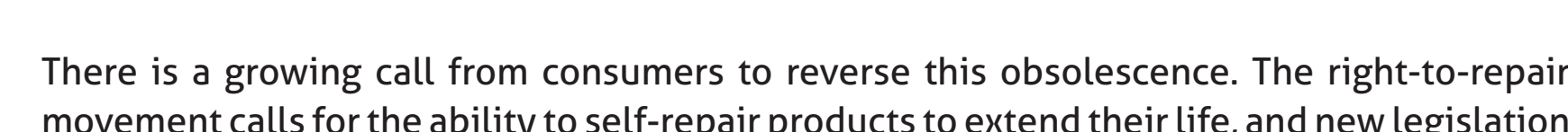

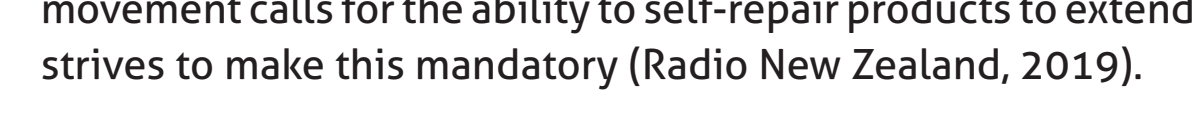

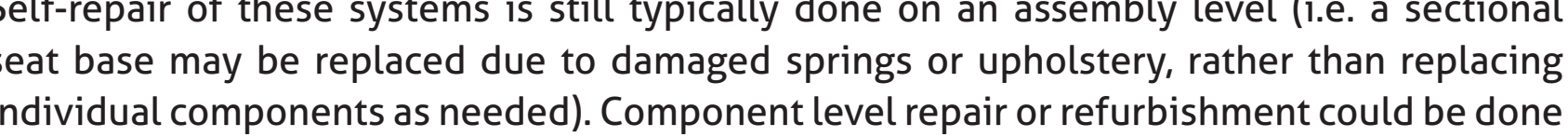
professionally, but offen isn't due to cost. Whil there are many models designed to solve sustainability issues, the Circular Economy
(CE) model-which integates aspects from other models into a holistic systematic aproach-shows the most potential to solve the issue of product obsolescence.

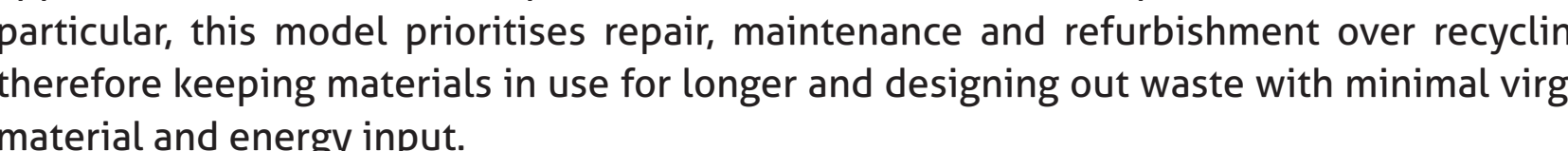

This presents an opportunity to investigate sofa design in the emerging CE context. This
would focus on the abbility to adapt and self-repair a sofa to deffy obsolescence. CE

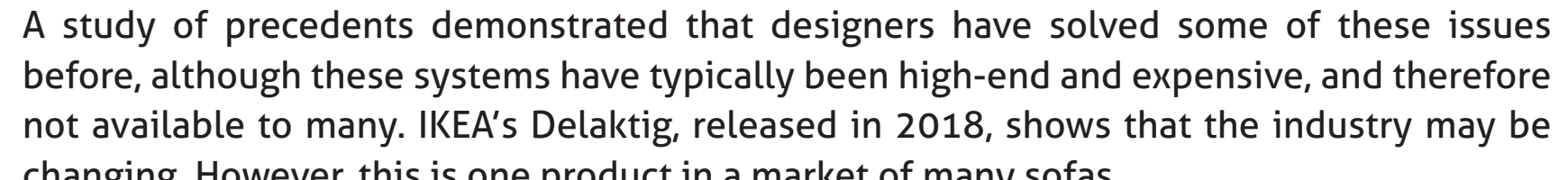

The next section of this research will investigate how the principles of $C E$ can be more fully 


\section{Inspiration}

a. Systems in nature

Circular Economy thinking often takes inspiration from natural systems, which prompted
me to consider the sofa as an ecosystem in which parts can break away and flow.

The stages of mitosis in yesst cell division, wherein new cells 'bud' off from the parent cell
to create new generations, , rovided design inspiration.

Bringing this thinking to the sofas system, unwanted add-ons or frame parts could also 'bud'
off and merge into new or existing systems elsewhere.

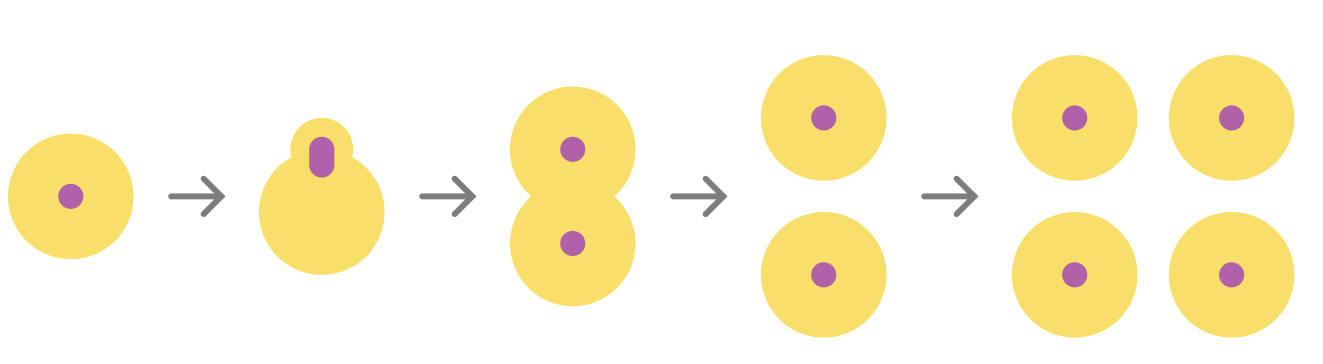

Fig.58, Yeast cell mitosis
Adapted from: Neiman (2011)

b. What would IKEA do?

IKEA offers customers a proposition; if you help with the assembly your reward is greater
affordability and choice (Bengtsson, 2010).

Millennials have grown up familiar with IKEA designs and systems and have an expectation
of funniture simplicity, therefore this concept needs to be as simple, as or simpler than, IKEA

systems.

Ikea products require simple or common tools to assemble. The Billy bookcase requires
the use of one hex key tool (Bengtsson, 2010); the lisabo table leg joint uses only one
screwdriver (Fiirs, 2017).

This suggests that if the CE soff is to successfully encourgee users to maintain and self-
repair it must be possible to achieve this within the general capability and expectations

repair it must be possible to achieve this within the general capability and expectations
of surers, and that it is i important to reduce the design to one fixing requiring a common
household tool. or design and provide a special tool

household tool, or design and provide a special tool.
In order to change behaviour we need to reward the behaviour we want. In this case, we want

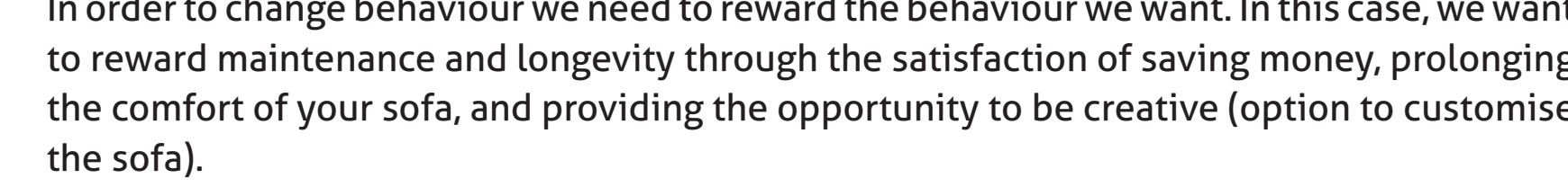

c. What would Dieter do?

Much of Rams' design philosophy predates the Circular Economy, but echoes its values

Working with Vitsoe, Rams implemented significant developments to the 622 chair design
to foster "lifelong adaptability" including the addition of a bespoke tool (Vitsoe, n.d.).

This was developed to aid repair and make adpptation easier. Giving the customer the tool
with their first purchase opens the dialogue to adaptability.

While magnets in the tool hold the bolt securely in place preventing accidental slipping
which could scratch the panel, giving greater simplicity and making the process more

The design nf the Vitsoe chair lalso celebrates the joining of these components and frinings,
rather than hiding them, makking them important details.

This all comes together to aid functionality while being beautiful.

"Less, but better-that's the way."

- Dieter Rams (cited in Terstiege, 2009)

In existing linear manufacturing systems this could be seen as wastefful, as return logistics,
refurbbishment and redistribution are not well established, and so these parts would be

refurbibshment and redistribution are not well established, and so these parts would be
waste. However, moving to a CE Eysten encourages design of interchangeable parts which
can be redistributed to other users. 


\section{Design experimentation and critical reflection}

a. Circularity testing methodology

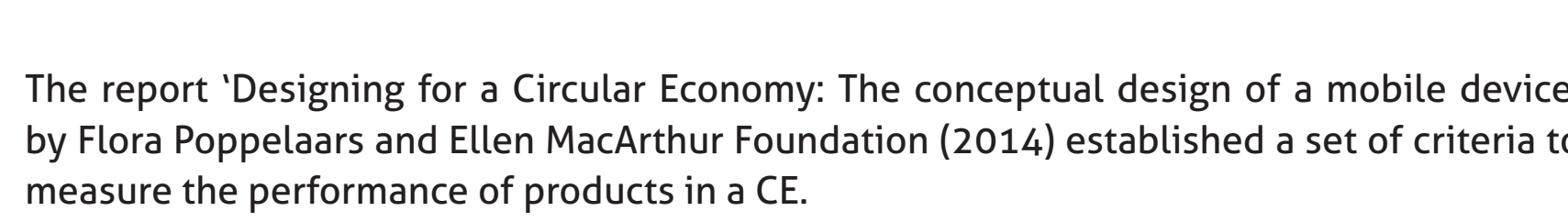
These criteria were adapted to measure the development of iterative soff concepts and,
based on observations unique to sofa obsolescence, a 'reconfiguration' score category was
added. based These are outlined below and in the table on the right hand page.

Reuse (Share)

A system which enables sharing or passing on of products and components means they can Repair

Repair allows worr or damaged parts to be replaced to reinstate functional performance,
with the intention that voreral performance is maintained at an acceptable level. Ideally Reconfigure

This allows adpatation of form and aesthetic to meet changing user needs, such as
lengthening or shortening the soffa, changing firmness, shape to style of cushions, fabric

While this could b b done by either the user or service provider, the ability to adppt the sofa
yourself is more viable as it is more effordable. Refurbish

This involves full dijassembly, inspection and reassembly with new or repaired components,
to address functional issues such as warped or damaged panels, corrosion, unevenenly worn
.

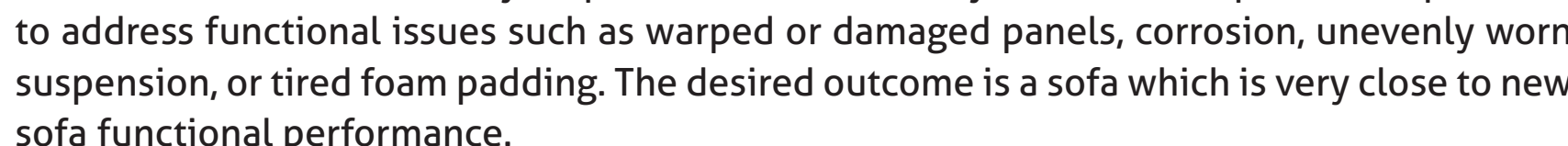

This level lof maintenance would moss tikely be done by a service provider or manuffacturer
offsiste, therefore a design which can break down into a compact unit for transport would b beneficial.

Remanufacture

This involves full disassembly and reworking gof components to reinstate the sofa to new
aesthetic and functional performance. This would support tesale or leasing. This system requires full design for deconstruction allowing for separation to a material
level, as different materials (e.g.t timber and steel) require different skills to remanufacture. Recycle (or waste)

After the ebove methods have been exhausted, some parts may be uneconomical to re-work,
and thereferoc closed-lop recycling is preferered. For example steel springs and frraming re-
smelted into metal stock

'Downcycling' (also referred to as 'cascading' in CE models) is the next preferred method, for example chipping waste PU foam into gym mats. If these strategies are unsuccessful, material goes to waste or incineration as in a linear If these strare
economy.

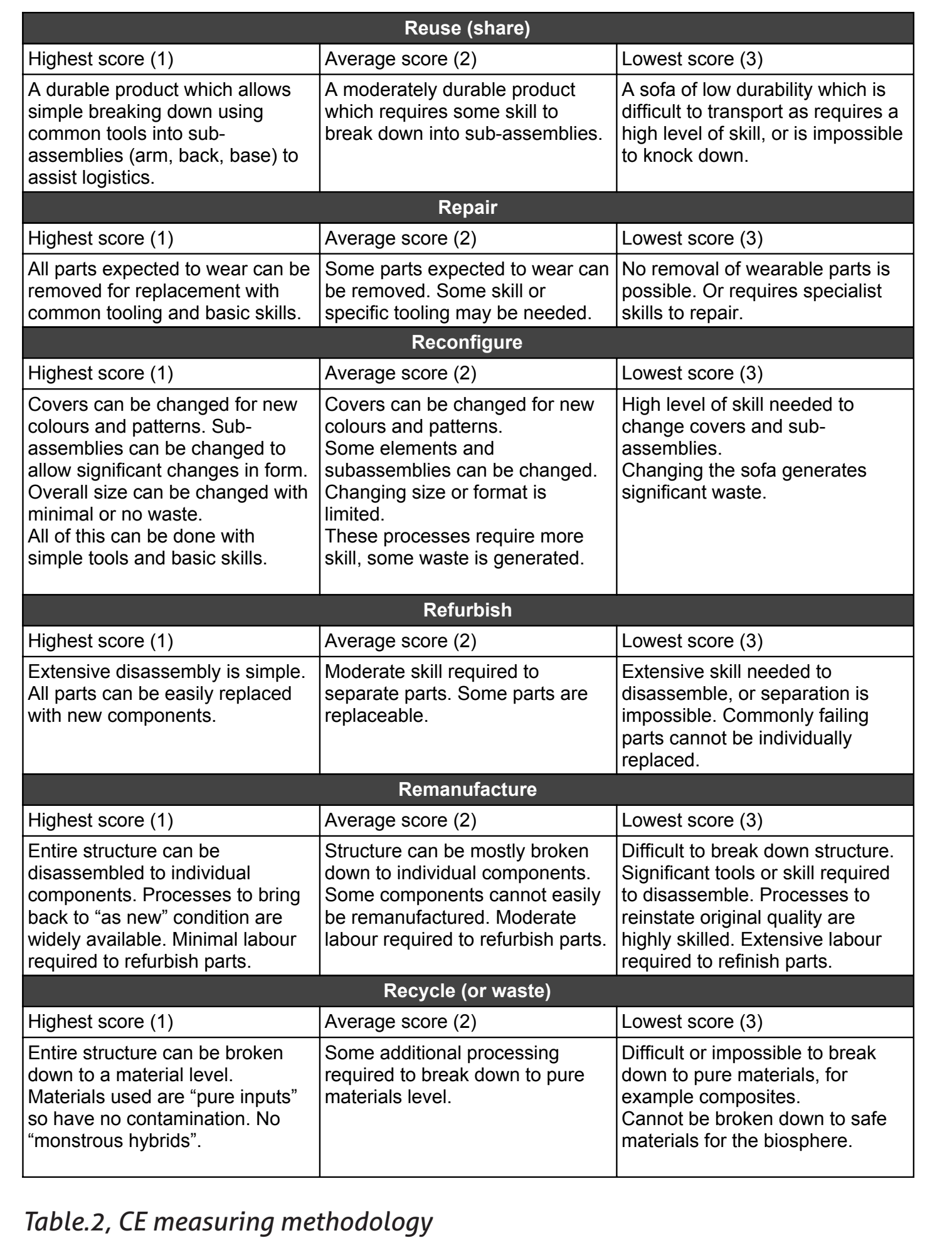

Table.2. CE measuring methodology
Adapted from: Poppelaars, 2014 b. Experimentation and critical reflection

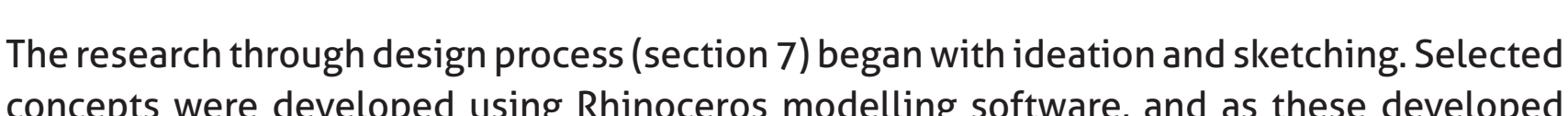
they were assessed against CE C criteria ( section 13a). Where necessary, physical models were constructed to give more data for testing (see
Appendix C). Empirical reflection was used to hightight strengngths and weak points, and the design concepts presented in this section follow a col

Pleae refer to Appendix B for prototypes in iteration orde 


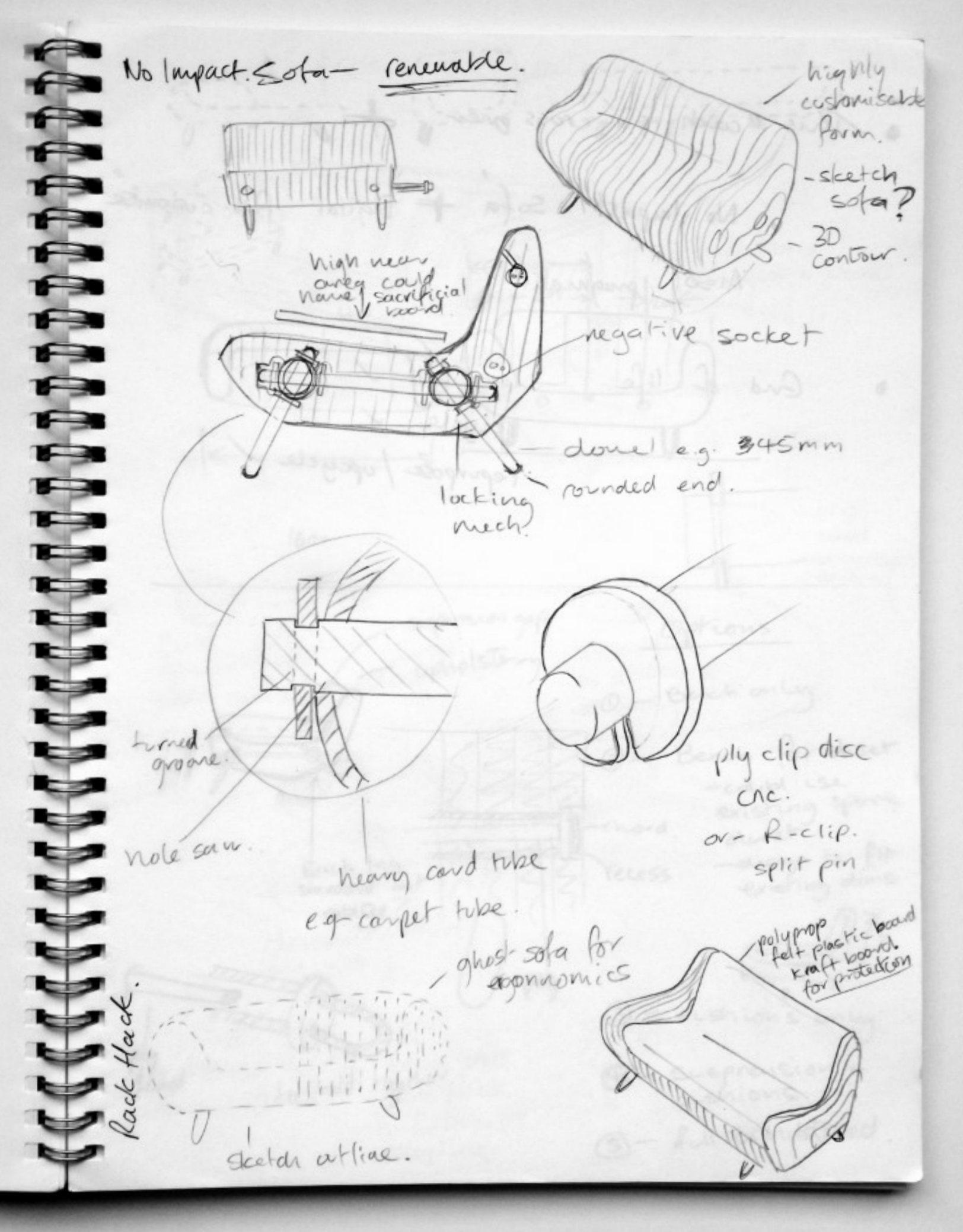



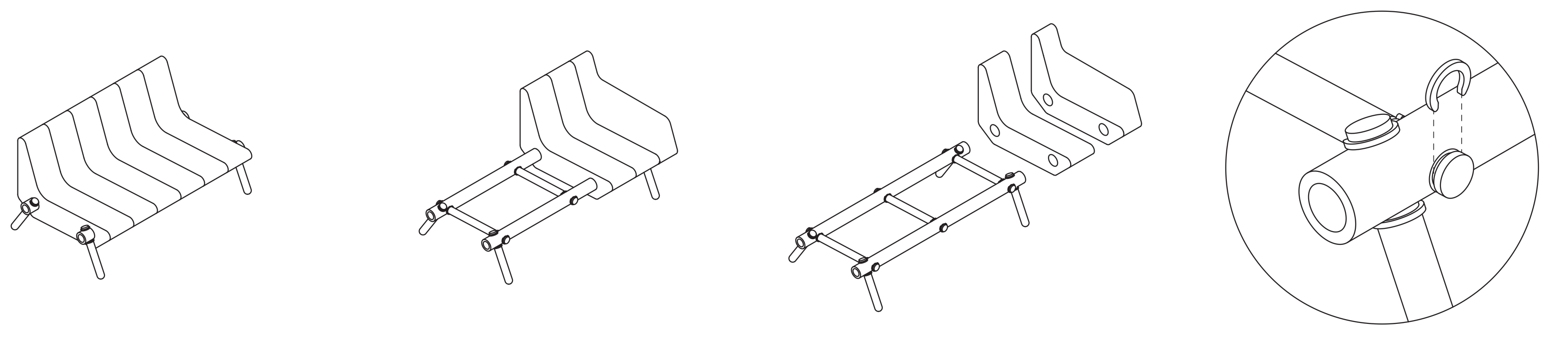

Laminated corrugated cardboard sheets, profile cut
Heavy duty cardboard tubing, interlocked to form frame

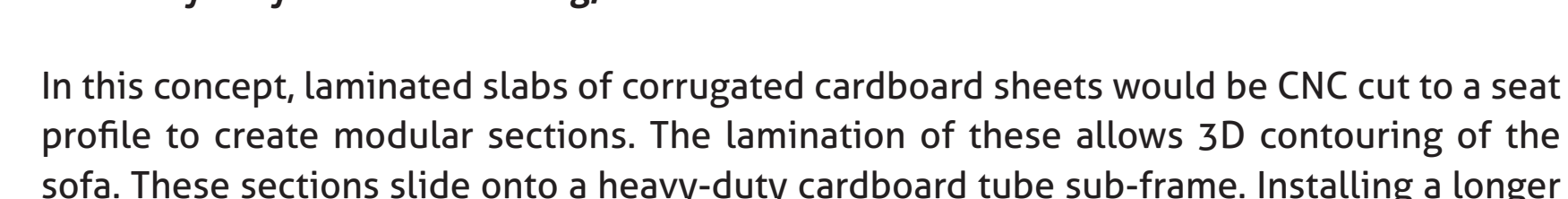
sofa. These sections slide onto a heavy-duty carbboard tube sub-frame. Installing a longer or shorter sub-frame allows
sections can be installed.

Reuse

necycle

All parts can be 100 percent reyclede, or returned to the biosphere to close the loop. This
design excels in this area, however in a circular economy recycling is the least desirable Summary

This design is moderately adaptable due to being broken into sections over a sub frame

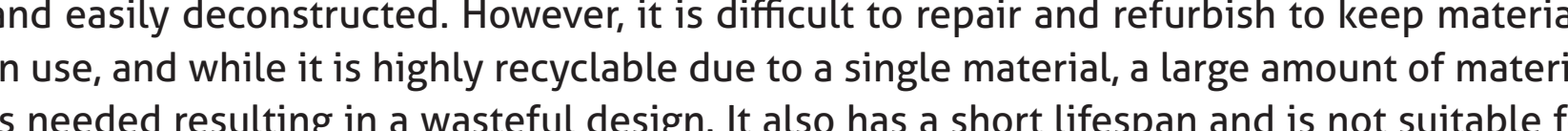

The collapsibility of this helps reuse through sharing as sitthnocks sown for efficient transport, concept has low durability sols chinely to stand up to reuse. Repair

Worn sections can be replaced easily, however outer sections would need to be removed to

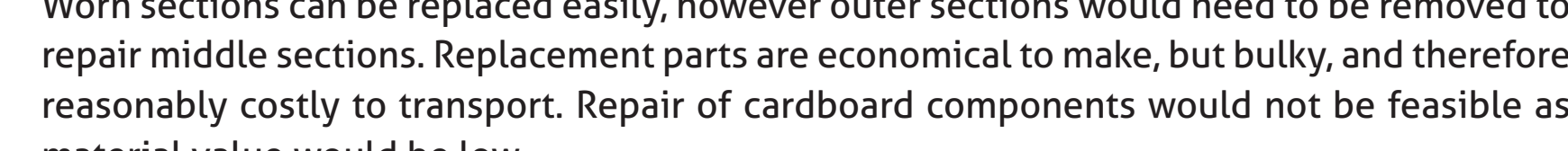
Reconfigure

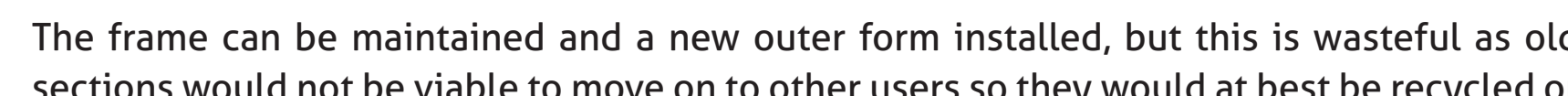
sections would dnot be viable to move on to o ther users so they would at best be recycled of composted. The frame can be extended or shortened to expand the system easily. While it
is adpaptable, changes are wasteful here as it relies on replacement. Refurbish

A si i is not practical to repair such low cost prts, refurtishment would realistically mean
replacicing most of the parts. This defeats the point of refurblishment. Remanufacture

Remanufacturing isn't practical as material value is low.

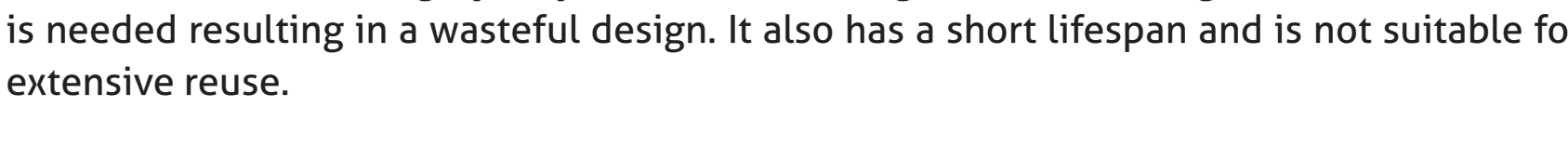

This concept was not taken further as reuse is the most valuable loop in acirculare coconomy

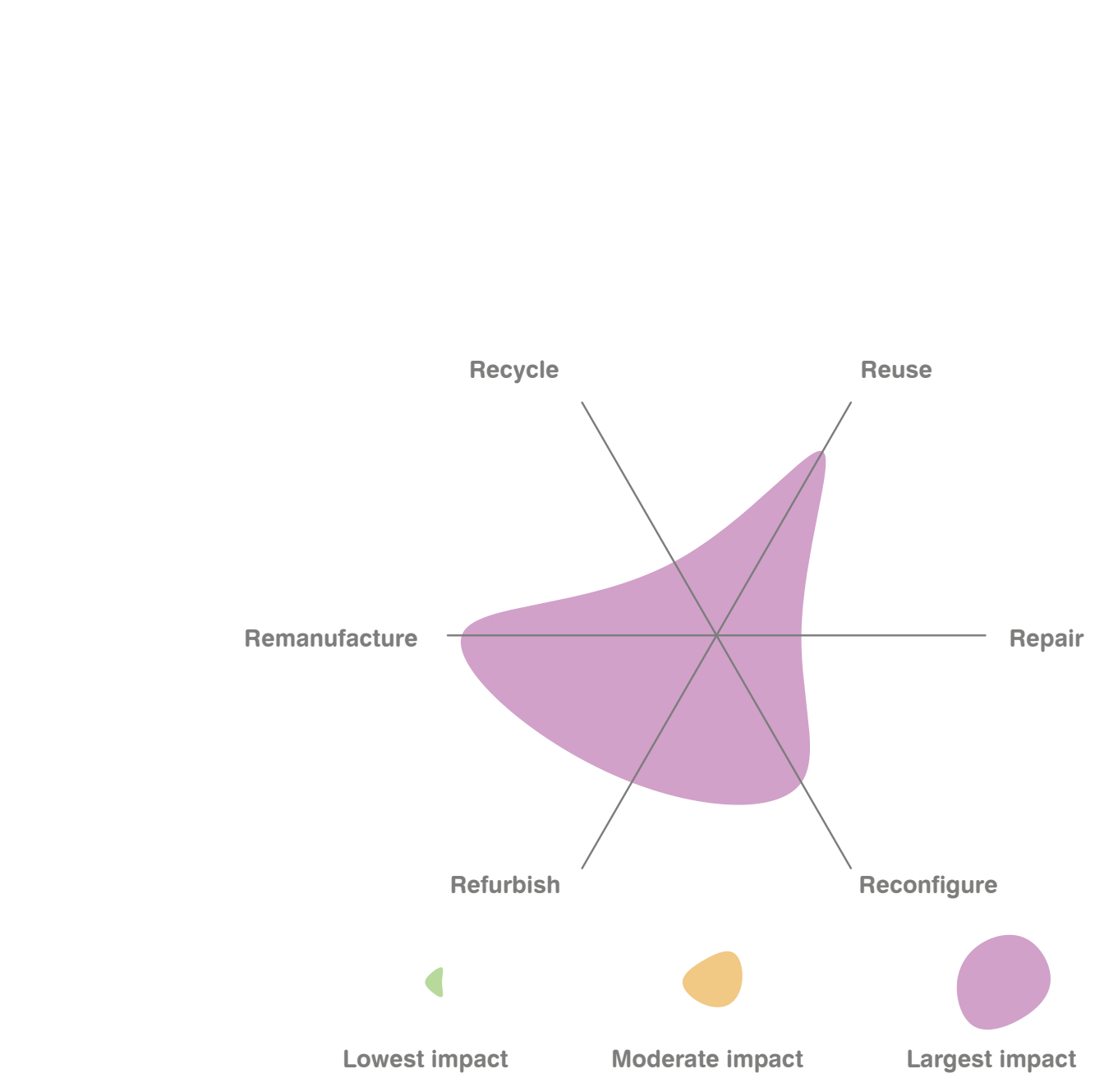




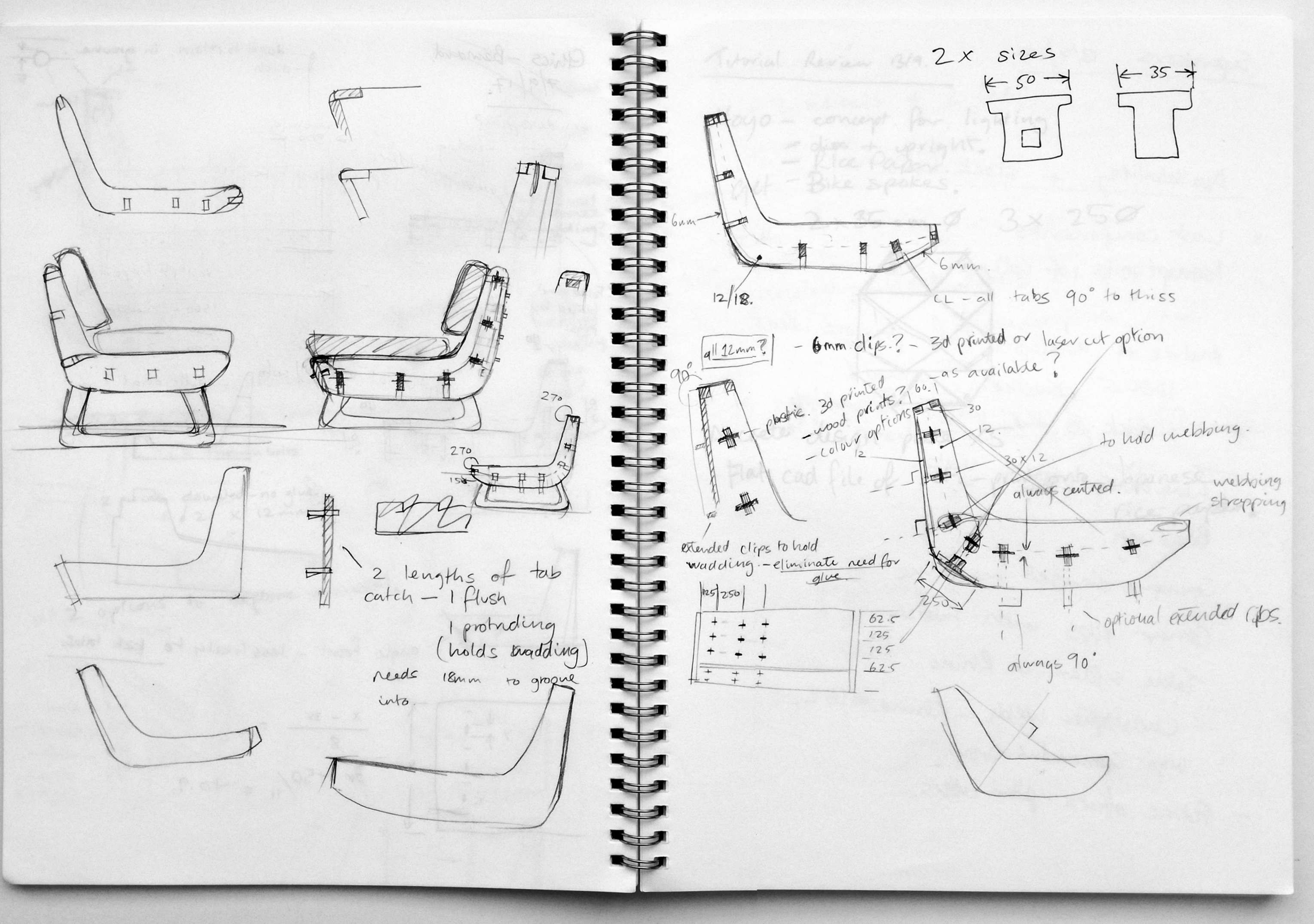

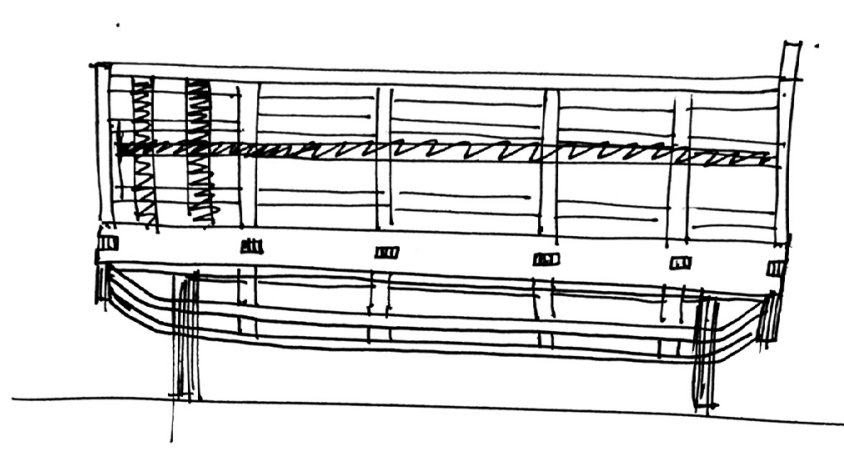

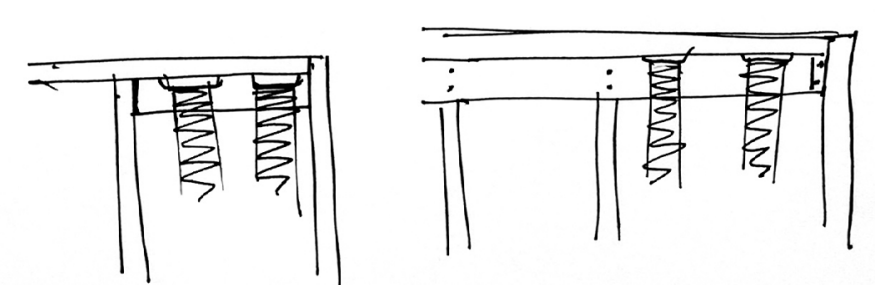

पा

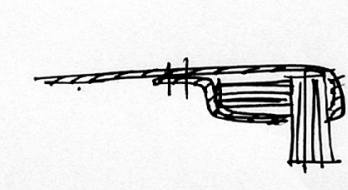

$\forall M$
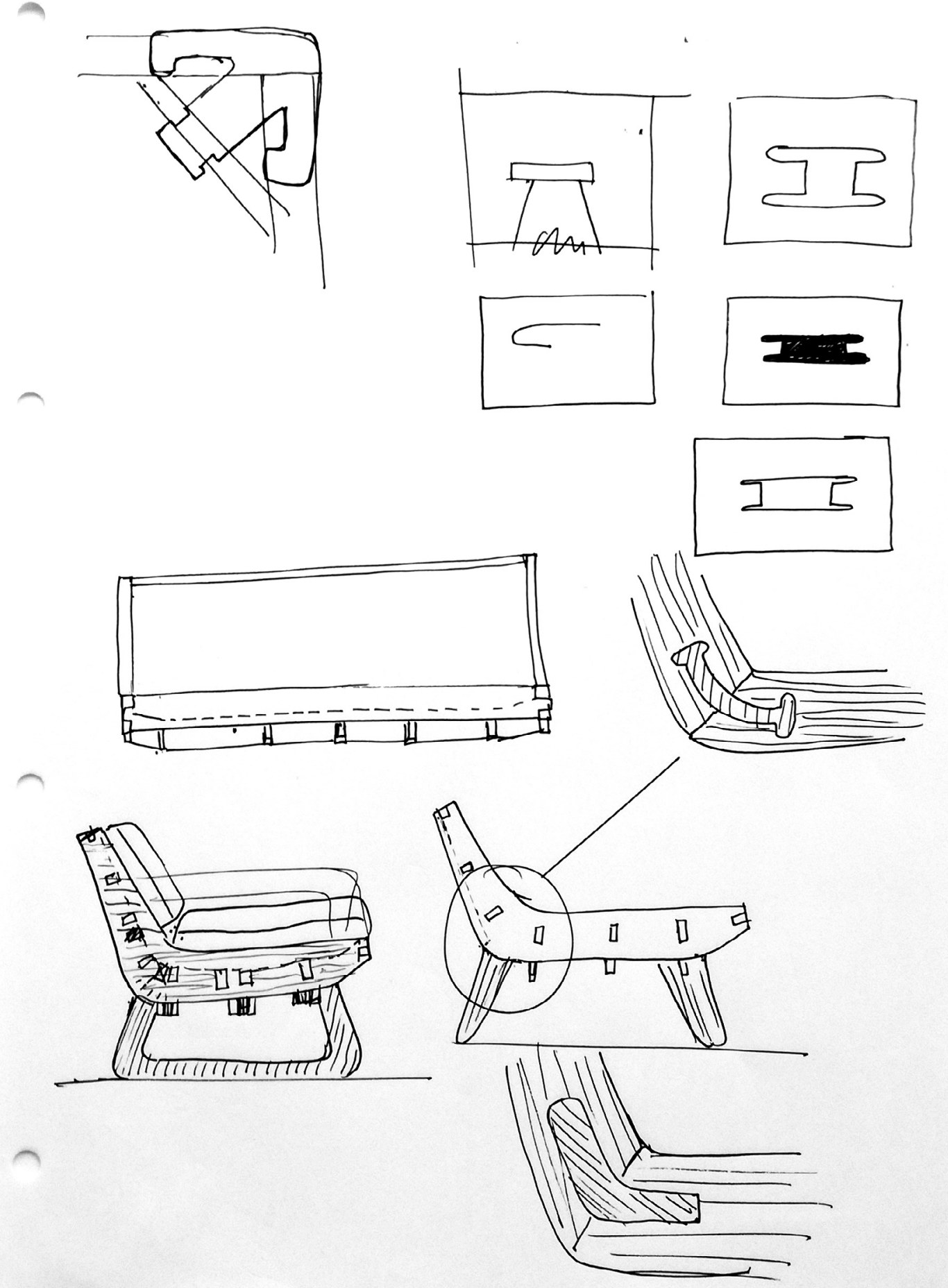
$\infty_{1}^{\infty}$
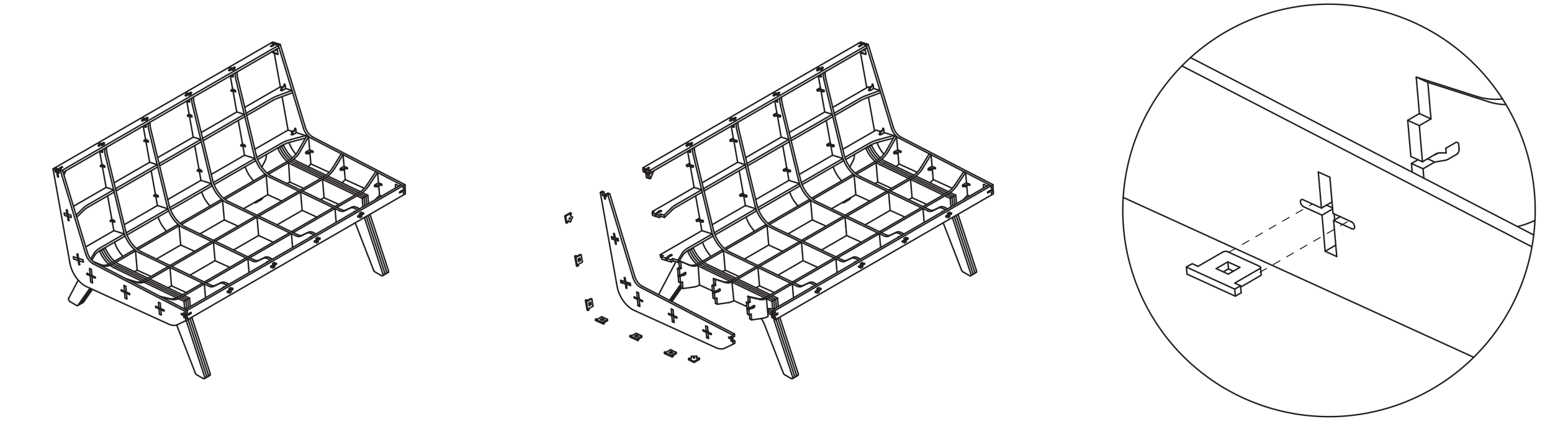

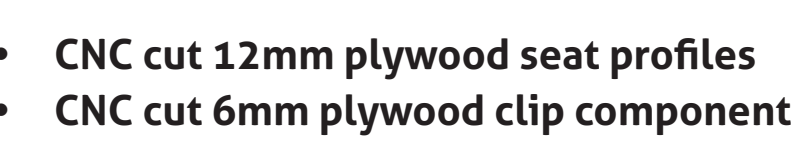

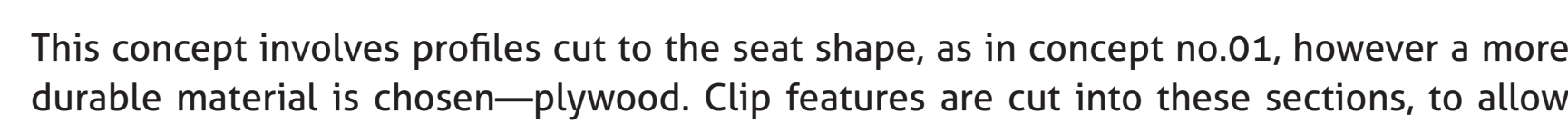

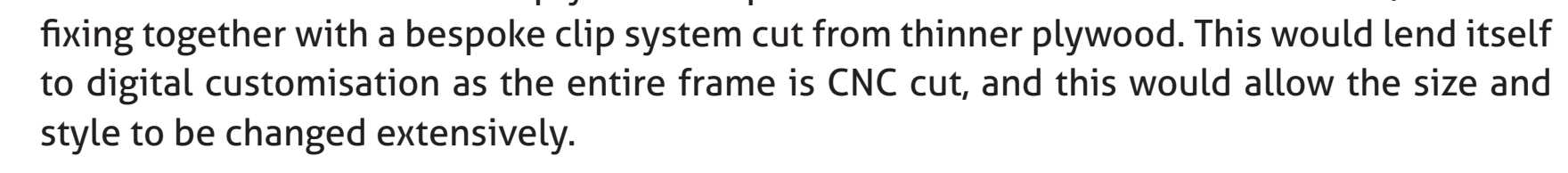

Reuse

This design has high durability due to the plywood structure. It can be deconstructed compar
not tool

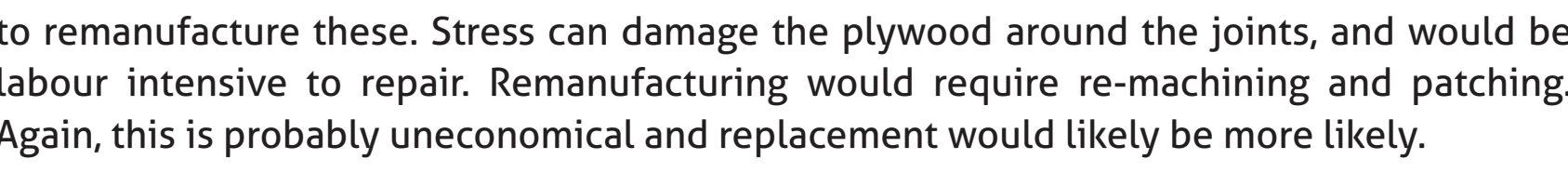
Reycle

Plywood cannot be closed-loop reycled. It can cascade into engineered timber board,
however this requires adhesives and finishing which may prevent the material from being however this requires adhesives and finishing which may prevent the material from being
successfully returned to to the biosphere at end-of-life. Waste plywwood is most likely landfilled or incinerated for energy.

summary

Repair

Repairing individual frame parts would be difficult, and so replacement is more practicalreplacement parts can be shipped efficiently. No tools are required to disassemble, but
speciific clips are needed. These can only be replaced via the manufacturer or service

Reconfigure

Reconffguring the piece could be difficult and wastefful. For example, changing to o day bed
style, or increasing back height would require exchanging the plywood sections for ter profiles. Longitudinal beam proffles can be replaced to extend or shorten the sofa, but new

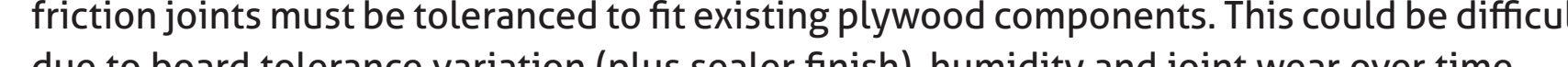

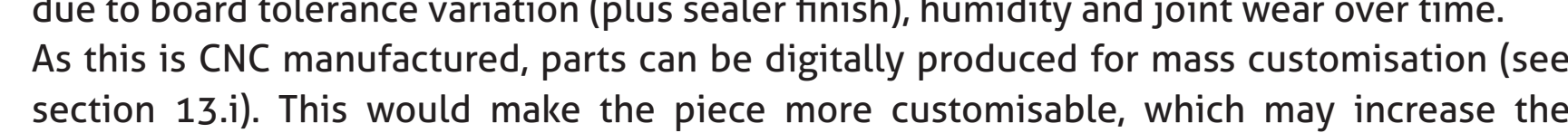
section $13 . i)$. This would make the piece more customisable, which may increase the
likelinood of the user maintaining the soff (emotional design). However, it could make this
bespoke sofal ess successful in a leasing modelel as ongoing adaptation could be problematic. Refurbish

Refurtibhing this system would be labour-inten nive due to the number of ply components
to refrinish. It would likely be more economical to replace them. Remanufacture

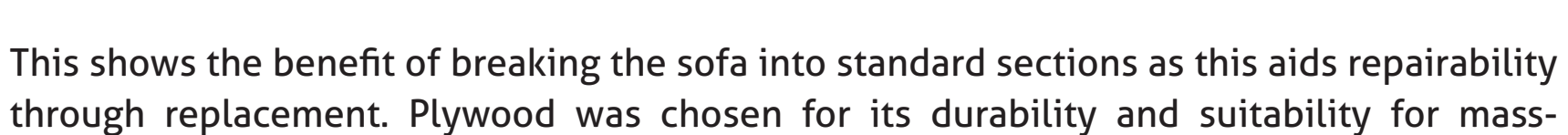
customisation, allowing design to be produced in short (even one-off) runs. However, this

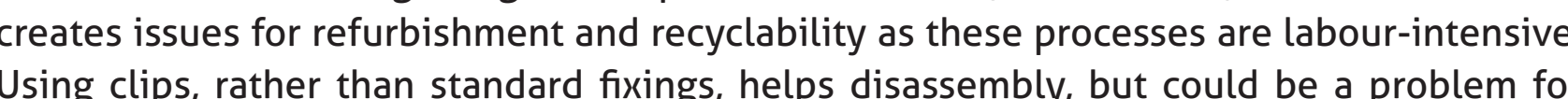
repair asiti is n non-standard part so has to be sourced from the retailer. Though the clips are standardised, there are many of them making disassembly arduous 


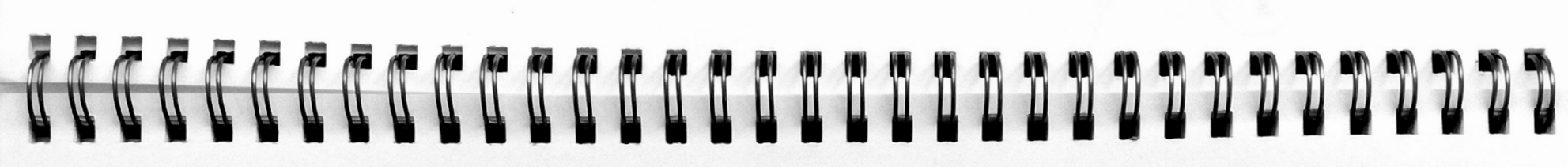

们

Q

$\varpi$

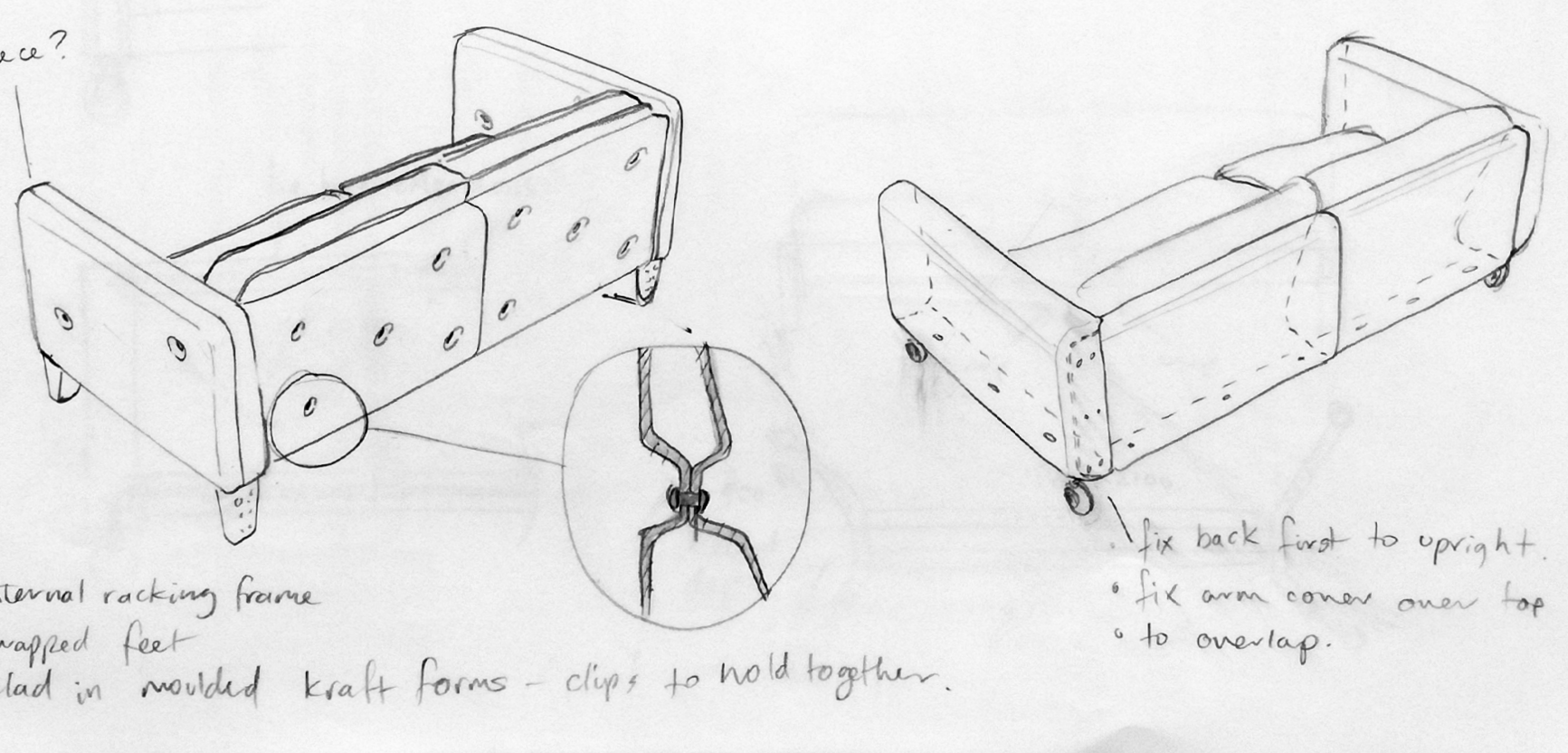




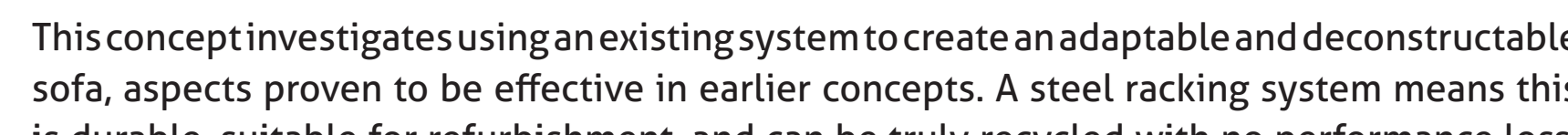
Continuing the theme of repurposing, constrtuction timber is used for cross beamss, and viny
ovvertising banner is tensioned between these beams to create a seat and back sing. heuse

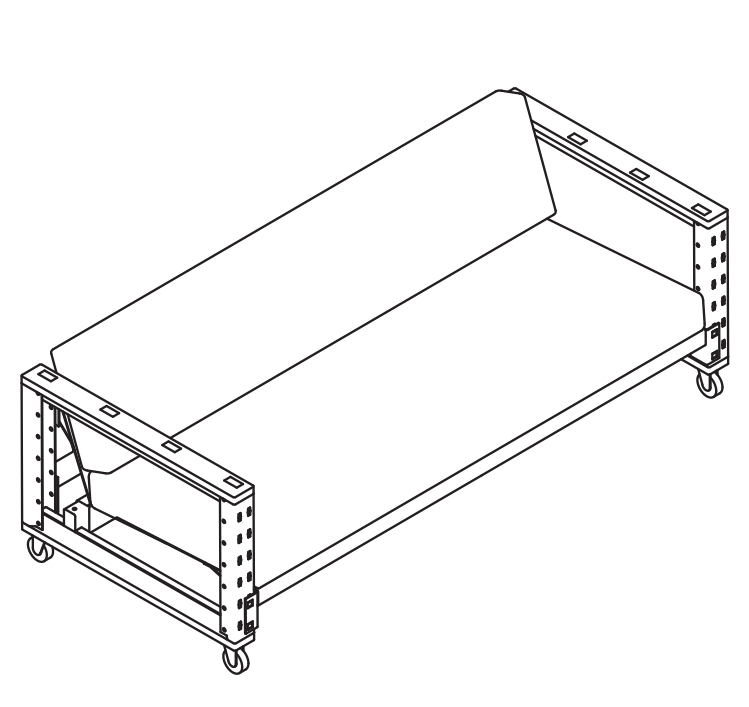
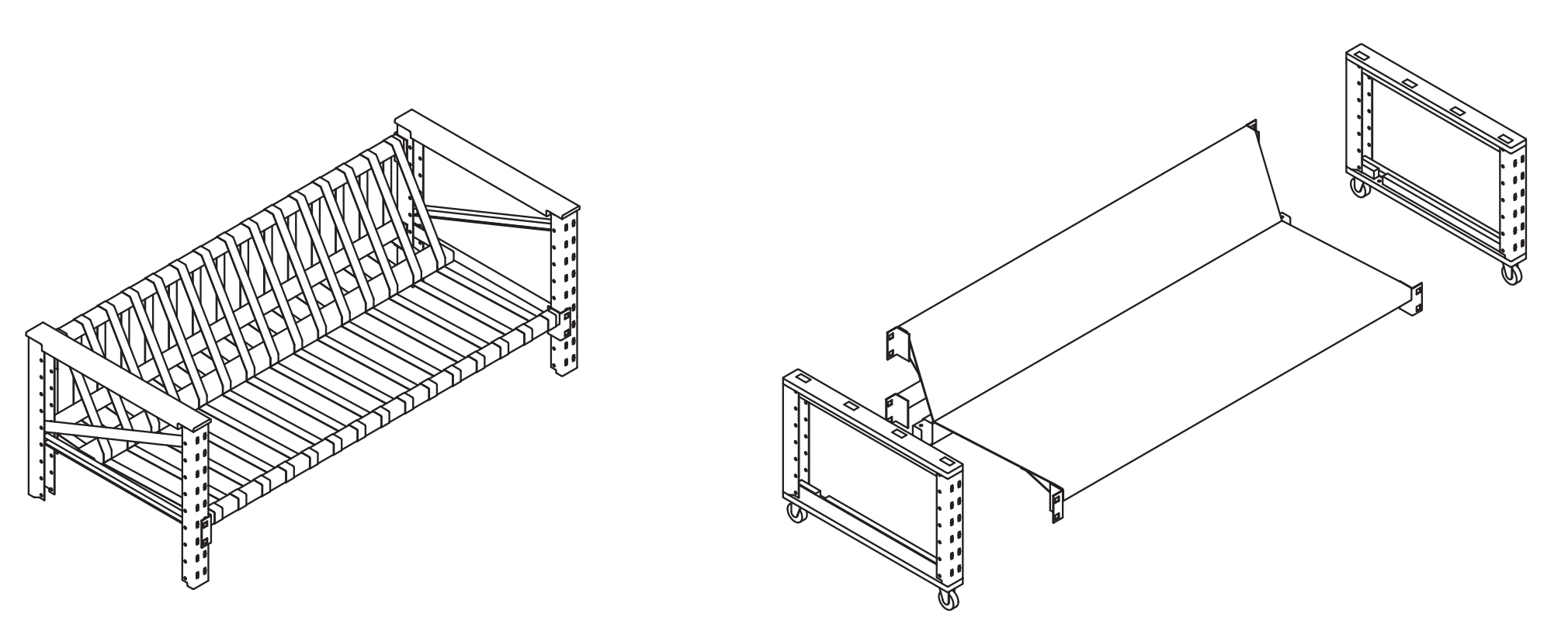

This system is very suitable for reuse due to durability of materials and collapsibility. The
system is altready reused as it was formerly storage racking, and can go on to be anothe

Repair

Asiti is an assembled yystem using standard tools sand simple processes it lends itself well to repair. As the sling is stretched into place, this tension must be released before disassement the beams can then be removed and the sling slid from the crossbeams. The sling can then
be replacece or repaired. Arm rests, feet and frame components can be removed easily as they are fixed with standard bolts.

neconfigur

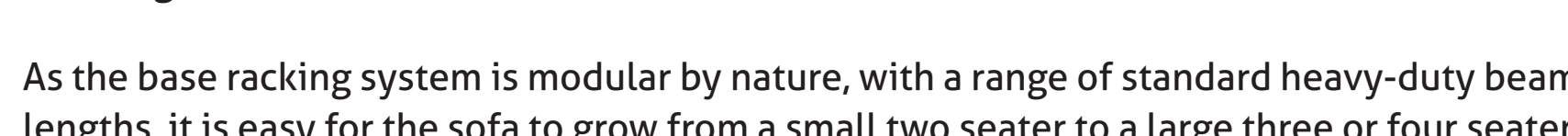

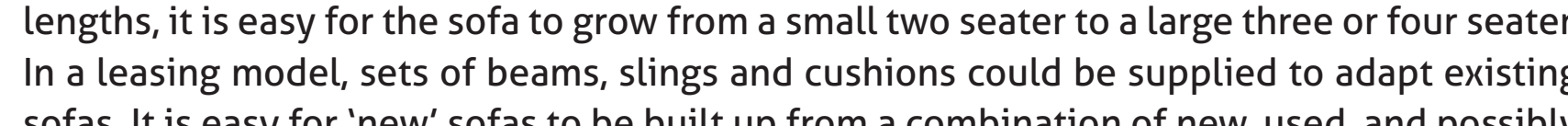
remanufactured, parts.

Refurbish

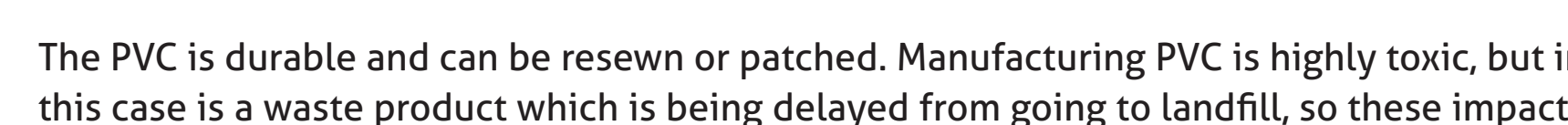
could be considered neutral. Frames can be completelely rebuilt tusing approved parts, which be replaced easily.

Remanufacture

amaged steel frame parts can be re-welded easily. Paint finishes can be removed by
blasting and reapplied by wet spraying or pouder coating-both are common processes necycle

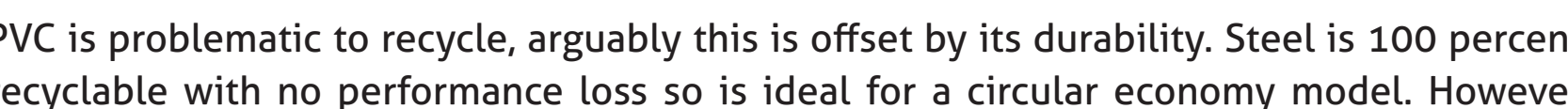
polyurethane foam is is ikely to to be downncycleded into matting and thereforore doess't texist in Summary

Though unrefined, this concept performs well in most aspects of a circular economy, du
lo ease of deconstruction and separable materials (pure inputs). This makes it simple to A

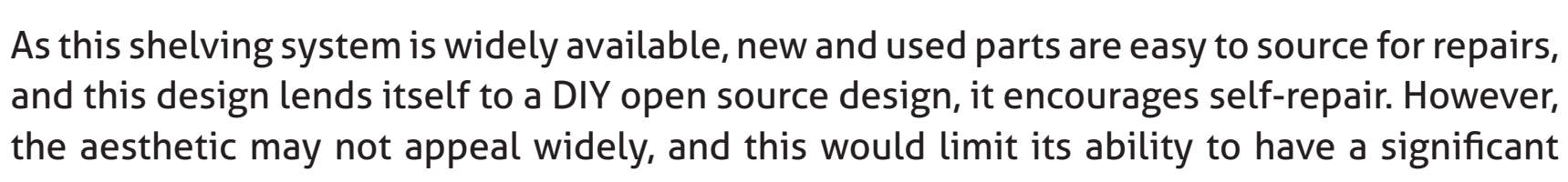

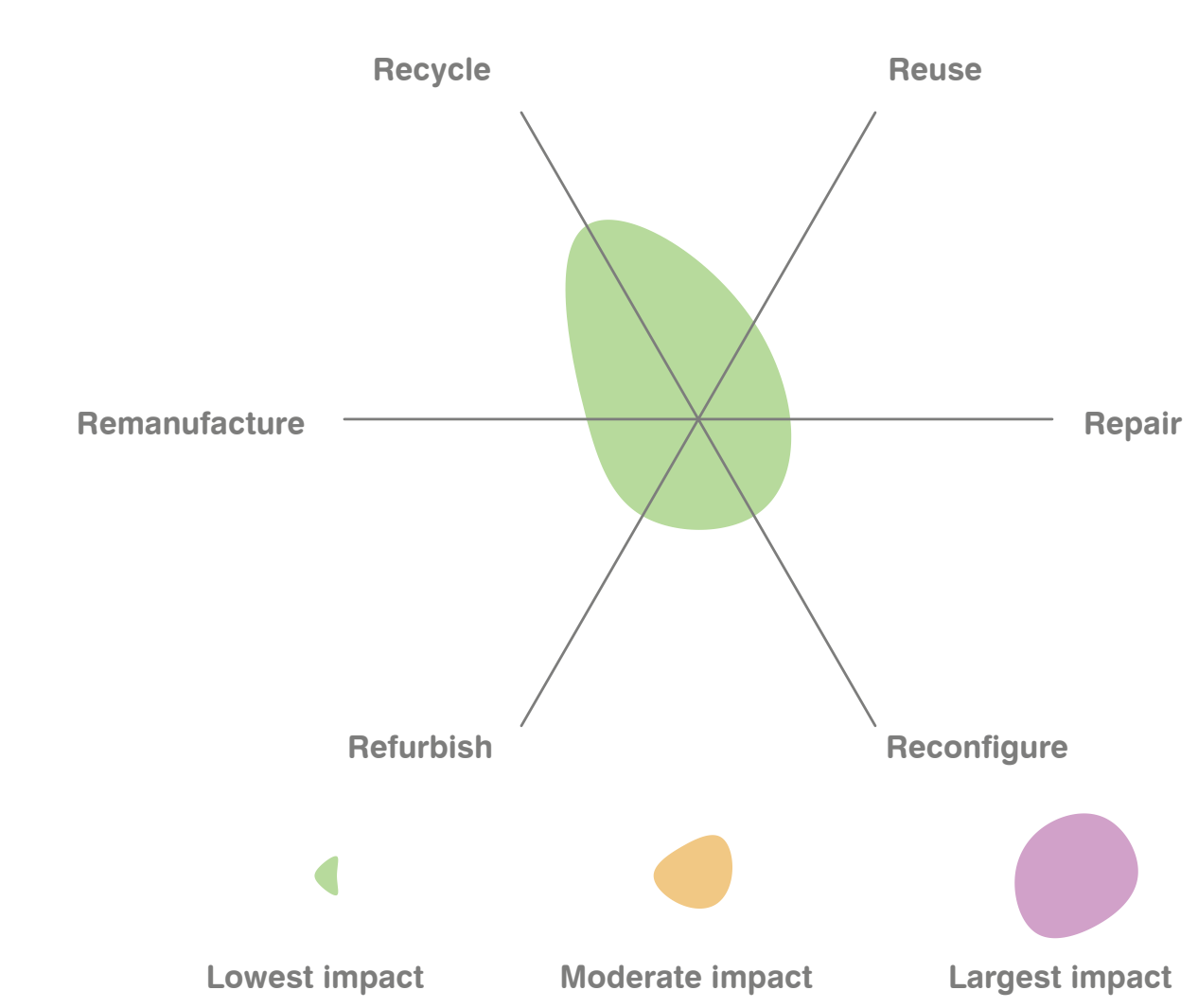



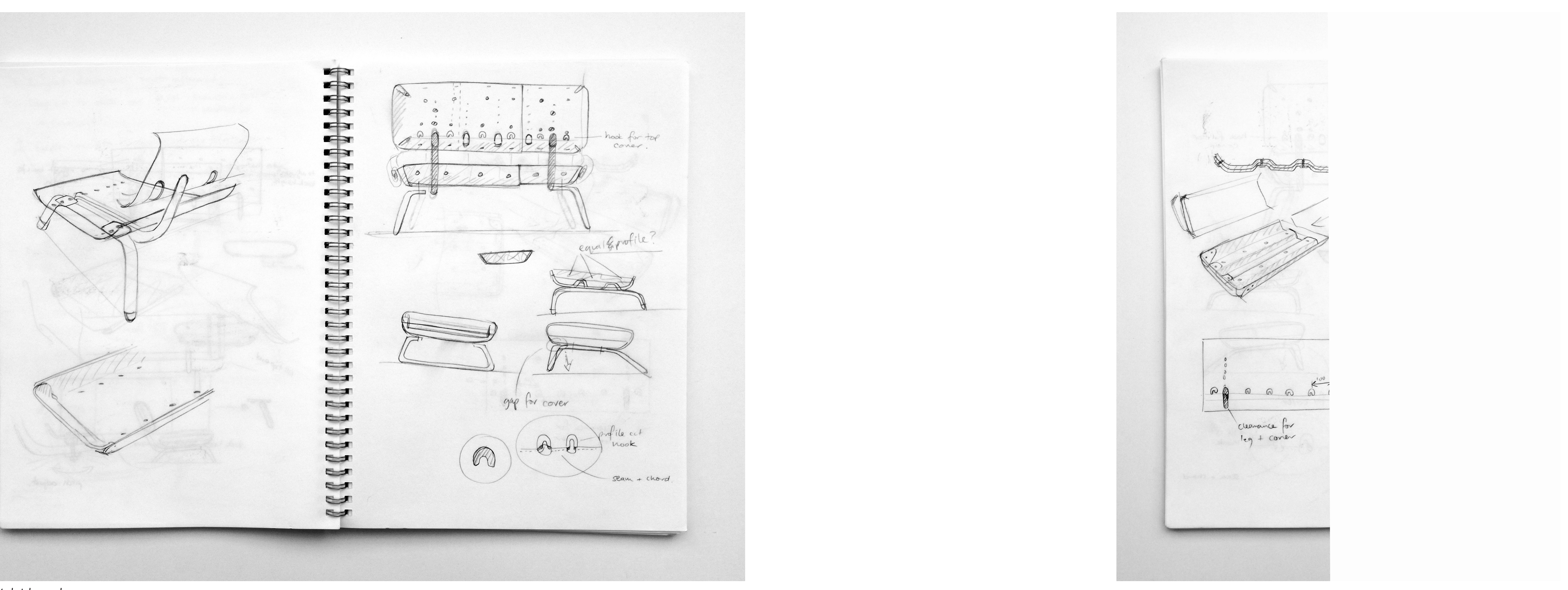
Iteration no.04

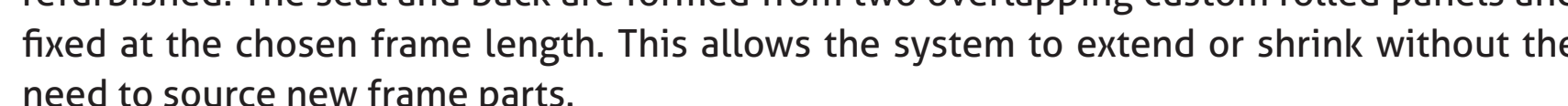
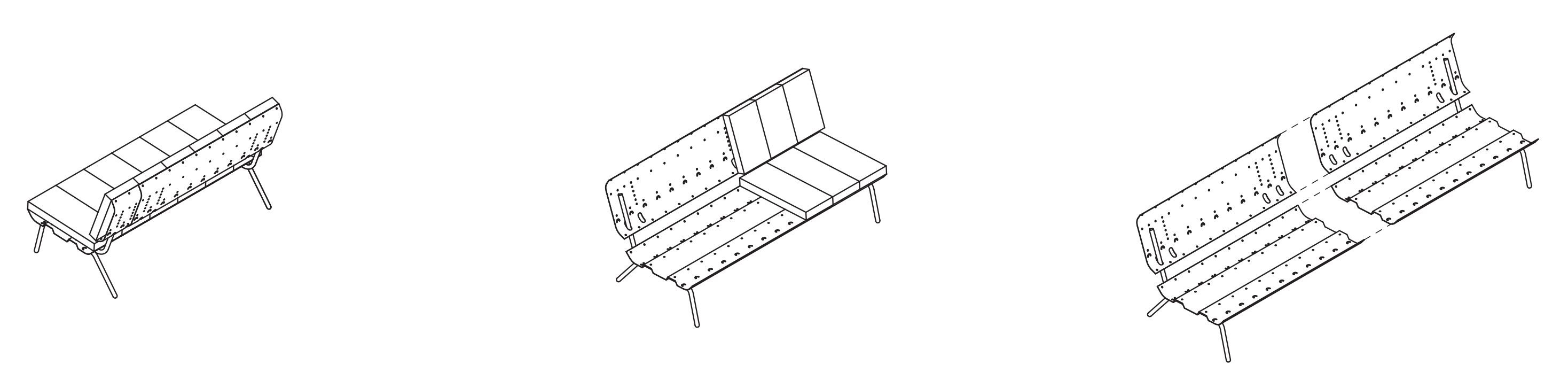

1.5mm rolled mild steel panels
$22.2 m m$ O
RRW mild steel tube

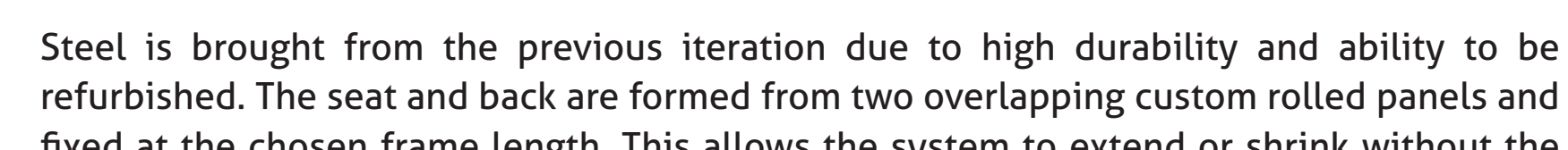

See Appendix B for a 1:6 scale mockup of this iteration

Reuse

Remanufacture

As the structure is entirely mill steel it reduces the number of skills and tols needed for
'emanuffacture. In this case readjiusting, stripping, welding and recoating. The waste from stripping old coatings is is roblematic for disposal

Recycle

As the frame is a single material i is s simple to recycle, even with minal deconstruction Summary

This collopses well for transport which supports reuse, and the steel frame is durable,
thending the sofas potential lifespan. Repair

The seat and back sections are assembled from two overlapping steel panels. This makes it simple to replace alarge parts of the structure at once. Using the CNC steel cutting process
to include fixing points to attach covers reduces componentry which reduces potential to include fixing points to attach covers reduces componentry which reduces potential
breaking points. This means failure of a small feature in a large part can render the whole By increasing the adpatability of the soffi it has become more wastefful due to extra material
needed. As the extending panels sare fully covered the whole system must be deconstructed

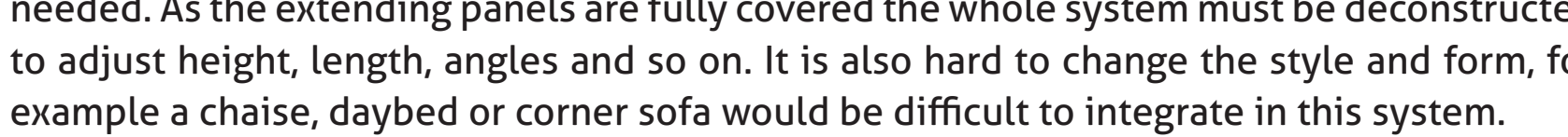
Wastes creating during remanuffacturing should be considerede alongside the total impact of
manufacturing, remanuffacturing and recycling over the full life-cycle. These impacts should This shows there needs to be balance between isolating potential breakge points to be
replaceable and simplifying the design to require less components. Reconfigure

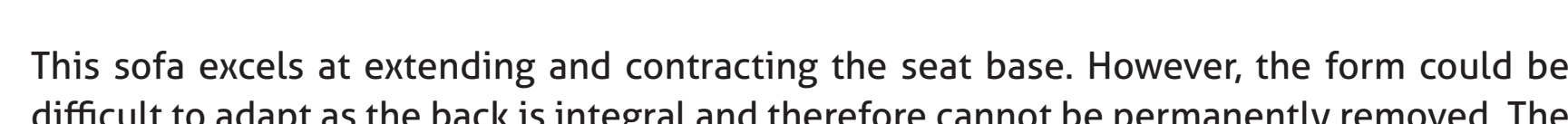

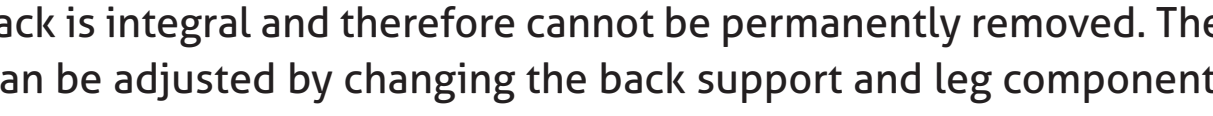

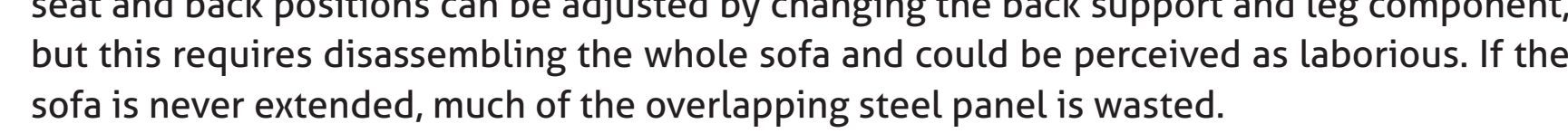

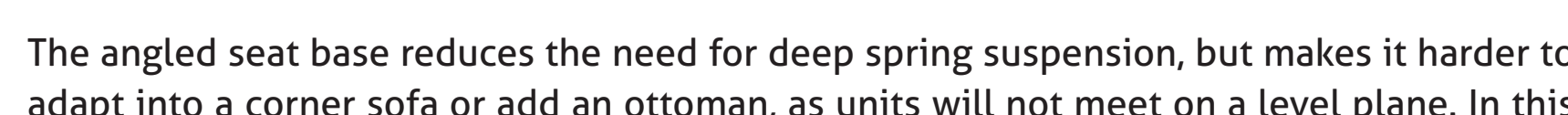
instance reducing material in one aspect increases potential overall material ussge. Refurbish

As the system is fully deconstructable and uses durable materials it can be fully refurbished.

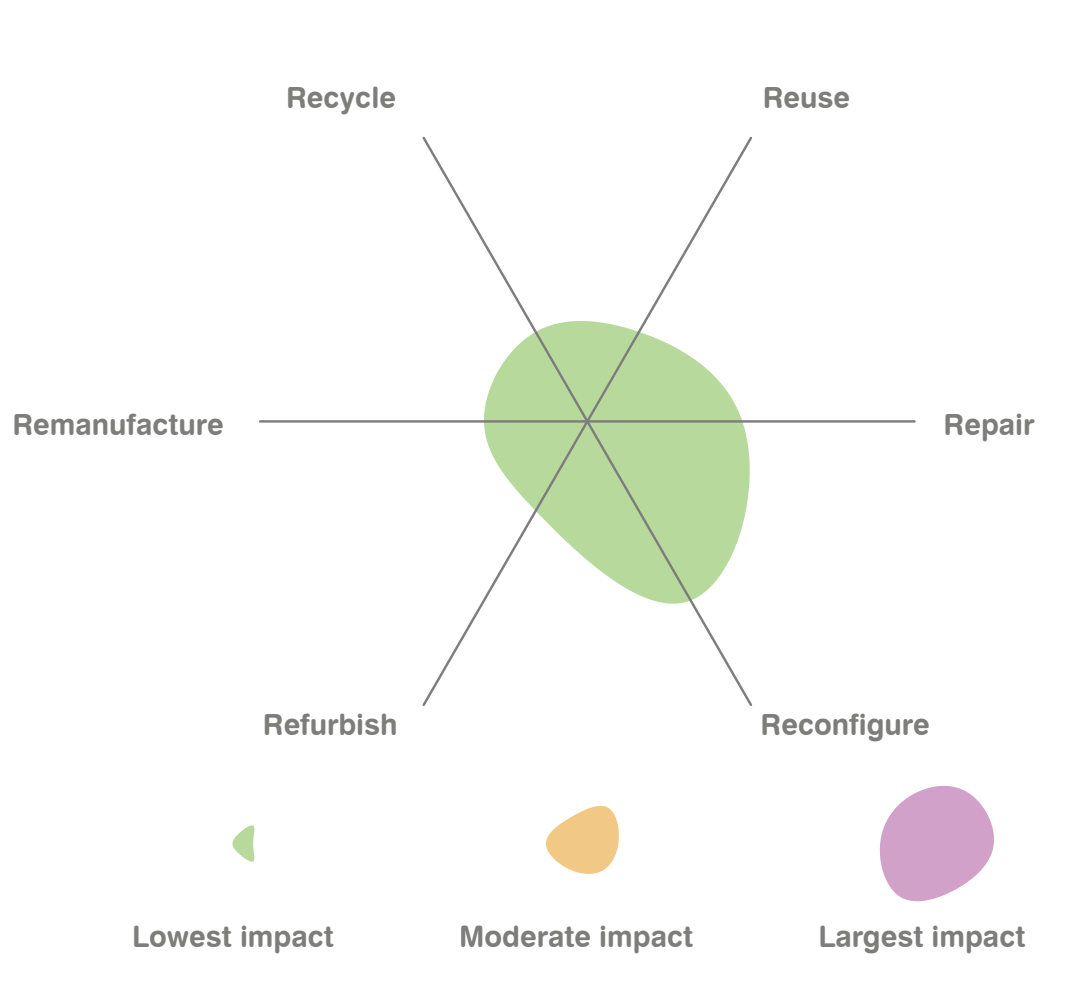




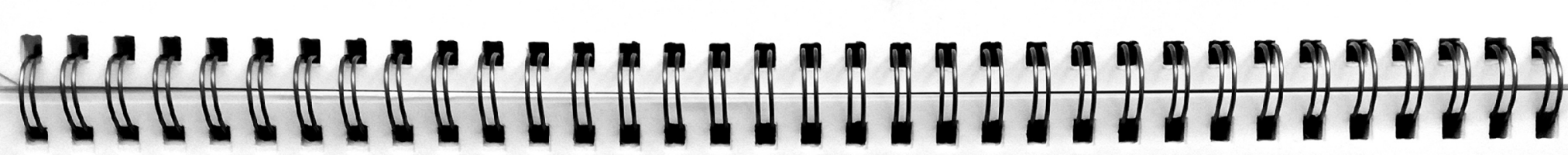
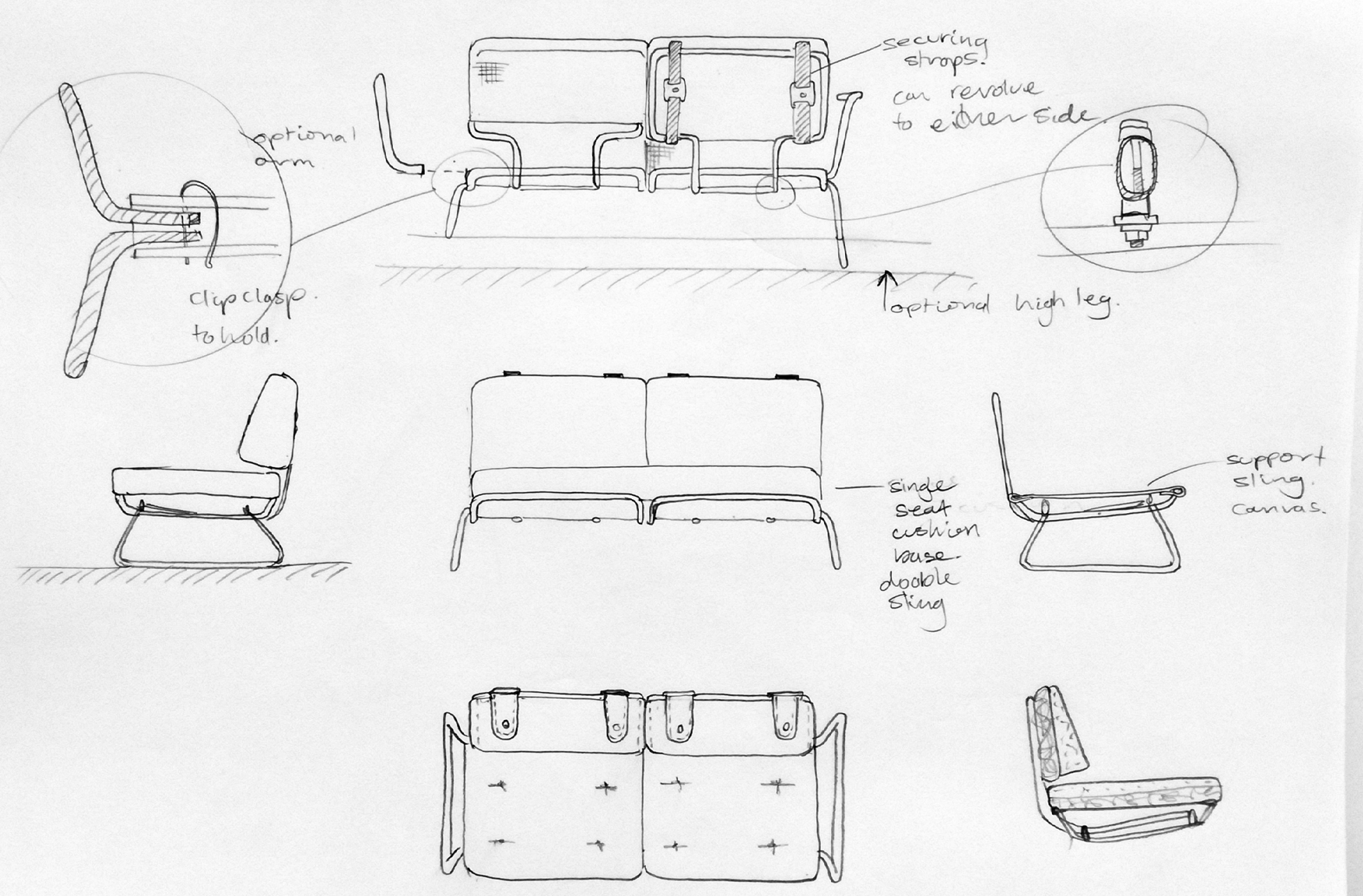

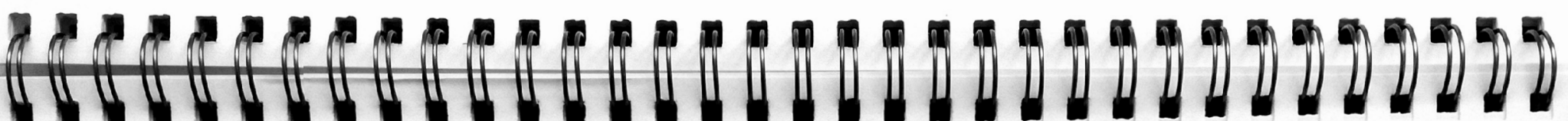

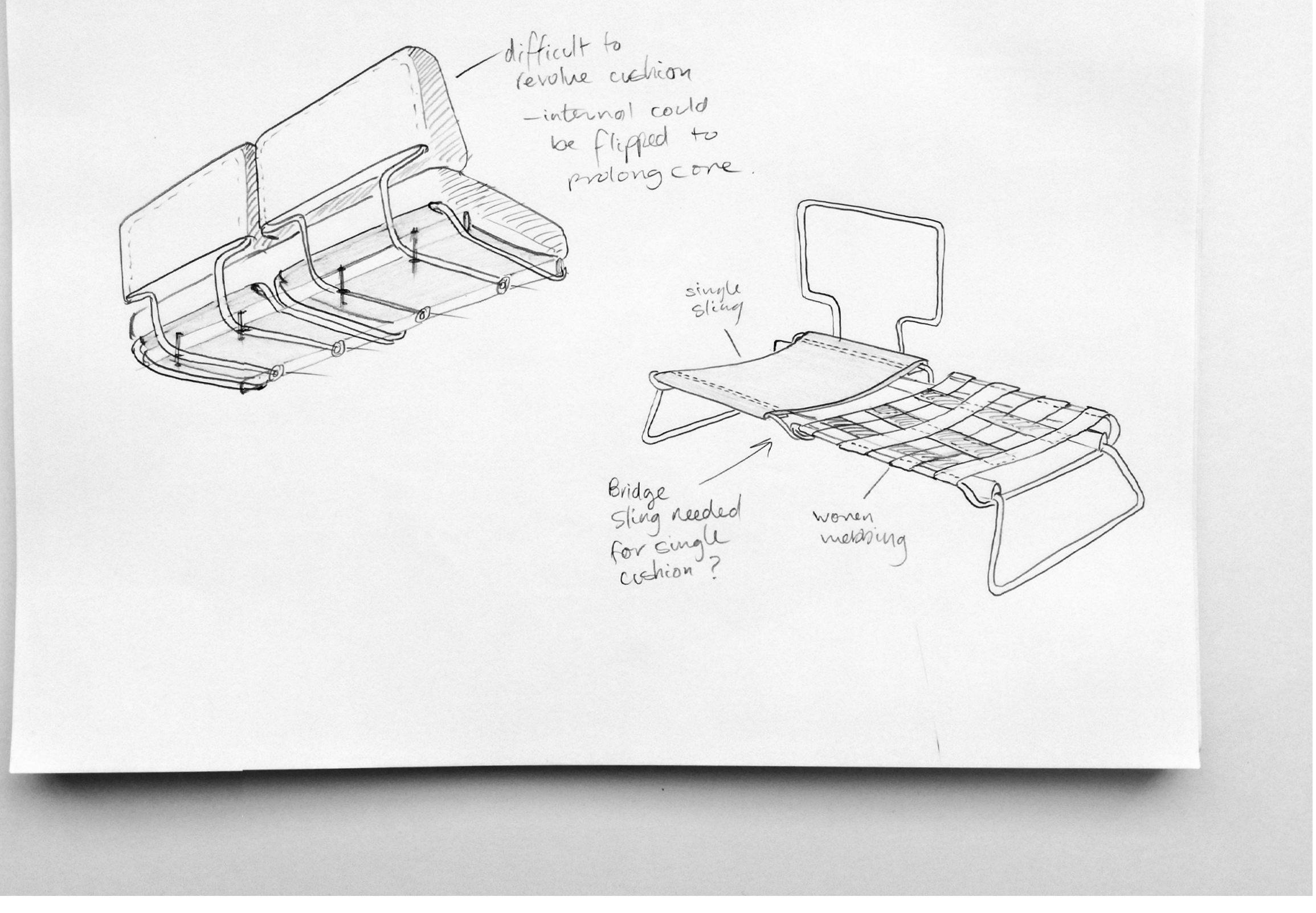




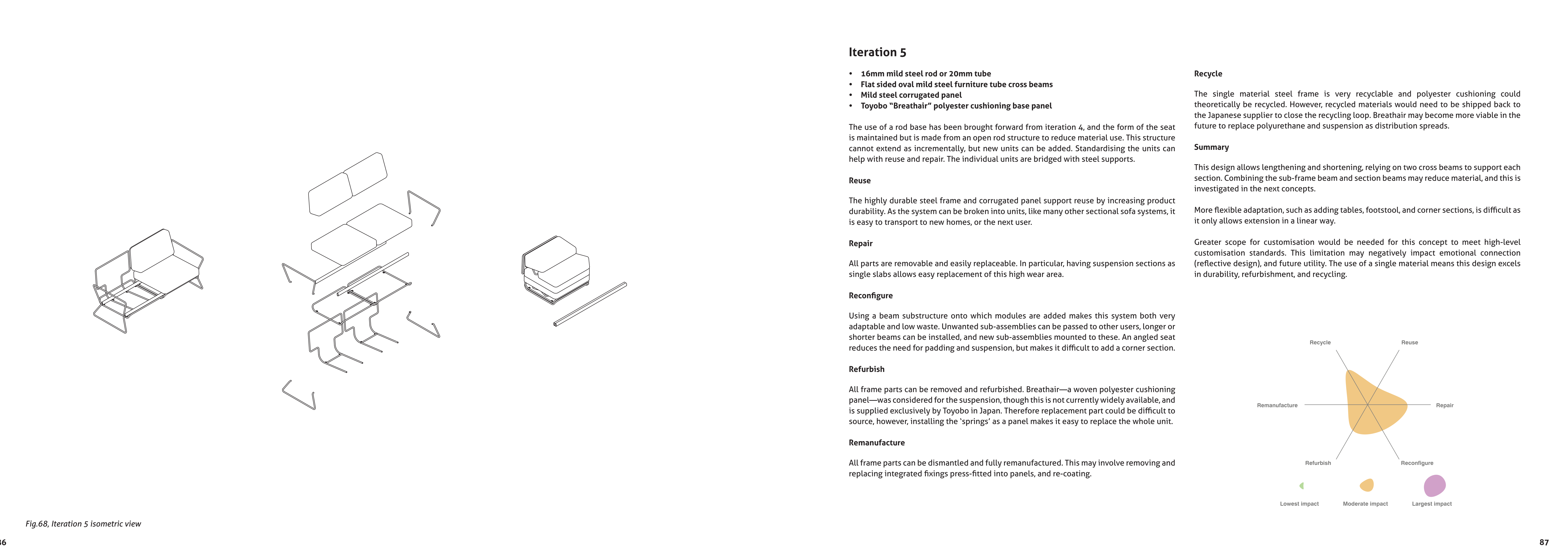



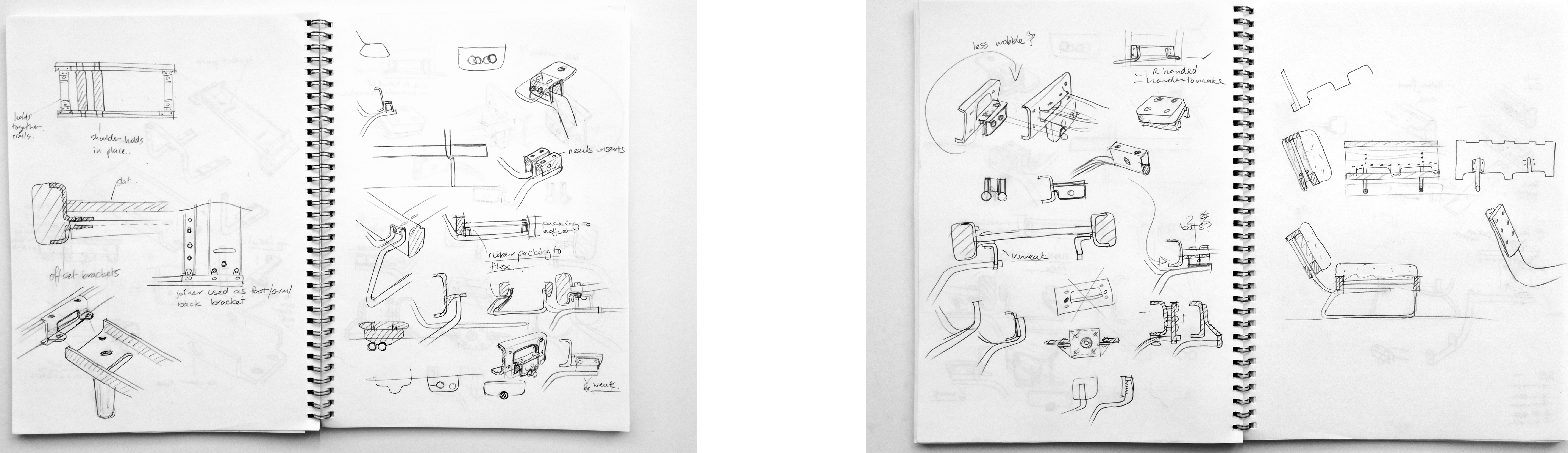
Iteration 6

$70 \times 45$ solid timber beam sections in $300,600,900$ units creates 1.2-1.8m sofas Folded mild steel brackets
$12 m$ m lywood panels
Rod base, arm and back suppers

Various lengths of units give greater fexibility as they can be combined into muttiple used in eartier iterations with plywood panels held by linear timber beams. Back support
can be exchanged between systems to change the back angle, and the seat base can be fixed in multiple positions to a djust the seat depth to user preferences. See Appendix B for a 1:6 scale mockup of this iteration.

Reuse
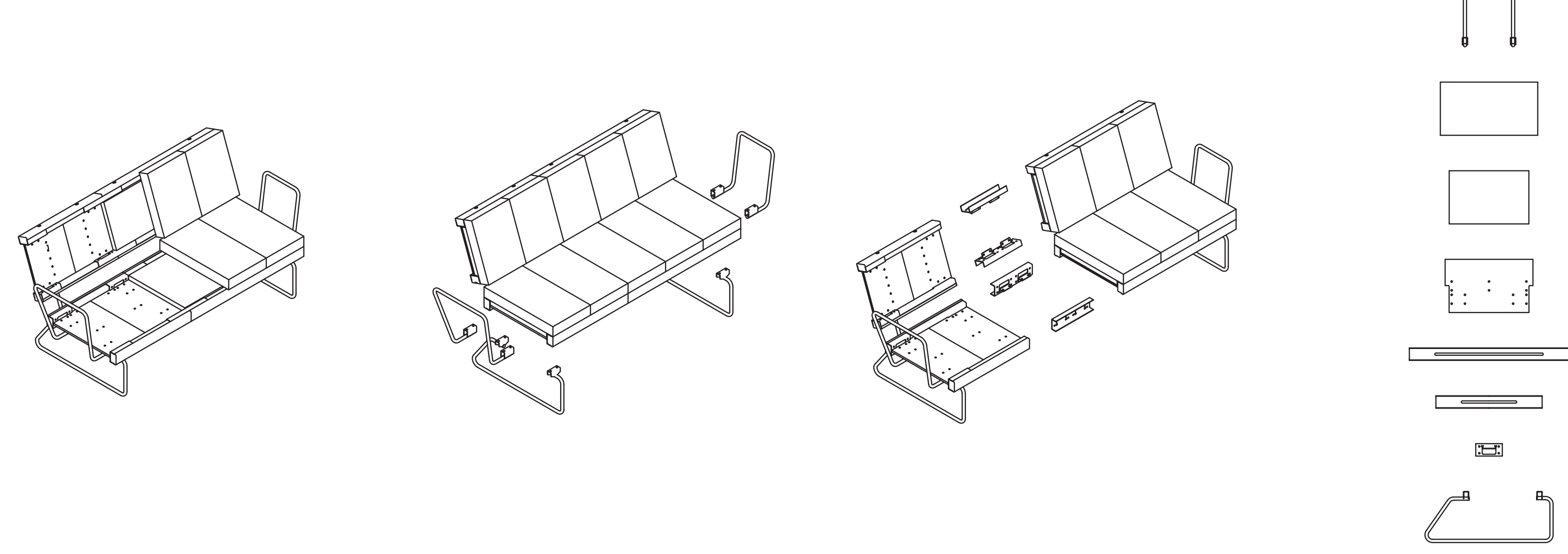

Compact and deconstructable, this design is easy to transport and reuse. The system
is durable as it uses timber beams and steel less, however plywwood panels for the seat base may warp and need replacement. The deck format, with attached componentst, allows
revurpsosing into d daybed bench or chaise. Removed elements can be passed to other users Repair

If part of the frame was damaged, the whole cover, frame and panels would need to be
diisassembled and may deter more bracketeting and fixing than earrier it iterations 5 to allow for additional a daptabability.

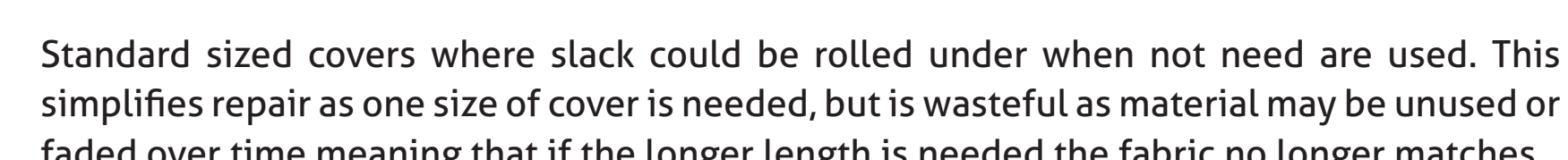
Reconfigure

The added assemblies (back and arm) fix to the base panel. The back can be adjusted to
increase the seat deth increase the seat desth, and a new brackete can be used to change the angle of the sear
Other than these small functional adiustments, changing the general aesthetici is difficult as whole sections of the structure would need to be replaced to to ignificantly change the form Refurbish

The steel and solid timber structure is fully deconstructable and so can be refurbished
easily. The plywood seat panels may warp and would dikely need to be replaced. Inserts and fixing points in timber are difficult to remanufacture as the timber fibres can
be stripped. This could be addressed by sing sleeves and inserts but this males recycling Recycle

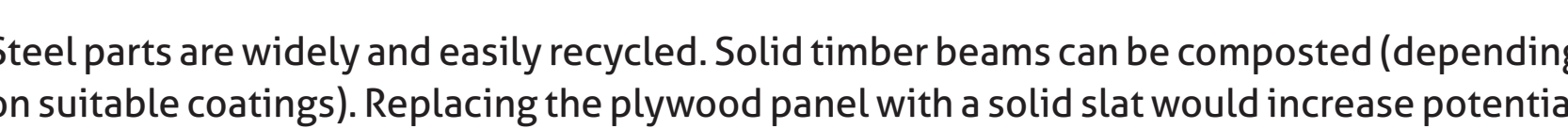
(a) Summary

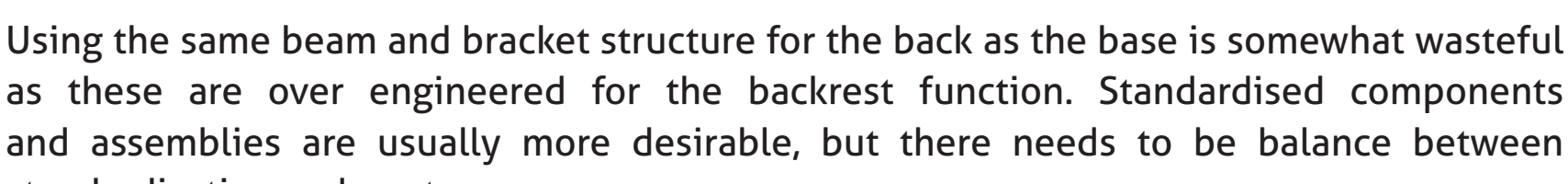
Astimber is a carbon sinkit can be used sustainably, but to achieve this it needs to be in use

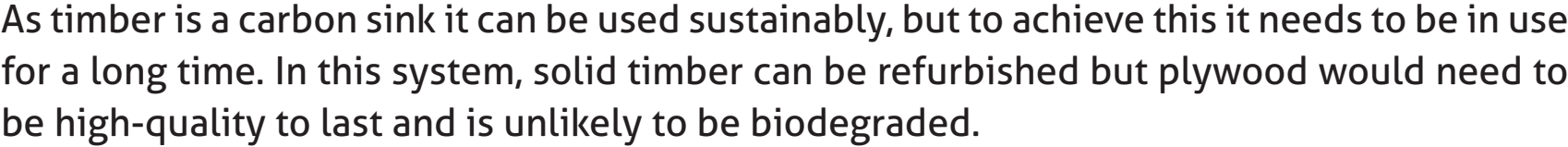

The ladder/bracket/panel system adds adaptability, but decreases potential refurbishing

The ladder/bracket/panel system adds adaptability, but dect
due to the use of mixed materials and processes required

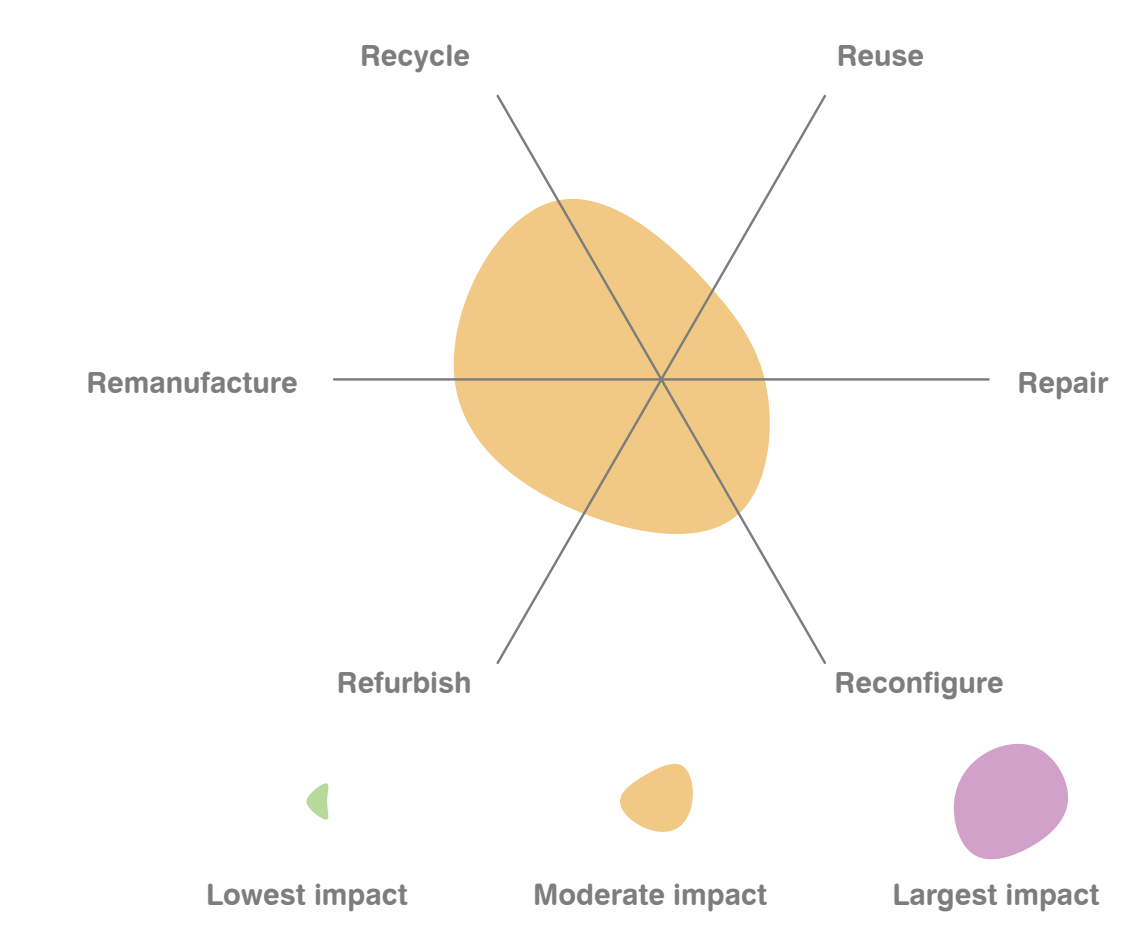



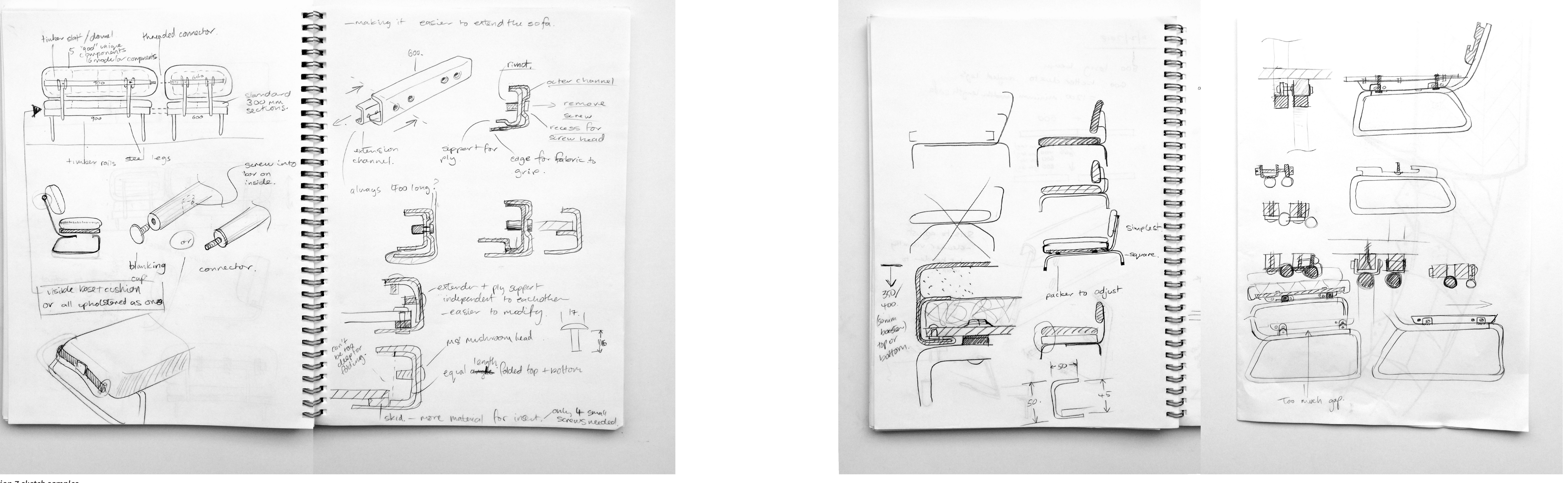
Iteration 7

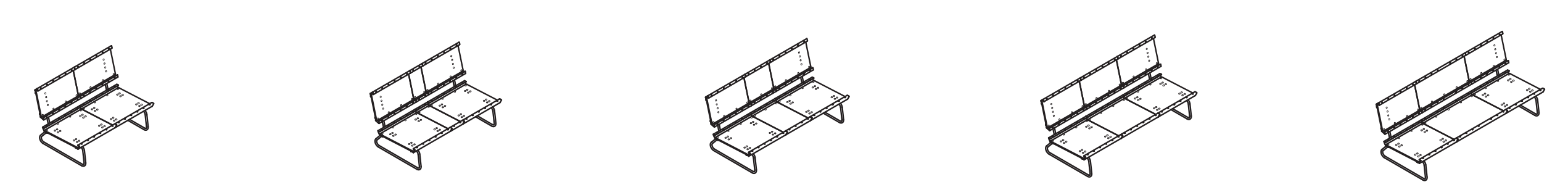

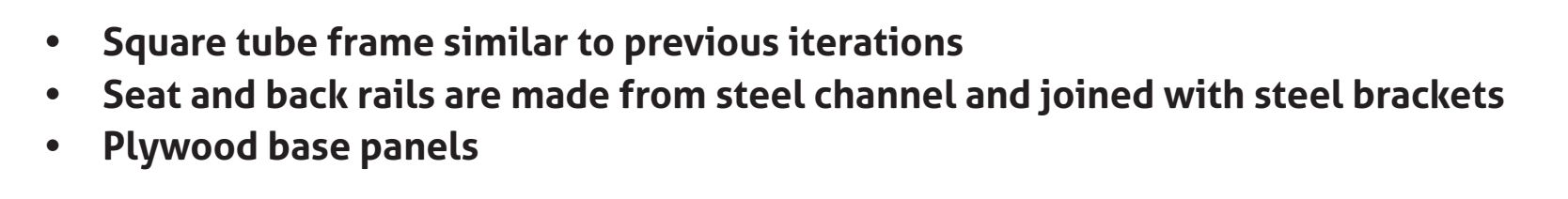

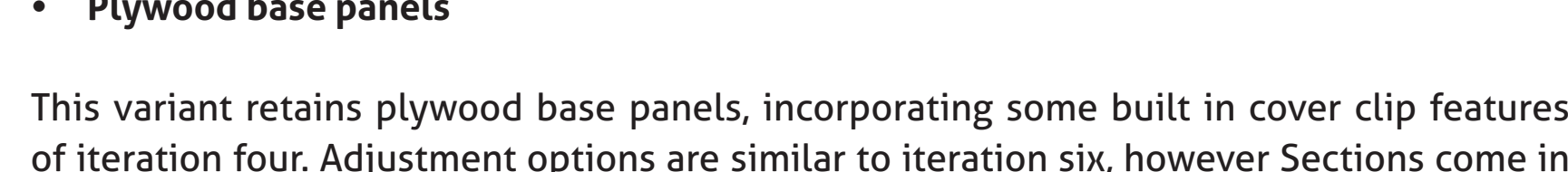

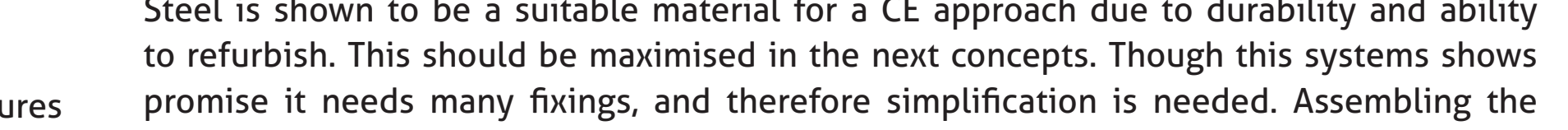

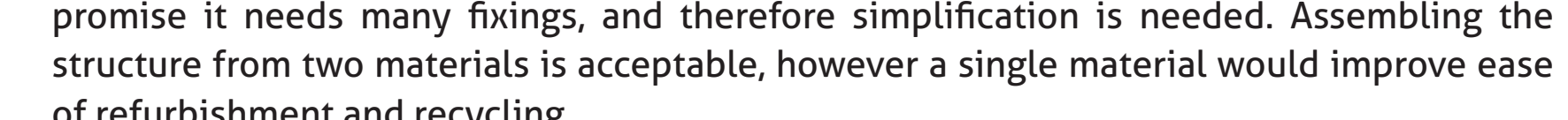

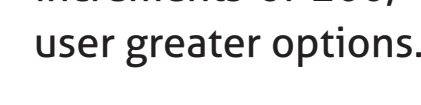

See Appent
Reuse

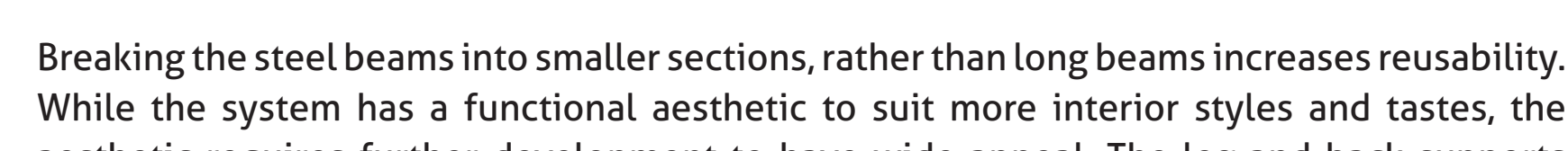

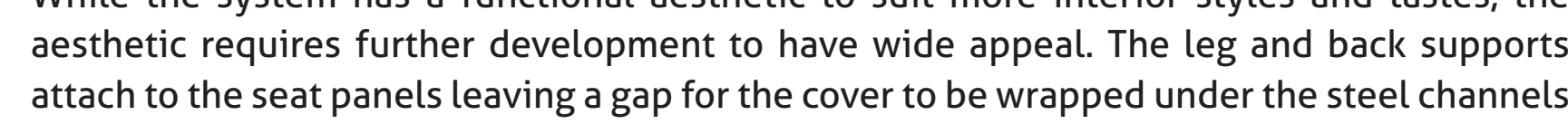
Repoir

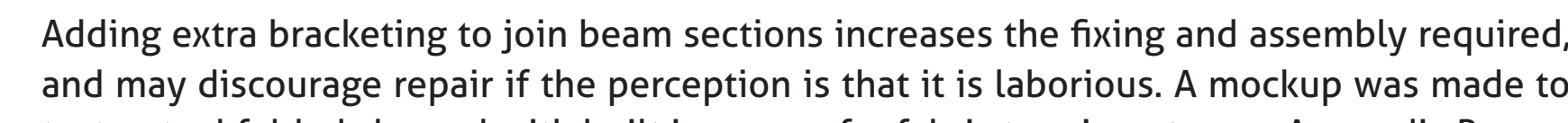

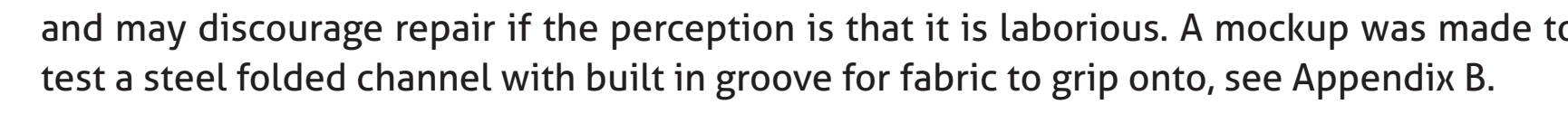
Reconfigure

Summary of refurbishment and recycling

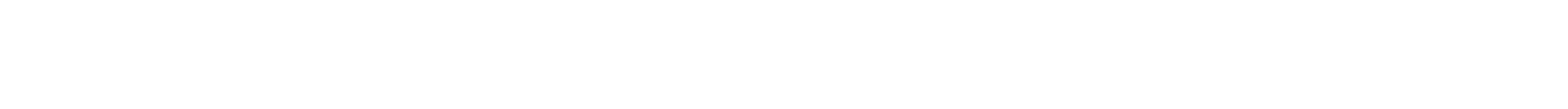



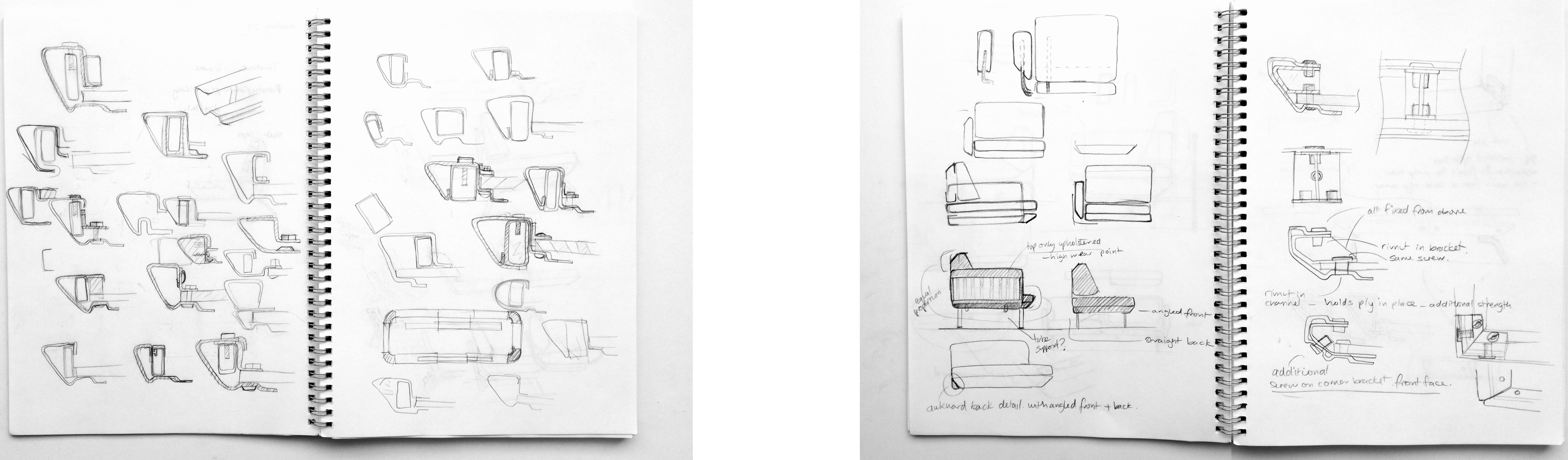
Iteration 8

Steel channel support and end beams
Steel corner brackets

Rolled steel roocing sheet seat and back panels

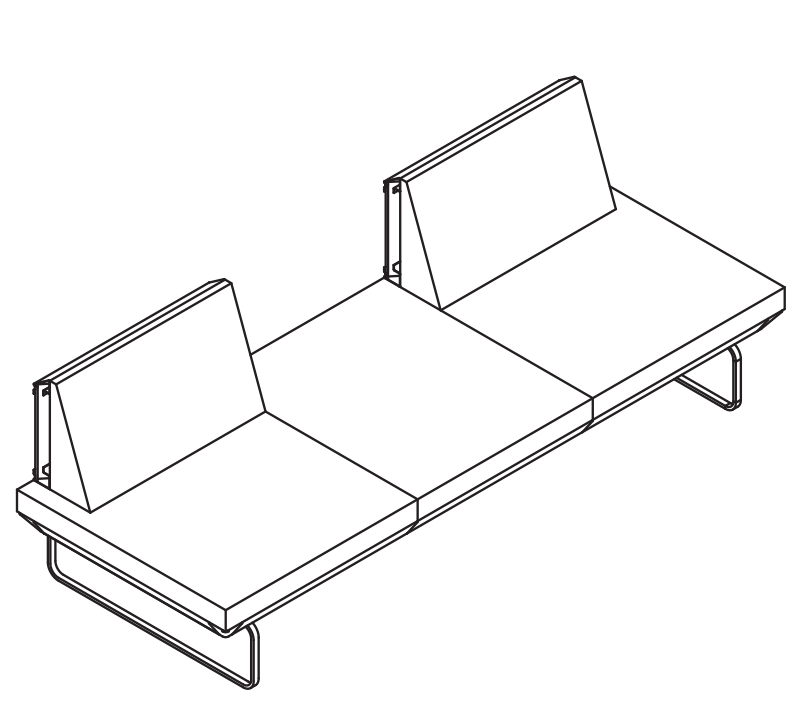

Steel channels are reteined from previous iteration, however this design nims to use just
one material for the frame, and plywwood is replaced with sheet metal which is lightweight

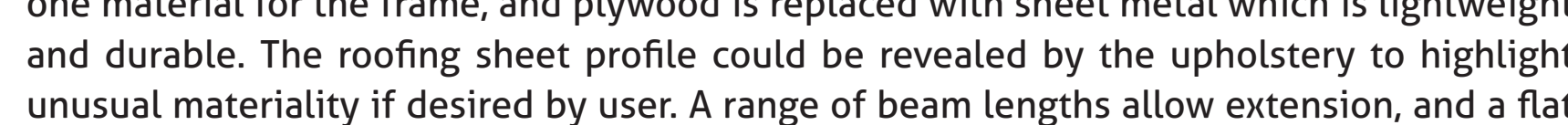
seat base has been selected for simplicity and increased adaptability as it allows for corner sections to be added

See Appendix B for a 1:6 scale mockup of this iteration.

Reuse

Highly durable steel has a long-lifes supporting reuse. The design is s also deconstructrable so

Repair

Recycle

As discussed in earlier sections, steel can be reycled with no performance loss. Foan may be possible with future technology and infrastructure. Atternatively, latex foam and

Summary

Using roofing sheet avoids the problems of plywood, and means the entire frame is made
rom a single material This mans end of lite recycling is much simpler and the system

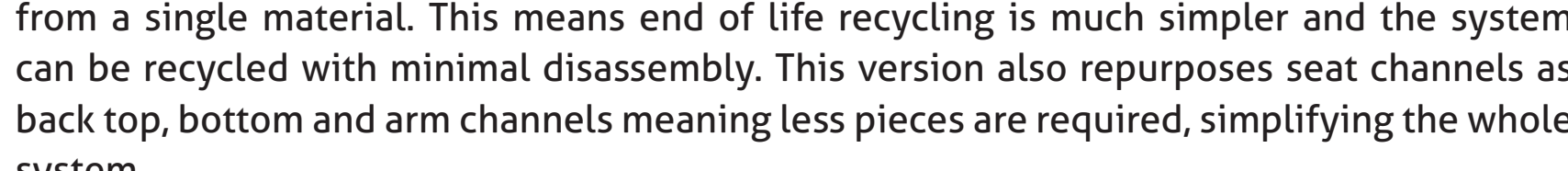

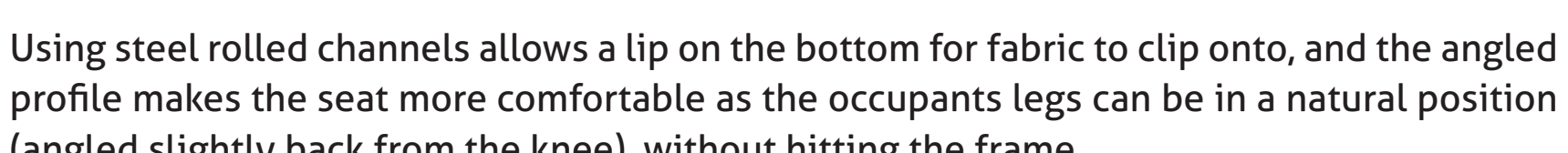

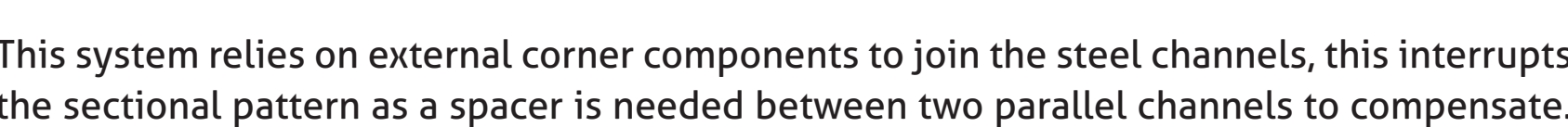
This is an issue as covers will only fit specicic section lengths, meaning they are less

This could be resolved with flat end cap, which makes she linear extension simpler, though
it is aesthetically 'clunky' to end the section with a flat, opposed to an angle as at the front of damaged steel parts is is difficult. cushions can be easily removed and repheced, and replacement suspension parts can be easily plugged into the frame

Reconfigure

A new section can be added to extend the system, however a special bracket would be
needed to ensure all seat cushions are a standard size. This adds complexity to the system.

Refurbish

Cussions are easily removed from the frame and no glue or stapling is used making
reupholstering straightforvard. All other parts are similarly simple to replace. Remanufacture

Steel lends itself well to remanufacturing and as the frame is one material, processing is
simple.

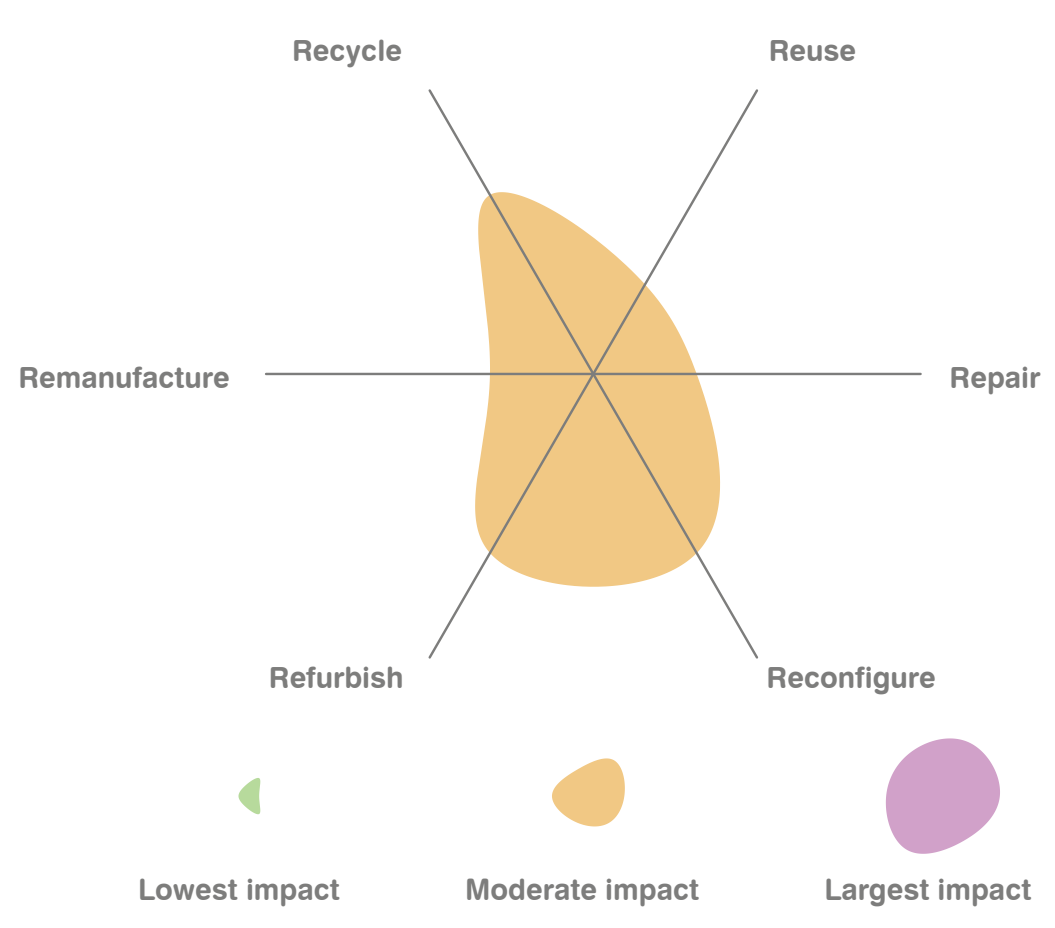




$$
\text { (1) }
$$

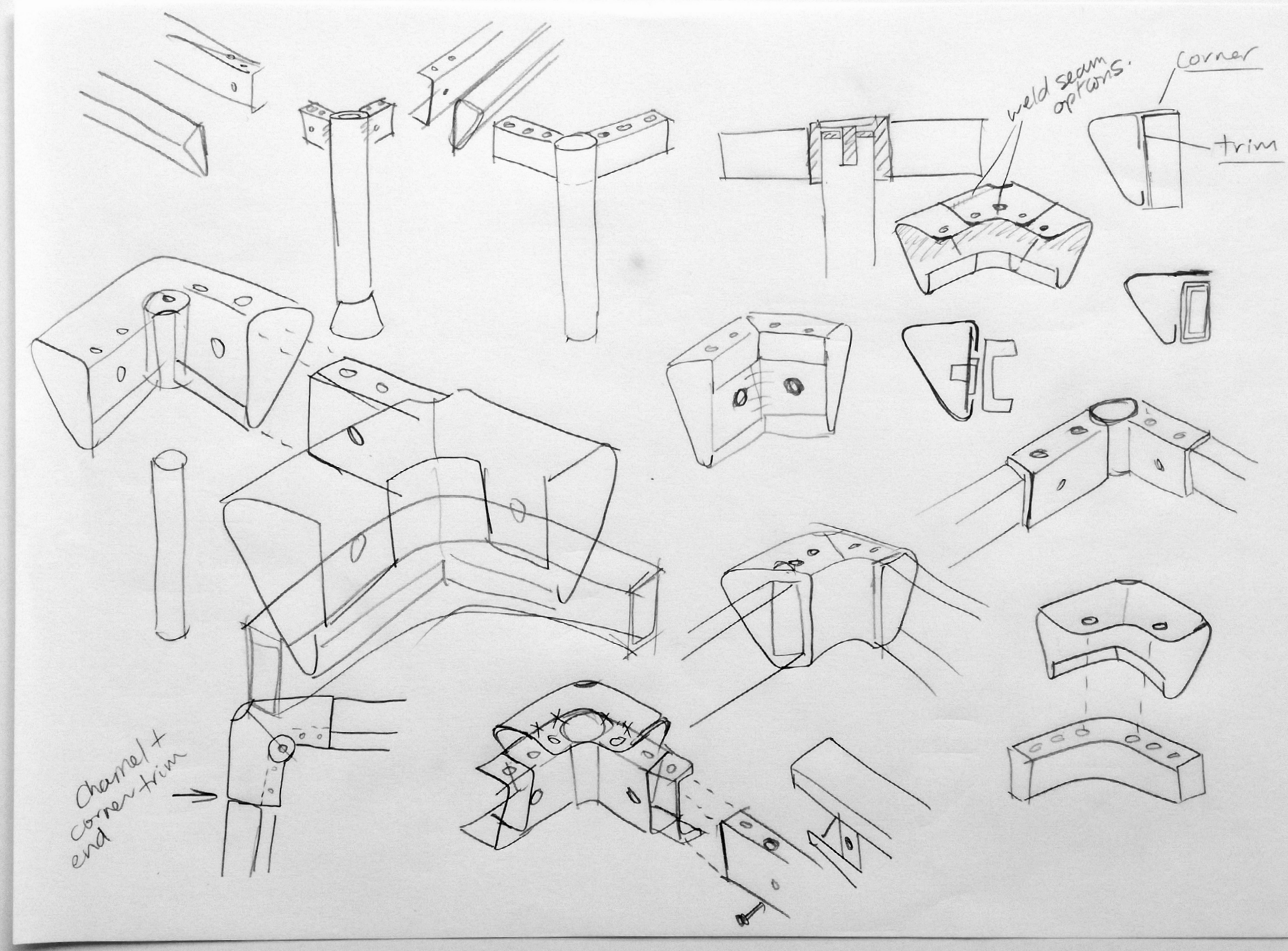


Q

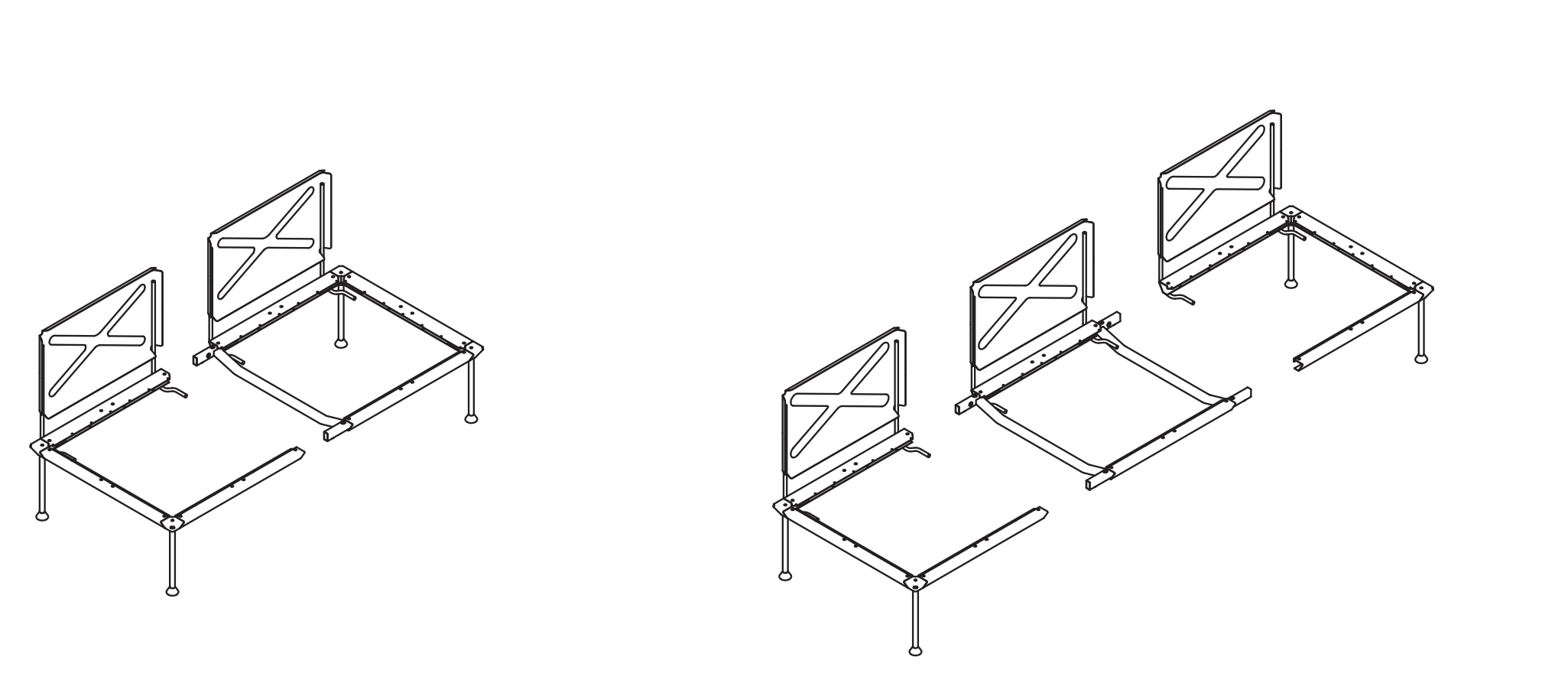



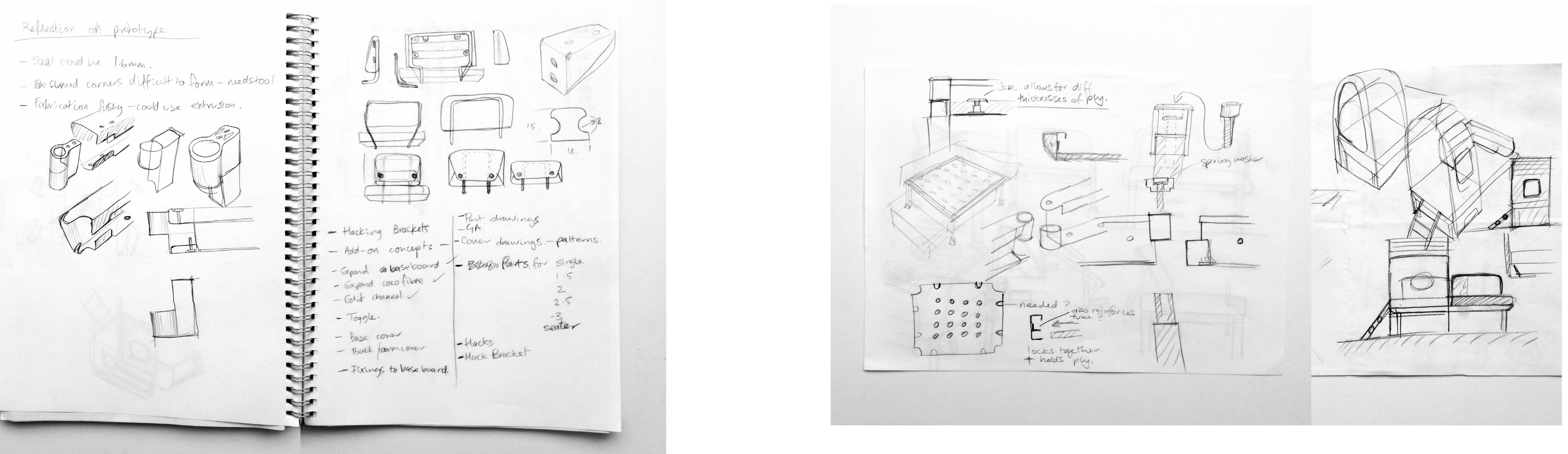
Iteration 10 Add-on assemblies formed from steel tube with plywwood panel

Tubular steel legs
Coir suspension and loose box cushions

echanged between users. 1 is easily disassembled and con be made compact for easy
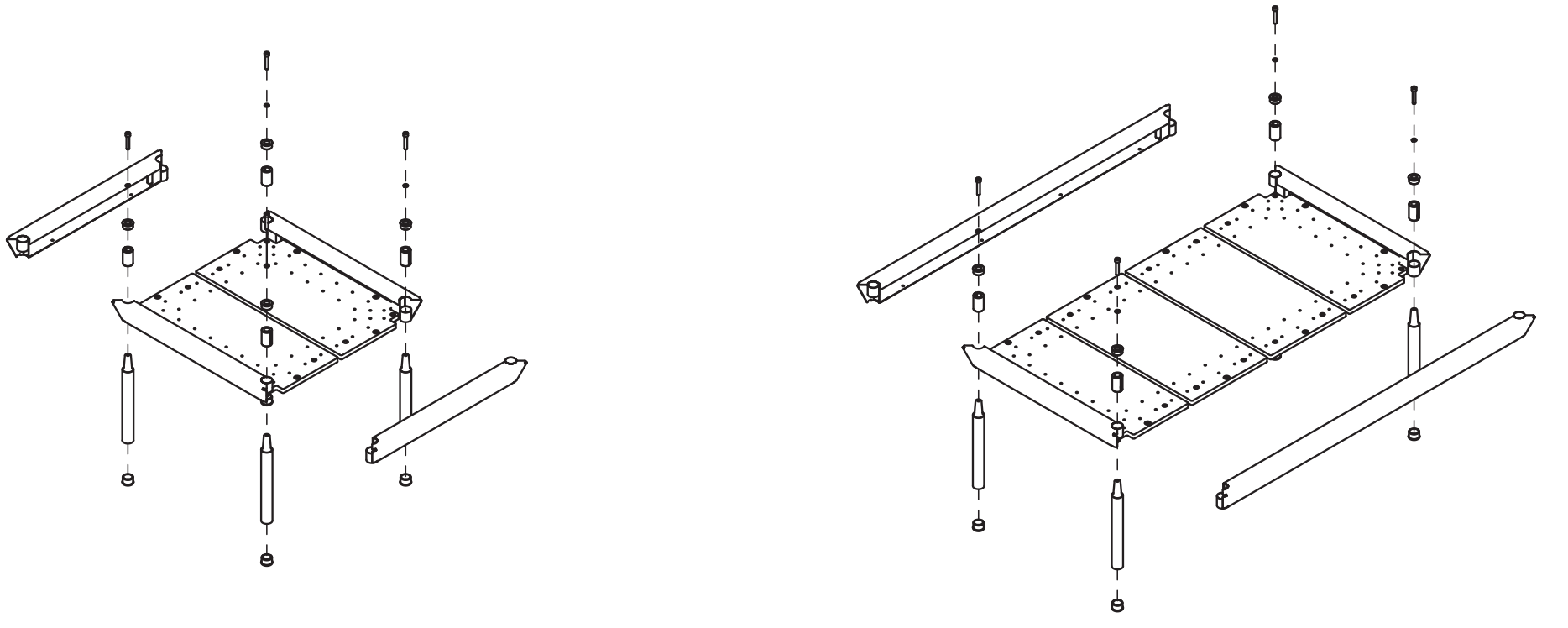

4 reupholstered. While coir cannot be repaire, using a simple slab means whole sections of
Steel outer channel frame

The final iterations incorportates many learnings from previous iterations. Specifically, the
us o of steel, interchangeable beam lengths, legs used as beam connectors, add-ons fixed to

cir suspension is introduced.

See Appendix B for a 1:6 scale mockup of this iteration.

This system again uses interchangeable steel beams, which are highly durable and can be

Repair

manufacture

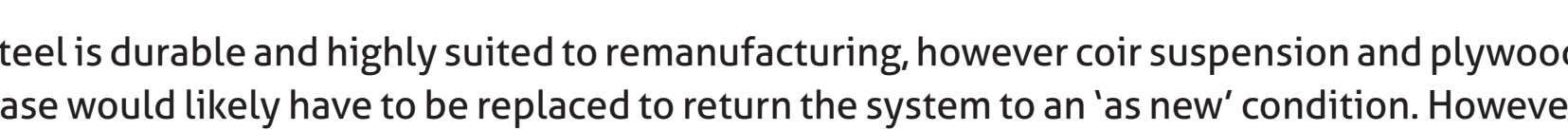
they fit the preferered criteria of a $\mathrm{C}$

Recycle

As discussed for previous iterations, steel is shighly recyclable with no loss of performance.
Birch plywood can be cascaded into engineered panels, and the use of emerging bio where the processess used in cascading would prevent this, direct return to the biosphere is

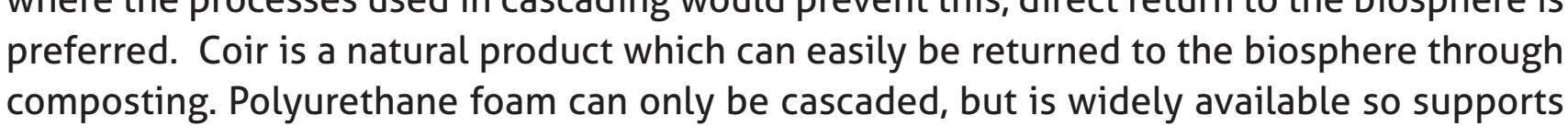
air and refurbishment

summary

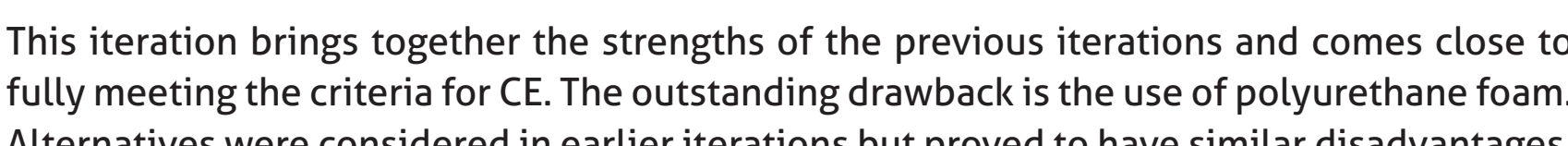

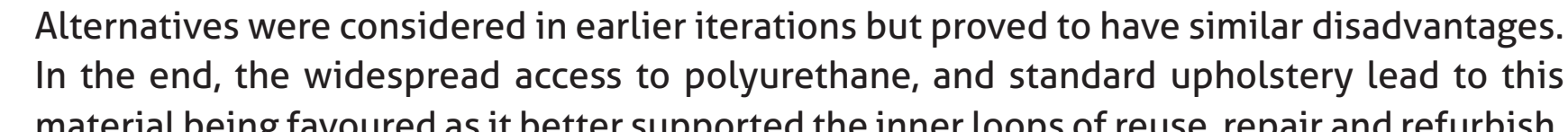

simplifies is isolation of fframe parts for repair. Box cushions can be easily removed to be ins enta

Reconfigure

Perforteded Plywood panels give an increased range of reconfifurration options, which can
include arms, tables, seats, and so on The retained flat cat include arms, tables, seats, and so on. The retained flat base continues to allow increased
flevibitity for a dde-ns to suspension is one piece, different densities can be chosen based on user prefererence and alternative material options for cushioning and upholstery can be exchanged or replaced to
give further options. Refurbish

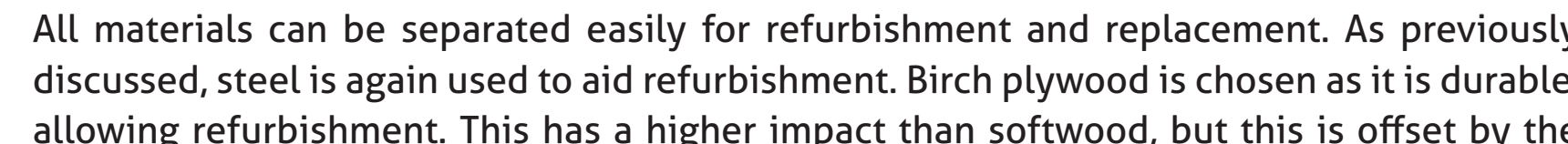
material having a longer-life.
In section 19, a full walkthrough of the system explains this iteration in more detail.

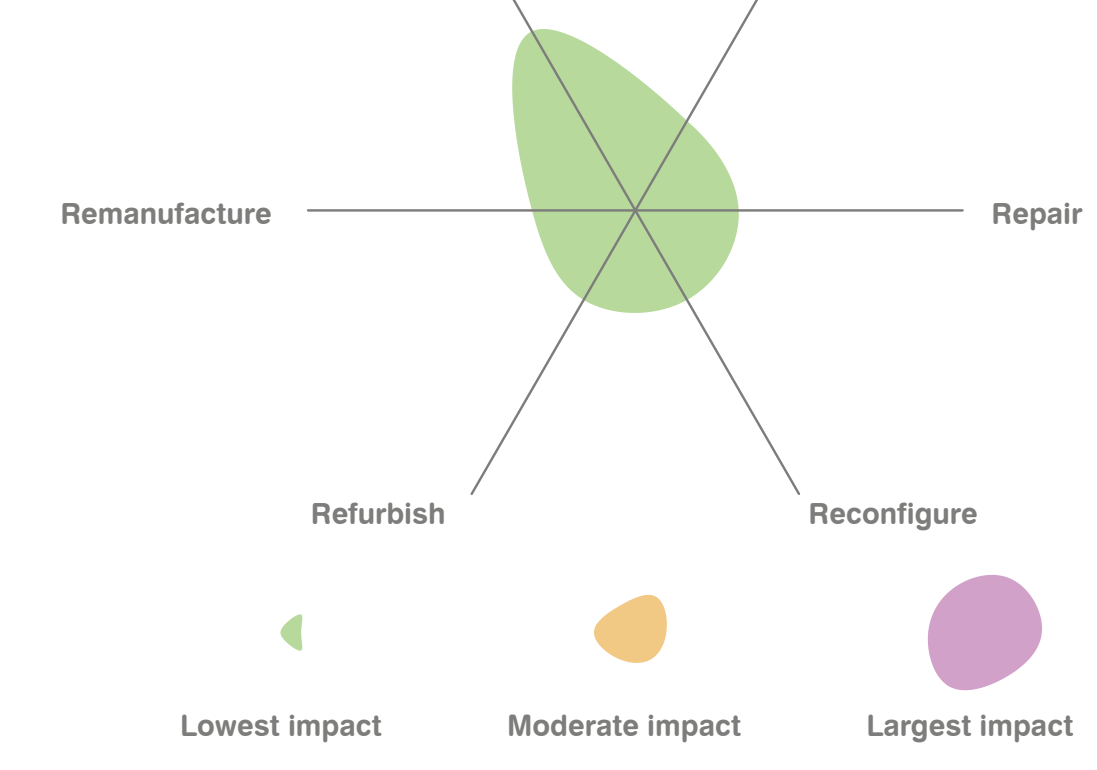


c. Discussion

The design iteration process has further hightighted how sustainable design is a 'wicked
probolem'- -showing there is no single 'right' solution, and trade-offs are needed to balance As the Circular Economy framework prioritises modes such as sharing and maintenance over reycling, this helped guvide the design process and where trade-offs were made. Som Plywood base over steel or slatted base

This is less ideal for reyccling or returning to the biosphere, but gives greater durbility
and addatability Coenpostable adhesives are being deverloped which should allow full biodegrading of plywood in the future, and can be phased into the system as they be
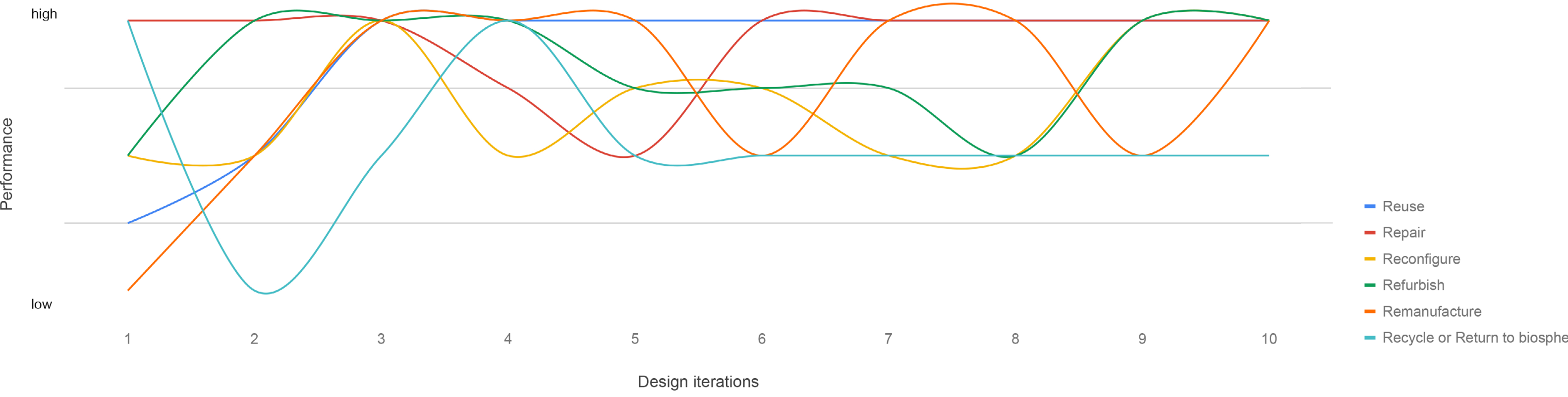

Fig.79, Design iteration CE perform
Interchangeable full-length frame beams over connected sections

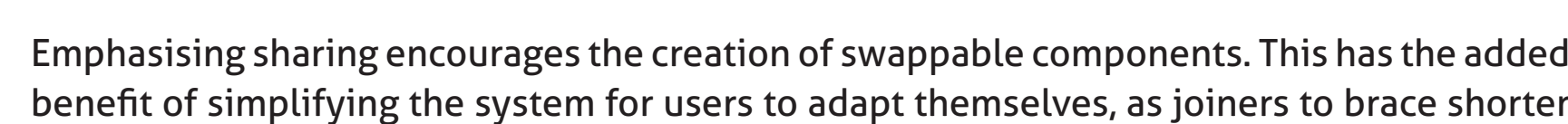

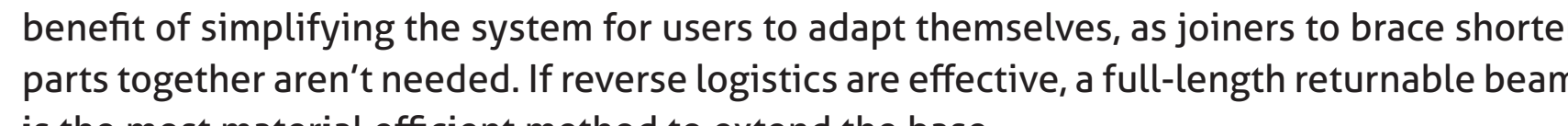

The precedent used here was industrial racking, which can be configured with any length
of shelf beam. Surplus parts can be used in other systems, and it is the simplest method to gow the system.
grow the

Coir (Coco fibre) over springs

The coir spring slab can be plugged into the frame without tools or dificicult tensioning. For
this reason it was chosen over steel plastic or webbing springs. The fibre is waste roddy and is bonded with natural latex, so at end-of-life it c can be returned to the biosphere. Integrated beam leg connection over corner joiner

Integrating bracket details into the beams adds complexity to these parts, and could make
manufacturing more complicated than for a standard corner joiner and leg connector.

However, this sis easier for the user to a ssemble and may encour

"Reduction should be used with care. It can both simplify and complicate elsewhere." - Per Mollerup (2015)

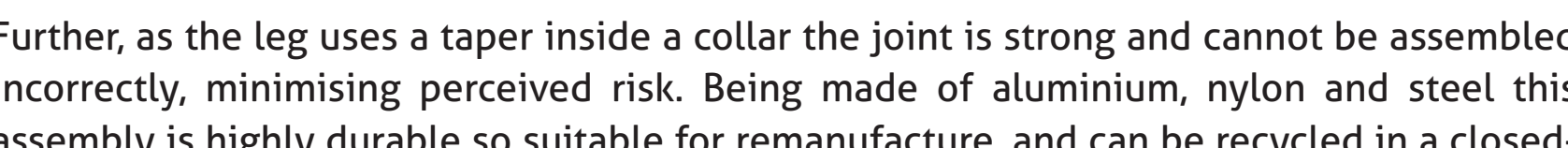

"We prefer objects that are self-explaining. If they are not, we prefer to get along by reading Traditional upholstery box cushions

Box cushions are an established upholstery method, meaning reparing and replacing covers
should be straightforward.

No fixings are used, so seat and back cushions can separate easily. The back support locates
the back cushion in a fabric sleeve, while the texture of the coir suspension grips the seat usshion in position. This also increases ease of recycling as materenils can be instantly The frame is left exposed to add transparency and minimise upholstery materials

Added grid holes in base

Grid holes increase ventilition, keeping the coir and foam in good condition for longel
They also future proof the system, allowing for ease of adaptabilitity.

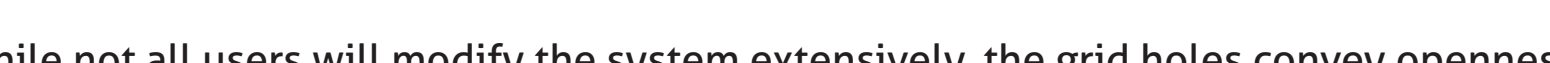
Summary

When designing to strengsthen one CE criteria, others were inevitably impacted. The CE
model priorities allowed for these trade-offs to be manngeged (e.g repair vere refurbbishment). However, it tilso became clear that CE c criteria are not the only ones that must be met, and the functional and emotional needs of the user must also be prioritised. There is ititle point

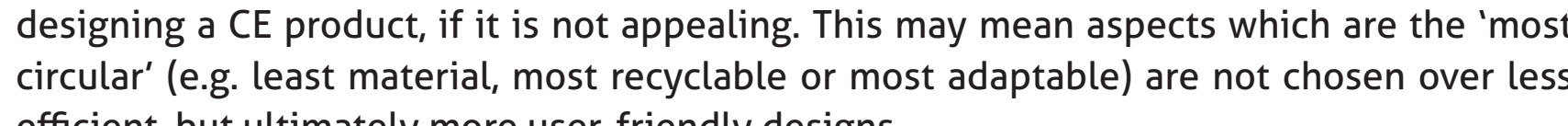
efficient, but uttimately more user-friendly designst 
In section 20 - Validation, the impacts of different user models and materials are compared
and it was found that exchanging materials shifted, rather than solved, negative impacts. Therefore, the decision was made to choose materials based on their performance and
ability to flow effectively in a CE system, reducing the need for-and impacts of- virgin
material input over time. Different materials can flow differently, potentially cascading multiple times or existing in
a closed-loop. This can make comparisons difficult when considering a range of options and systems. Materiat flows were mapped in terms of performance (i.e. frame, suspension and

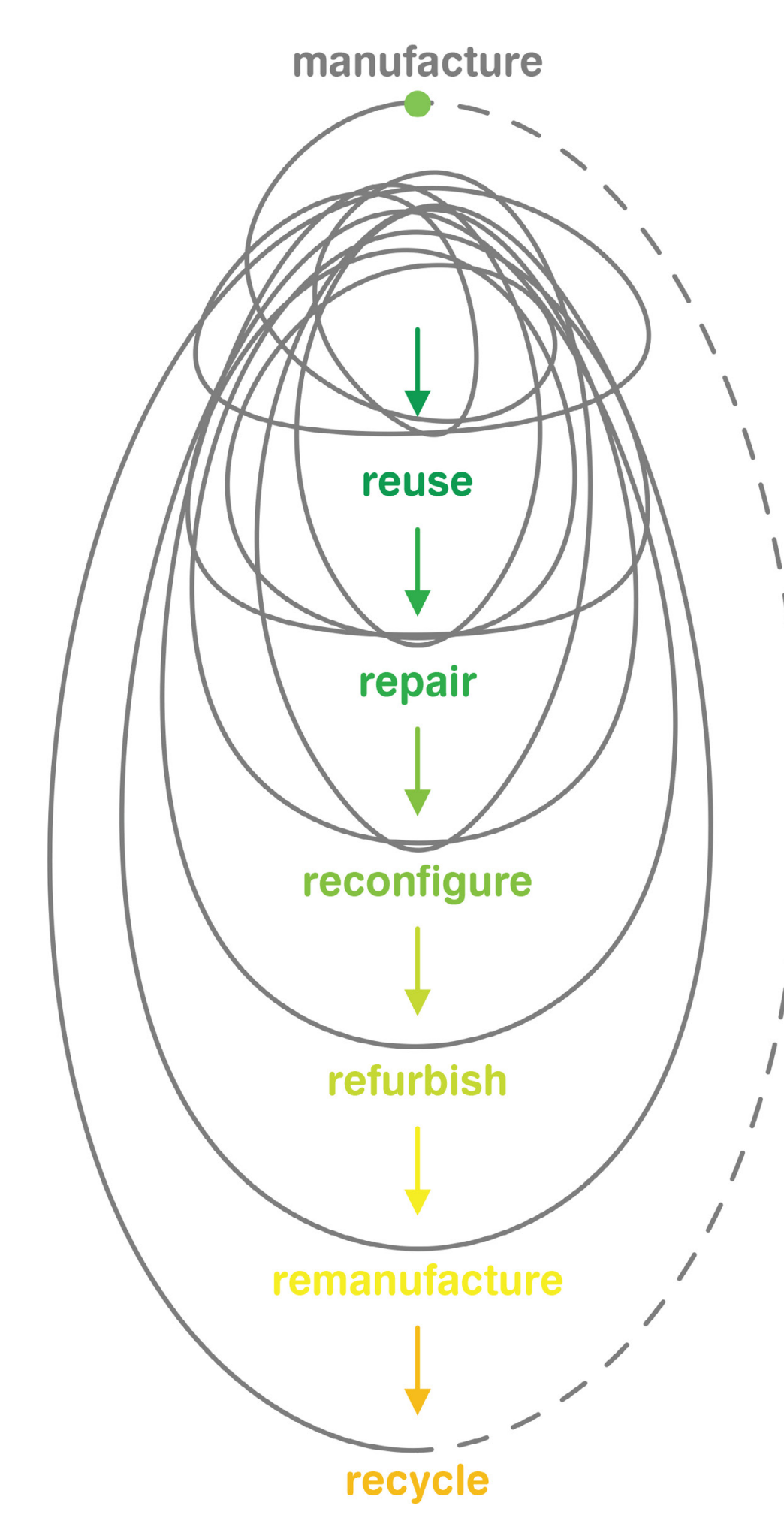

\section{Frame materials}

Technical loops

This diagram highlights how aluminium, lasstic and steel can flow in all closed loops of
refurbisismentst, repait, sharing and lastly, recycling. This is dependent on them being kept refurbishment, re
as pure inputs.

Plastics, atthough less suited to refurbishment, can flow in a closed loop with the emphasis
more on recycling.

Biologicalloops

While using renewable materials may seem the best way to move to a circular economy.
they often cannot low

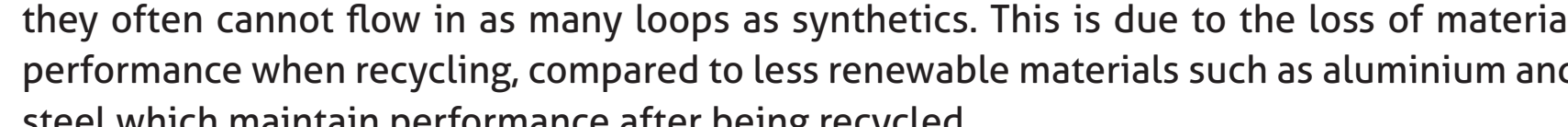

"It is out of the question that food should be scacrificed to make a chair for example. Even for atternatives such as linsed or hemp, these take up land that could be used for
growing food,"cascade flows

The flow of plywood and timber is highty impacted by surface treatment or adhesive. An untreated solid timberp part finished with biodegradable sealer, could flow in the technical
share and repair loops, and also the return to biosphere loop. Extensive refurbishmment is less viable as it is labour intensive. A plywood part, (timber
veneers laminated with synthetic resin) could flow in the share and repair loops, but not
be returned to the biosphere. This would be cascaded (chipped and bonded into panels) or incinerated for energy-these are linear pathways. As it is more desirable to close the loop than cascade, the best path may be to fully
biodegrade after one loop rather than cascade, if cascading leads to waste. This may seem

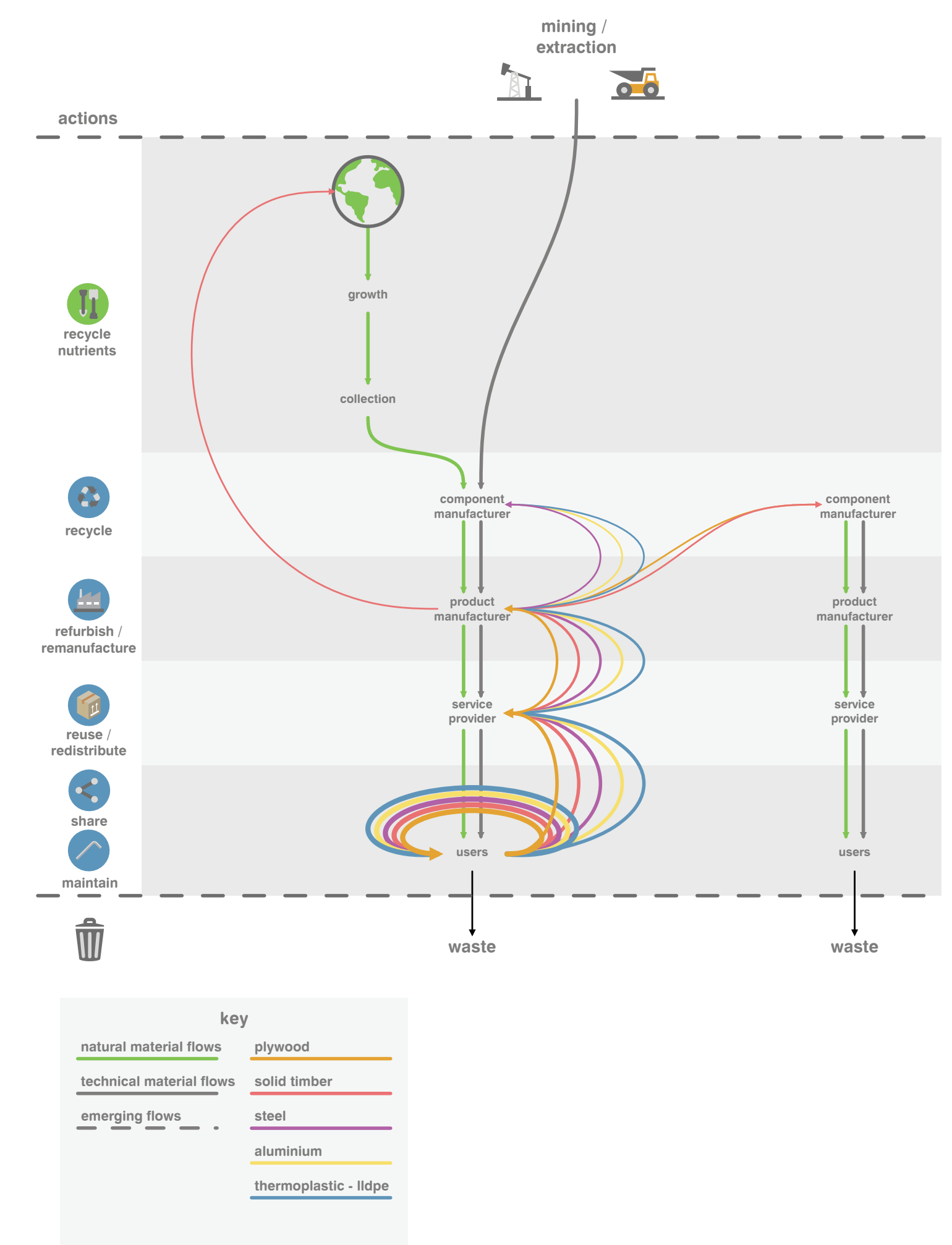

Fig.81, Potential frame material loops 
Technical loops

Many ysspension materials can flow in a closed loop, including coir, latex foom, nylon and

Atthough nylon flowed effectively yue to its durability, repairability and recyclability.
because of it qualities were critical) and not the larger spring base.

Biological loops

Depending on processing and toxicity, both coir and latex foam can be returned to the
biosphere.

Cascade flows

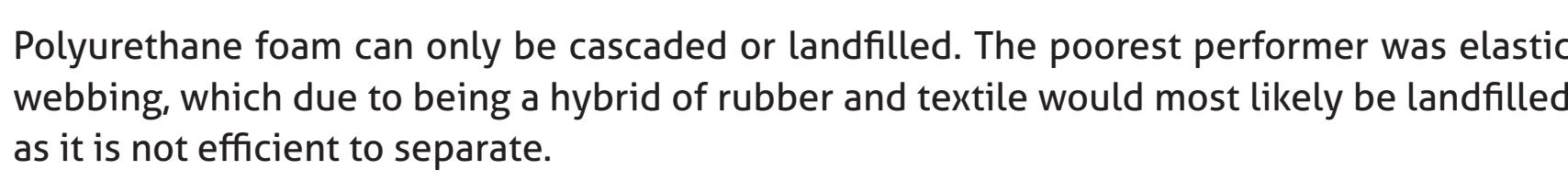

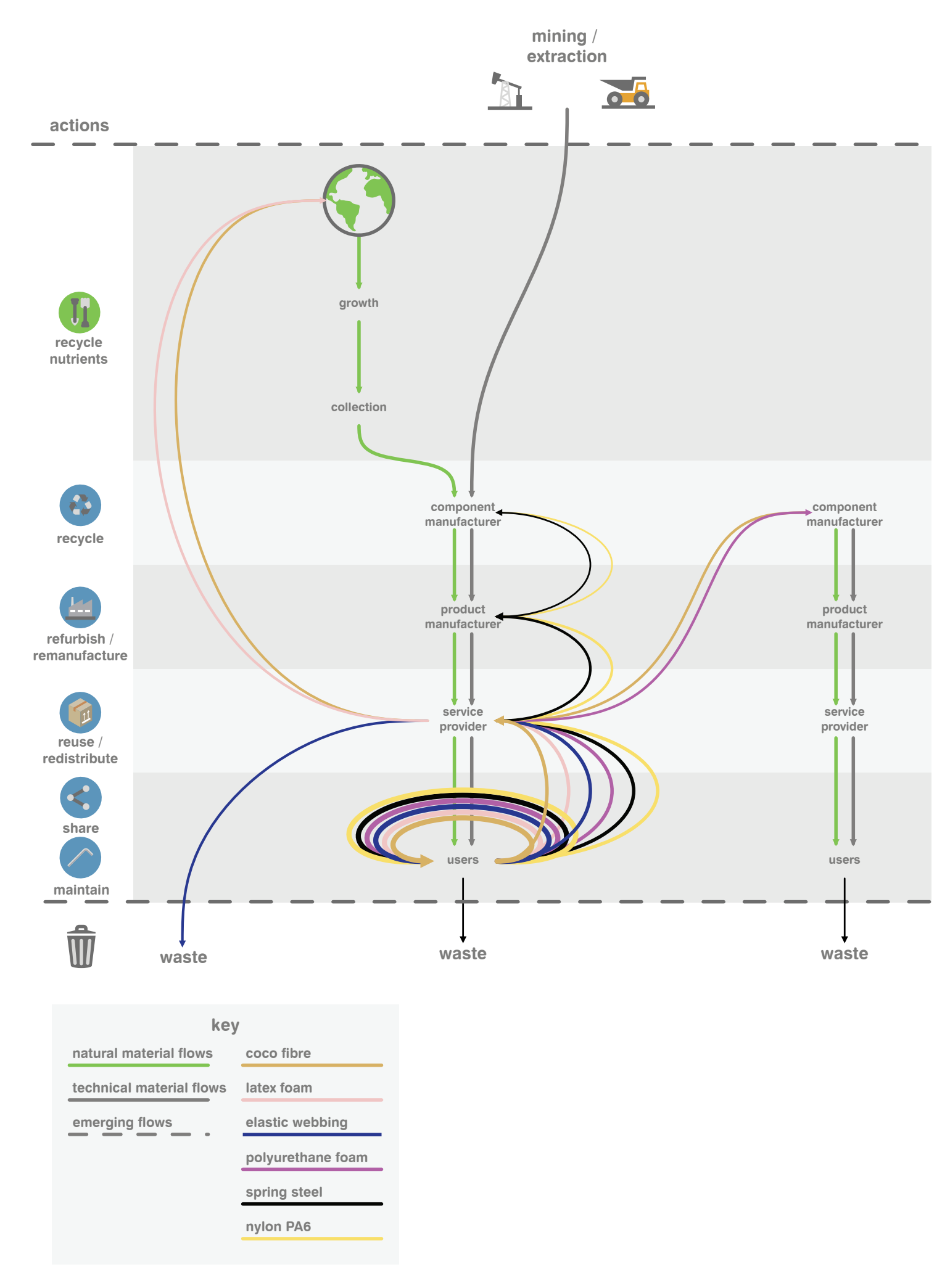

Fig.82, Potential suspension material loops
Upholstery materials

Durable textiles such as wool and polyester, can flow in share, and repair loops Polyester flows the most easily in a closed-loop as it can be re-polymerised into a rom
material and processed with no loss of performance. Emerging technology may be needed to separate blended fabrics into pure inputs. This is
currently not widely vavilable, resulting in mived fores Biological loops

Natural fibres can be returned to the biosphere (depending on treatment i.e. chlorine, dye).
This may be preferable to some forms of cascading to avoid contaminating these materials. Cascade flows

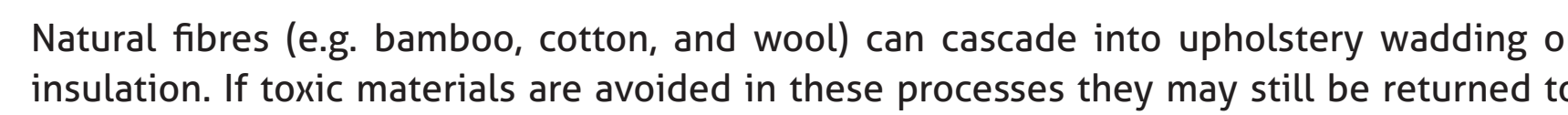

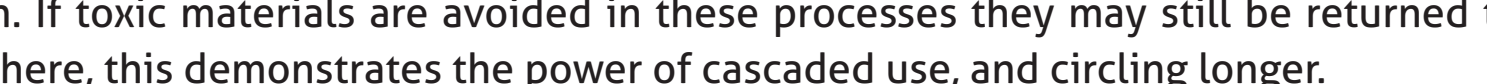

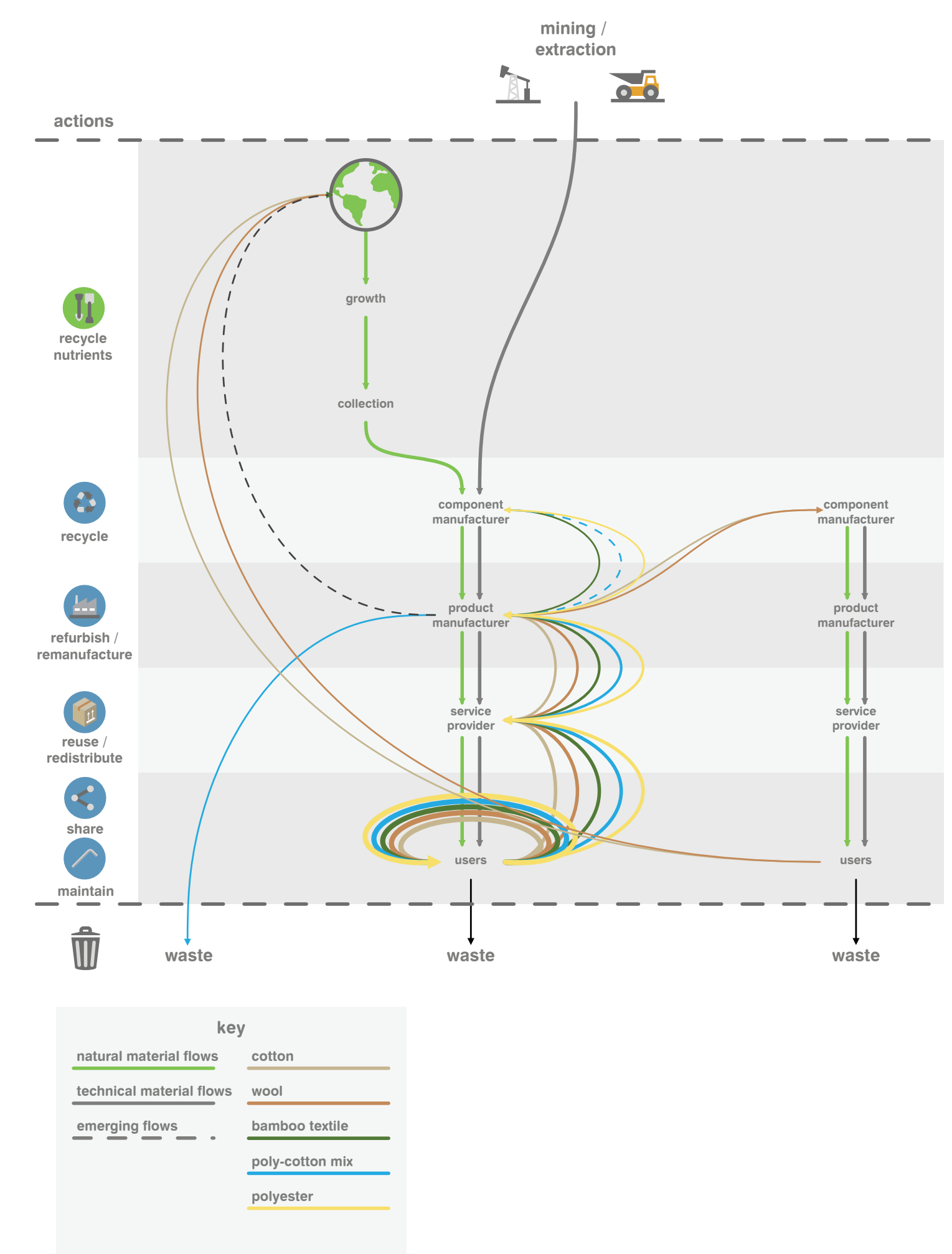

Fig.83, Potential upholstery material loops 

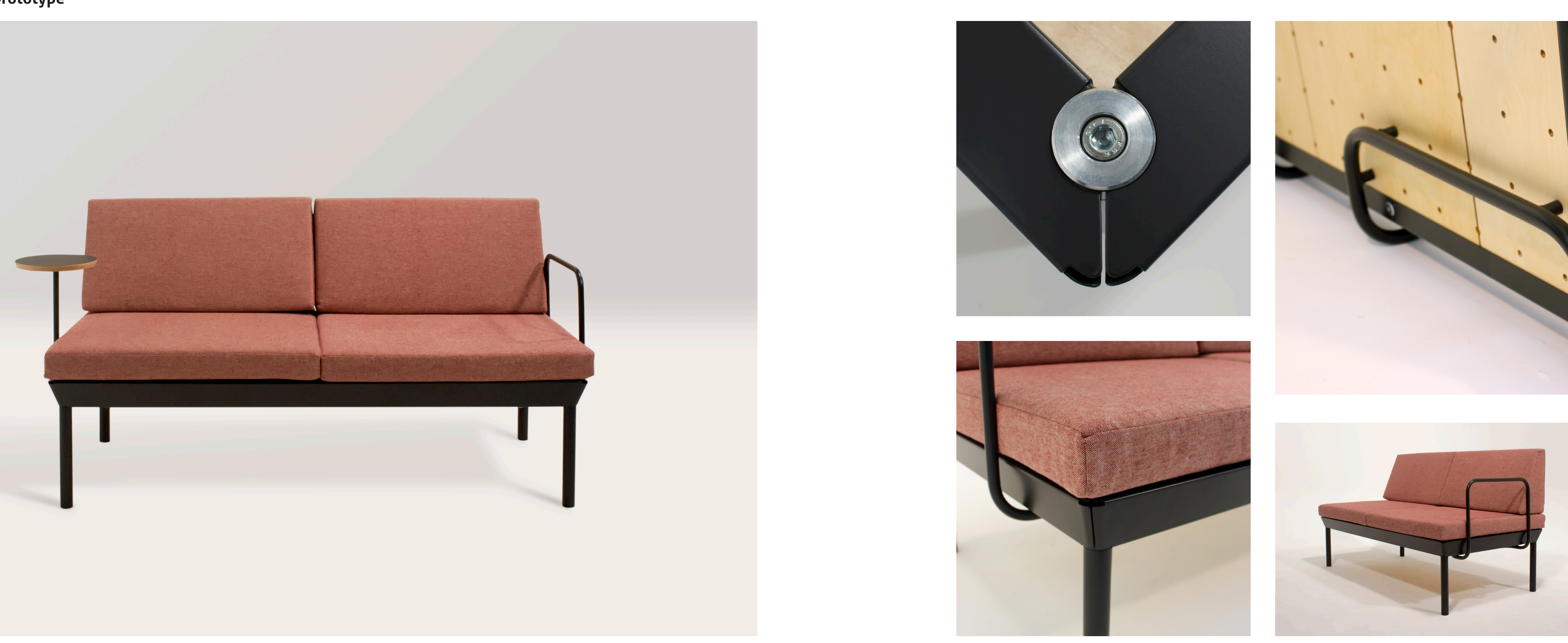


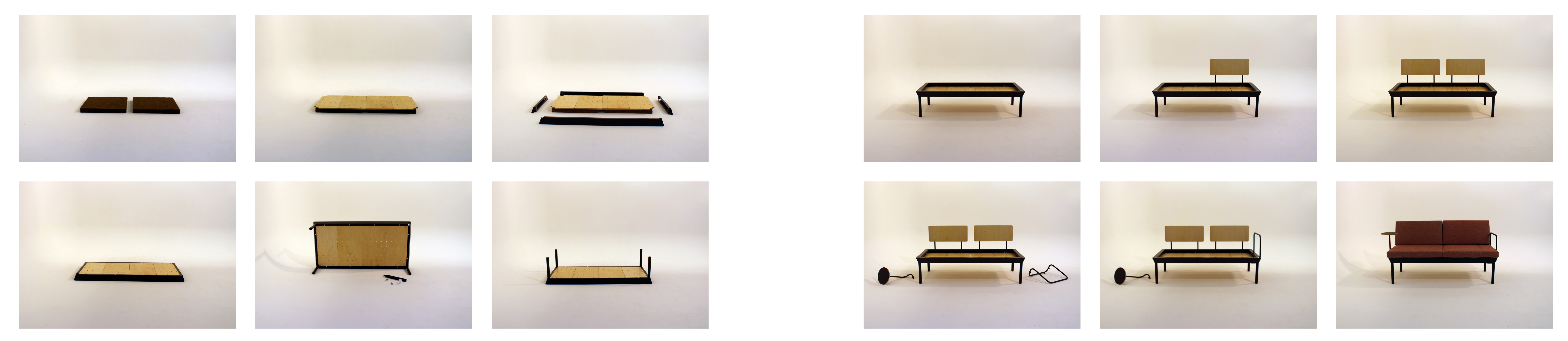


19. System walkthrough

System base unit - see G.A. Drawing, Appendix D.

The system is based around a $750 \times 750$ unit. This size was chosen as it is shallower than
many armchairs or sofas 5 is more compact, benefitting transport and is more fitting to

This system maintains a typical $450 \mathrm{~mm}$ seat height and $550 \mathrm{~mm}$ seat depth, atthough height
can be changed with alternative legs.

The steel folded channels are chamfrered to convey lightness and increase comfort, as the
users caves will not clash with the frame. Folding the channel with a double bend adds
strength and therefore saves materiat

strength and thereforte saves material.
The square format allows seat cushions and coir suspension panel to be fipped or rotated
to spread wear evennly, and potential add-on parts to be fitted on four sides.

The base can be used dalone, as a seat or footstool, and have optional components (e.g. arm,
back, table) added-similar to the Delaktig system.

The seat base is not reclined, research showed this
suspension is rrovided by a $60 \mathrm{~mm}$ coir panel.

A $365 \mathrm{~mm}$ back height is compact, and fits current fashion for sleek low sofass, however if
trends change, this can be easily exchanged for a higher back

trends change, his che

This means a system of leasing or refurbishment and redistribution is more viable as parts
can go into more potential systems or s senararis, widening the potential pool of users. 


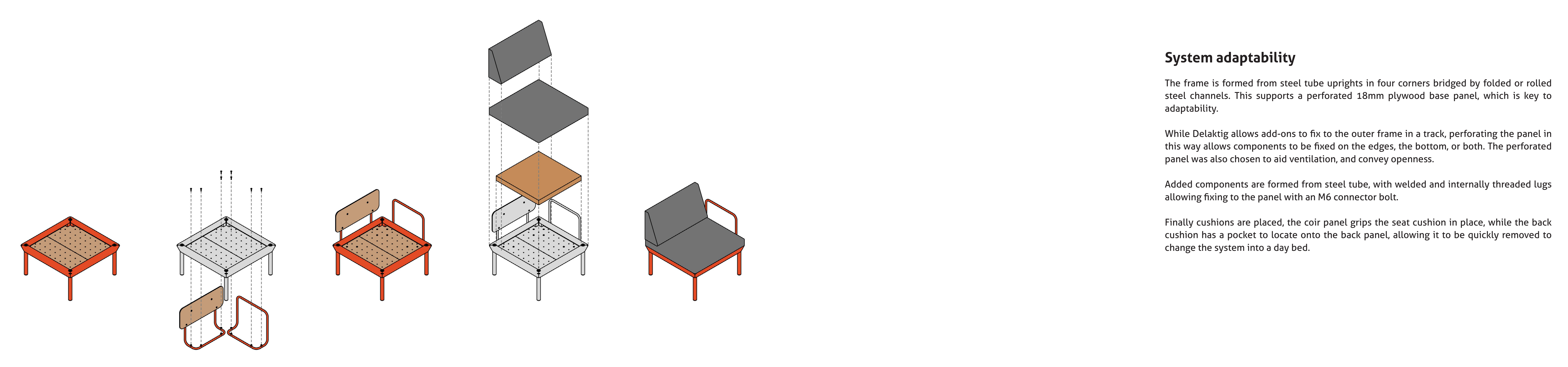


$a_{1} \phi_{1} \Leftrightarrow \infty$

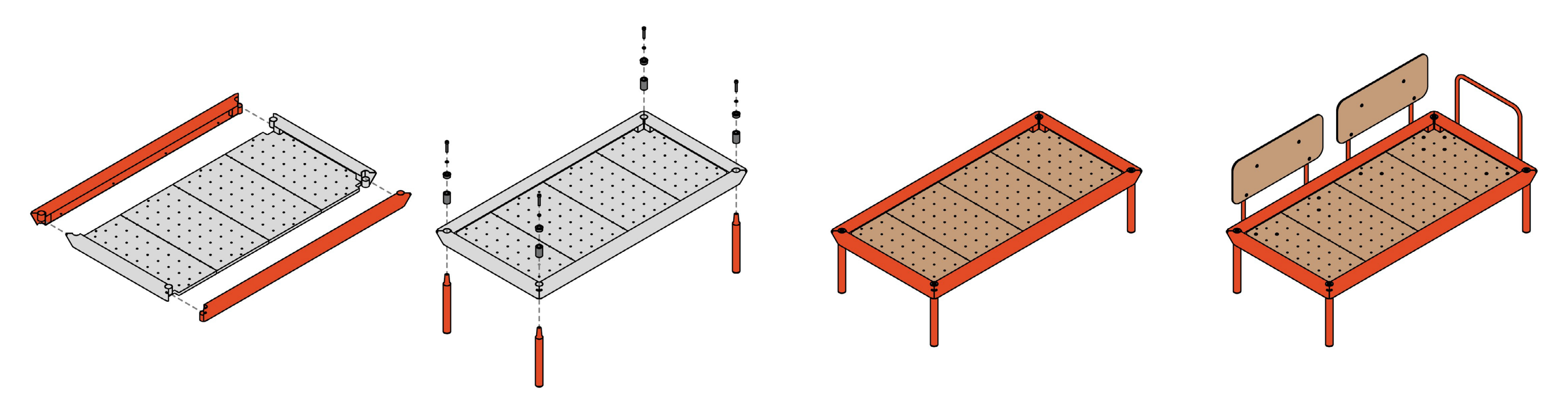

System extension

The frame is held together and supported by corner legs which are standard to all
conffurarations.

All four legs and end beams are identical, allowing scuffed parts to be moved to less visible
positions if necessary.

The leg-beam connector uses a nylon tapered locking clamp, compressed by an M10 fxing
bolt to sodidly clamp the three parts (beam, beam and leg) together. Refer to Appendix B for
test modelliyng of this connector.

To extend or shrink this system, the legs are first removed, allowing the front and back
beams to be separated for replacement. Unwanted beams can be returned to the provider

Additional base panels can then be added together with new beams.

The base panels are are "halt' panels-this allows the end panels to remain in place, while
middle panels are added or removed. Importanty, this also allows halt sofa sizes le.g. 2.5

seater) to be configured.

This is a key feature of this system as extension is typically done by adding a whole unit
(sectional system), rather than extending the existing system. 


$$
=
$$




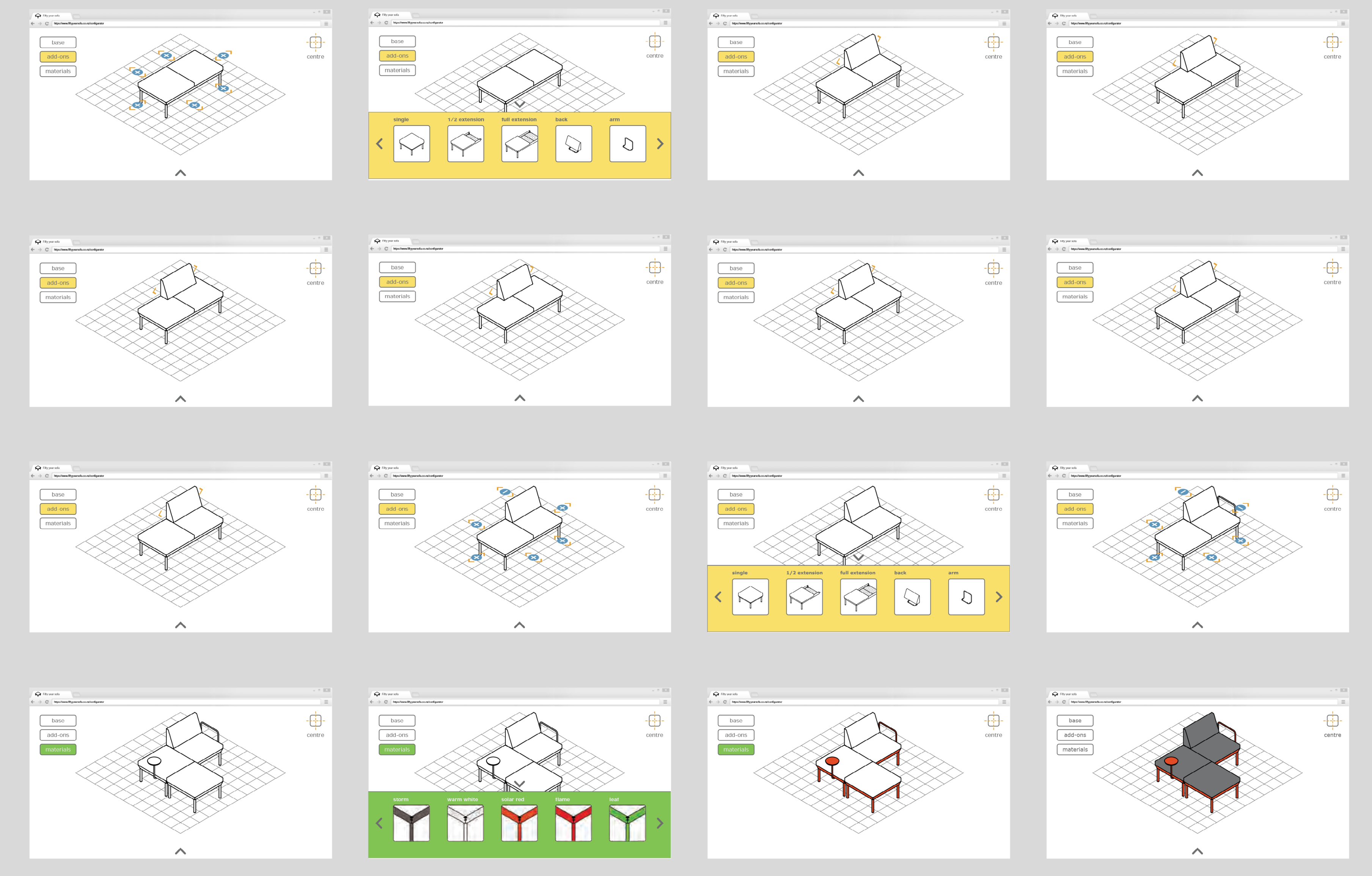

Configuration

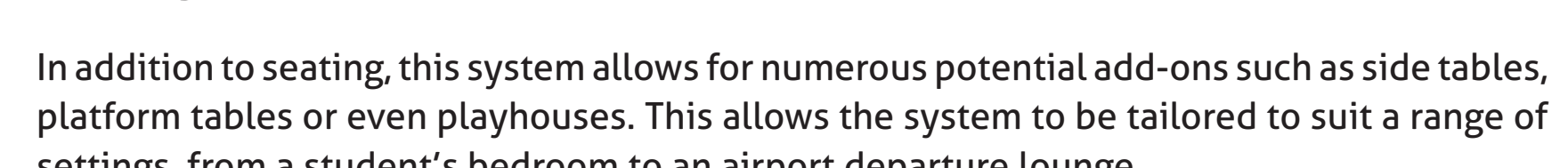

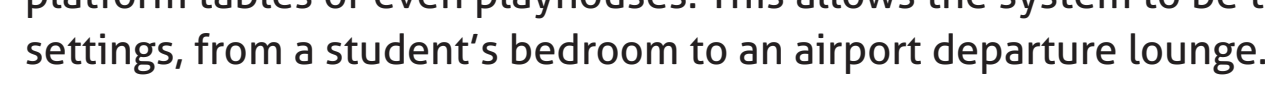

This widens the potential pool of users and parts.

An online configurator could be used to foster co-creation. This could automatically generate
a parts list, and cost estimate for a design. Kits can then be shipped to the user.

This portal could also track your current configuration over multiple iterations, email users
to prompt them to rotate and flip their cushions and spring panel and suggest potential 


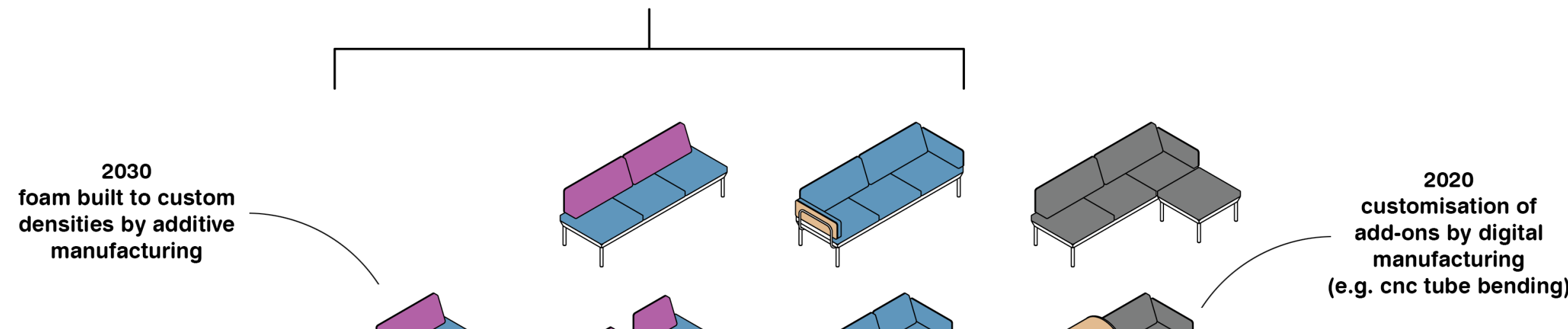

$$
\begin{aligned}
& \& \text { \& \& } \\
& \text { \& \& \& \& \& \& }
\end{aligned}
$$

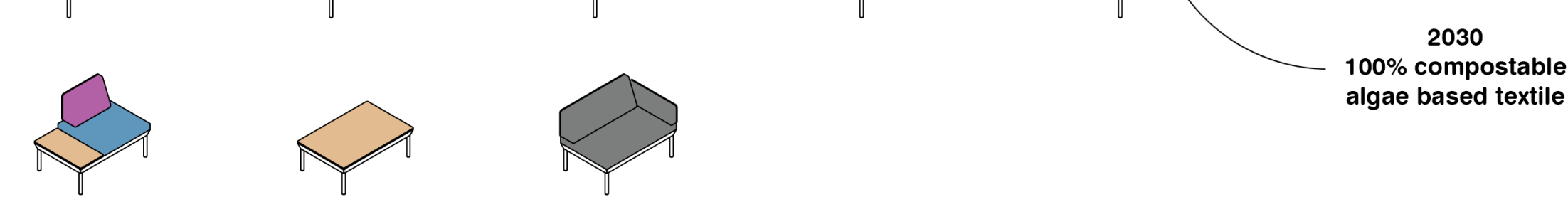

$$
\begin{aligned}
& \phi \phi
\end{aligned}
$$

Tailored versions

Asthis system can be assembled from a menu of materials
tailored versions can be offererd, allowing users greater

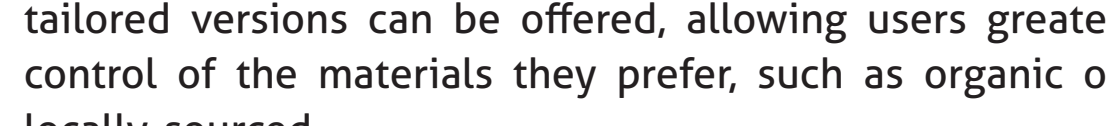

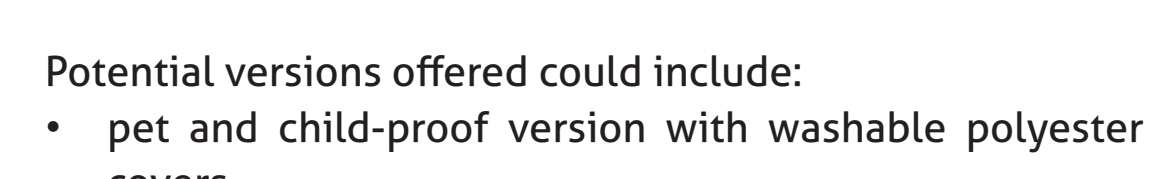

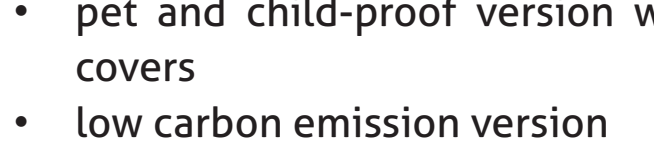

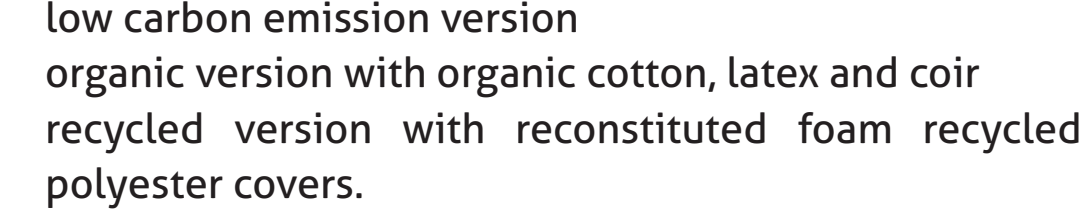

standard version

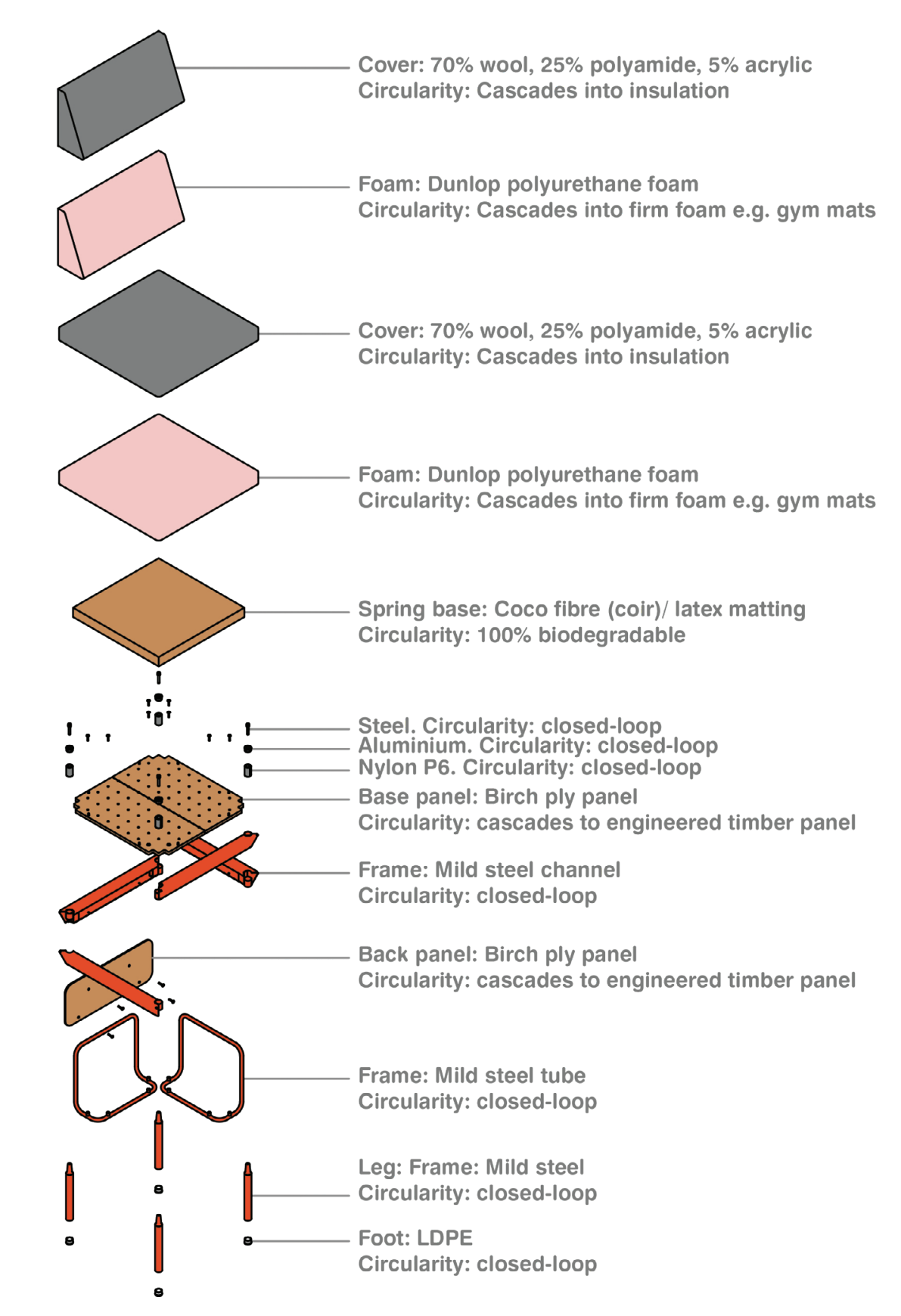

organic versio

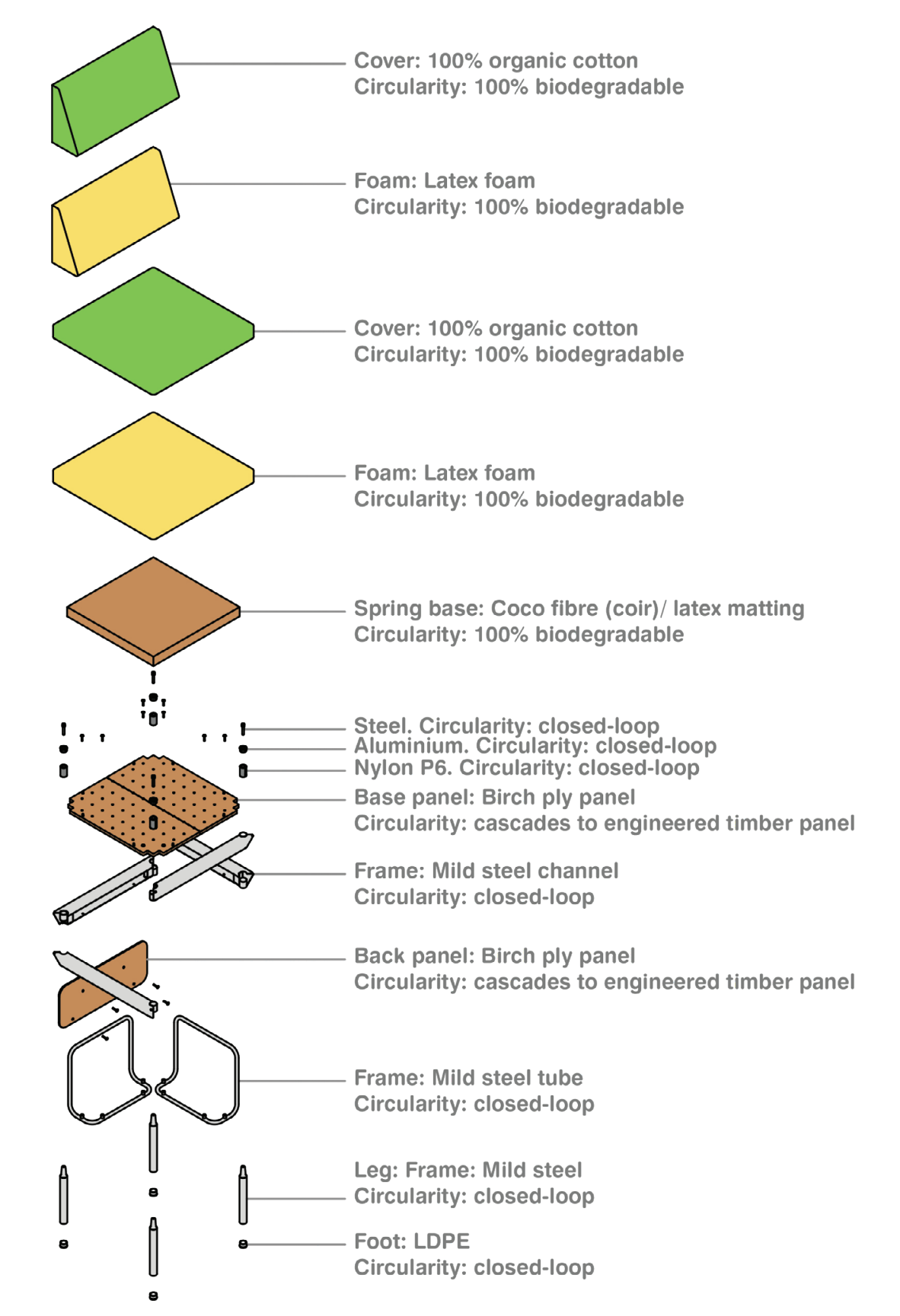


start your 30 year sofa,
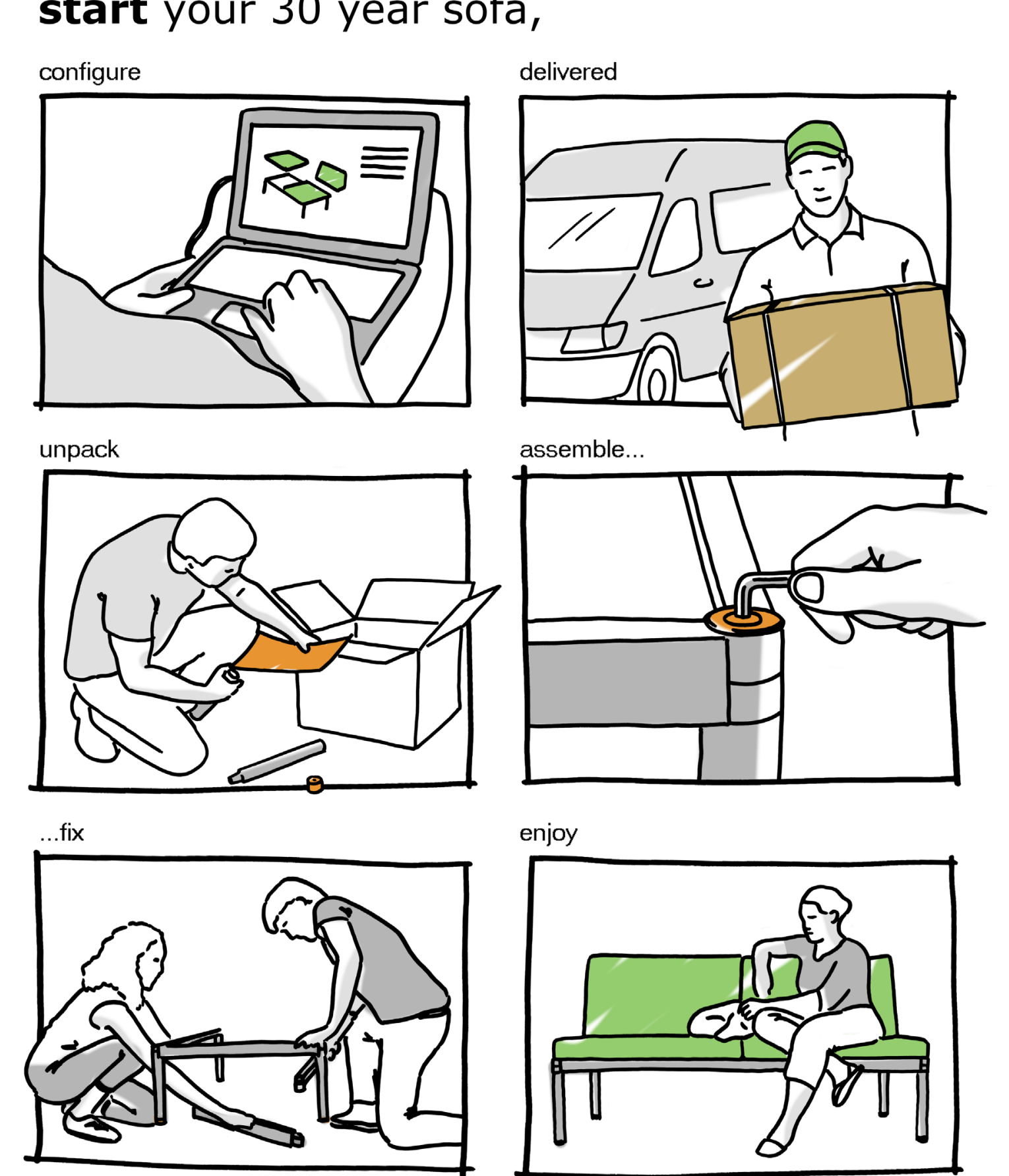

maintain your 30 year sofa,
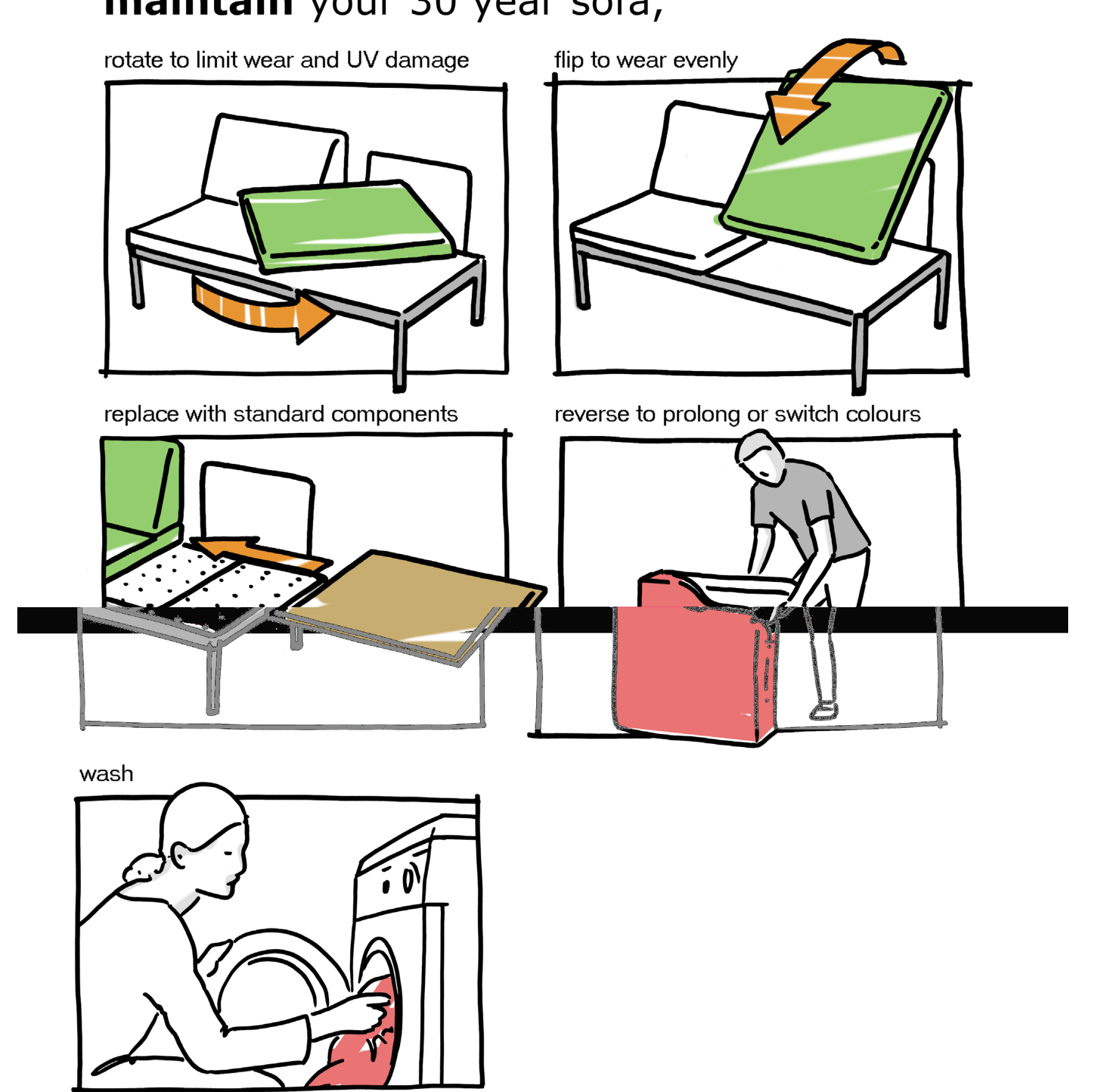

move your 30 year sofa,
or we'll take it back.

modify your 30 year sofa,
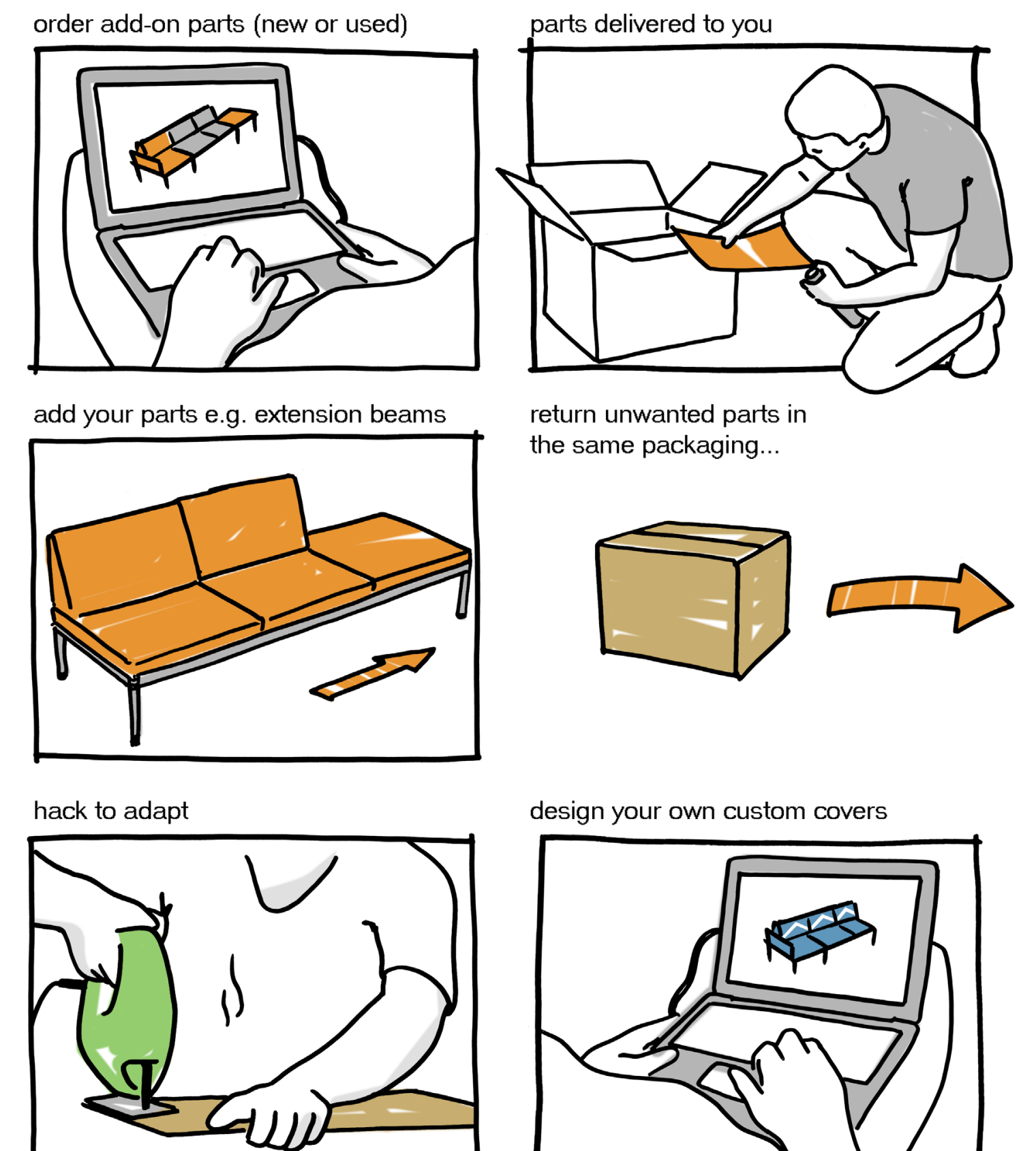

$\square \square$

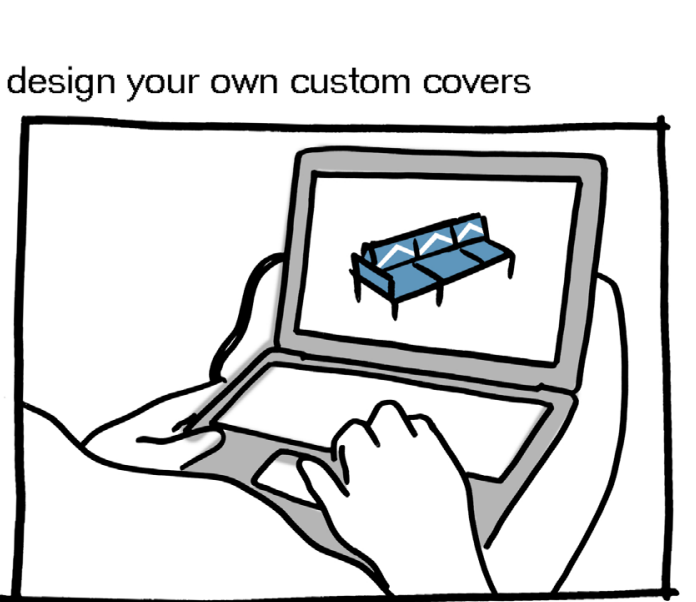

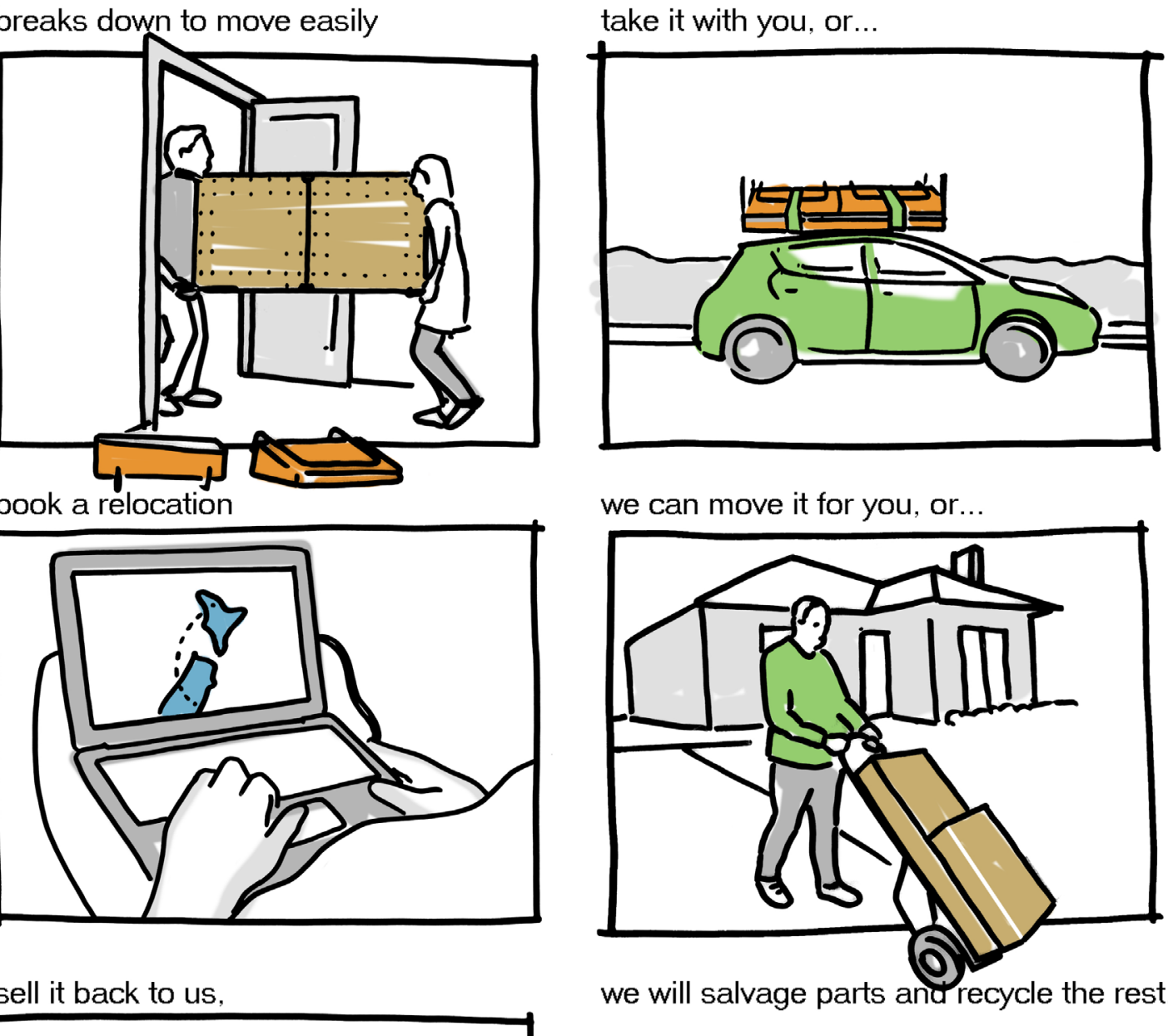

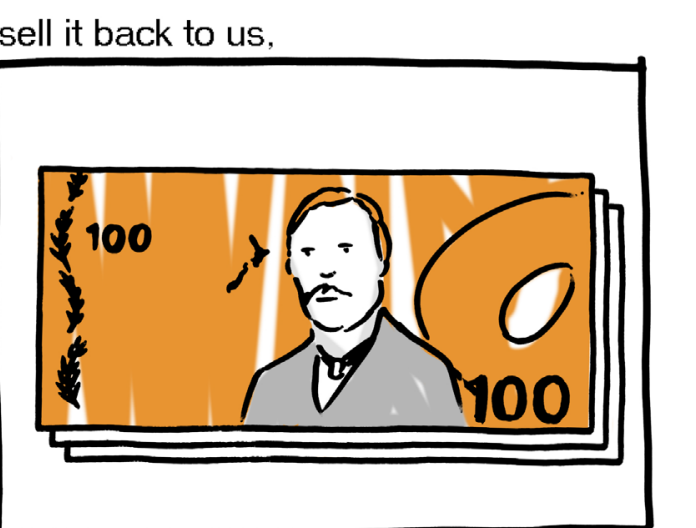




\section{Validation: eco-cost indicators} To confirm these design decisions are building towards long-term sustainability the new Datasets Where possible all three models assumed the use of identical materials and form
seater soff with two arms, using cotton upholstery and polyurethene foam.

The repair pattern assumed is based on typical sofa warranties and reported lifespans
(section 10 ).

Note: working out for this section in Appendix A.2 - A.6.

The three models compared are.

A mass-produced sofa with replaceable covers, based on the IKEA Klippan sofa and 10 -
year warranty-this comparison assumes she cover is is replaced every five years and the

Frame: particle board

Suspension: steel springs
foamm polyurethane form 2. A mid-range sofa with reasonable repair undertaken-this comparison assumes
professional re-upholstery is required after 10 years, and the sof is is disposed of a
years

Frame: radiata plywood
Suspension: steel springs

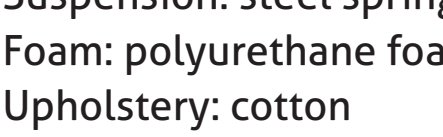

The circular economy sofa model with reasonable repair undertaken-this comprisison

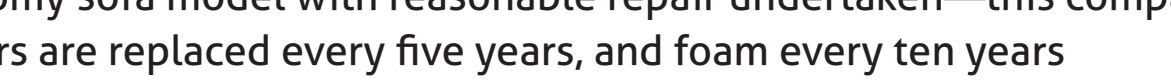

Frame: mild steel
Suspension ceir

Suspension: coir panel
Foumb polyurethane form
Upholstern: cotton

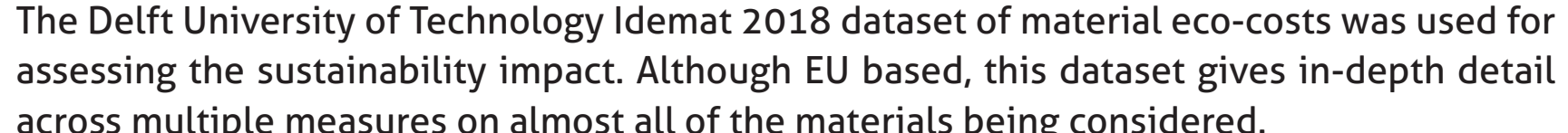

Coir was not included in this dataset, and so alternative CABi figures were used. However
this datasset only covers Co2 footorint.

Transport emission factors used: Guidelines for Measuring and Managing Co2 Emission
from Freight Transport operations, European Chemical Industry Council (2011).

Material data for the budget model: Fire-LCA Model: Furniture Study. Anderson et al (2003)

Time period
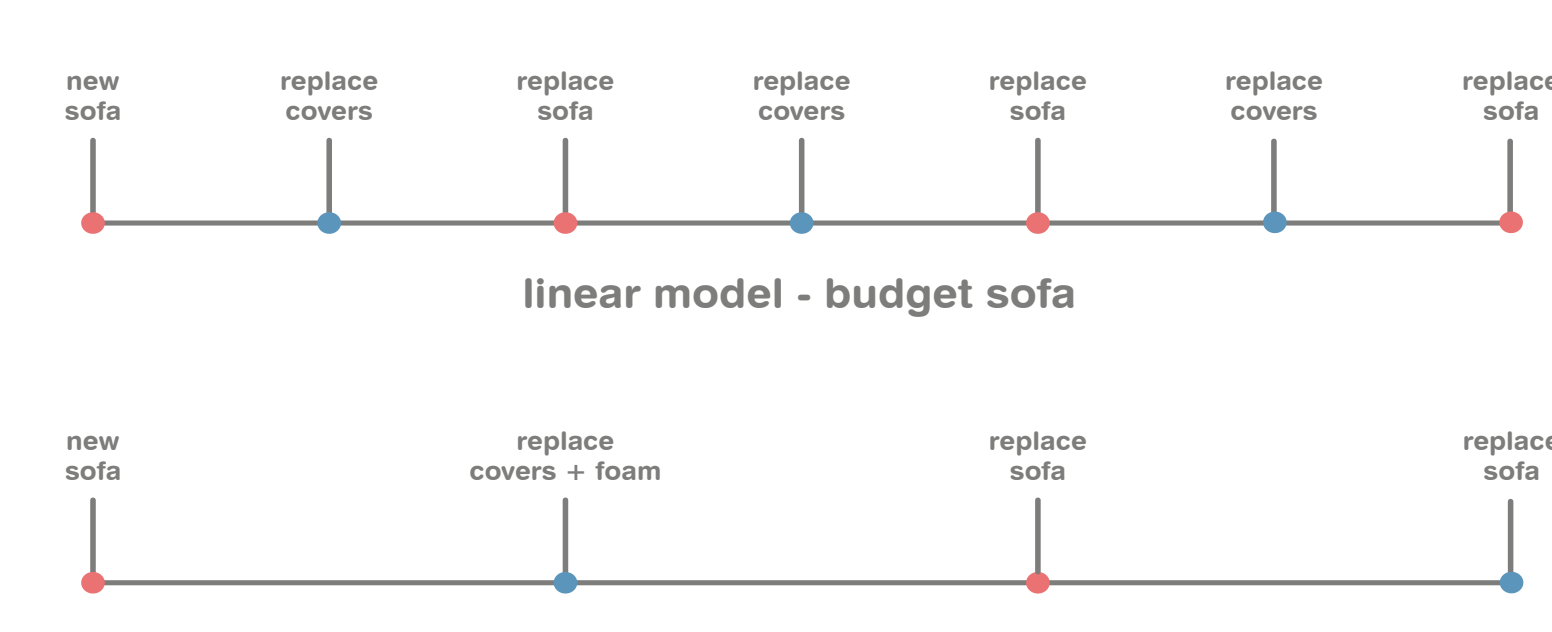

Inear model - high end sofa

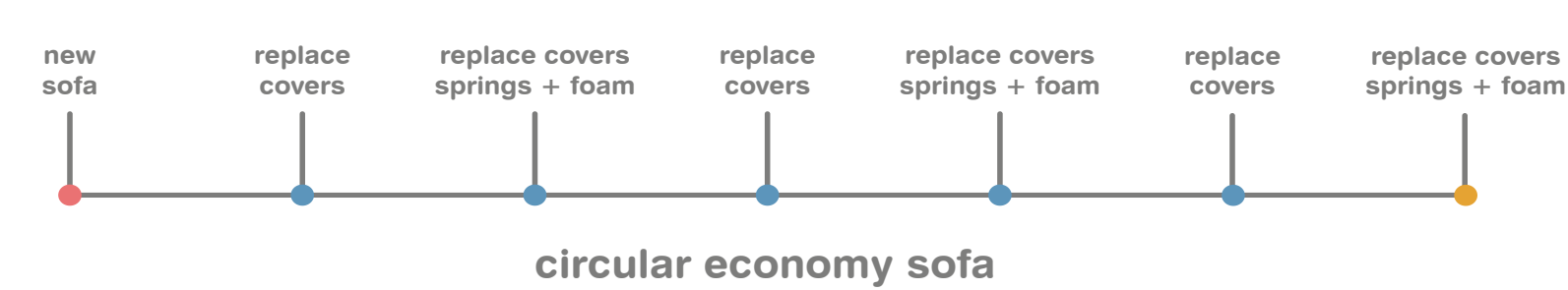

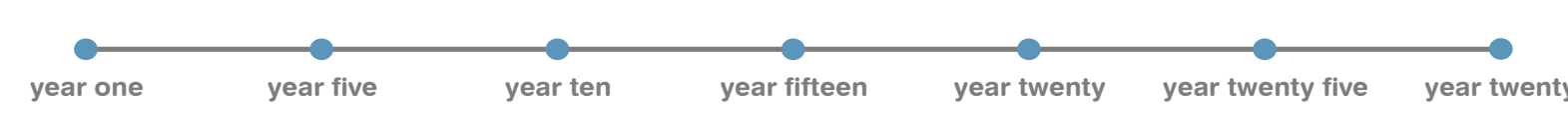

Fig.96, Assumed sofa repair and disposal
The budget soff model has replaceable covers and it is assumed these would be
replaced after five years to address visual and functional wear and tear, increasing

When both the budget and mid-range sofa models are disposed of they are replacee
with an equivalent model.

The mid-range model is based on the budget model, however plywwood is used in place
of particle board.

For this comparison, all sofa models are calculated as if made from virgin materials.
Cascaded materials could b b phased into the circular economy model over time,
however this is not considered for fintess

The mid-range sofa model would require less regular repair and maintenance
compared to the budget sofa model. It s s ssumed this would be reupholstered at 10

years due to wear and fashion changes, and replaced at 20 years

For the purpose of calculating transport differences consistently the following ports

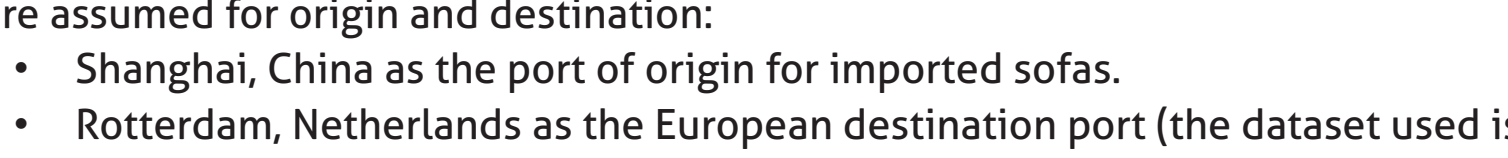
- from Delft, which is headduarted in this city).
Wellington as the destination port in New Zealand.

Local manufacture is assumed to be
models, but not for the budget sofa

For locally manufactured soffs, a distance of $1000 \mathrm{~km}$ was assumed as the distance
from origin to destination. This is equivalent to Christchurch to Auckland, or Milan to
Rotterdam b. Boundaries

Wume to landifli is calculated based on post-consumer waste only. Pre-consume

Due to different waste management practices in the EU and NZ only volume (kg)
londfill and no other impacts (water pollution, groundwater contamination) are

This is an indicative test to validate design decisions, and not a full LCA report as this
would require too many assumptions of processes, sources and waste processing to be

of value and would be out of research scope.

Transport emissions are considered separrately to material emissions

- The functional unit for all three sofa models are consistent in size and function; a two
seater with two arms.

Idemat provides costs in euros, these were converted to NZD for conclusions based on
exchange rate as at anuary 2019.1 Uuro: 1.7065NZD 


\section{c. Carbon footprint}

In total, $198 k$ Co2 is created by producing and repairing the CE sofa model over this period
This is equivalent to driving an avergage car for almost 8 hours (Yousustain, n.d.)

Compared to the budget soff modele the CE sofa model immediately reduces the carbon
lootprin tof the sofa by 57 percent growing to a 69 percent gap over the 30 year period. The

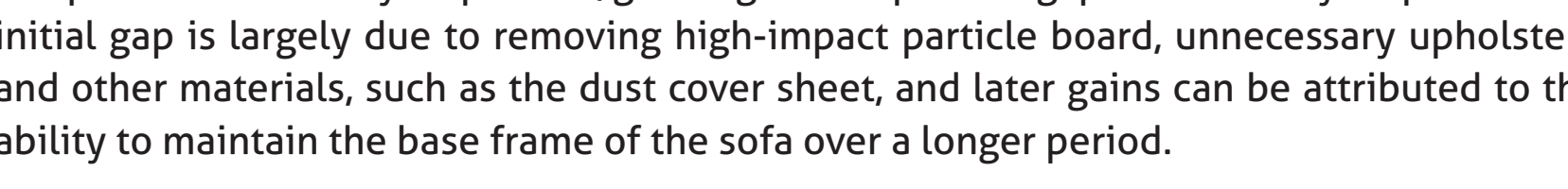

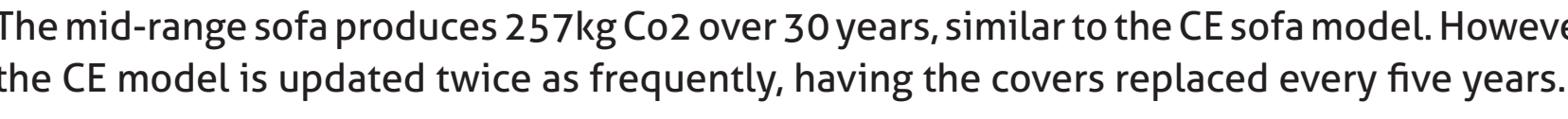
Eco-cost of Co2 over 30 years (NZD)

Linear model $=\$ 123$

Mid-range model $=\$ 53$

Circular model $=\$ 36$ d. Embodied energy

In the budget sofa model, the frame (particle board, sawn timber, springs, and fixings model's design and use of steel reduces the frame embodied energy by 80 percent to
$363 \mathrm{M}$ ). Using recycled steel would reduce this even further to $230 \mathrm{Mr}$. Budget model total embodied energy (year one) $=10870 \mathrm{M}$ Circular model $=981 \mathrm{MJ}$

Over 30 years the circular model has a 71 percent reduction in embodied energy compared
to the budget model.

$$
\begin{aligned}
& \text { Embodied energy over } 30 \text { years }(M) \\
& \text { Linear model }=10870 M] \\
& \text { Mid-range model }=4114 \mathrm{MJ} \\
& \text { Circular model }=3151 \mathrm{MJ}
\end{aligned}
$$

e. Human health

With this design, the majority of toxicity to human health is caused by the polyurethane
foam used in the upholstery. This is due to the vapours and gases from production of foam components (Europur, n.d.). Foam is also one of the key areas which wears out on a sofa
esulting in the object losing performance.

This can be reduced by a significant 80 percent by replacing polyurethane foam with natural

However, this replacement increases resource depletion significantly as naturar latex form
lequires rubber from plantations, which can lead to other issues such as destructioan of carbon sequestrating native forest, loss of fland that could be used for food production, and
habitat loss.

This highlights a challenge in designing sustainable products. The most renewable option
that which exists in the biosphere) can be a bad choice for the environment while the

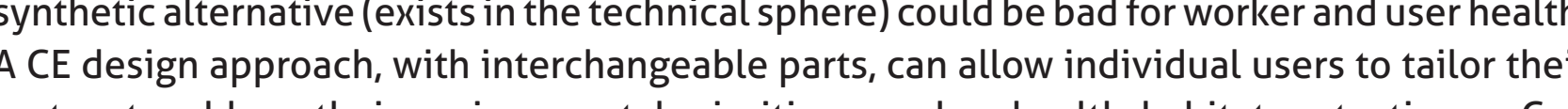
lootprint. Howevere, arguabably the best way to improveve perforrmance on all measurues is to f. Resource depletion

The largest contributor to resource depletion across all sofa models is cotton. Multiple

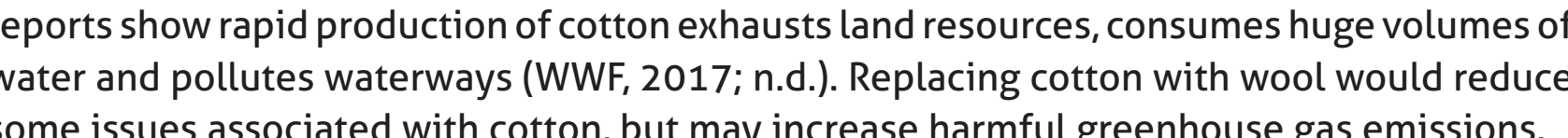
Reducing the amount of upholstery significantly reduces this impact-highlighting the
valuu of reducing material rather than replacing it with less bad' atternatives.

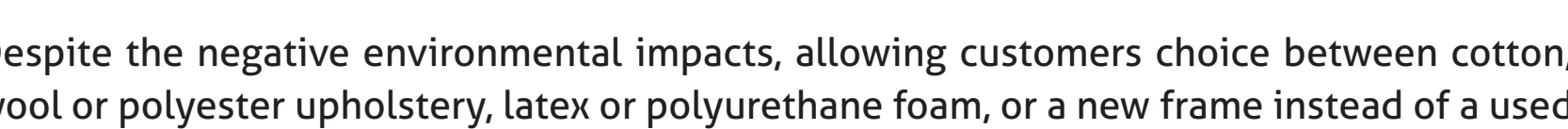
frame is acceptable as the long-term impact reduction is achieved by keeping the produc

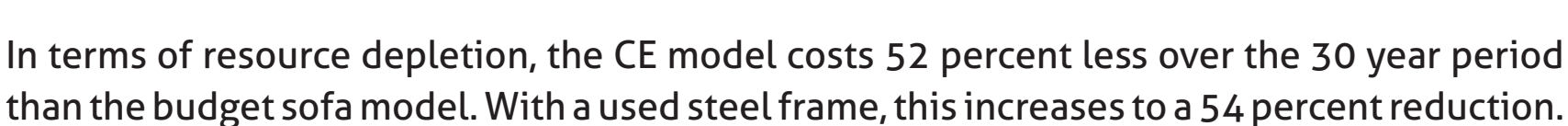
pletion over 30 years (NZD) Linear model $=\$ 245$ Mid-range model $=\$ 187$ Circular model $=\$ 119$ 


\section{g. Transport}

key benefft of using less material is the reduction in freight emissions

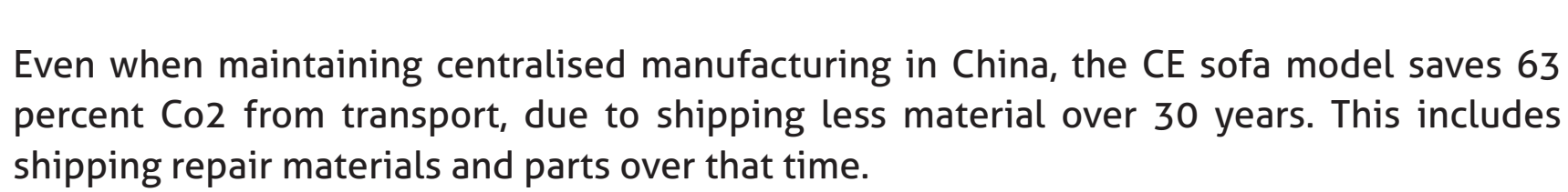
Purchasing a mid-range soffa produced in China with double the lifespan saves 38 percent
of transport co2 compared to the budget soff model. These comparisons highlight the importance of quality, repairability and manuffacturing
location considerations in designing and manufacturing sofas. Steel was chosen primarily for its durability and ability to be refurtibhed and recycled, ad
well as its comparative lightness, benefiting transport related Co2.
h.Waste to landfill (kgs)

This is where the largest difference between the sofa and ownership model san be seen
The budget sofa model is not designed to be recycled, and so, with a lifetime of just ten

Material to landfill over 30 years

Linear model $=184 \mathrm{~kg}$

$$
\text { Mid-range model }=68 \mathrm{~kg}
$$

Circular model with current metal recycling and coir composting $=38 \mathrm{k}$ Circular model r with steel recycling, foam downcycling foam and coir composting = 221] Circular model with additional plywood biodegrading, textile recycling and LDPE / nylon
recycling $=2 k g$

With currentrecycyling abilities, we can expect the steel to be recycled, and the coir removed
and composted. This results in $146 \mathrm{~kg}$ less waste to landfill over 30 years in the CE soffa
model Textile recycling is becoming more available and in the near future we can expect the
textile fibres to be recycled or at least composted. This results in a further $9.6 k$ g of material

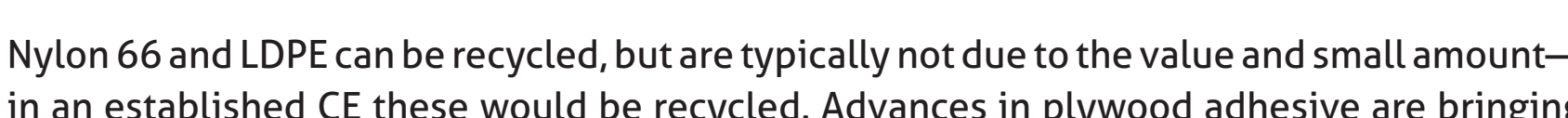

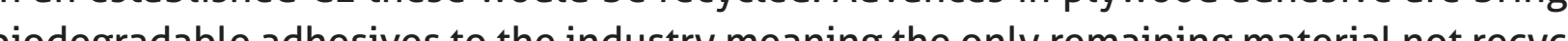

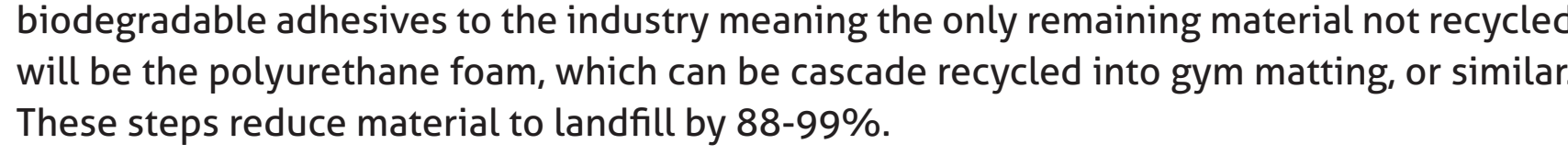
The abity to recycle or reuse polyester wadding would bring this to 100\% diversion from
landfill.
Discussion

CEstrategies show promise to reduce the amount-and associated impacts-of material
and transport required to manufacture and deliver a sofa. A key insight from these comparisons is that the ability to keep a material in a closed loop
for a significantly longer time frame can surpass any gains from 'eco' choices.

Savings by shifting to a circular economy model (compared to budget sofa model) Ecc-costs to human health: $20 \%$, increasing to $39 \%$ with recycled steel Cost of resource depletion: $52 \%$, increasing to $54 \%$ with recycled steel Embodied energy: $71 \%$, increasing to $74 \%$ with recycled steel Waste to landfill: $79 \%$ with moderate recycling, increasing to $99 \%$ with extensive
recycling Transport emissions: 63\% Total eco-costs: $56 \%$ increasing to $60 \%$ with recycled steet With greater societalemphasis and attention on waste minimisation and pro-environmentel
behaviours, recycling infrastructure is expected to improve in the near future. Combined with efficient reverse logisitic systems and incentives this should encourage an
increasing shift to refurbishing and recyching. Over time, these materials can be phased

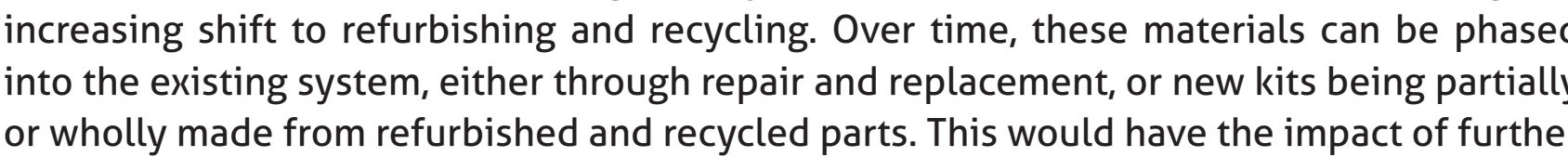
or wholly made from refurbisised a
reducing the eco-costs of a C C sofia
"Continuousimprovementis betterthan delayed perfection" Mark Twain 


\section{Validation-Industry feedback}

The proposed CE sofa system as outlined in section 19 was presented to key figures in the Peter Thomson-CEO, The Formary
New Zealand sustainable business network.

And the question posed: "How does this academic design research relate to the industry
and how might it be applied commercially or conceptually within your company or the field
in generit"

These interviews are approved by the Victoria University of Wellington Human Ethics
Committee: Application ID: 0000024294

Direct quotes from the interviews are reproduced here
The Formary is a global leader in fibre redesign that works with businesses snd organisations
worldwide, transforming fibre waste into valuable, marketetable prodsests

"This research shows the need to be pragmatic and practical as there is no ideal solution. potentially manufacture locally."

"This design-led thinking is what we know needs to happen for a sustainable future."

"Most t think the Circular Ecconomy is just better recycling, this research shows that repair and
reuss are also important."

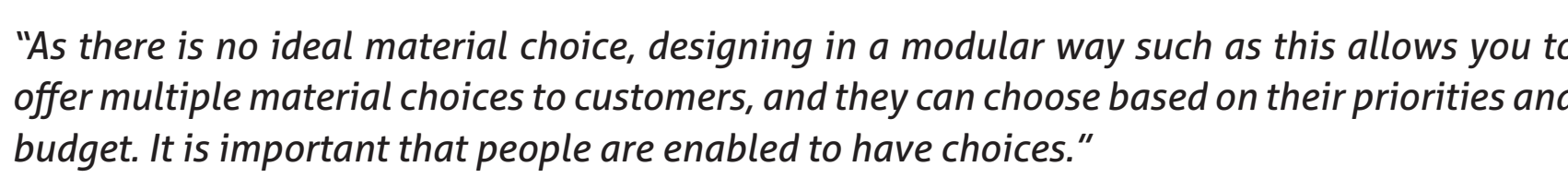

"This research shows there is actually nothing eass about solving
in this way allows incremental improvement in sustainability."
Richard Latham-Design Director, Wishbone Design Studio

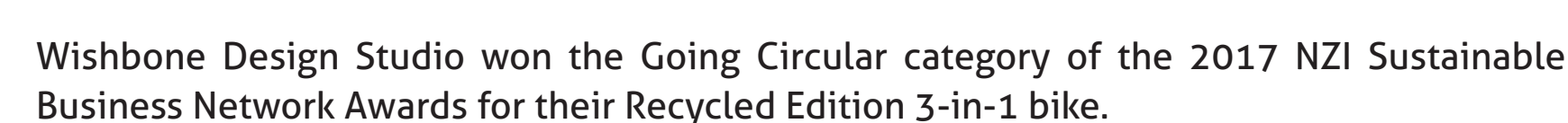

"Using a single material for most of the product helps with recycling." "Environmental solutions need to be practicicl. It's one thing to be idealistic, but it's better to
inplement small changes and in incrporate new technology over time." "Designing in this way allows you to have a mk.1 and a mk.2. The mk.1 can have all the ided

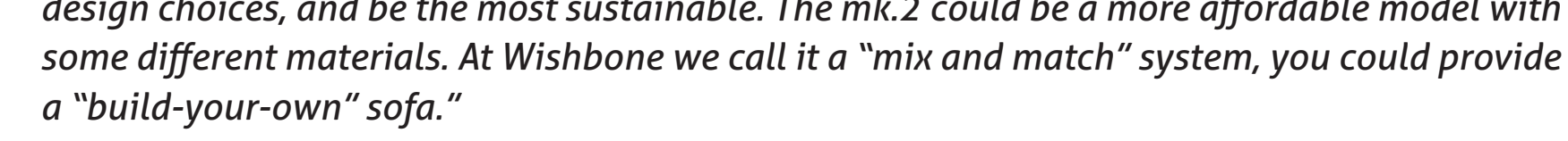
"f each component has on e or two options, it creates a much more versatile produc.
James Grififin-General Manager, Circular Economy Accelerator

Part of the Sustainable Business N Network, the Circular Economy Accelerator is leading the
effort to accelerate NZ to a circulare economy.

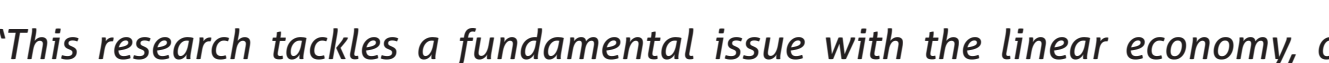

"Adressing this issue at scale is an absolute requirement for a move towards a circular

Dverall the process, considerations, design and ultimate conclusions of the thesis clearly
esent not only a compelling and inspiring approach to defying obsolescence in sofa design. "ut in multiple products and sectors." "The thesis demonstrtasc
economy principles" "The concept goes beyond a simple incorooration of circular design elements to crucially
demonstrataing how such principiples can enhanance both the functionality nand overall appeal of "I would love to see such a design commercialised and certainly believe it has the potential to 


\section{Conclusions}

CE design strategies siginificantly reduce
impocts on the whole, even with current CE is an effective model to reduce impact
and waste from manufacturing and and waste from manufacturing and
consumerism, and can be adopted with
current materials and infrastructure. By designing a circular system, virgin
material input is minimised. Thisis is critical
because whichever material choics are to because whichever material choices aret
be made, the most effective way to reduce long-termimpact ist toeeee those material
in use for as long as possible. A system which prioritises repair and
adpatability appeals to users' growing
desire for longer lasting products which cause less environmental harm reconfiguration allowing the unit to dijus
changing user needs over time. While

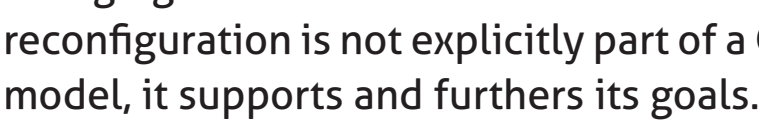

A CE helps us build towards a future of
abundance $\begin{aligned} & \text { Designing g good system is more effective } \\ & \text { than choosing 'good' materials }\end{aligned}$

There are few barriers to designing for CE

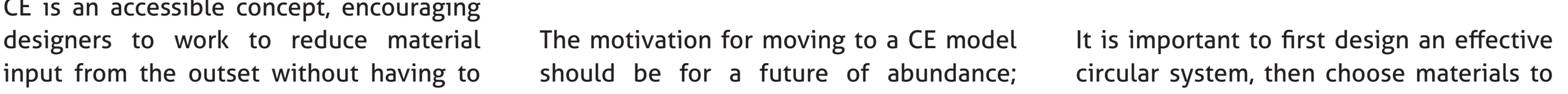

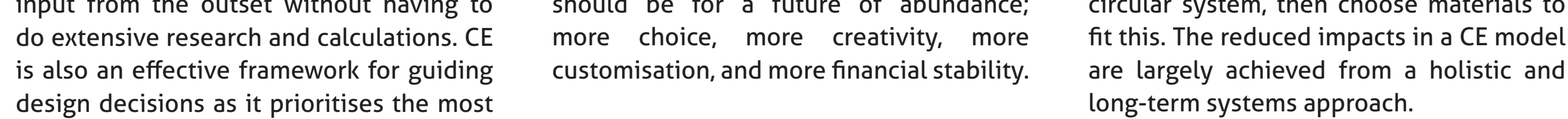
effective strategies, favouring repar and refurbishment over reycling. This
is positive as recycling is a problematic

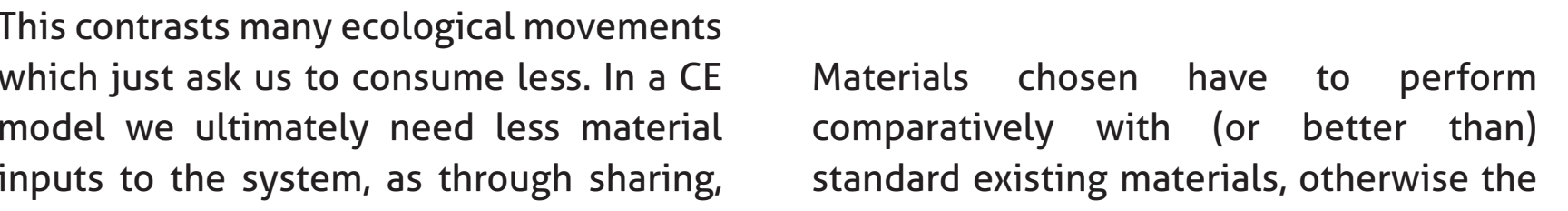

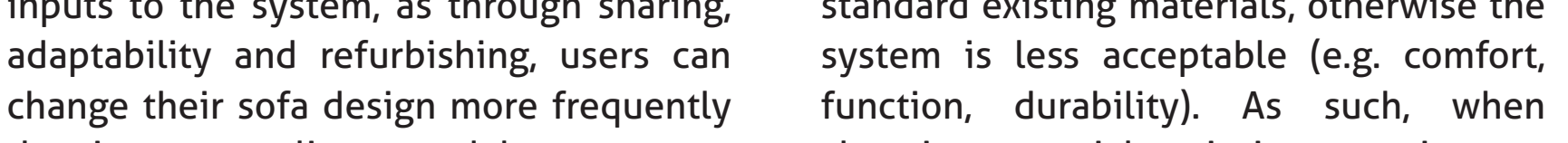
than in a current linear hose with long term durability gavd high

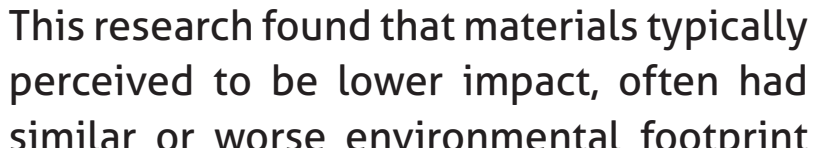
(n) measures. Biological materials are typically
less iurable, and when recycled lose performance, needing virgin material
input. This means technical materials which are durable and able to be recycled
with no loss of performance, can be better

Material choices should be thoroughly
researched early to avoid moving the
problem

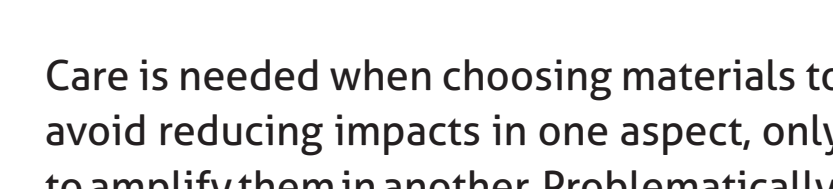

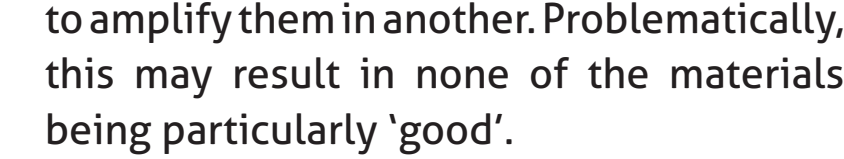

In this research, material impact validation
was investigated as the design solidified on reflection, conducting prelimitay typical and alternative materials couvd have improved the research case study
sofa outcome. For example, knowing the impacts of foam
options synthetic and natural) aerlier,
would hyve encouraged designing would have encouraged designing
system which required no foam at all and system which required no form at all and
could have broughn new design solutions
reducing impacts further. Aside from the obvious advantages of deconstruction (refurbishment and
recyclingl, this approach opens the system

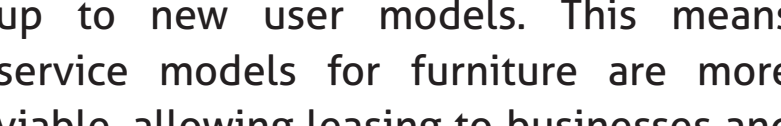
stic users.

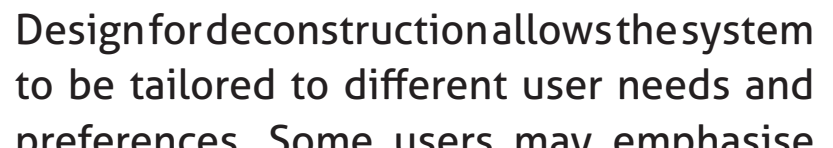
preferences. Some users may emphasise
repait, others may emphasise natural materials. Deconstruction demorcratises
the design process by allowing the user to
choose through co-creation. Ahough the CE has many advantages and
trengths, it only buys us time and should Cale model. Current materialas tie us into ece-effficiency,
but do not mote us to a system where
material impacts are positive (referered to as eco-effectiveness in $(22)$. Designers
and and manufacturers have to demand and
support material developments to move to support material developpentint so move to
artryly sustainable ciricular, cradle to cradle

"We really should consider very carefully whether we constantly need new things, I have been

arguingfor a long time for less, but better things." 


\section{Appendices}

\begin{tabular}{|c|c|c|c|c|c|c|c|c|}
\hline sereat & 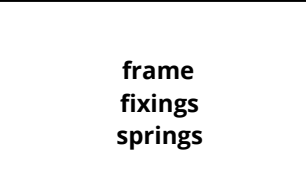 & mims & 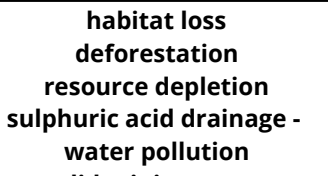 & was & 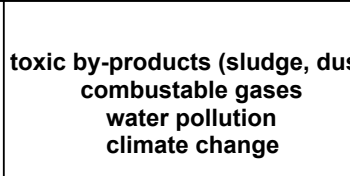 & \multirow{11}{*}{ 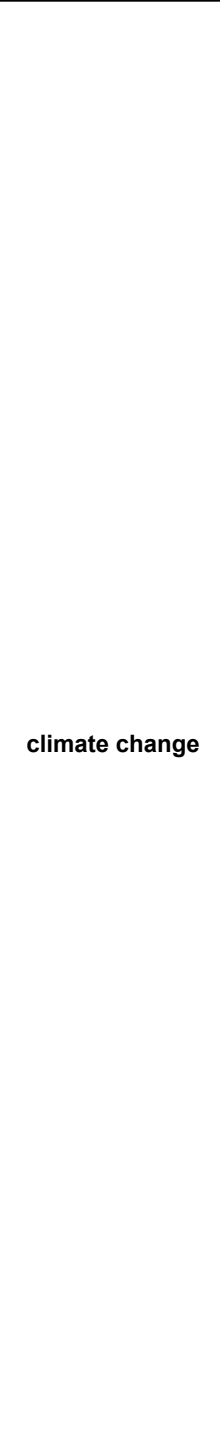 } & \multirow{11}{*}{ 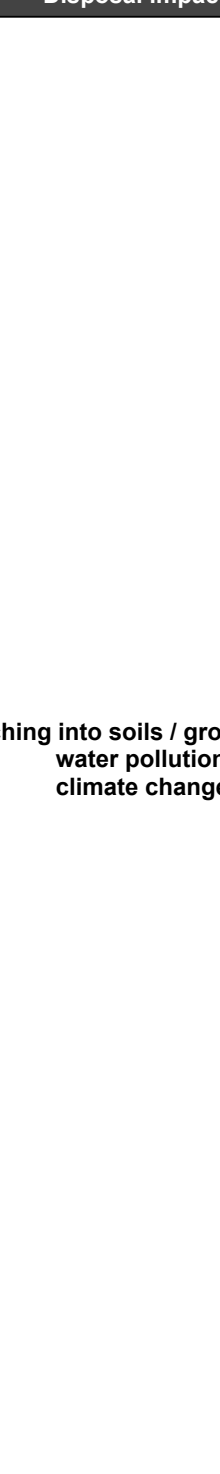 } & 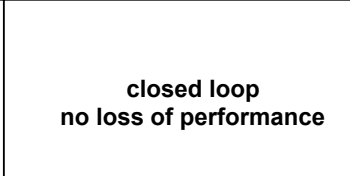 \\
\hline Numinium & trane & mining & 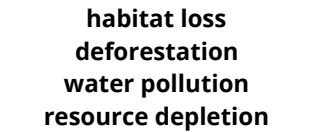 & wa & 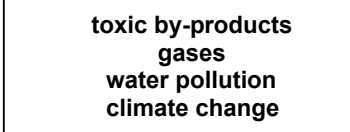 & & & 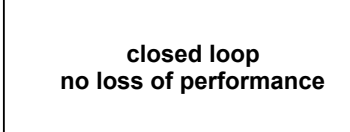 \\
\hline 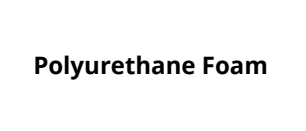 & canthouras & 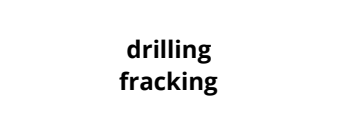 & 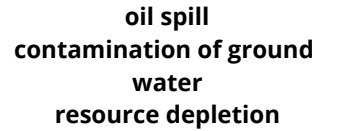 & wa & 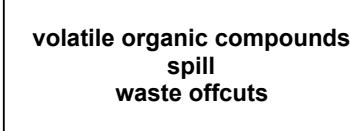 & & & 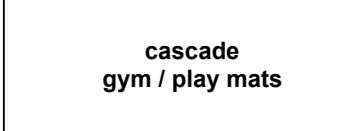 \\
\hline polvesear & unoberarer & stats & 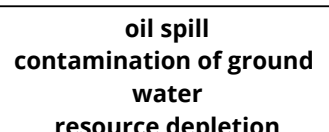 & $\ldots$ & mestasenen & & & 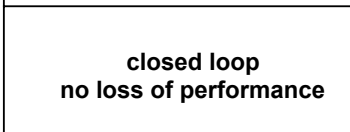 \\
\hline 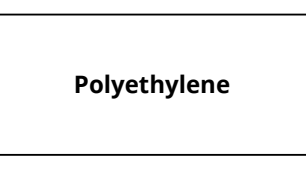 & 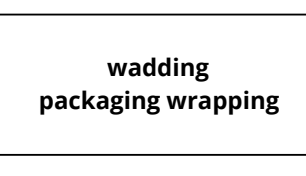 & 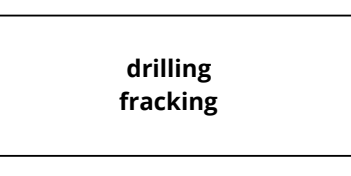 & 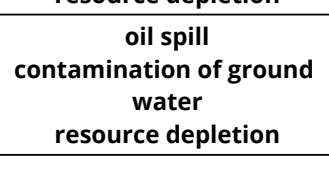 & "w & 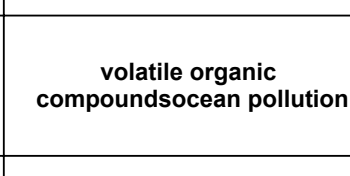 & & & 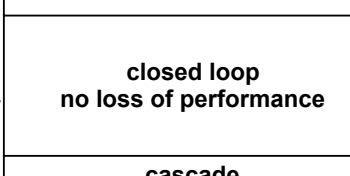 \\
\hline Trmater & traming anduture & 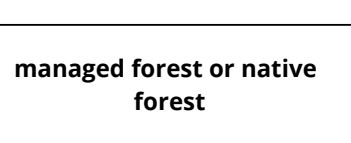 & "w & 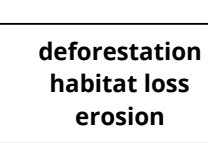 & $=$ & & & 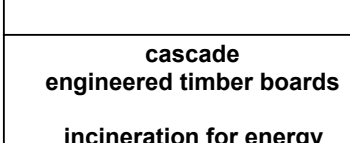 \\
\hline 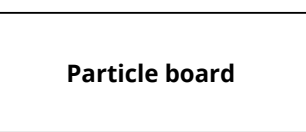 & temingestructure & 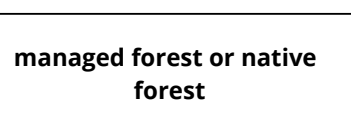 & 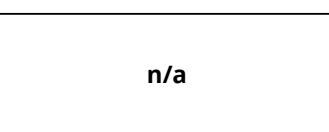 & 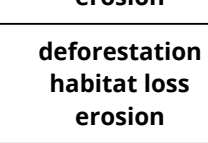 & 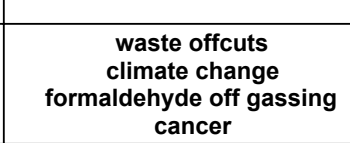 & & & 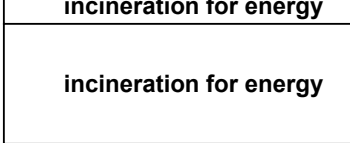 \\
\hline sumarthex & entumans & panaration & 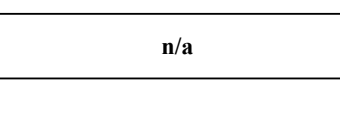 & mabaratases & 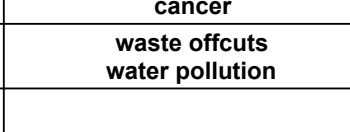 & & & 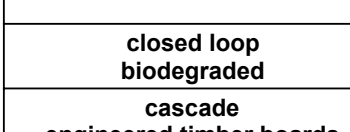 \\
\hline sarmbo & rameramanaurar & cop & wa & moserat ass & 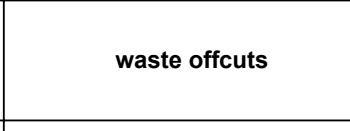 & & & 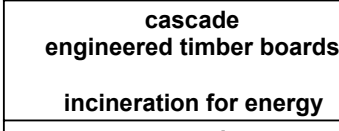 \\
\hline catono & unosuatery & copp & no & 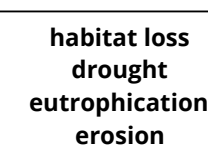 & 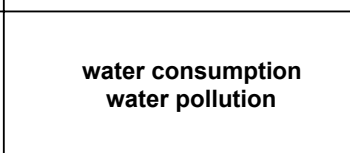 & & & 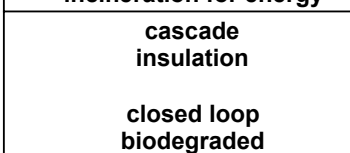 \\
\hline mara & underater & inematactap & $\cdots$ & 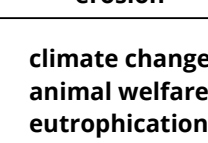 & 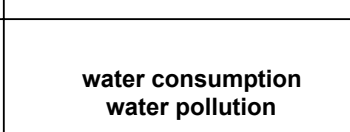 & & & 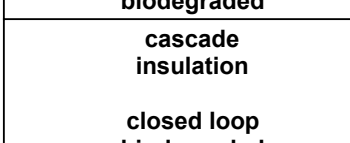 \\
\hline
\end{tabular}




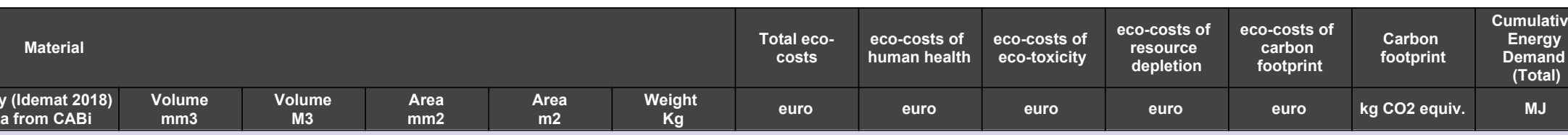

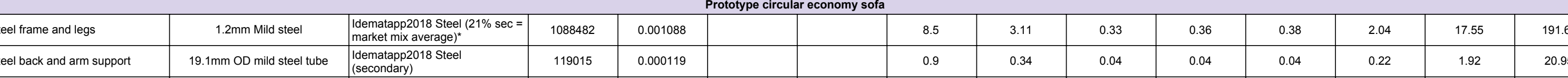

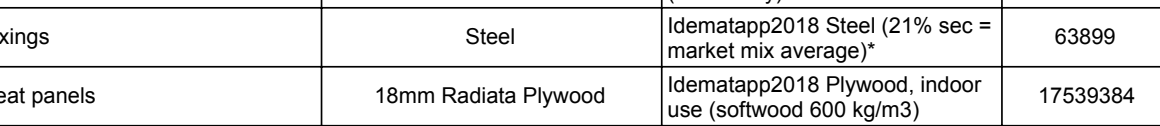

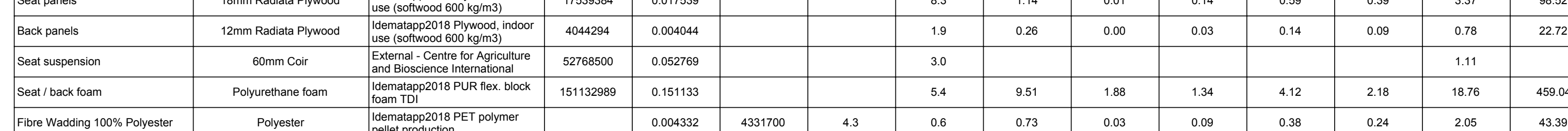

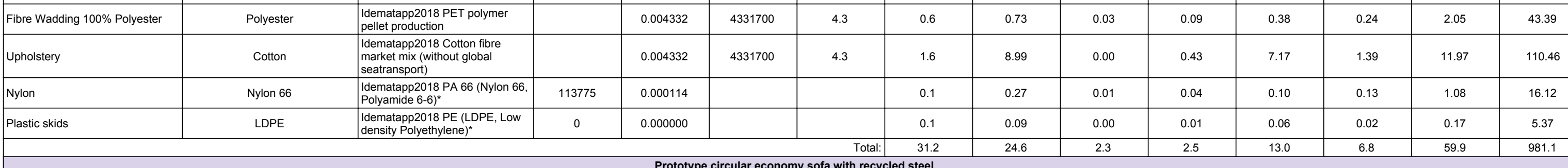

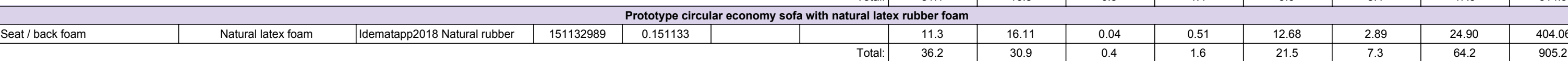

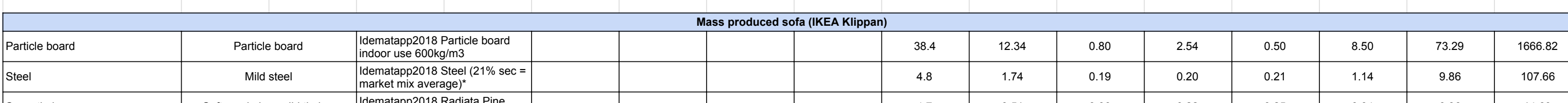

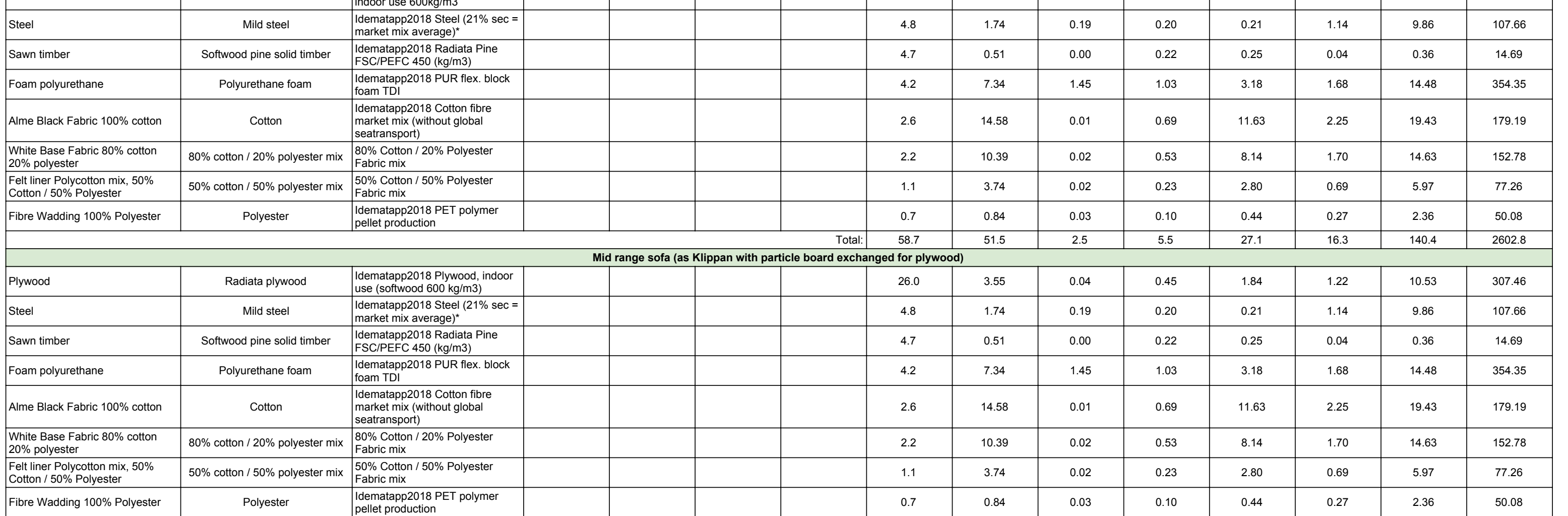

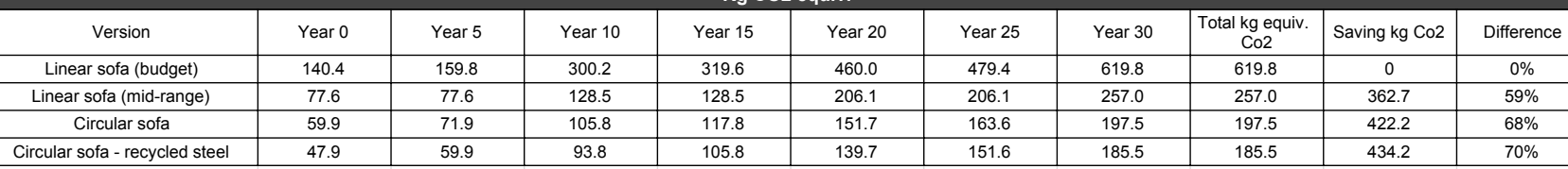
$=\frac{10}{20}$

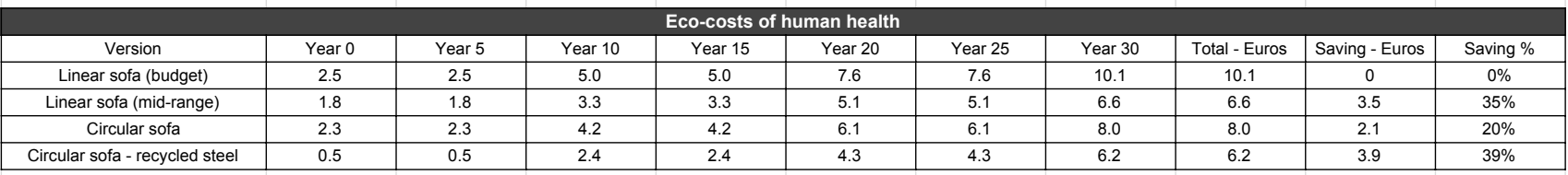
$5=\frac{1}{20}$

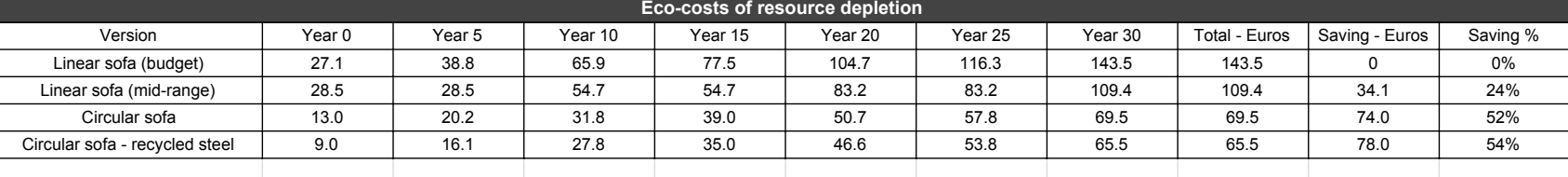

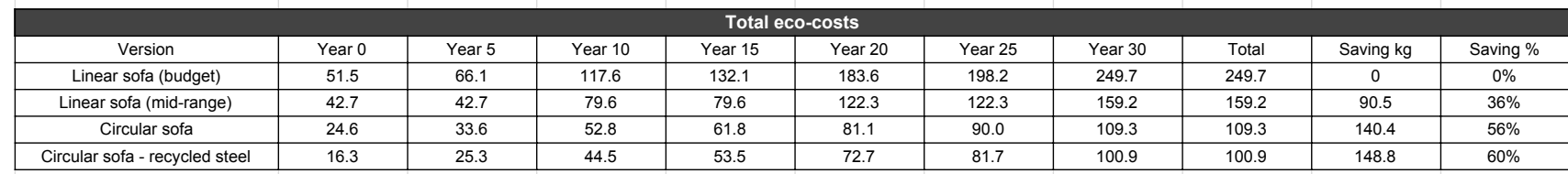
$-2$

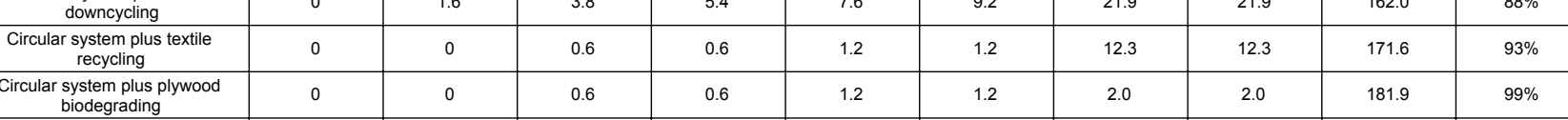
Cow

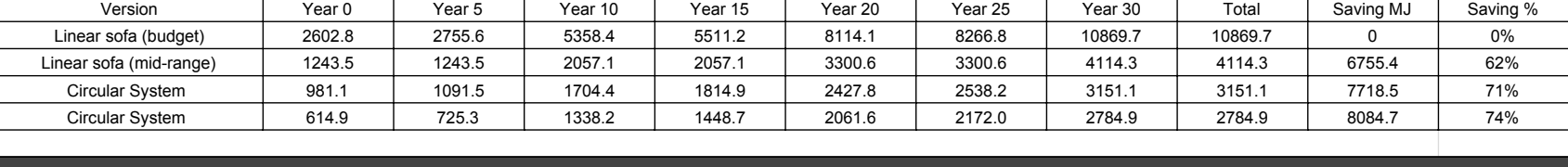

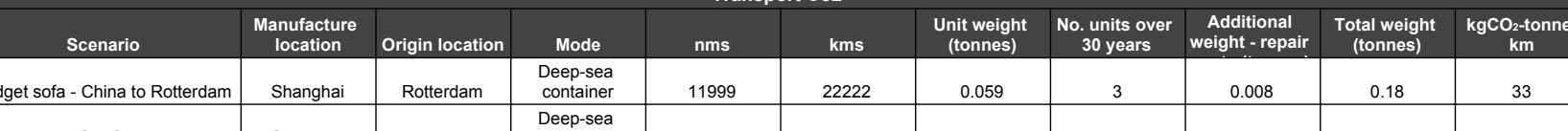

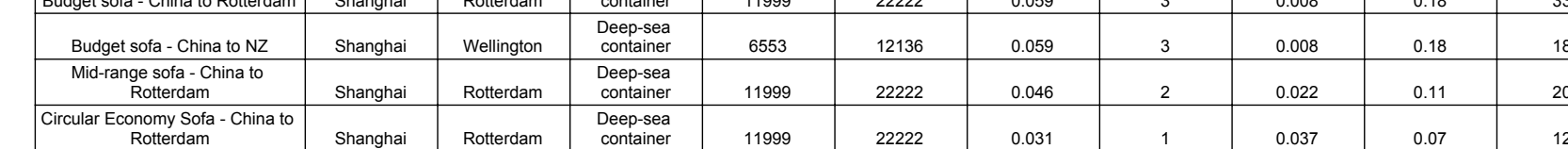

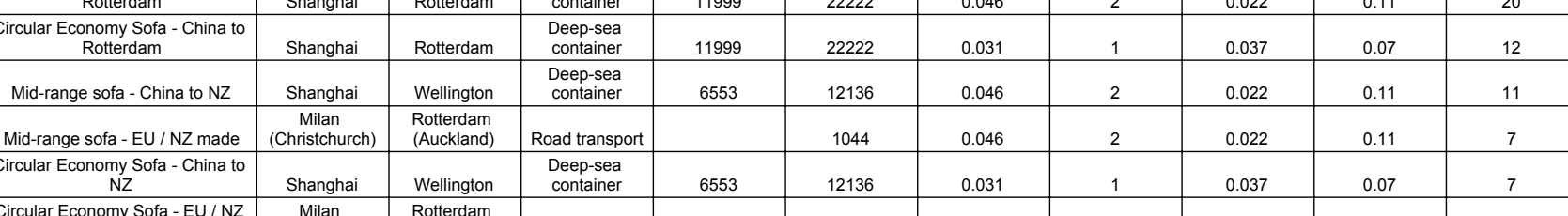



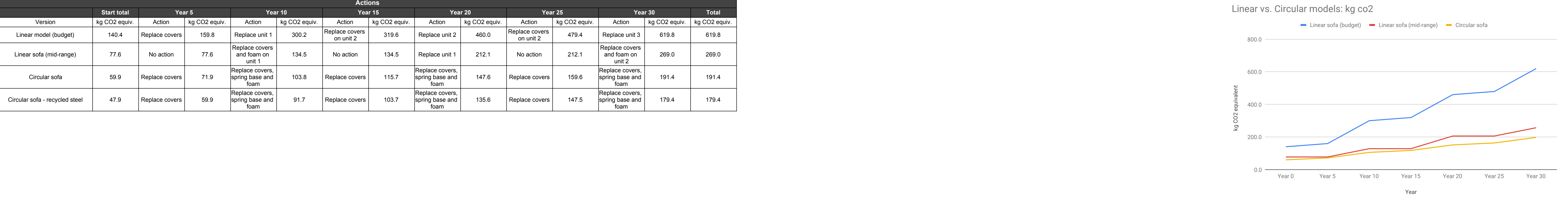

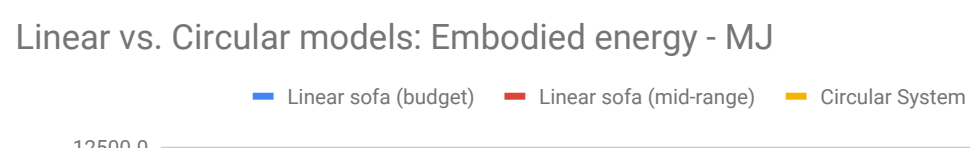
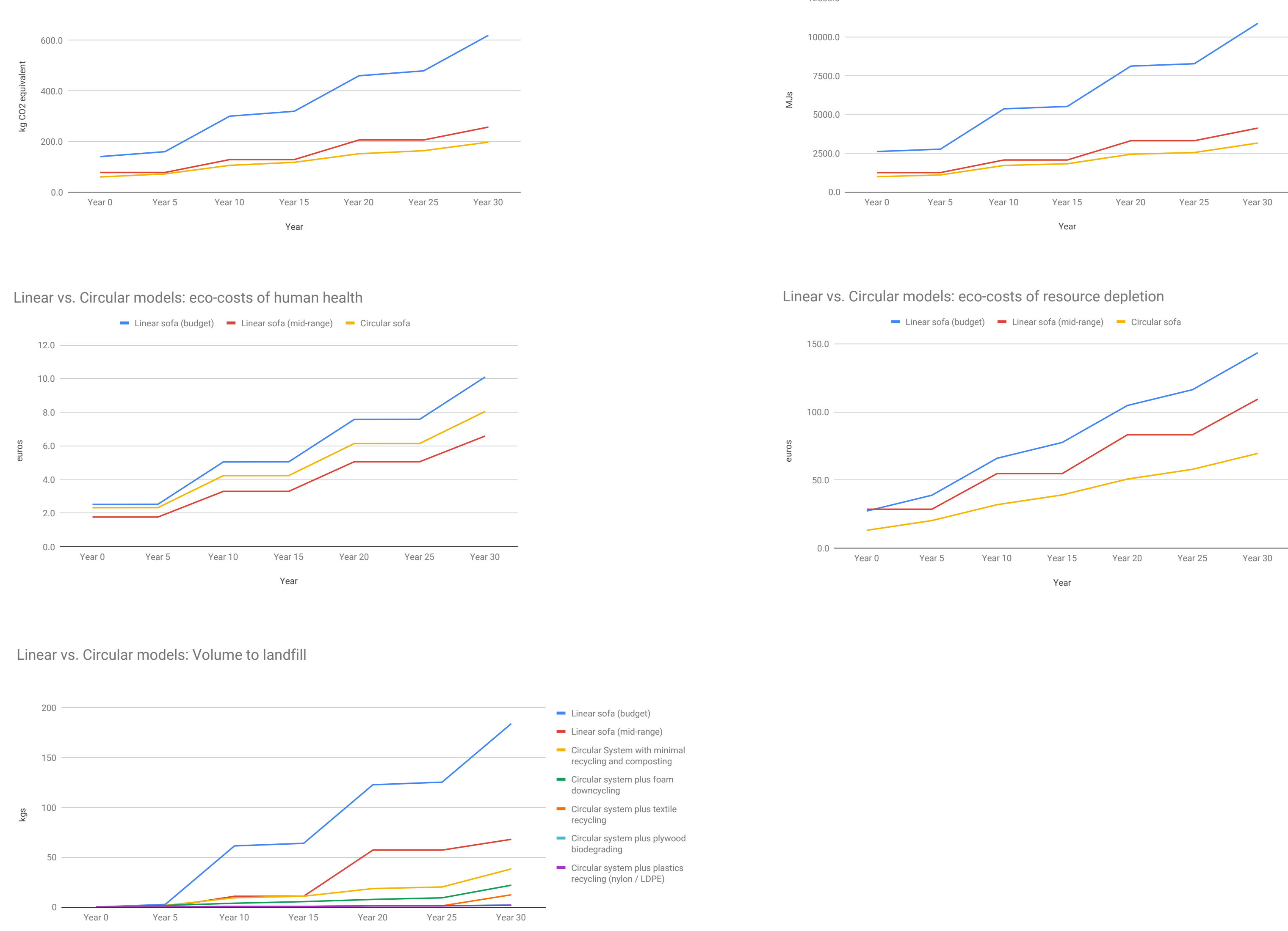
Appendix A.6 Transport impacts

\begin{tabular}{|c|c|}
\hline secenario & 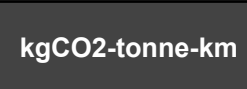 \\
\hline 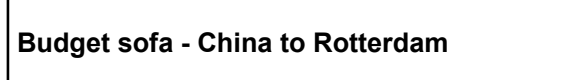 & 32.69 \\
\hline Budget sofa - China to NZ & 17.85 \\
\hline Modranges sola - China a R Roterdam & 20.30 \\
\hline 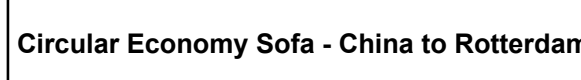 & 12:10 \\
\hline Midr-ange sofa- China to NZ & 1.09 \\
\hline 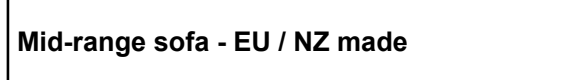 & 7.39 \\
\hline 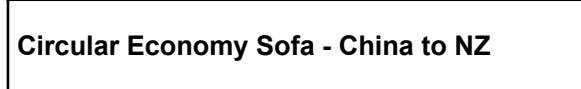 & 6.61 \\
\hline Circular Economy Sota - EU / NZ made & ${ }_{441}$ \\
\hline
\end{tabular}

Transport Co2

Hinne 

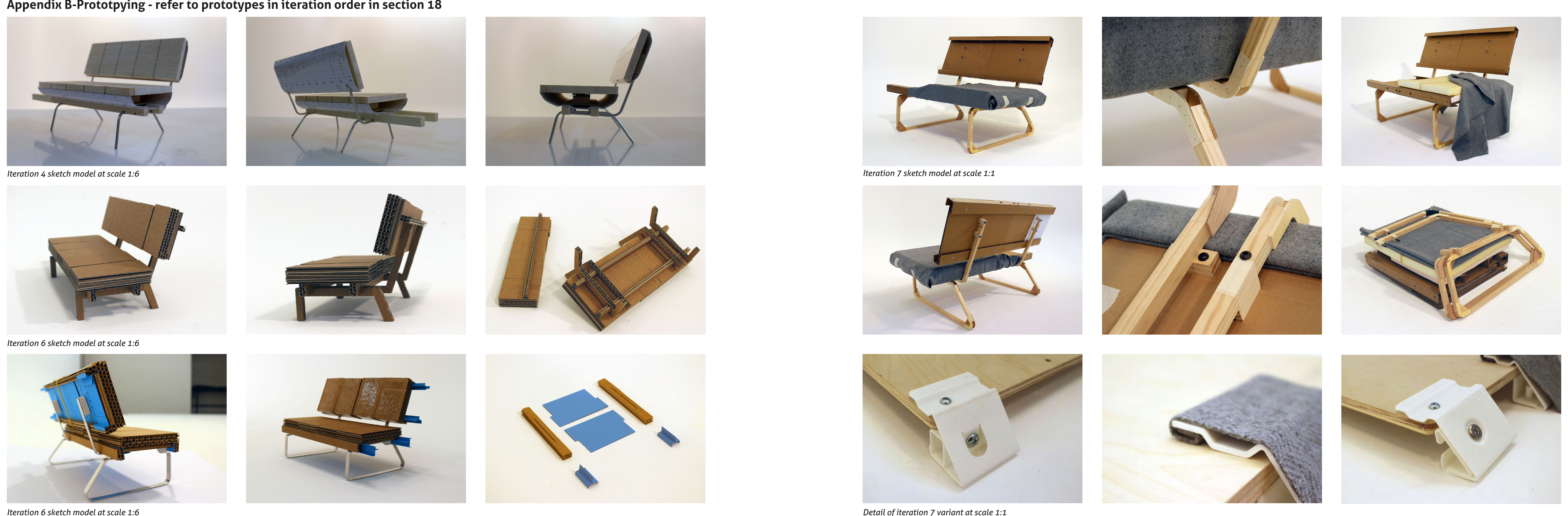

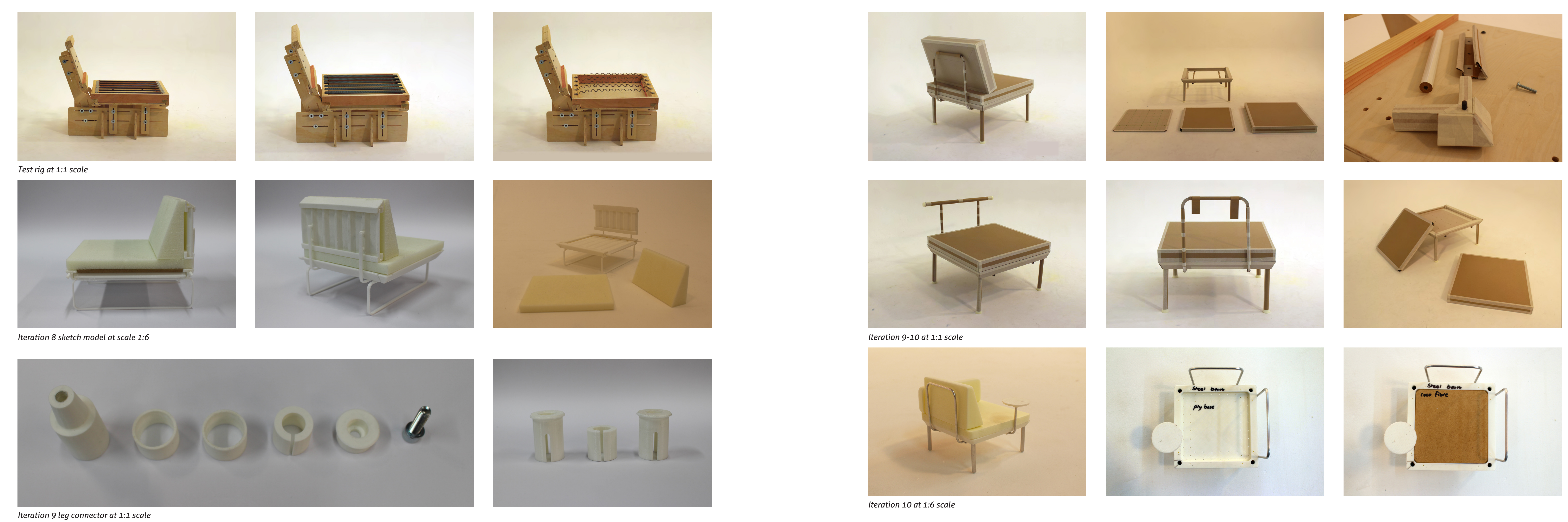

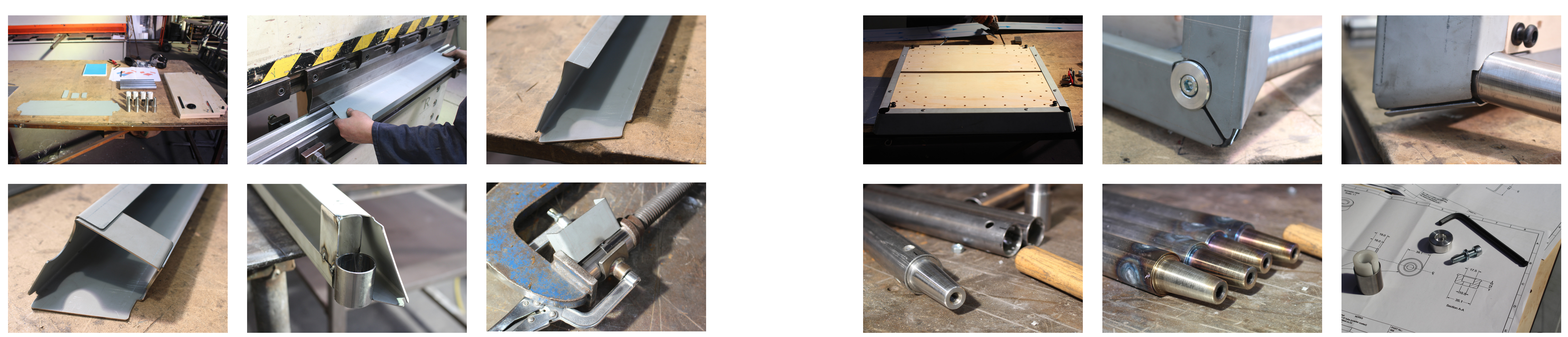


\section{References}

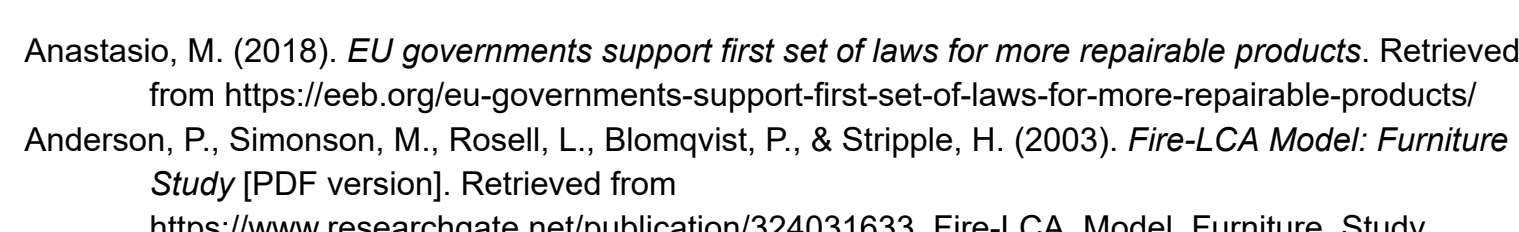

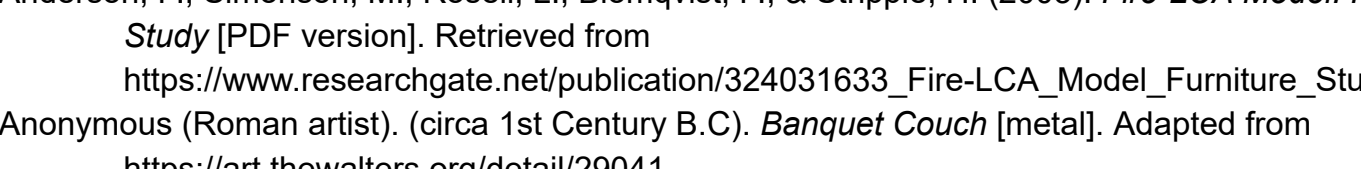

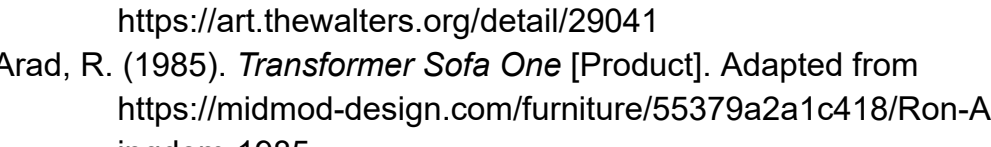

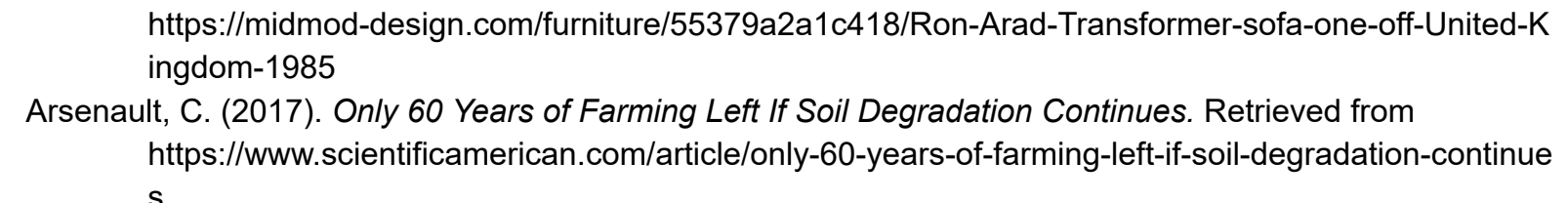

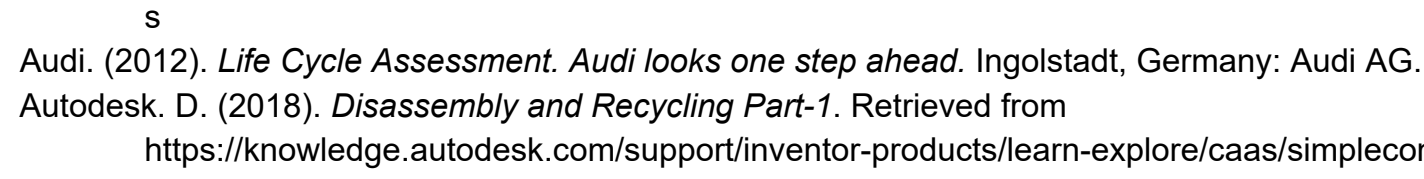

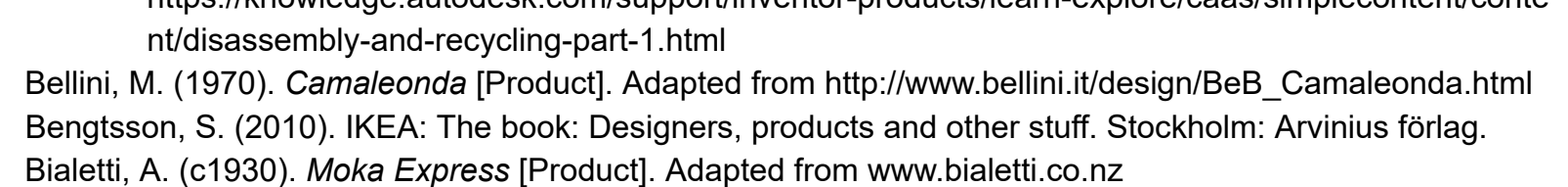

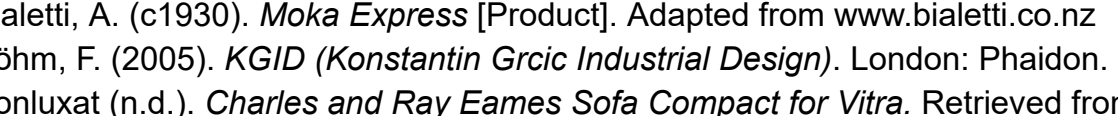

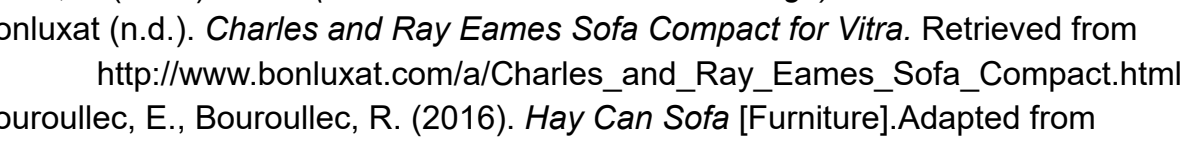

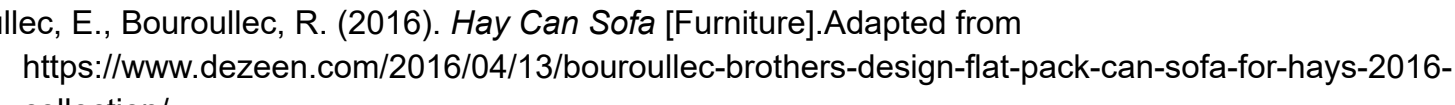

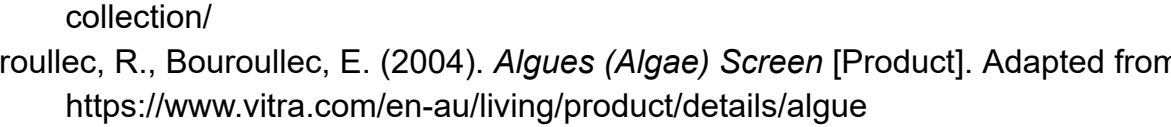

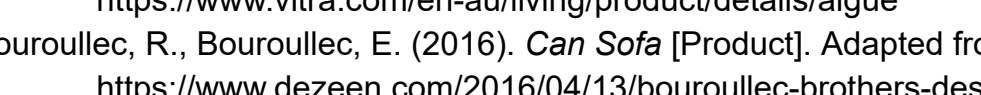

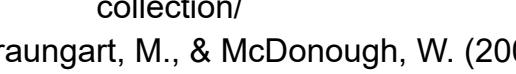
Vintage.

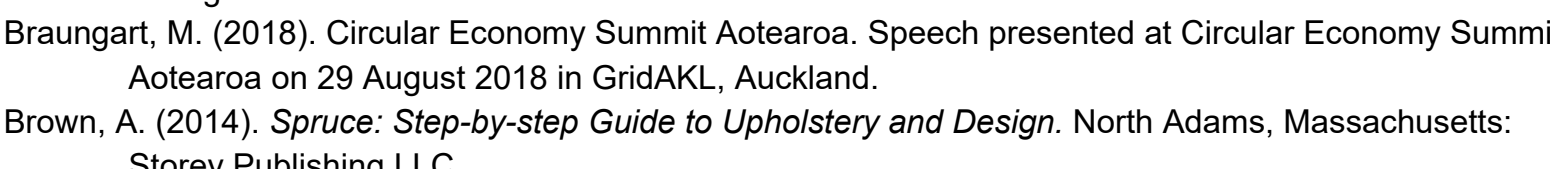

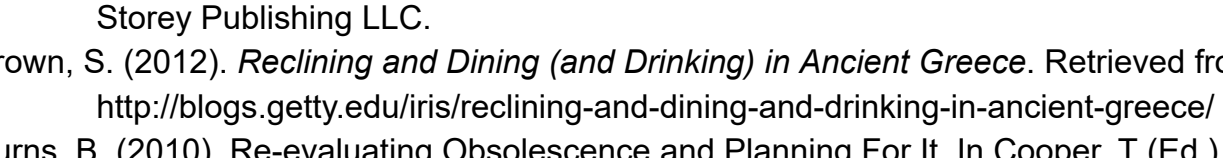

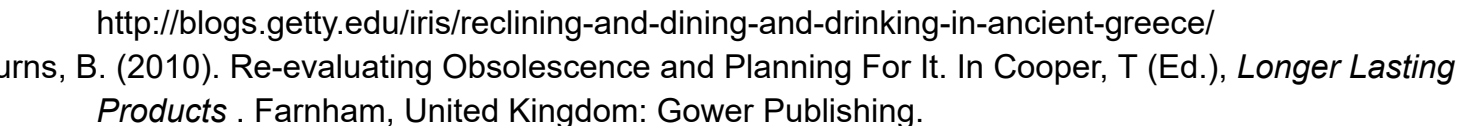

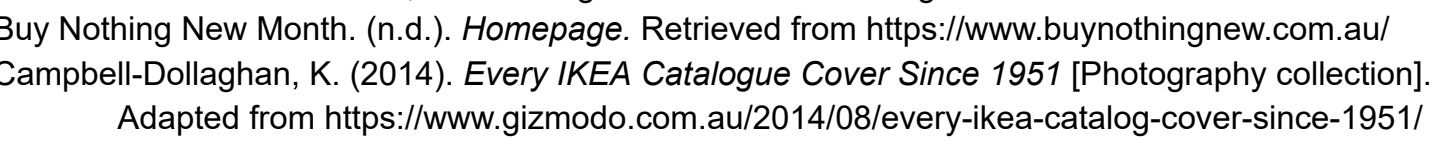

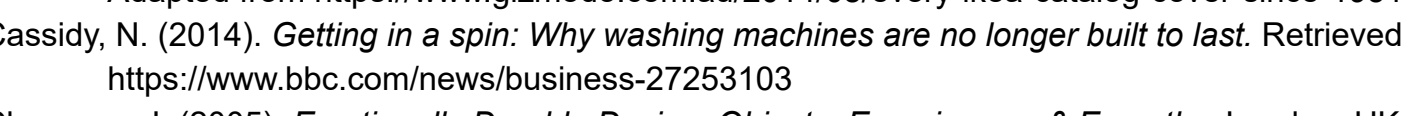

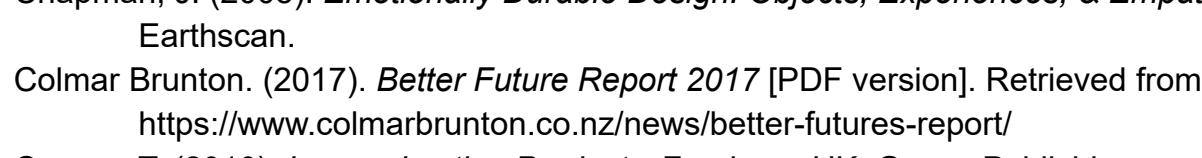

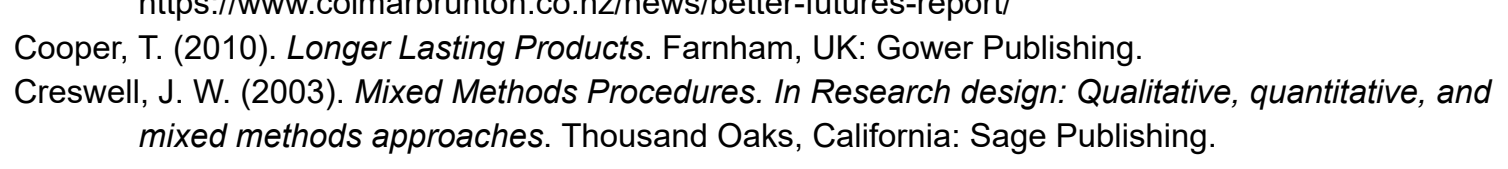

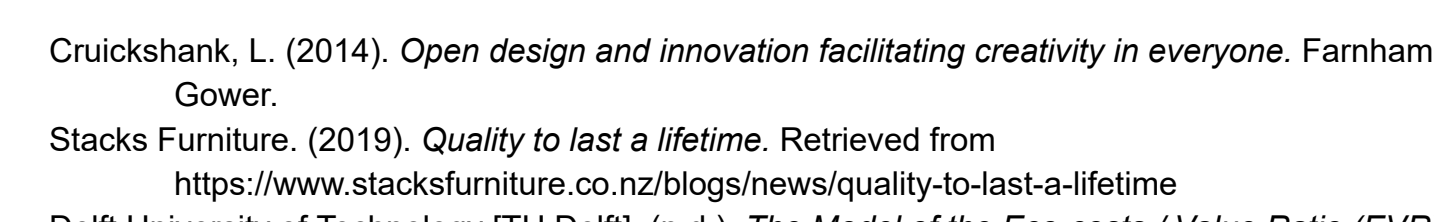

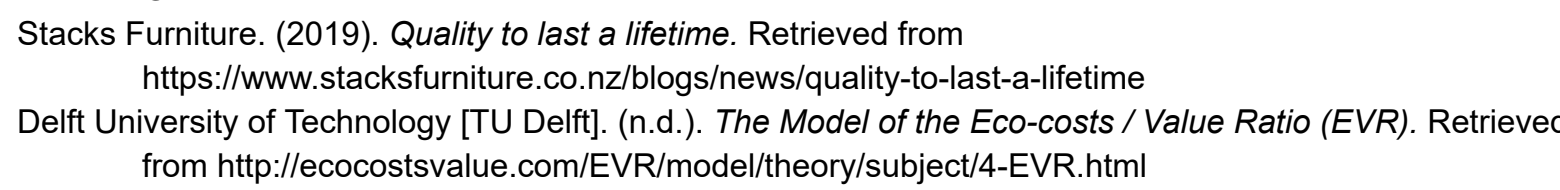

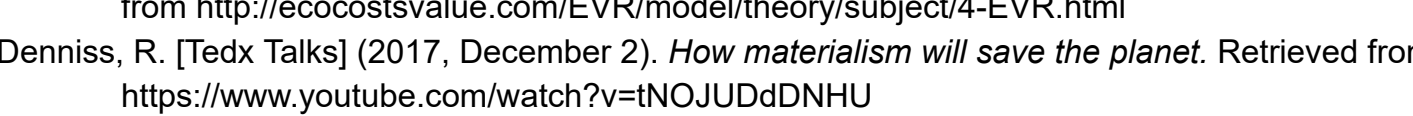

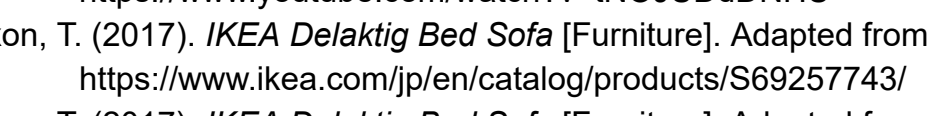

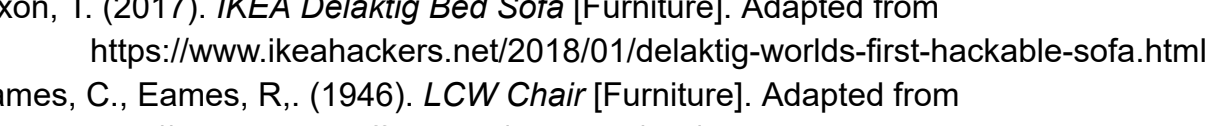

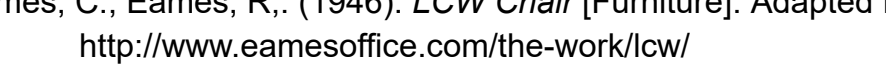

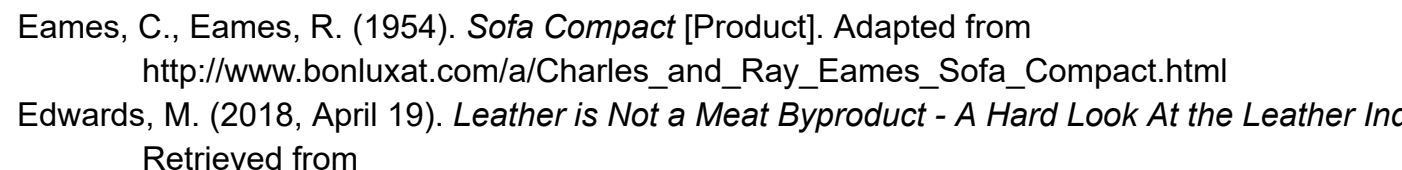

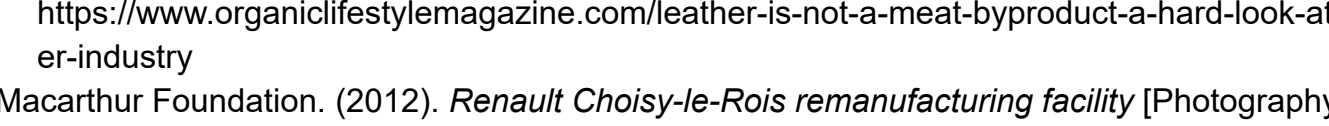
(1) dustry-2 2 -

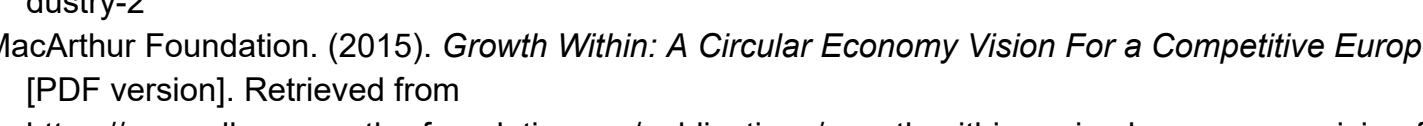

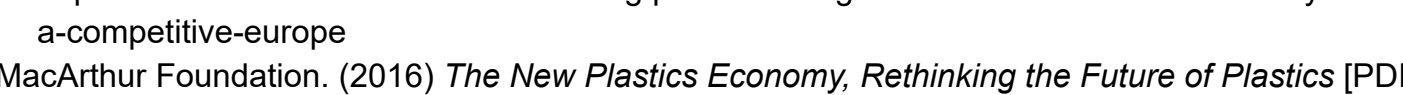
-

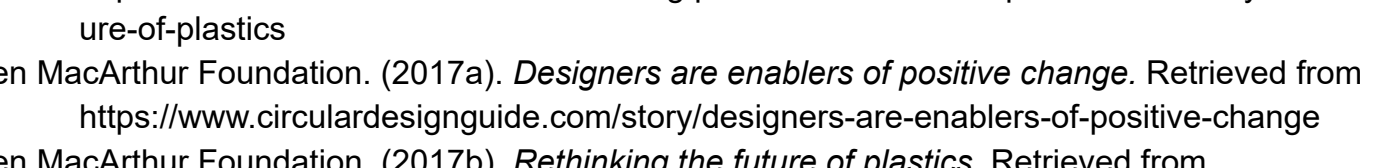

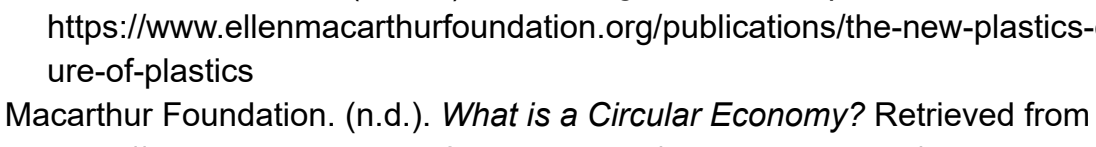

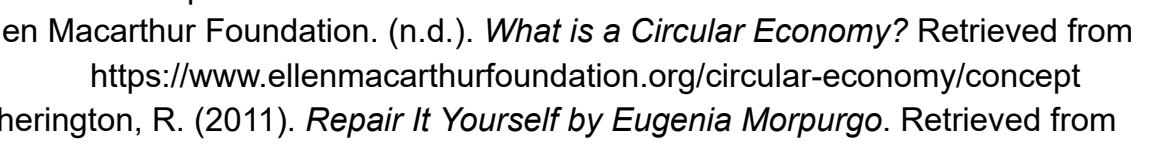

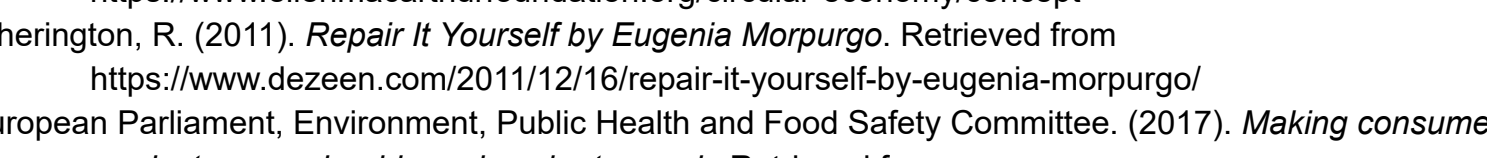

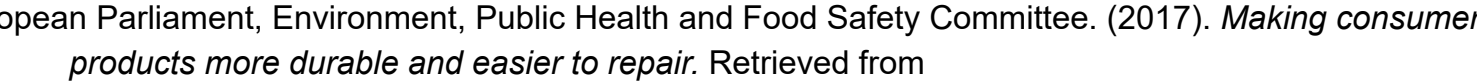

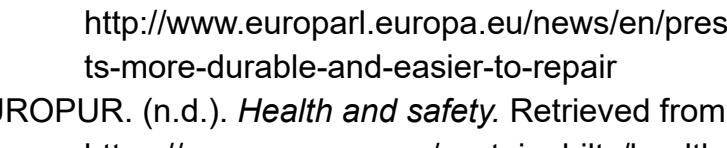

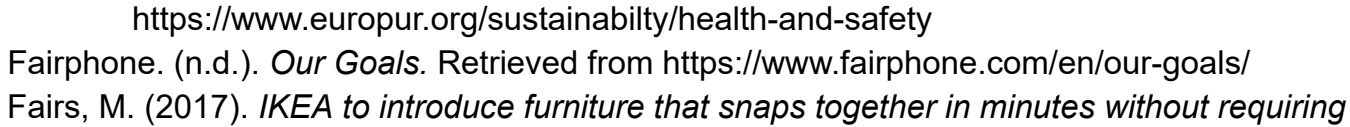
Rerrever trom

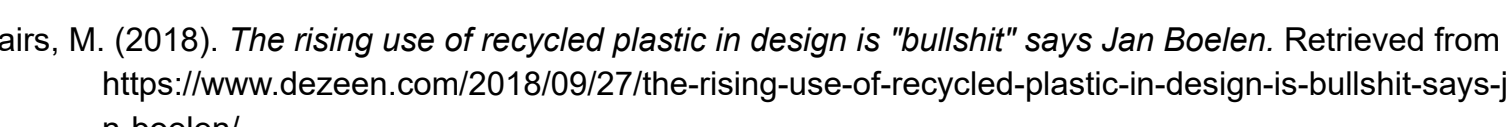

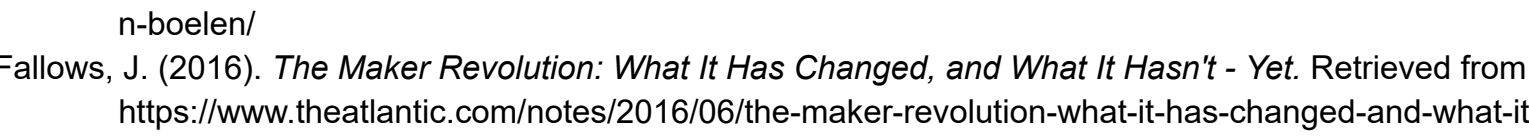

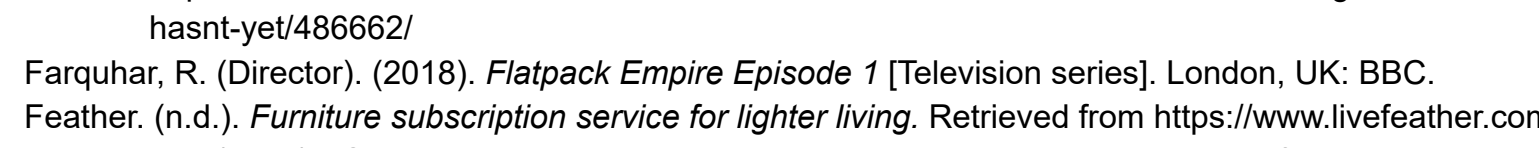

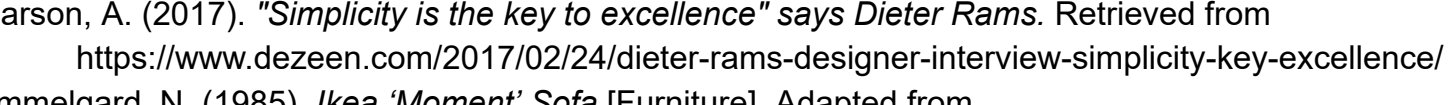

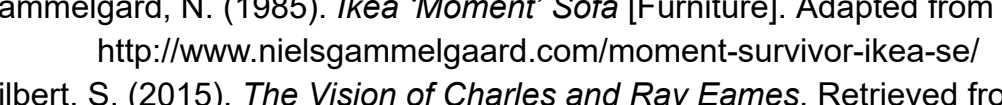

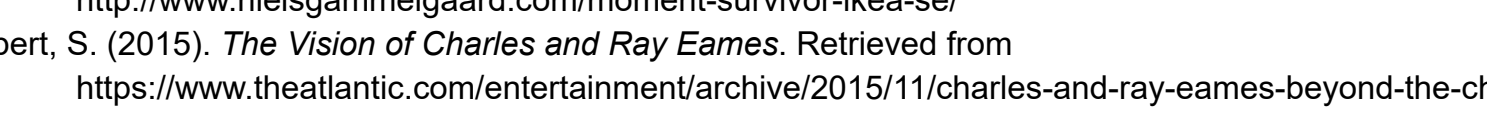

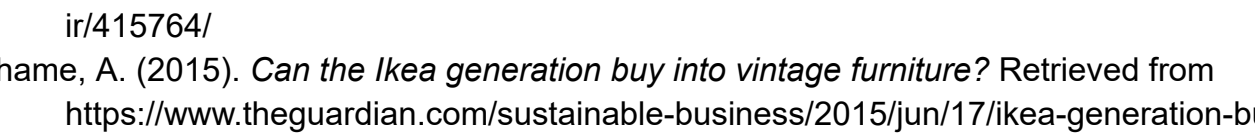

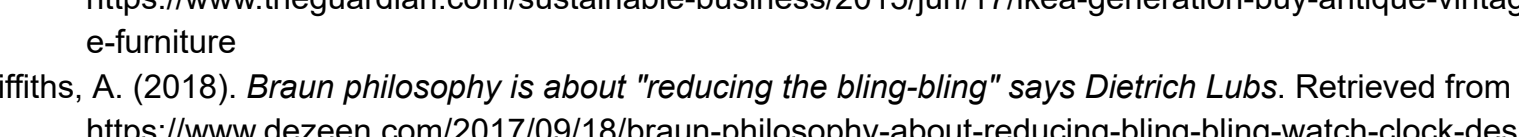

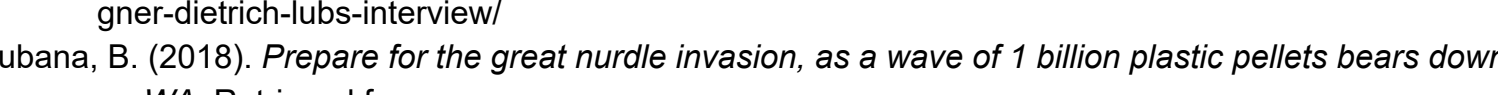

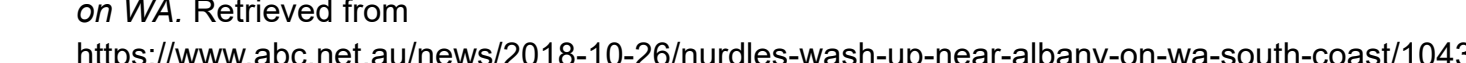

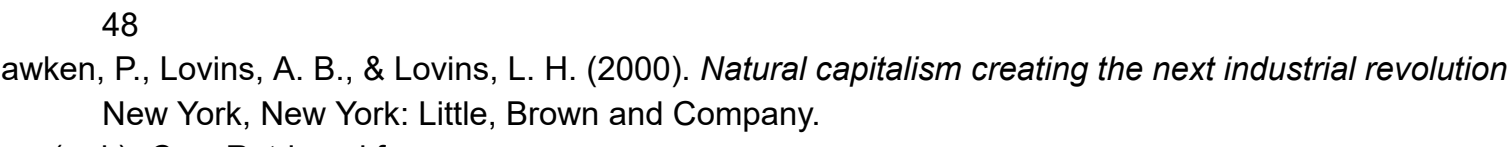

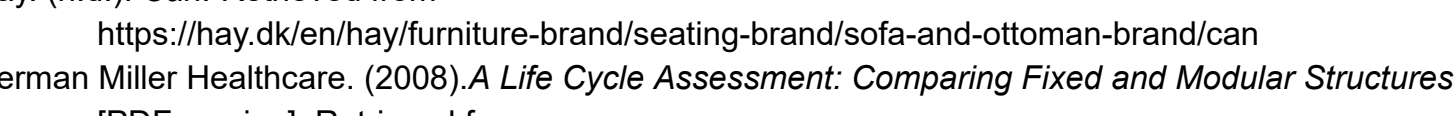

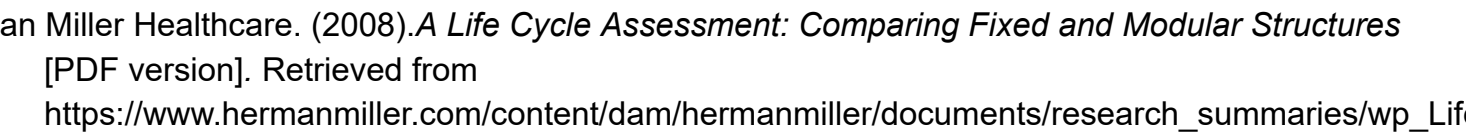

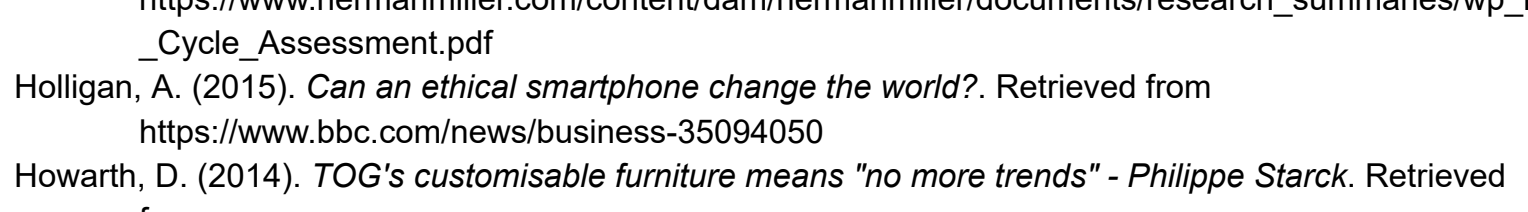

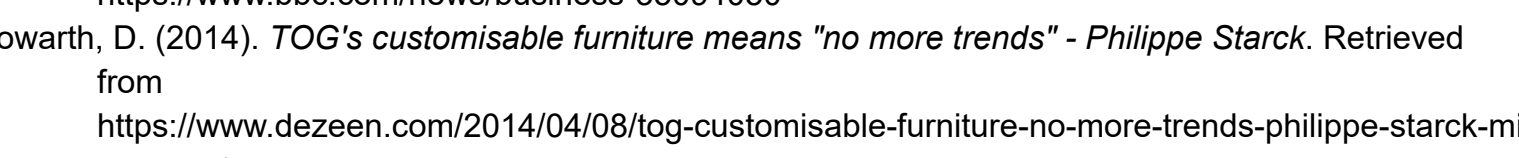

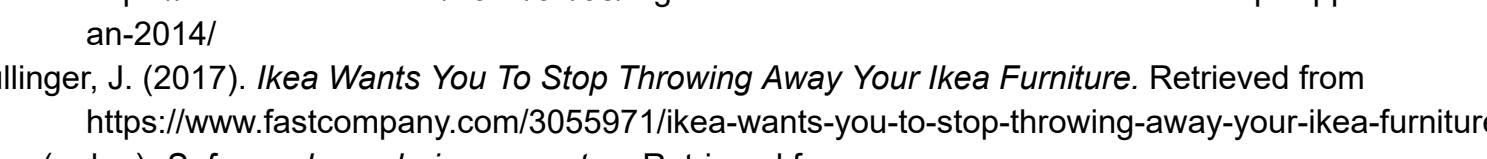

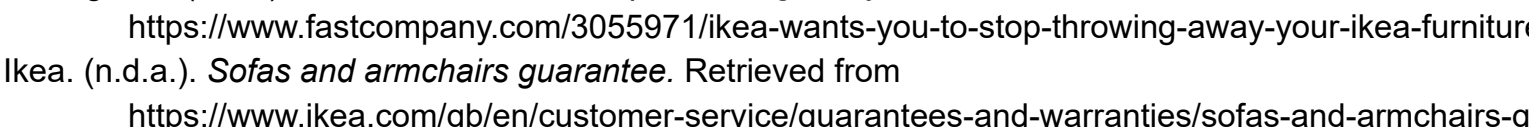

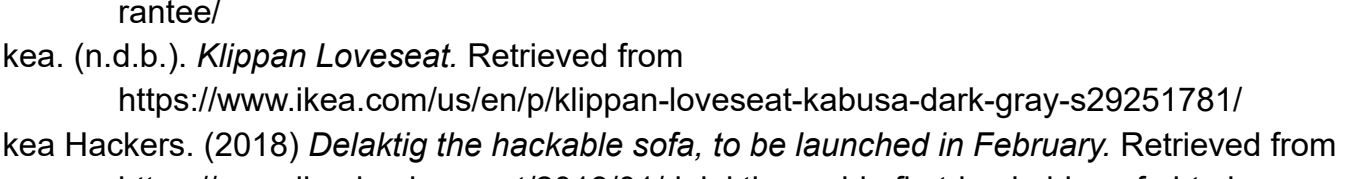

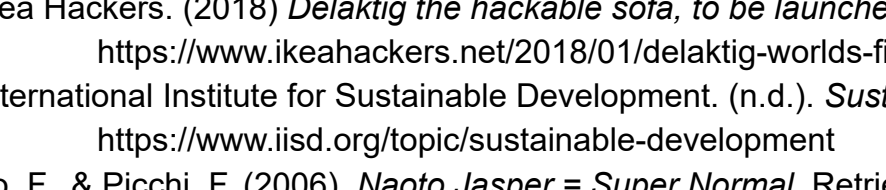

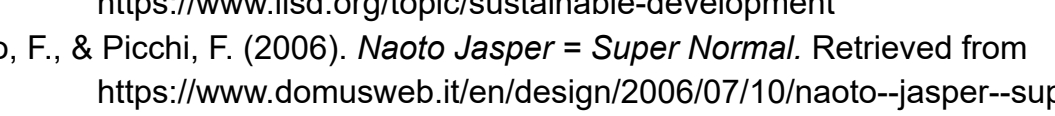

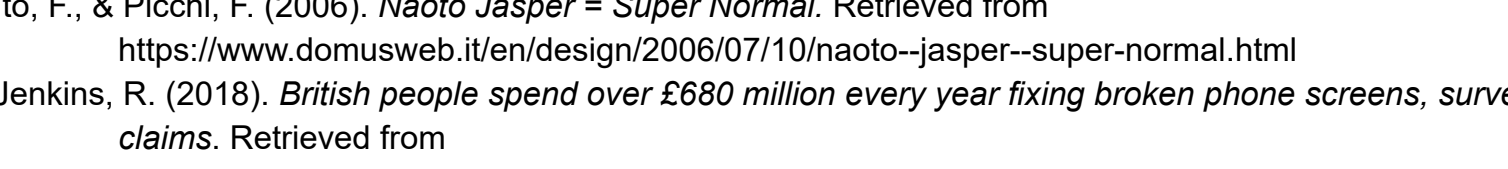

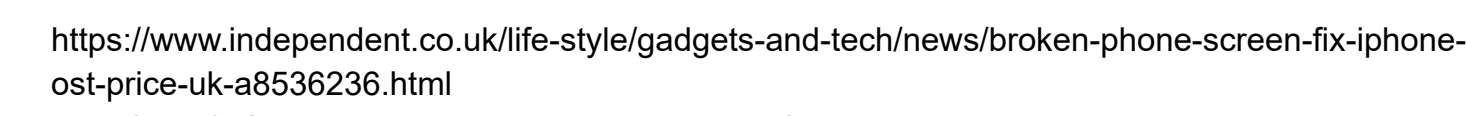
tit.

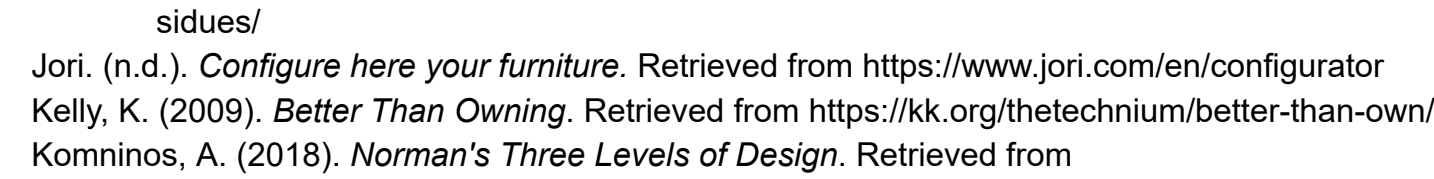

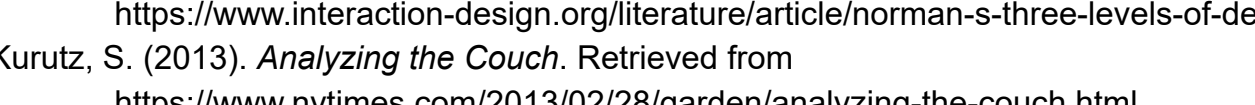

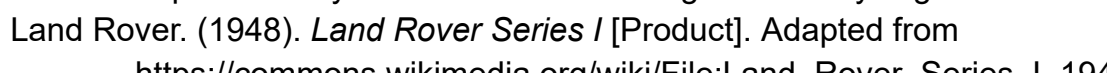

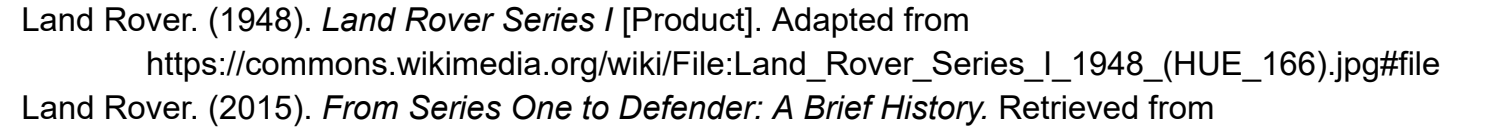

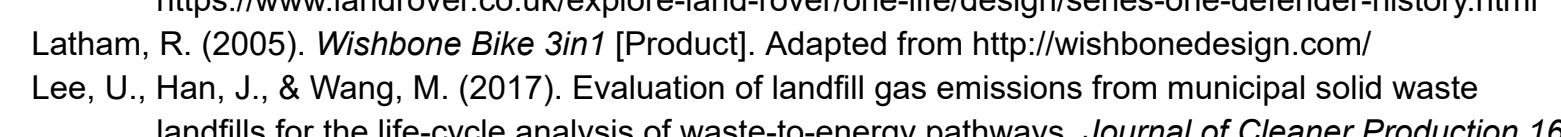

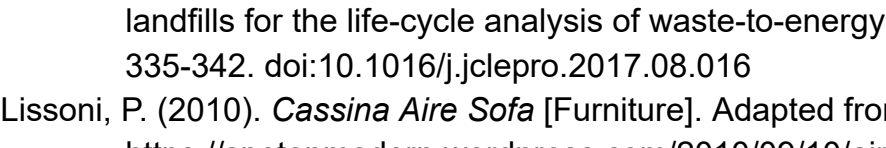

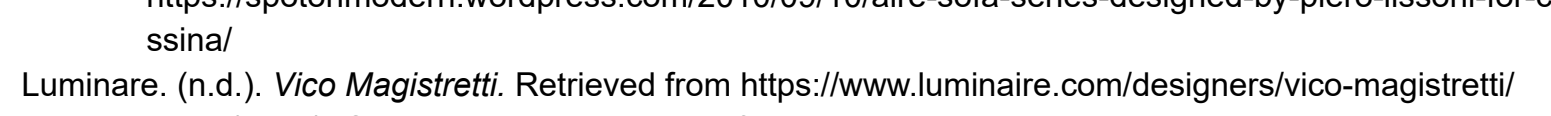
hithes

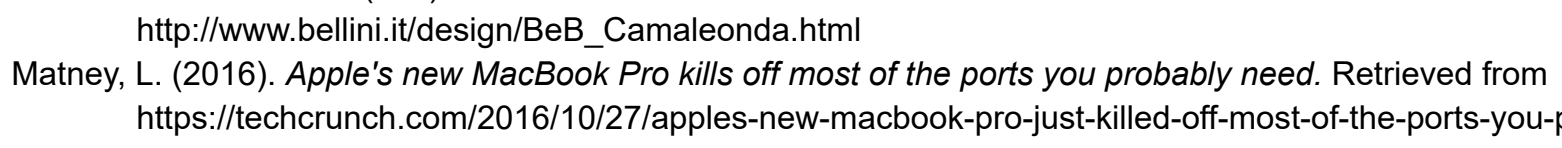

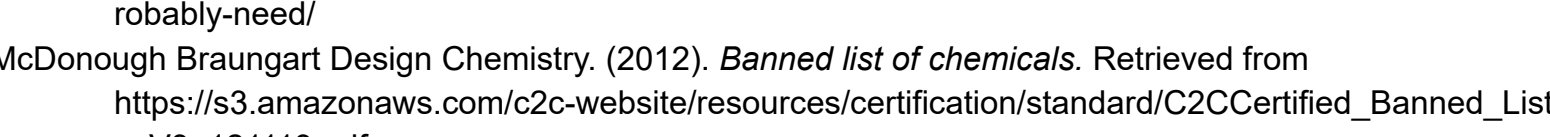

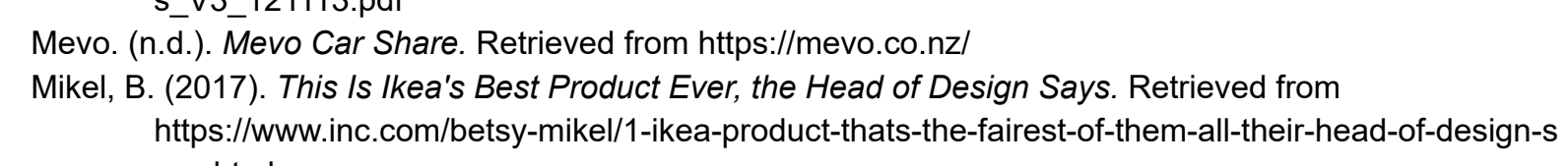

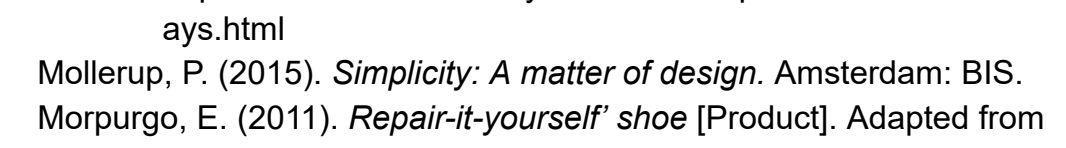

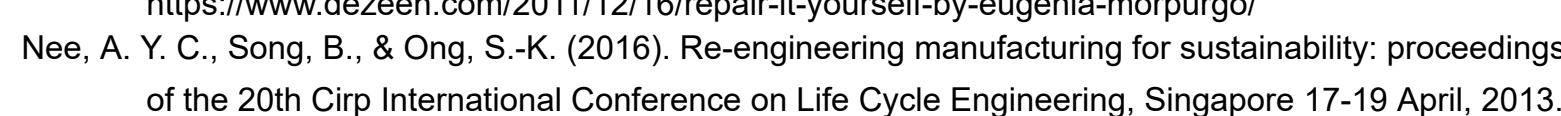

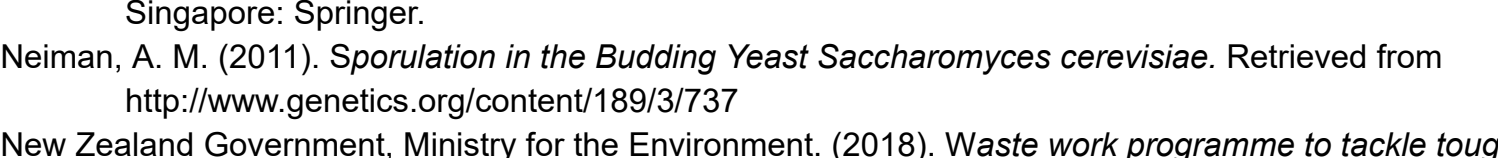

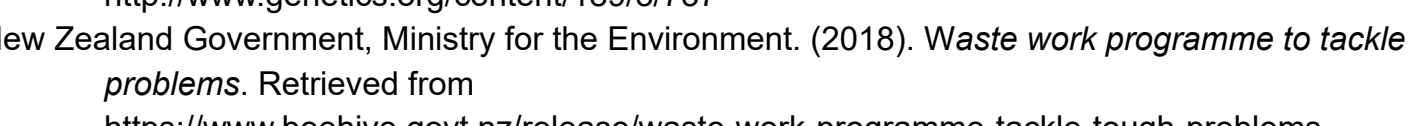

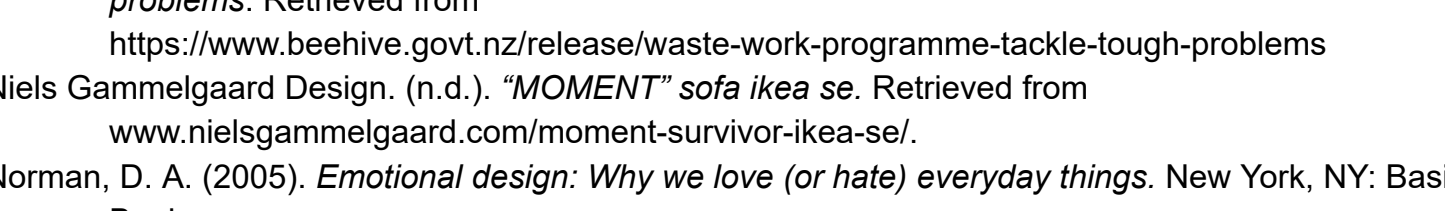

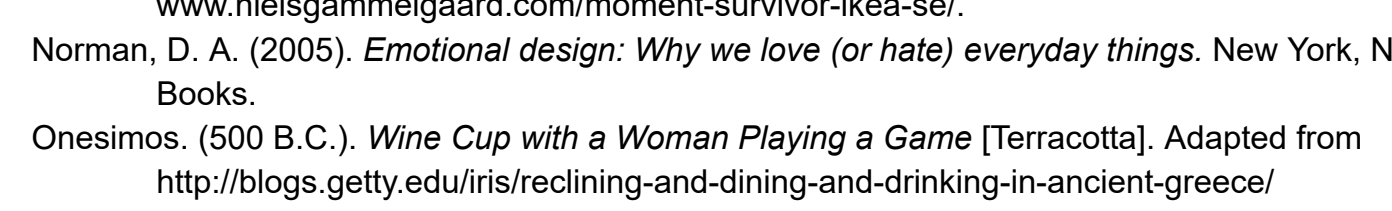




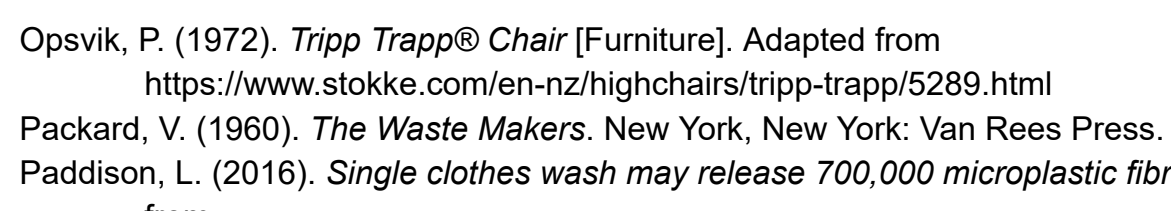
ton

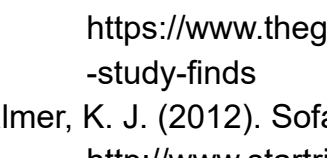

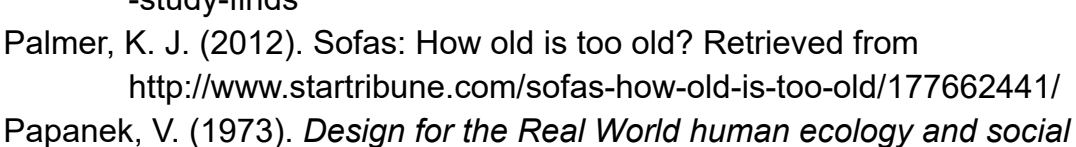

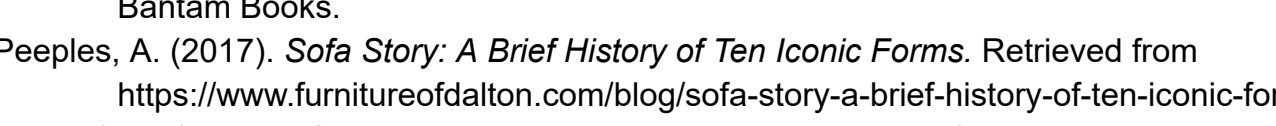

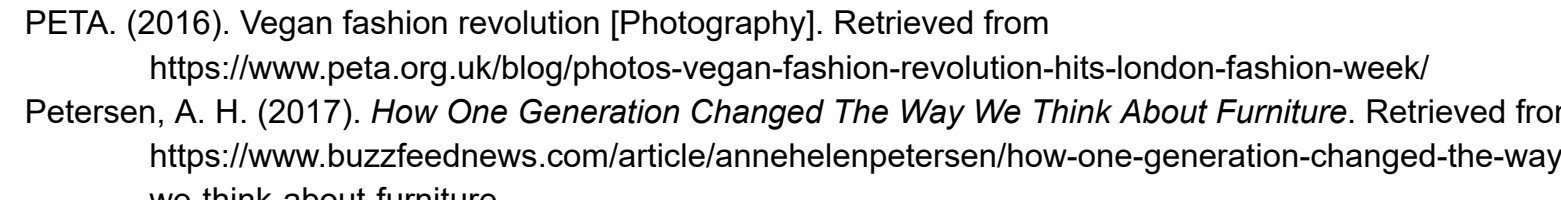

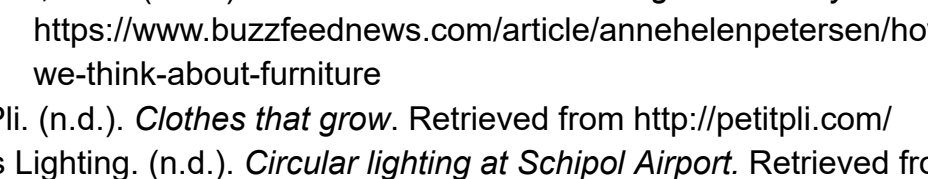

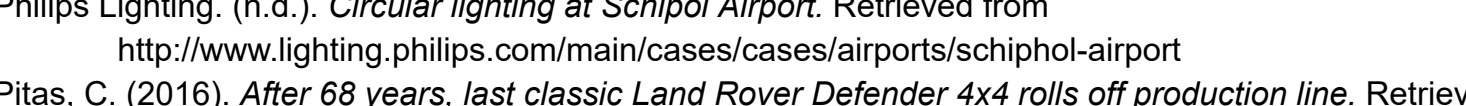

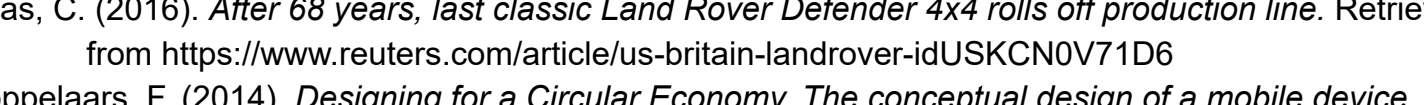

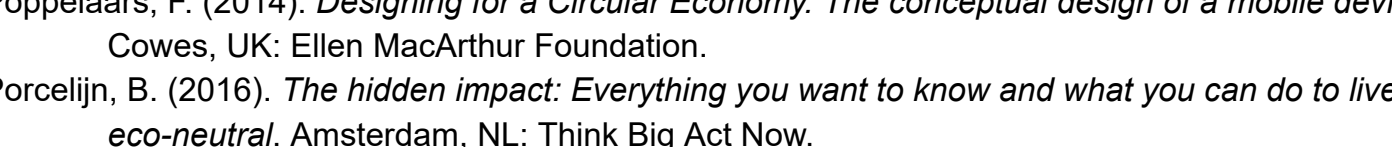

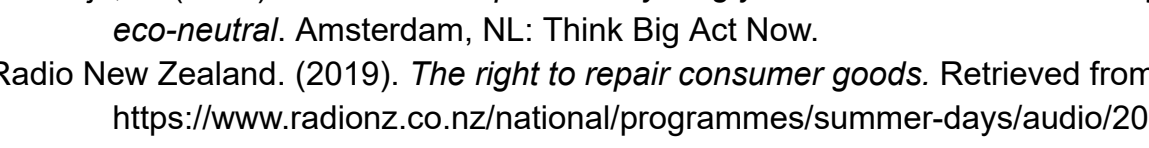

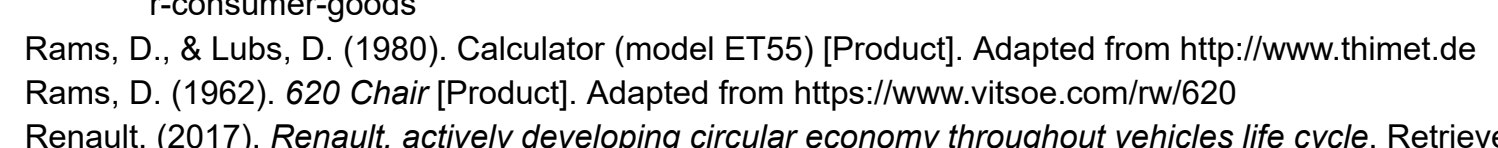

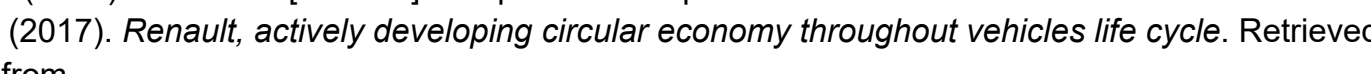

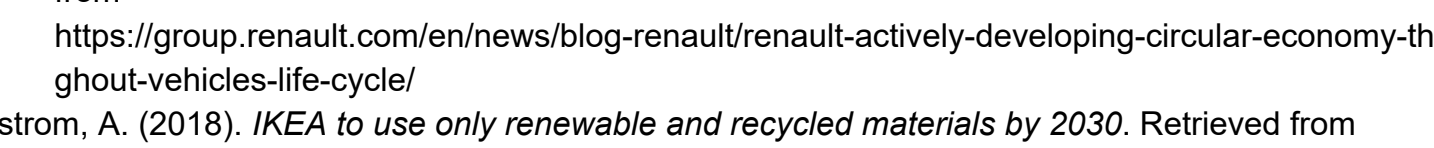

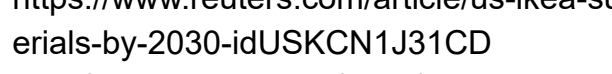

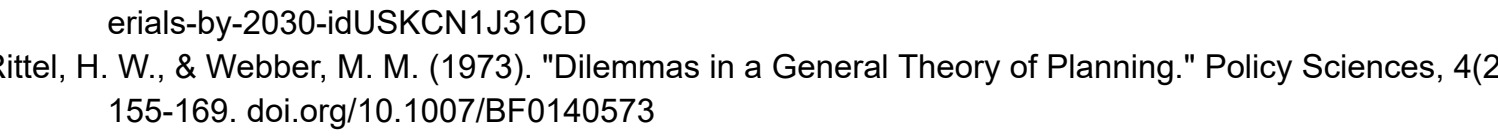

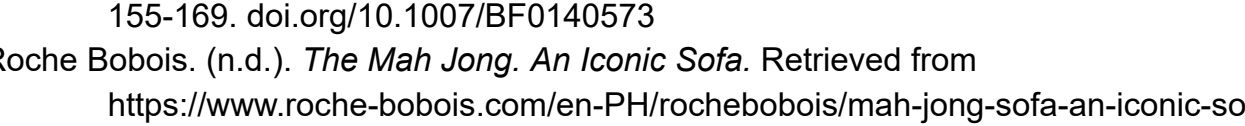

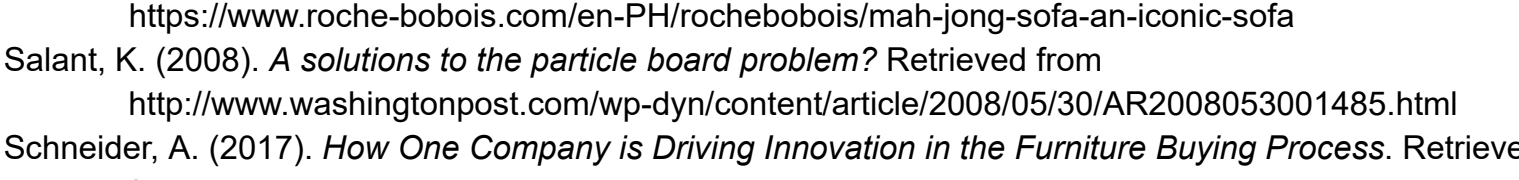

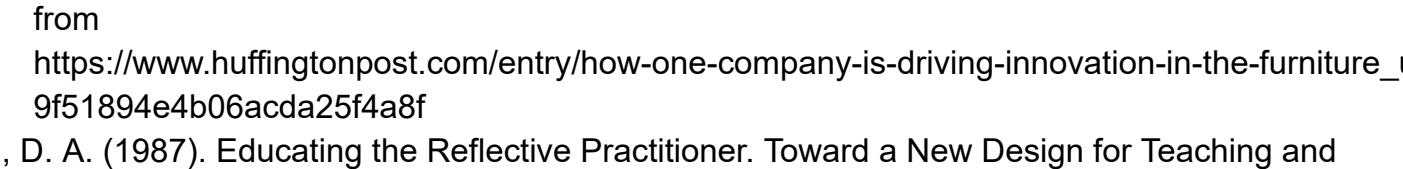

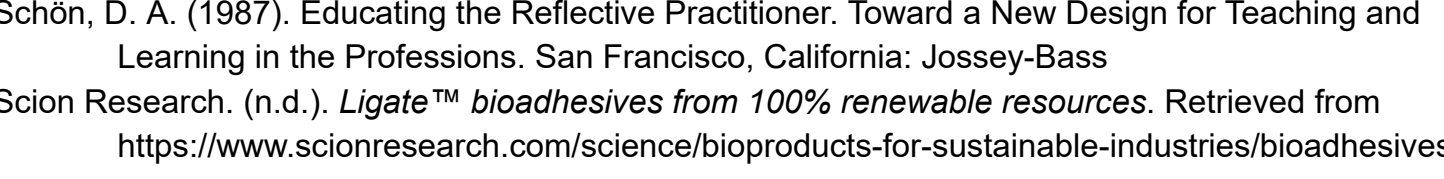

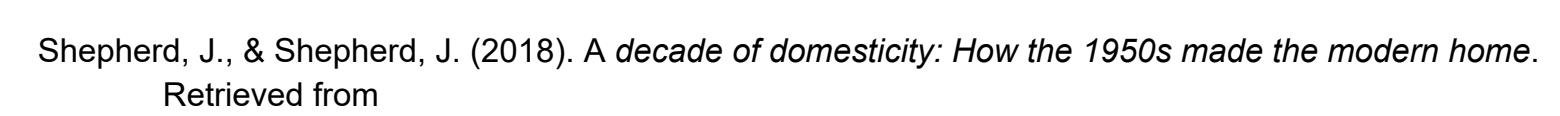

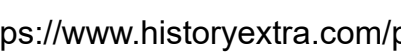

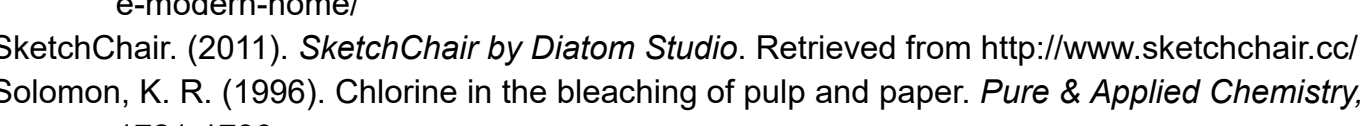

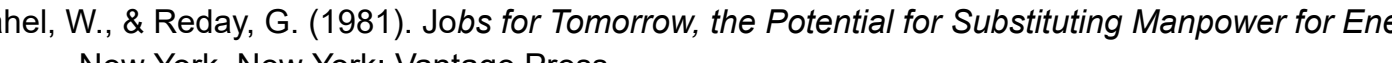

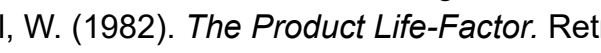

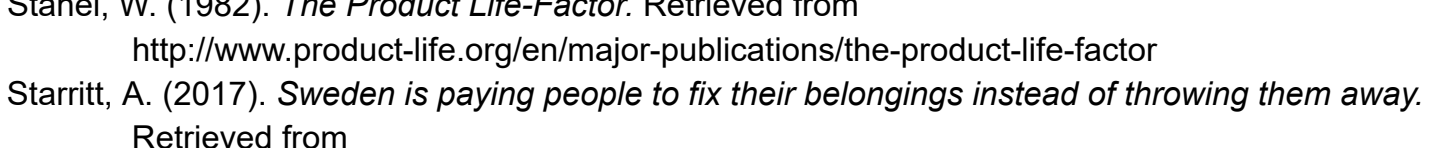

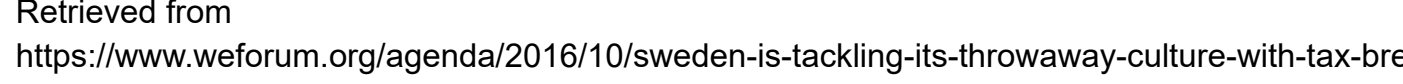

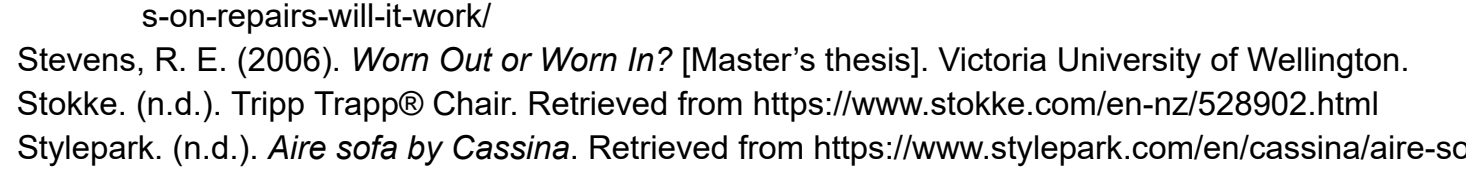

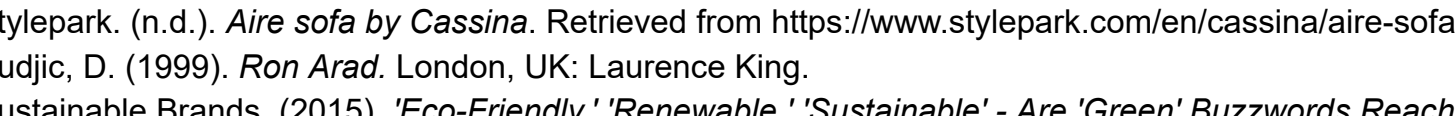

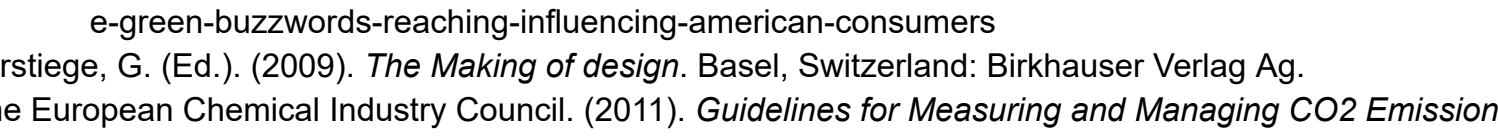

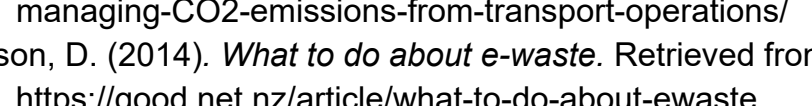

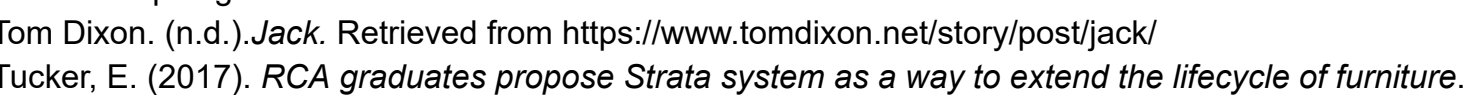
terevertiom

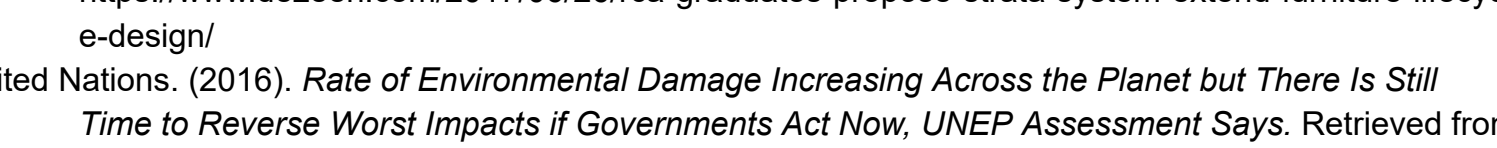

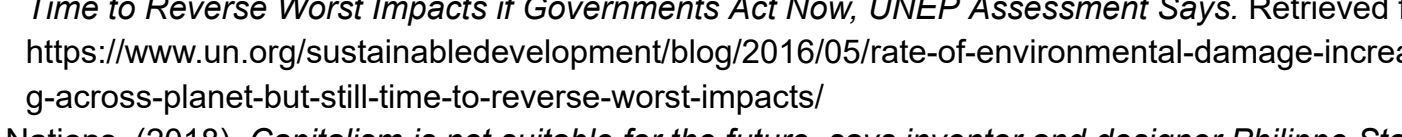

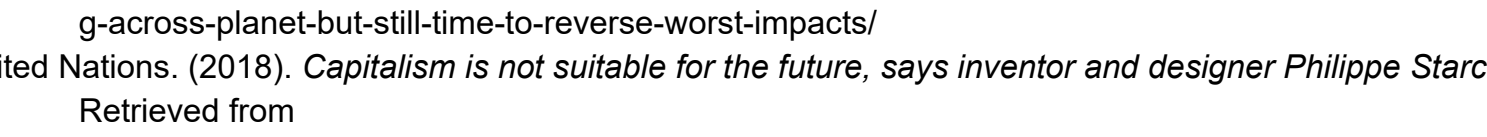

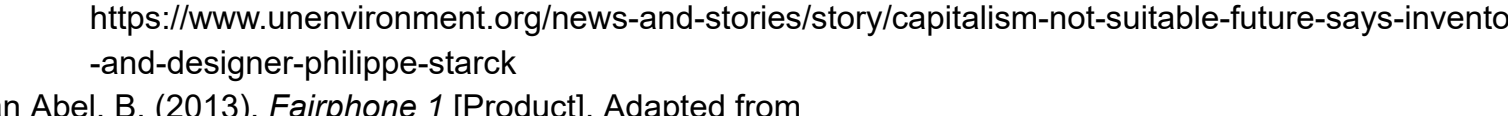

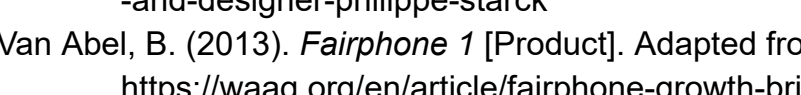

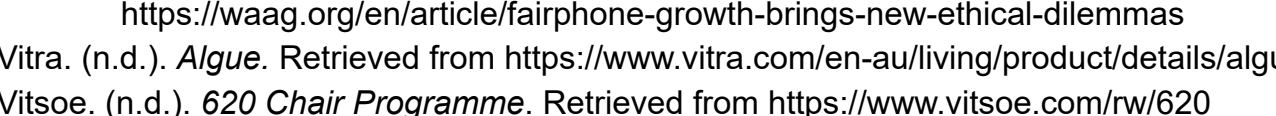

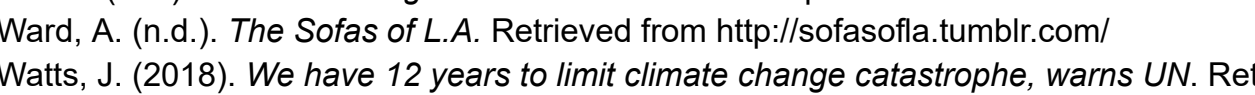

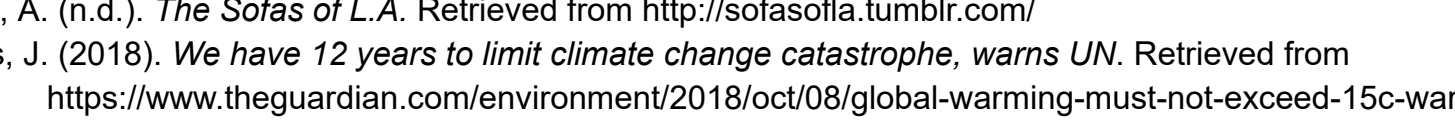

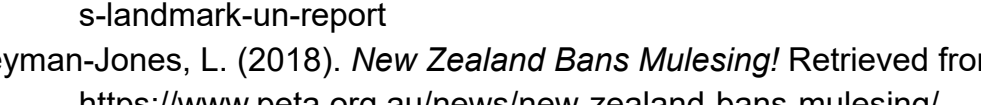

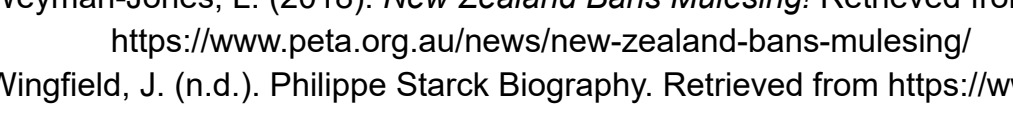

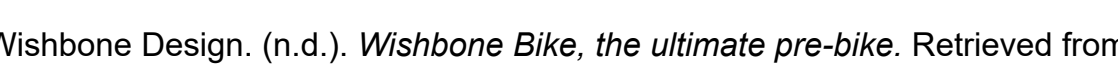

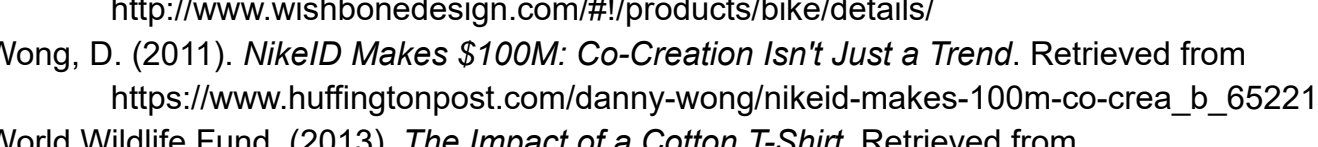

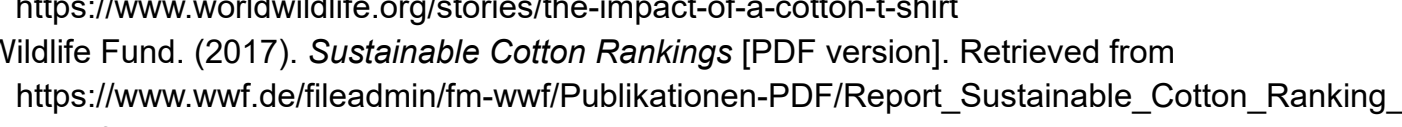

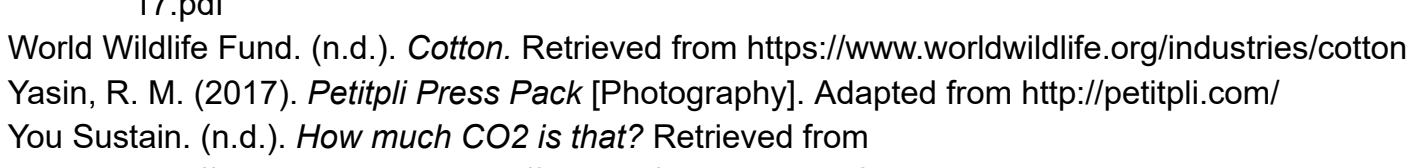

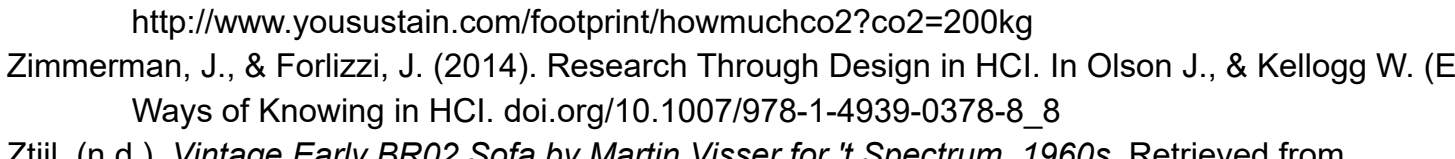

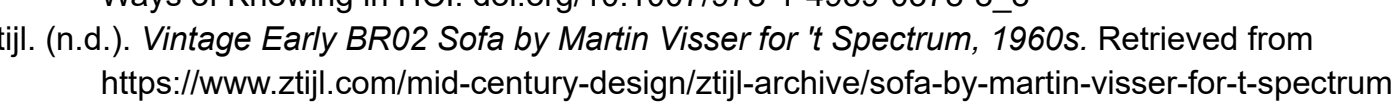




\section{Bibliography}

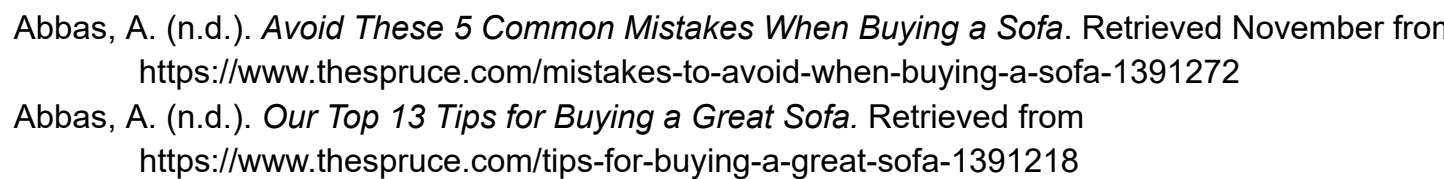

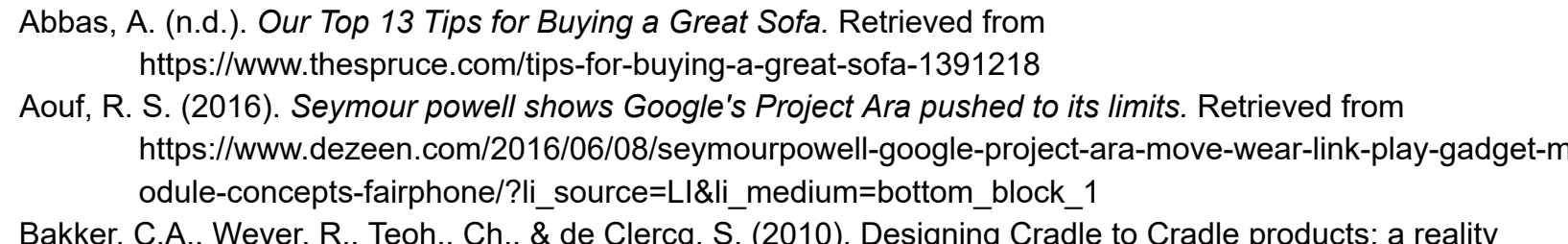

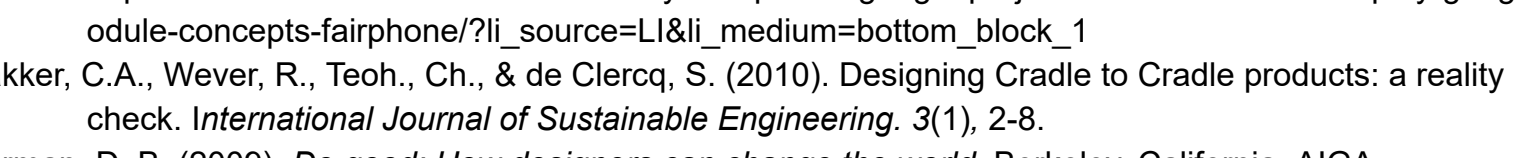

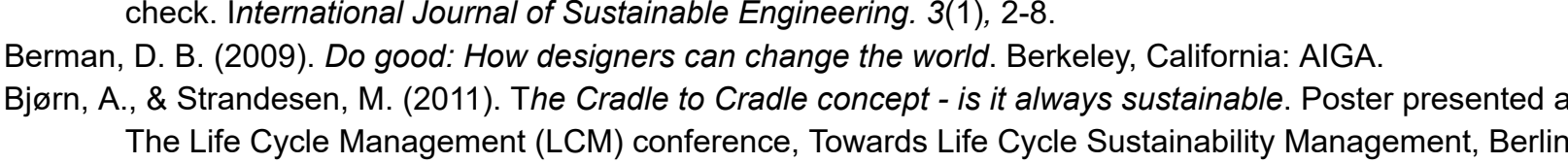

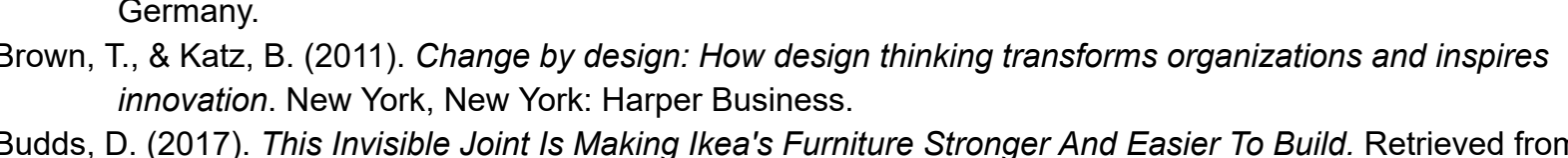

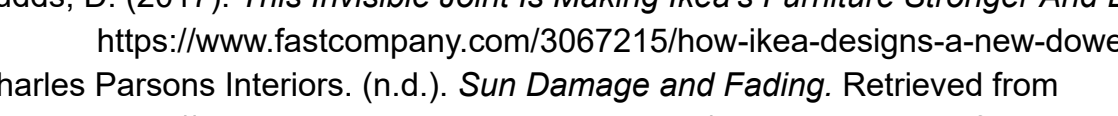

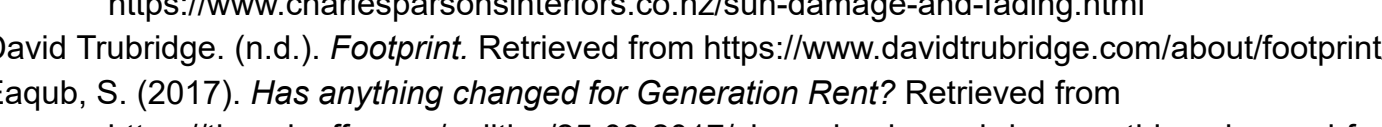

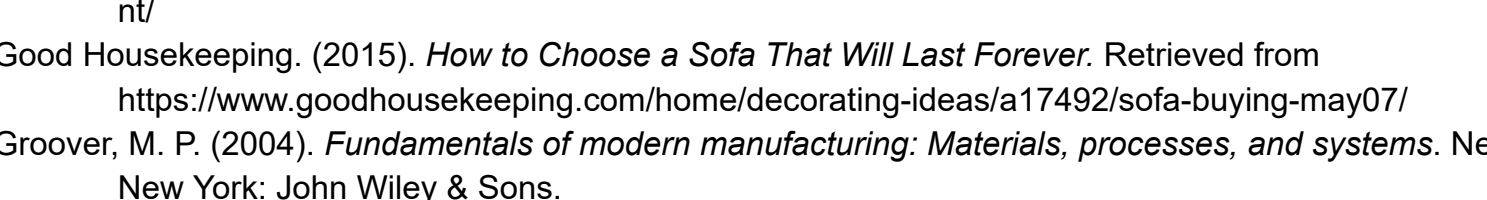

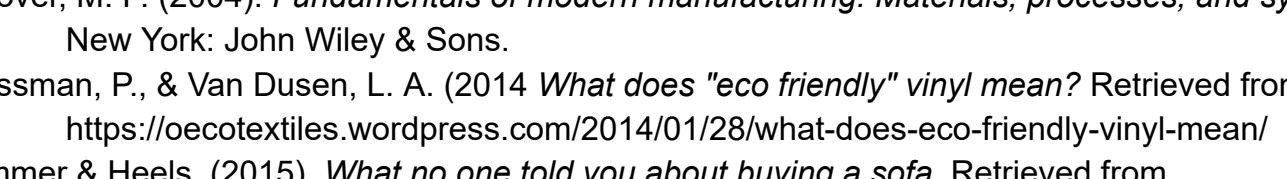

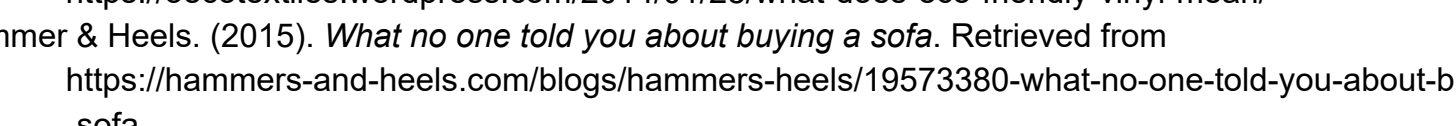

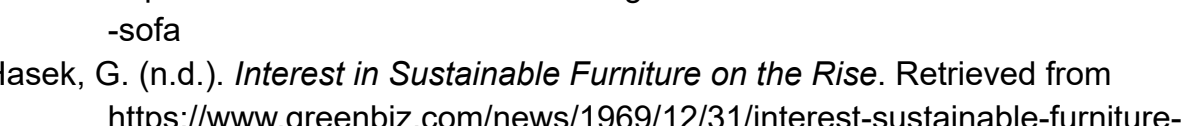

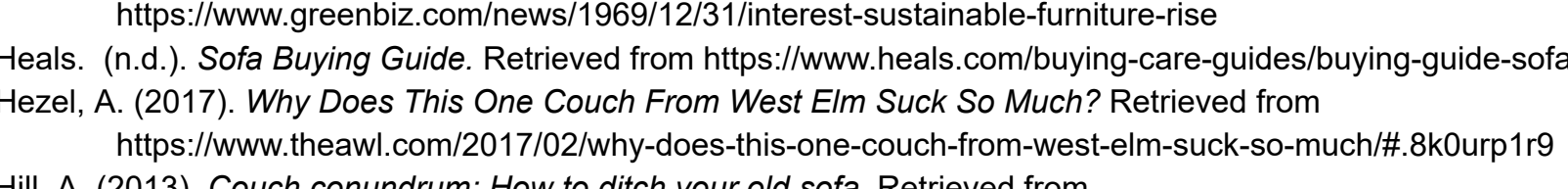

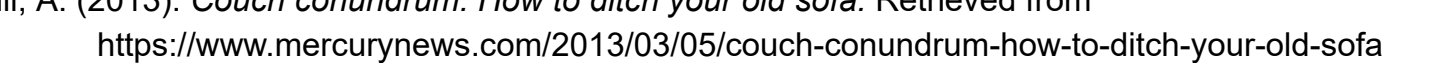

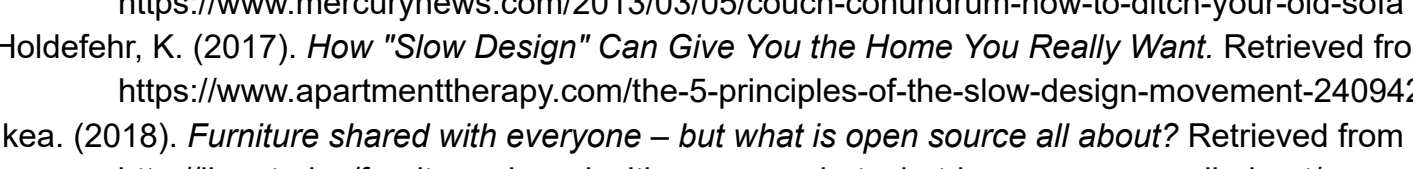

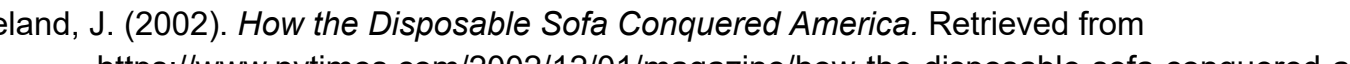

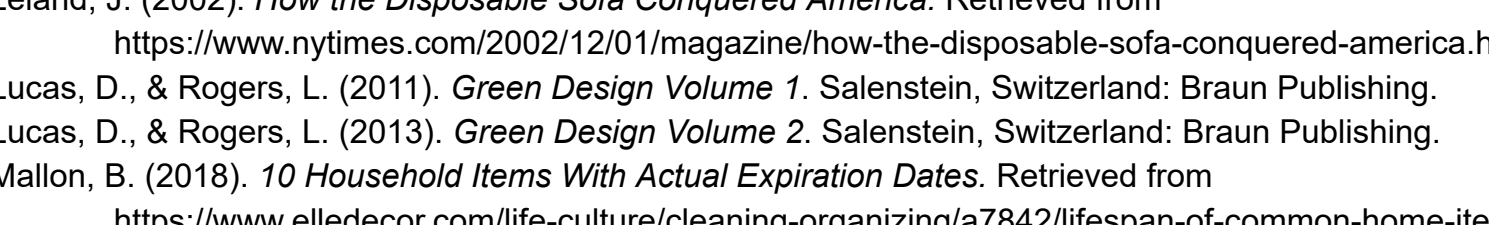

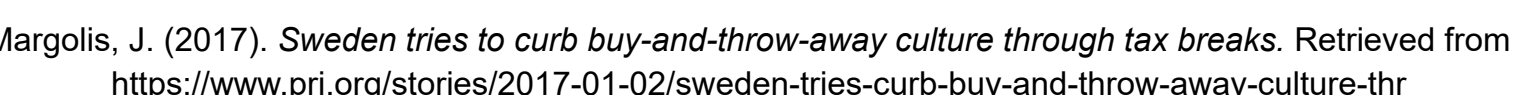

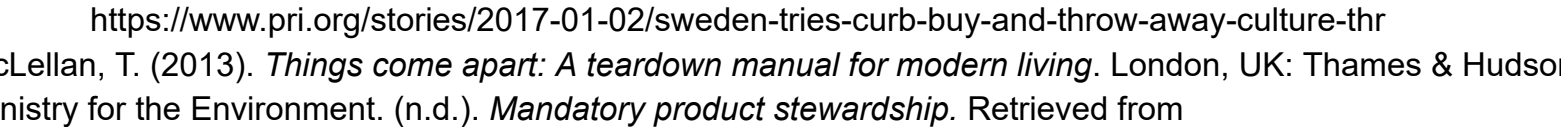

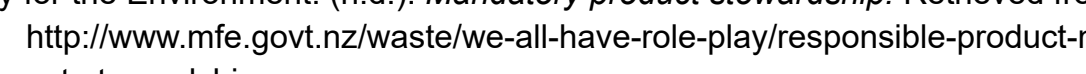

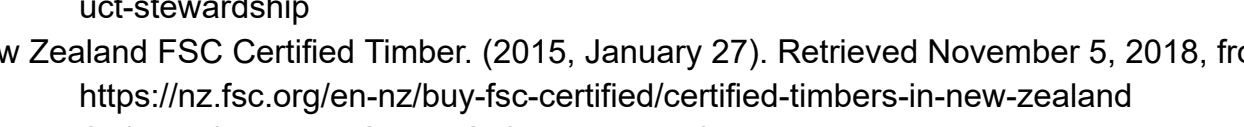

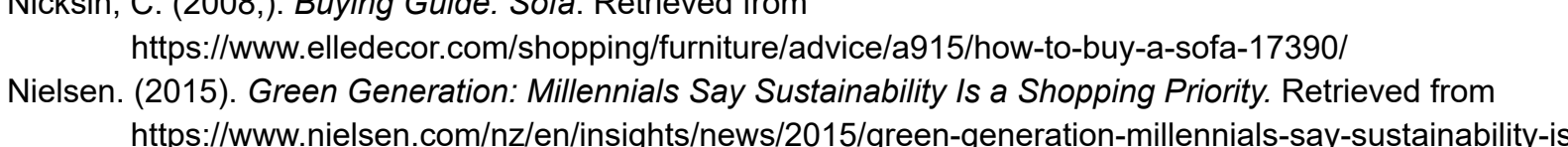

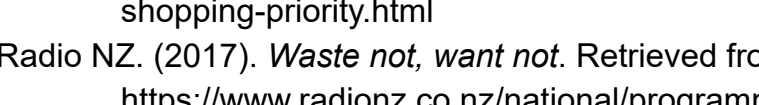

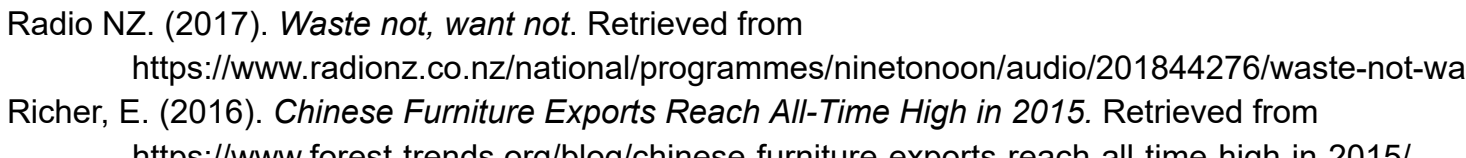

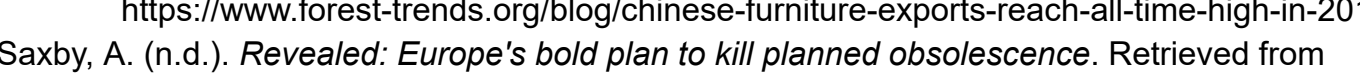

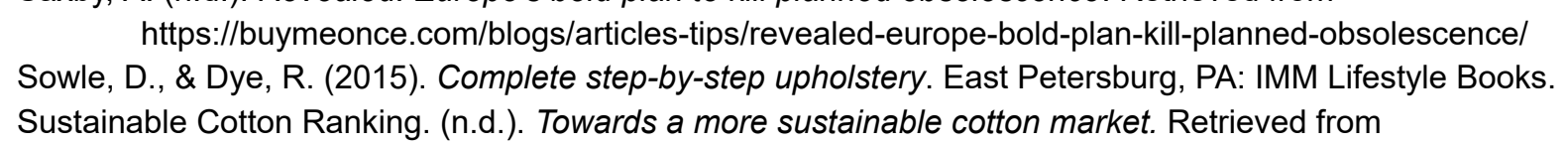

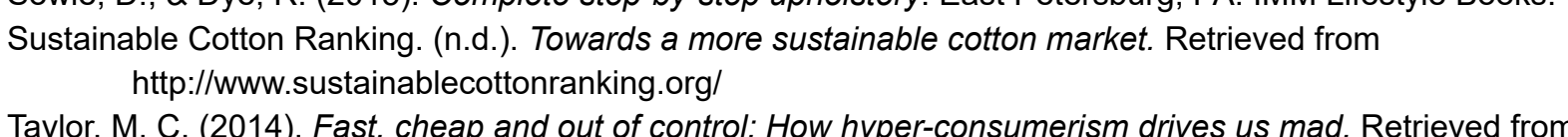

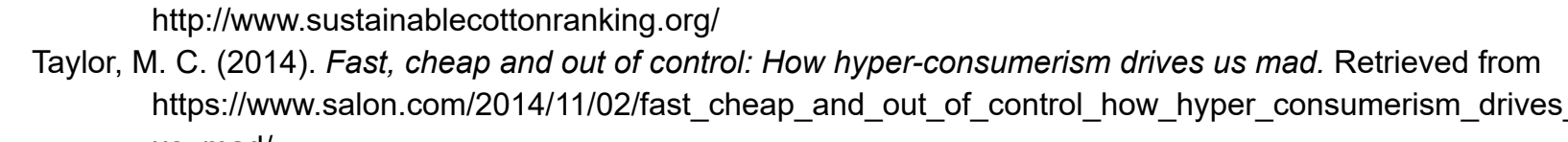

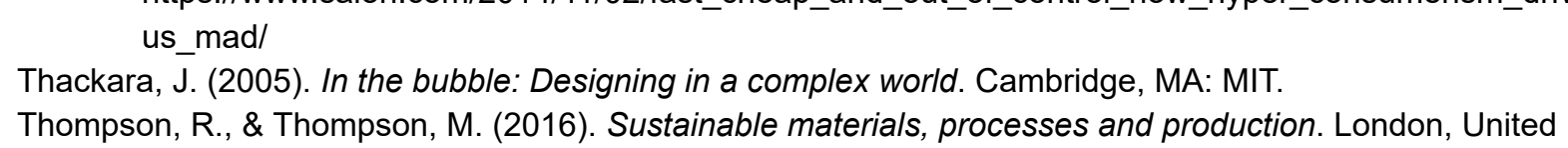

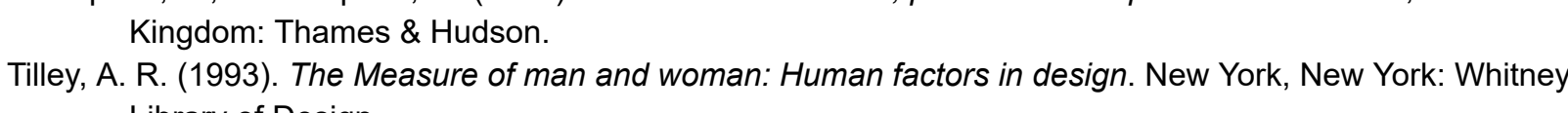

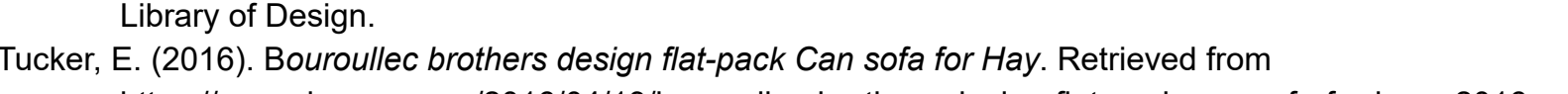

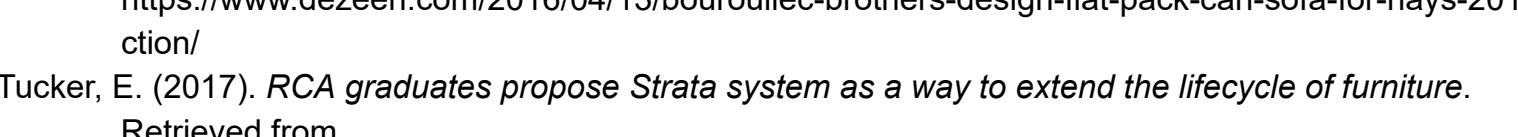

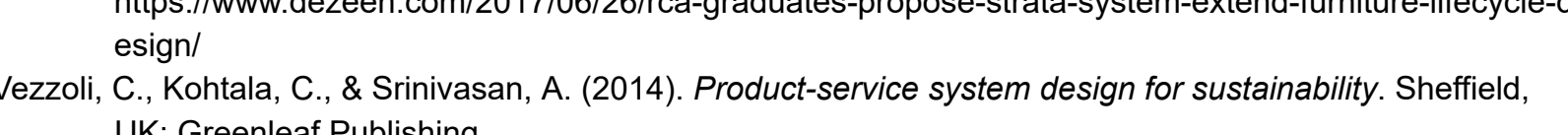

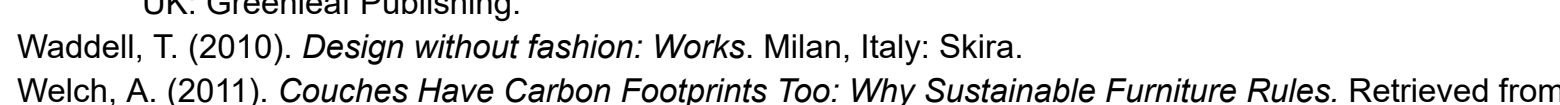

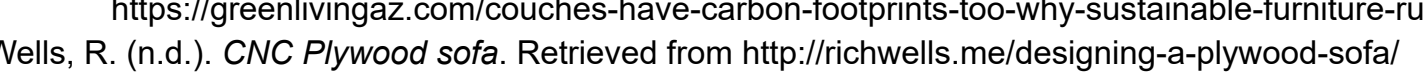

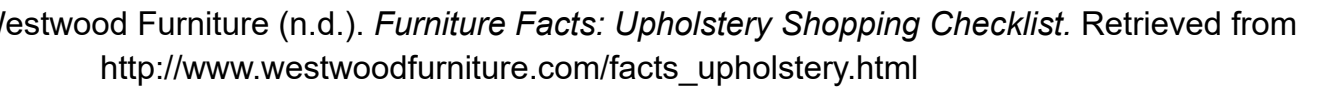

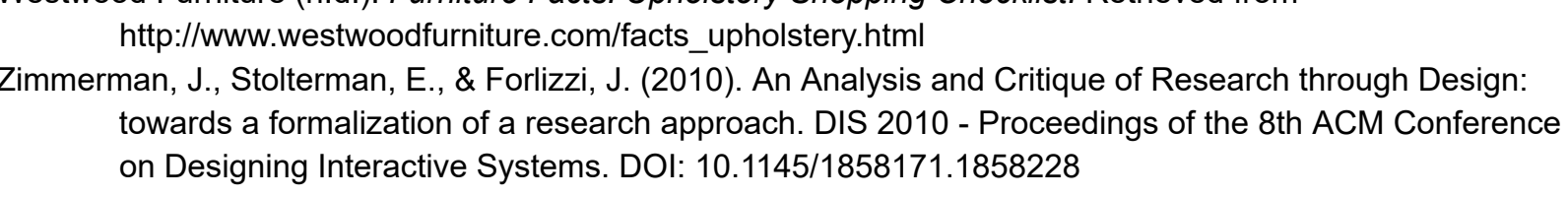

